Universidad Politécnica de Madrid Escuela Técnica Superior de Ingeniería y Diseño Industrial

Structure Characterization, Optical and Magnetic Properties of Silver Scheelite Double Tungstates/Molybdates and Perovskites $\mathrm{Sr}_{2} \mathrm{LnSbO}_{6}(\mathrm{Ln}=\mathrm{La}-\mathrm{Lu}$ and $\mathrm{Y}$ )

Tesis doctoral

CHAOYU YOU

Ingeniero de

Materiales 

Departamento de Ingeniería Mecánica, Química y Diseño Industrial Escuela Técnica Superior de Ingeniería y Diseño Industrial Programa de Doctorado en Ingenieria de Producción

\section{Structure Characterization, Optical and Magnetic Properties of Silver Scheelite Double Tungstates/Molybdates and Perovskites $\mathrm{Sr}_{2} \mathrm{LnSbO}_{6}(\mathrm{Ln}=\mathrm{La}-\mathrm{Lu}$ and $\mathrm{Y}$ )}

Tesis doctoral realizada por:

CHAOYU YOU

Ingeniero de Materiales

Dirigida por:

Dr. FRANCISCO FERNÁNDEZ MARTÍNEZ 



\section{LECTURA DE TESIS}

Tribunal nombrado por el Sr. Rector Magnífico de la Universidad Politécnica de Madrid, el día de de 2016.

Presidente: D.

Secretario: D.

Vocal:

D.

Vocal:

D.

Vocal:

D.

Realizado el acto de defensa y lectura de la tesis el día de de 2016 en la Escuela Técnica Superior de Ingeniería y Diseño Industrial. Los miembros del tribunal han decidido otorgar la siguiente calificación:

El Presidente,

Fdo:
El Secretario,
El Vocal 1,
Fdo:

El Vocal 3,

Fdo:

Fdo:

Fdo: 

Dedicated to all who assisted my education prior to and during my study in the Polytechnic University of Madrid (UPM). 



\section{ACKNOWLEDGMENTS}

This dissertation is not only the result of my own work but also the efforts of many other people. I would like to take this opportunity to acknowledge all the help that I have received along the way.

The greatest thanks must go to my advisor FRANCISCO FERNÁNDEZ MARTÍNEZ and Prof. CRSITÓBAL COLÓN HERNÁNDEZ. They have been in all regards the ideal mentors, giving me a great deal of independence while at the same time always being available to help. I am also very grateful for the many opportunities they have given me to travel for international conferences. These experiences have greatly enhanced my education as well as being a great deal of fun. Their experience positively influenced my education and his impact will last long after I leave this group.

There are several other people who have been important mentors to me. I am very grateful to my group member MARÍA ISABEL DE ANDRÉS-GARCíA for all her assistance, support, friendship and insightful discussions during my stay. I would also like to express my appreciation to my college Dr. S.SUPRIYA that influenced my understanding of material science.

I have to present great thanks to ALBERTO ANDRÉS DÁMASO and CRISTINA MORENO DÍAZ that I have learned greatly from. They gave me a great deal of assistance during my work in the laboratory and as well my daily life. They also passed on a great deal of knowledge to me on my Spanish.

I also appreciate all the assistance I have received form CRISTINA ALMENDRA during the early stages of my study.

Finally, I would like to acknowledge all the people who have assisted me in data collection of various types. 



\section{INDEX}

INDEX

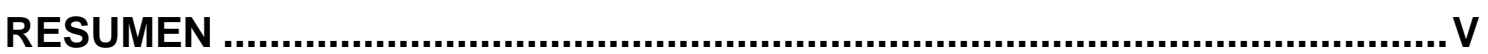

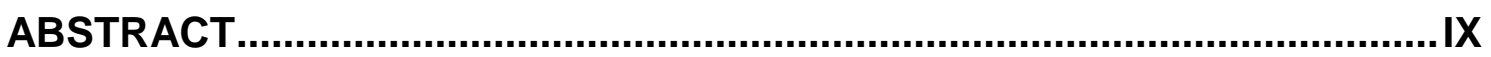

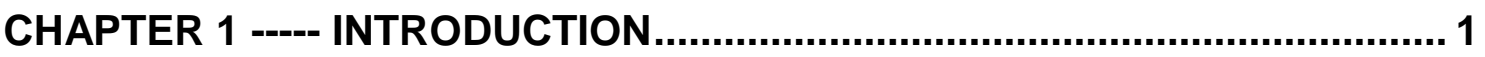

1.1 Introduction of the rare earth elements ................................................ 1

1.2 Scheelite related structures double tungstates and molybdates.............. 2

1.3 Perovskites and related structures $\mathrm{Sr}_{2} \mathrm{LnSbO}_{6}$ compounds ..................... 6

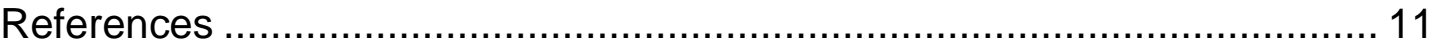

CHAPTER 2 ----- INSTRUMENTAL TECHNIQUES AND METHODS............. 15

2.1.-Introduction of Varies Preparation Techniques of Samples.................. 15

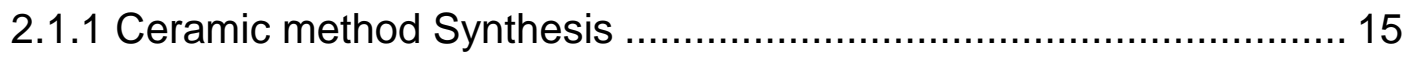

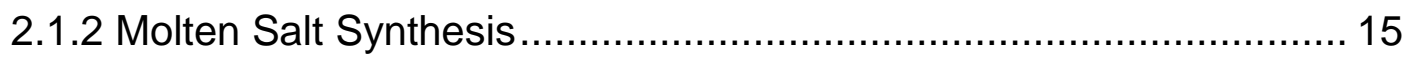

2.1.3 Chemical Co-precipitation Method ............................................... 16

2.1.4 Hydrothermal Synthesis ............................................................. 17

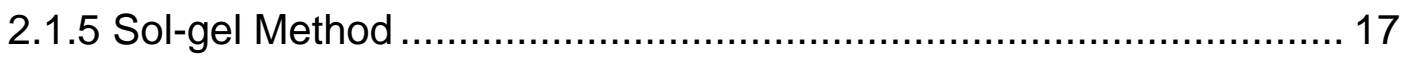

2.2. - Sample Preparation of $\mathrm{AgCe}\left(\mathrm{WO}_{4}\right)_{2}$ with $\mathrm{Eu}^{3+}$ and $\mathrm{Tb}^{3+}$ ions as dopants

2.3. - Sample Preparation of AgLn( $\left(\mathrm{WO}_{4}\right)\left(\mathrm{MoO}_{4}\right)$....................................... 19

2.4. - Sample Preparation of $\mathrm{Sr}_{2} \mathrm{LnSbO}_{6}$ double perovskites ....................... 20

2.5. - Structure Characterization............................................................... 21

2.5.1 Simultaneous Thermo gravimetric and Differential Thermal Analysis

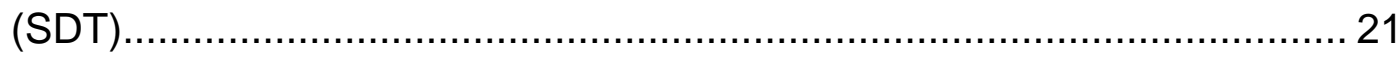

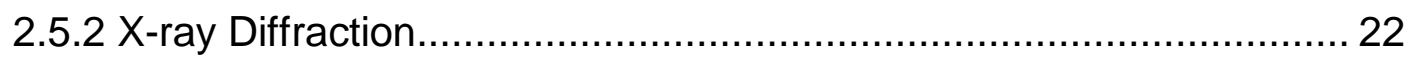

2.5.3 Infrared Spectroscopy (FTIR) .................................................. 25 


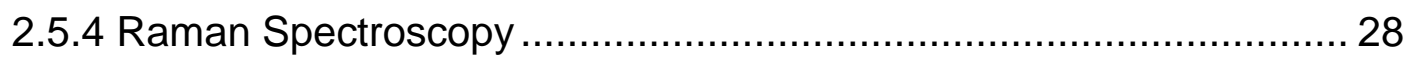

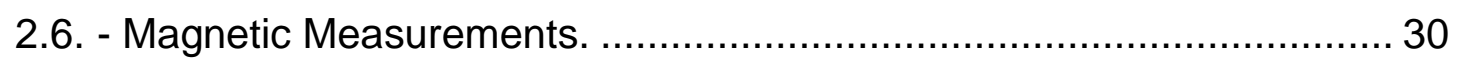

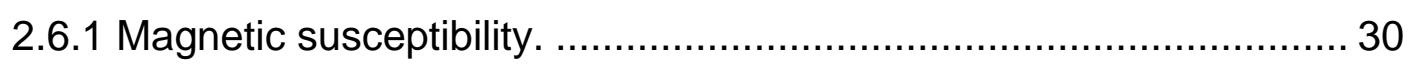

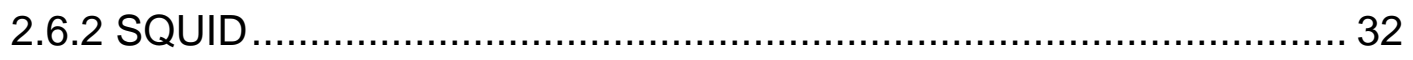

2.7. - Fluorescence Properties ................................................................... 33

2.7.1 Photoluminescence Spectroscopy ………………....................... 33

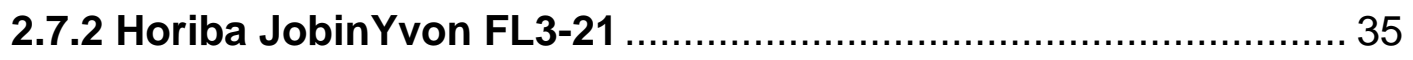

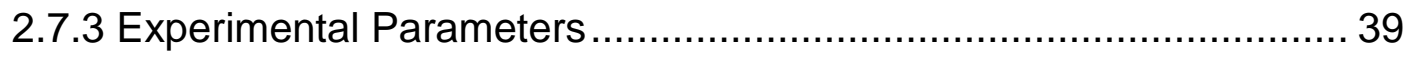

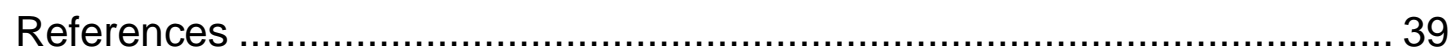

CHAPTER 3 -.-- RESULTS DISCUSSIONS ................................................. 43

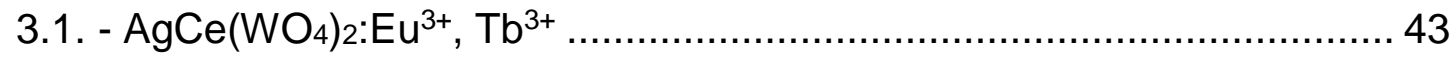

3.1.1 Thermal Behavior of the Mixture Precursors of $\mathrm{AgCe}\left(\mathrm{WO}_{4}\right)_{2} \ldots \ldots \ldots . . . .43$

3.1.2 High Temperature X-ray Diffraction ......................................... 47

3.1.3 Structural Study by X-ray Diffraction. ............................................ 49

3.1.4 Vibrational Study by FTIR and Raman Spectral............................ 52

3.1.5 Magnetic Properties ................................................................. 56

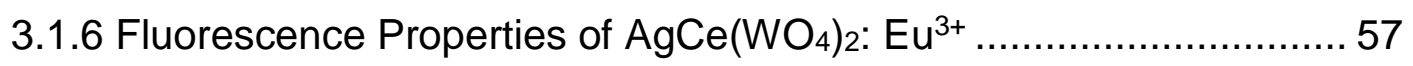

3.1.7 Fluorescence Properties of $\mathrm{AgCe}\left(\mathrm{WO}_{4}\right)_{2}: \mathrm{Tb}^{3+} \ldots \ldots \ldots \ldots \ldots \ldots \ldots \ldots \ldots \ldots . . . . . . . . . . . . . .64$

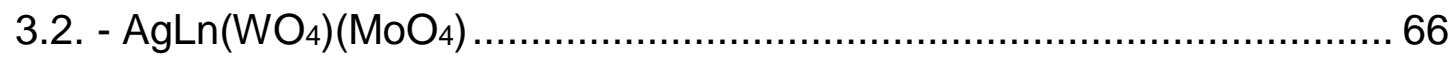

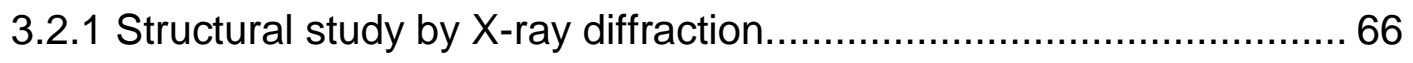

3.2.2 Vibrational study by FTIR and Raman spectral. ............................. 68

3.2.3. - Fluorescence Properties ........................................................... 83

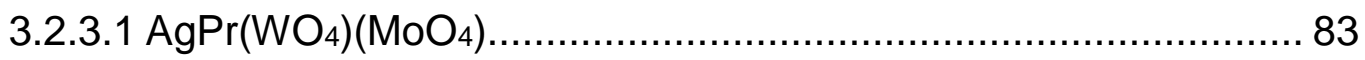

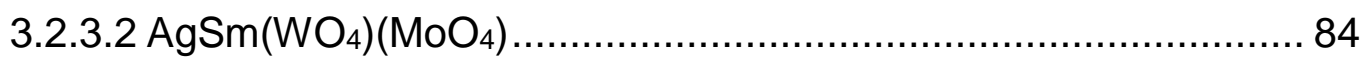

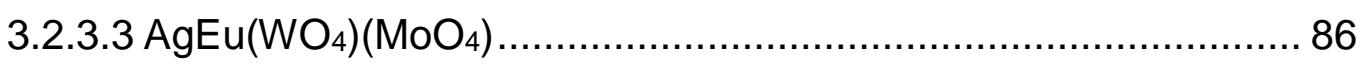

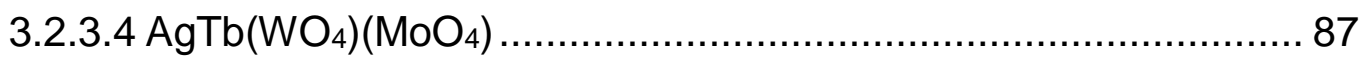

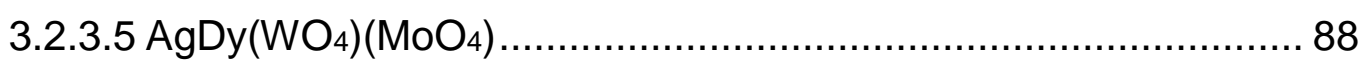




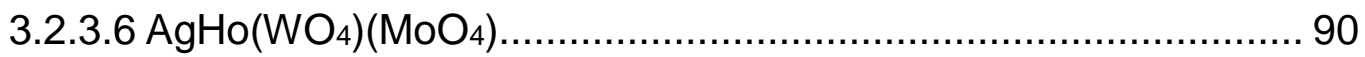

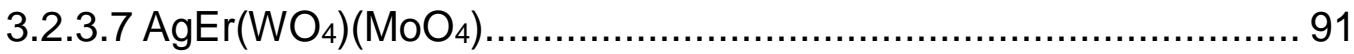

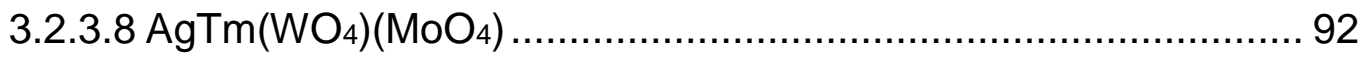

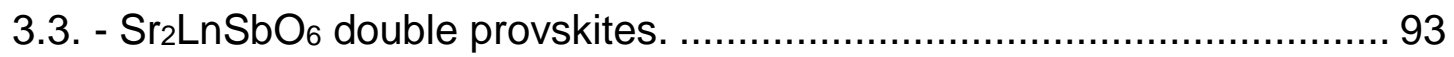

3.3.1 Thermal behavior of the mixture precursors of $\mathrm{Sr}_{2} \mathrm{LnSbO}_{6} \ldots \ldots \ldots \ldots . . . . .93$

3.3.2 Structural study by X-ray diffraction................................................. 99

3.3.3 Vibrationalstudy byFTIR and Raman spectral. ........................... 108

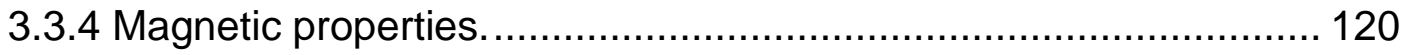

3.3.5 Fluorescence Properties of $\mathrm{Sr}_{2} \mathrm{LnSbO}_{6}$ Oxides ............................ 126

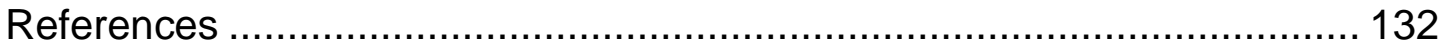

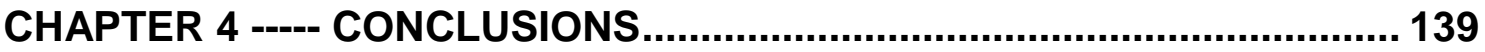

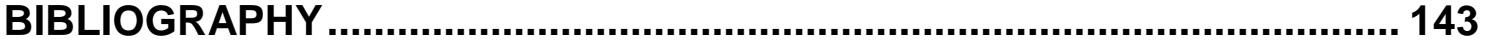




\section{RESUMEN}

El trabajo presentado en esta tesis describe la síntesis y caracterización de dos series de nuevos compuestos: dobles scheelitas y dobles perovskitas.

El wolframato de cerio trivalente y plata, $\mathrm{AgCe}\left(\mathrm{WO}_{4}\right)_{2}$, que presenta la estructura scheelita, ha sido sintetizado por el método cerámico al aire, a pesar de la relativamente alta inestabilidad del estado trivalente del ion Ce en estas condiciones. Este comportamiento podría ser debido a las propiedades redox que presenta el $\mathrm{Ag}_{2} \mathrm{O}$ en la reacción de estado sólido a la alta temperatura al aire, lo que estabilizaría el estado de valencia trivalente del cerio. El análisis de difracción de rayos $\mathrm{X}$ y su refinamiento muestran que el compuesto presenta estructura tetragonal y grupo espacial $141 / a$ (No. 88). Inicialmente se utilizó el análisis térmico diferencial (DTA) y térmico gravimétrico (TG) para estudiar el proceso químico y su mecanismo de reacción. Los resultados de las medidas de susceptibilidad magnética confirmaron la existencia de el catión cerio trivalente en los compuestos $\mathrm{Ce}_{(1-x)} \mathrm{Ag}_{(1+x)}\left(\mathrm{WO}_{4}\right)_{2}$ (x desde 0 hasta $1 / 3$ ), y no la oxidación de el catión trivalente, $\mathrm{Ce}^{3+}$, a Cerio tetravalente, $\mathrm{Ce}^{4+}$, que se pretendía con la disminución de la concentración del cerio. Se realizaron y estudiaron los espectros de fluorescencia de $\mathrm{AgCe}\left(\mathrm{WO}_{4}\right)_{2}$ dopado con $\mathrm{Eu}^{3+}$ y $\mathrm{Tb}^{3+}$ para determinar los desdoblamientos de los niveles de energía que tienen lugar en estos compuestos por efecto del campo cristal. Los resultados de FTIR y Raman muestran que los compuestos $\mathrm{Eu}_{x} \mathrm{Ce}_{(1-x)} \mathrm{Ag}\left(\mathrm{WO}_{4}\right)_{2}$ (x desde 0.00 hasta 0.50) presentan simetría puntual tetraédrica con grupo $C_{4 h}^{6}$. No hay distorsión apreciable de la estructura tetragonal como el aumento de la concentración de $\mathrm{Eu}^{3+}$ debido a que $\mathrm{Ce}^{3+} \mathrm{y}$ ion $\mathrm{Eu}^{3+}$ presentan radios iónicos muy próximos. También se encuentra que el $\mathrm{Tb}^{3+}$ puede ser utilizado como sonda local de la 
estructura en lugar de $\mathrm{Eu}^{3+}$ dentro de el compuesto $\mathrm{AgCe}\left(\mathrm{WO}_{4}\right)_{2}$ debido a que en este último, las bandas características de $\mathrm{Eu}^{3+}$ se desactivaron en presencia de los iones de cerio.

Se ha sintetizado en forma de polvo cristalino la familia tungstato-molibdato de plata y tierra rara, $\mathrm{AgLn}\left(\mathrm{WO}_{4}\right)\left(\mathrm{MoO}_{4}\right)$, que presenta la estructura de scheelita. El análisis de difracción de rayos $\mathrm{X}$ y su refinamiento se llevó a cabo dentro del grupo espacial tetragonal 141/a (No. 88). Los espectros de FTIR y Raman se analizaron sobre la base del análisis de grupo factor y cálculos en coordenadas normales. Los espectros de fotoluminiscecia de excitación y emisión presentan las bandas caracteristicas de los iones de tierras raras en el entorno $\mathrm{AgLn}\left(\mathrm{XO}_{4}\right)_{2}$ incluso cuando $\mathrm{Ln}=\mathrm{Ce}, \operatorname{Pr}$ y $\mathrm{Tb}$ a pesar de la relativamente elevada inestabilidad al aire de estos iones en estado trivalente.

La familia de dobles perovskitas $A_{2} B^{\prime} B X_{6}$, en la que los huecos octaédricos están ocupados por cationes B y B ', ya sea con distribución al azar o de una manera ordenada, han sido ampliamente estudiados en relación a la estructura y las propiedades que presentan. En este trabajo, las dobles perovskitas $\mathrm{Sr}_{2} \mathrm{LnSbO}_{6}(\mathrm{Ln}=\mathrm{La}$ a $\mathrm{Lu}$ e Y $)$ fueron sintetizados mediante el método cerámico. La estructura y la pureza de estas fases de perovskitas dobles preparadas se estudiaron por difracción de rayos $\mathrm{X}$ y espectroscopía vibracional. El análisis sistemático de la estructura local de estos compuestos se llevó a cabo mediante espectroscopías Raman y FTIR. Los patrones de difracción muestran que estos compuestos presentan una simetría más baja que la cúbica que presentan generalmente las perovskitas dobles $\mathrm{Ba}_{2} \mathrm{RESbO}_{6}$. Los cuatro modos activos ( $A_{1 g}, E_{g}, y$ dos $\left.T_{2 g}\right)$ en los espectros de Raman y el modo activo ( $\left.T_{1 u}\right)$ en los espectros de IR que se ha descrito previamente en los datos espectroscópicos 
de los compuestos $\mathrm{Ba}$ han cambiado. De acuerdo con nuestros datos, las perovskitas dobles $\mathrm{Sr}_{2} \mathrm{LnSbO}_{6}$ pueden ser descritos mediante una célda con simetría monoclínica, grupo espacial $P 21 / n$ con los parámetros de red, $a=\sqrt{2} a_{p}$, $\mathrm{b}=\sqrt{2} \mathrm{a}_{\mathrm{p}}, \mathrm{c}=2 \mathrm{a}_{\mathrm{p}}$ y $\beta \sim 90^{\circ}$, donde $\mathrm{a}_{\mathrm{p}}$ es la constante de red de la perovskita cúbica. Sin embargo, en los casos de $\mathrm{Sr}_{2} \mathrm{LaSbO}_{6}$ y $\mathrm{Sr}_{2} \mathrm{PrSbO}_{6}$ los datos muestran que pueden tener una estructura alternativa que debería ser estudiada mediante técnicas de difracción de neutrones. Además, los parámetros de red disminuyen linealmente con la disminución del tamaño del catión $\mathrm{R}^{3+}$ de acuerdo con la contracción lantánida. Las medidas de susceptibilidad magnética para esta familia de compuestos muestran un comportamiento paramagnético hasta baja temperatura, $2 \mathrm{~K}$, sin ningún tipo de interacciones. La desviación de la linealidad observada a baja temperatura para algunos óxidos $\mathrm{Sr}_{2} \mathrm{LnSbO}_{6}$ puede ser explicada completamente por ley Curie-Weiss teniendo en cuenta el desdoblamiento del término funtamental del catión $\mathrm{R}^{3+}$ con la influencia del campo de cristal y sin tener en cuenta cualquier otro fenómeno magnético cooperativo. Las propiedades ópticas de estas dobles perovskitas se han investigado también. En los compuestos $\mathrm{Sr}_{2} \mathrm{LnSbO}_{6} \mathrm{de} \mathrm{Eu}^{3+}$ y $\mathrm{Tb}^{3+}$ sólo se observaron sus correspondientes bandas características. 


\begin{abstract}
The work described in this thesis explores the synthesis and characterization of a number of new double scheelites and double perovskites.

The trivalent cerium silver tungstate, $\mathrm{AgCe}\left(\mathrm{WO}_{4}\right)_{2}$, with scheelite-like structure has been synthesized by ceramic method despite the relatively high instability of the trivalent Ce ion. This behavior could be explained by the redox properties of $\mathrm{Ag}_{2} \mathrm{O}$ in the solid state reaction at high temperature in air, which stabilizes the trivalent valence state. X-ray diffraction analysis was carried out and the refinement was performed in the tetragonal S.G. I 41/a (No. 88). Initially differential thermal analysis (DTA) and thermal gravimetric (TG) were used to analyze the reaction process and chemical mechanism. The results of magnetic susceptibility measurement gave confirmed evidence that the trivalent cerium cation existed in the compounds $\mathrm{Ce}_{(1-\mathrm{x})} \mathrm{Ag}_{(1+\mathrm{x})}\left(\mathrm{WO}_{4}\right)_{2}$ ( $\mathrm{x}$ from 0 to $1 / 3$ ), and no transition from trivalent $\mathrm{Ce}^{3+}$ cation to tetravalent $\mathrm{Ce}^{4+}$ cation was observed with the decreasing of cerium concentration. The fluorescence properties of $\mathrm{Eu}^{3+}$ and $\mathrm{Tb}^{3+}$ doped $\mathrm{AgCe}\left(\mathrm{WO}_{4}\right)_{2}$ were investigated in order to determine the crystal field energy level diagrams. The results of FTIR and Raman showed that the compounds $\mathrm{Eu}_{x} \mathrm{Ce}(1-\mathrm{x}) \mathrm{Ag}\left(\mathrm{WO}_{4}\right)_{2}$ (x from 0.00 to 0.50 ) have tetrahedral symmetry with $C_{4 h}^{6}$ symmetry group, there is no appreciable distortion of the tetragonal structure as the increasing of $\mathrm{Eu}^{3+}$ concentration because of the analogous of the radius of $\mathrm{Ce}^{3+}$ ion and $\mathrm{Eu}^{3+}$ ion. It is also found that the $\mathrm{Tb}^{3+}$ is qualified as a local structure probe rather than the $\mathrm{Eu}^{3+}$ within the $\mathrm{AgCe}\left(\mathrm{WO}_{4}\right)_{2}$ compound because the characteristic bands of $\mathrm{Eu}^{3+}$ were quenched with the appearance of cerium ions.
\end{abstract}


Polycrystalline powders of the silver rare earth tungstate-molybdate family, $\mathrm{AgLn}\left(\mathrm{WO}_{4}\right)\left(\mathrm{MoO}_{4}\right)$, with scheelite-like structure have been synthesized by ceramic method. X-ray diffraction analysis was carried out and the refinement was performed in the tetragonal S.G. I 41/a (No. 88). The FTIR and Raman Spectra were discussed on the basis of factor group analysis and normal coordinate calculations. Photo luminescent excitation and emission spectra of the rare earth ions was presented with characteristic bands in the silver based host material especially for $\mathrm{Ln}=\mathrm{Ce}, \operatorname{Pr}$ and $\mathrm{Tb}$ despite the relatively high instability of these trivalent ions.

The so-called double perovskites $\mathrm{A}_{2} \mathrm{~B}^{\prime} \mathrm{BX}_{6}$, in which the octahedral sites are occupied by $\mathrm{B}$ and $\mathrm{B}^{\prime}$ cations either in a random or an ordered fashion, have been widely studied concerning the structure and properties that they present. In this present work, $\mathrm{Sr}_{2} \mathrm{RESbO}{ }_{6}$ double perovskites $(\mathrm{RE}=\mathrm{La}$ to $\mathrm{Lu}$ and $\mathrm{Y})$ were synthesized by ceramic method. The structure and phase purity of the prepared double perovskites were examined by X-ray diffraction pattern and vibrational spectroscopy. A systematic analysis of the compounds structure was carried out by Raman and IR. A simple inspection of the diffraction patterns shows that these compounds have lower symmetry than the cubic which can be usually found in the $\mathrm{Ba}_{2} \mathrm{RESbO}_{6}$ double perovskites. The four active modes $\left(\mathrm{A}_{1 \mathrm{~g}}, \mathrm{E}_{g}\right.$, and two $\left.T_{2 g}\right)$ in the Raman spectra and the active mode $\left(T_{1 u}\right)$ in the IR spectra which previously described in the spectroscopic data of $\mathrm{Ba}$ compounds have changed. According to our data, the $\mathrm{Sr}_{2} \mathrm{RESbO}_{6}$ double perovskites can be described by a monoclinic symmetry cell, space group P21/n with the lattice parameters $a=\sqrt{2} a_{p}, b=\sqrt{2} a_{p}$ and $c=2 a_{p}$ and $\beta \sim 90^{\circ}, \quad a_{p}$ being the lattice constant of the cubic perovskite. However, in the cases of $\mathrm{Sr}_{2} \mathrm{LaSbO}_{6}$ and $\mathrm{Sr}_{2} \mathrm{PrSbO}_{6}$ an 
alternative structure should be searched by neutron diffraction technique. Furthermore, the lattice parameters decrease linearly with the decreasing of the size of the $\mathrm{R}^{3+}$ cation according with the well-known lanthanide contraction. Magnetic susceptibility measurements for this family of compounds reveal a paramagnetic behaviour down to temperatures of $2 \mathrm{~K}$. The downwards or upwards deviation behaviour observed at low temperature for some of these $\mathrm{Sr}_{2} \mathrm{RESbO}_{6}$ oxides can be fully explained by the Curie-Weiss laws taking into account the splitting of the ground term of the $\mathrm{R}^{3+}$ cation under the influence of the crystal field without considering any magnetic phenomena as for example magnetic frustration and/or cooperative magnetic interactions. Optical properties of these perovskites compounds were investigated as well. Only characteristic bands of $\mathrm{Eu}^{3+}$ and $\mathrm{Tb}^{3+}$ were observed in the corresponding $\mathrm{Sr}_{2} \mathrm{RESbO}_{6}$ compounds. 


\section{CHAPTER 1 ---- INTRODUCTION}

\subsection{Introduction of the rare earth elements}

In the periodic table, there is a very strange big family, which is called "rare earth". It was discovered only 200 years ago. This big family is composed of 17

symbiotic siblings. Among them, except of yttrium (element symbol $\mathrm{Y}$ ) and scandium (element symbol Sc) two, the other 15 are the direct descendants, according to the ranking of atomic number from 57 to 71 , from lanthanum through lutetium. Headed by the first "lanthanum", these 15 elements series are called "Lanthanides", which is represented by the symbol Ln. These fifteen lanthanide elements, along with the chemically similar elements scandium and yttrium, are often collectively known as the rare earth elements, which can be normally represented by the symbol RE or $\mathrm{R}$.

The electronic configuration of scandium is:

$$
1 s^{2} 2 s^{2} 2 p^{6} 3 s^{2} 3 p^{6} 3 d^{1} 4 s^{2}
$$

The electronic configuration of yttrium is:

$$
1 s^{2} 2 s^{2} 2 p^{6} 3 s^{2} 3 p^{6} 3 d^{10} 4 s^{2} 4 p^{6} 4 d^{1} 5 s^{2}
$$

The electron filling mode within different lanthanide elements is :

$$
1 s^{2} 2 s^{2} 2 p^{6} 3 s^{2} 3 p^{6} 3 d^{10} 4 s^{2} 4 p^{6} 4 d^{10} 4 f^{n} 5 s^{2} 5 p^{6} 5 d^{m} 6 s^{2}
$$

The electrons number within the layer $s, p, d$ is nearly the same, only the electron number within inner $4 f$ layer $n$ increases from 0 to 14 . The outer layer $5 s^{2} 5 p^{6} 5 d^{m} 6 s^{2}$ is very analogous. The $5 d$ electron number $m$ is zero for most of the lanthanide elements. Only for $\mathrm{La}, \mathrm{Ce}, \mathrm{Gd}$ and $\mathrm{Lu}$ the number $\mathrm{m}$ is equal to 1 . Because of the similar outer electron layer, the chemical properties of lanthanide elements are very similar. And they often associated in the same kind of mineral which make it difficult to chemically distinguish them one by one. In order to identify them, thousands of difficulties have been overcome and various errors have been corrected from 1787 to 1947, which took 160 years of efforts. 
The characteristic valence of scandium, yttrium and lanthanide ions is +3 , except for $\mathrm{Ce}$ with normal state of +4 . When forming the trivalence ion, scandium atom loses the outermost two electrons of $4 \mathrm{~s}$ and one electron of $3 \mathrm{~d}$; yttrium atom loses the outermost two electrons of $5 \mathrm{~s}$ and one electron of $4 \mathrm{~d}$; lanthanide atoms lose two electrons of outermost layer $6 \mathrm{~s}$ and one inner electron of $4 \mathrm{f}$. And for La, $\mathrm{Ce}, \mathrm{Gd}$, Lu atoms, they will lose the outermost two electrons of $6 \mathrm{~s}$ and one electron of $5 \mathrm{~d}$. Their electronic configuration are:

$\mathrm{Sc}^{3+} \quad 1 \mathrm{~s}^{2} 2 \mathrm{~s}^{2} 2 \mathrm{p}^{6} 3 \mathrm{~s}^{2} 3 \mathrm{p}^{6}$

$Y^{3+} \quad 1 s^{2} 2 s^{2} 2 p^{6} 3 s^{2} 3 p^{6} 3 d^{10} 4 s^{2} 4 p^{6}$

$L n^{3+} \quad 1 s^{2} 2 s^{2} 2 p^{6} 3 s^{2} 3 p^{6} 3 d^{10} 4 s^{2} 4 p^{6} 4 d^{10} 4 f^{n} 5 s^{2} 5 p^{6}$

Rare earth is a big family with various specific properties. The specific properties of rare earth elements are due to their specific electronic configurations. In the periodic table, rare earth elements from lanthanum to lutetium increase their atomic number from 57 to 71 by filling electrons in the inner $4 f$ orbit. These $4 f$ electrons are shielded by the outermost $5 s^{2}$ and $5 p^{6}$ electron layers. The different movement way of $4 f$ electrons gives rare earth elements specific optical, magnetic and electric properties which is different from other elements in the periodic table.

\subsection{Scheelite related structures double tungstates and molybdates.}

According the Bastide's rule [1.1], for $\mathrm{ABX}_{4}$ compounds and taking account the ionic radious and coordination number for ${ }^{\mathrm{VIII}} \mathrm{Ln}^{+3}, \mathrm{VIII}^{\mathrm{II}} \mathrm{Ag}^{+},{ }^{\mathrm{IV}} \mathrm{W}^{6+},{ }^{\mathrm{V}} \mathrm{Mo}^{6+}$ and ${ }^{\mathrm{VI}} \mathrm{O}^{2-}$, these double tungstates and molybdates compounds are located in the sheelite zone. 


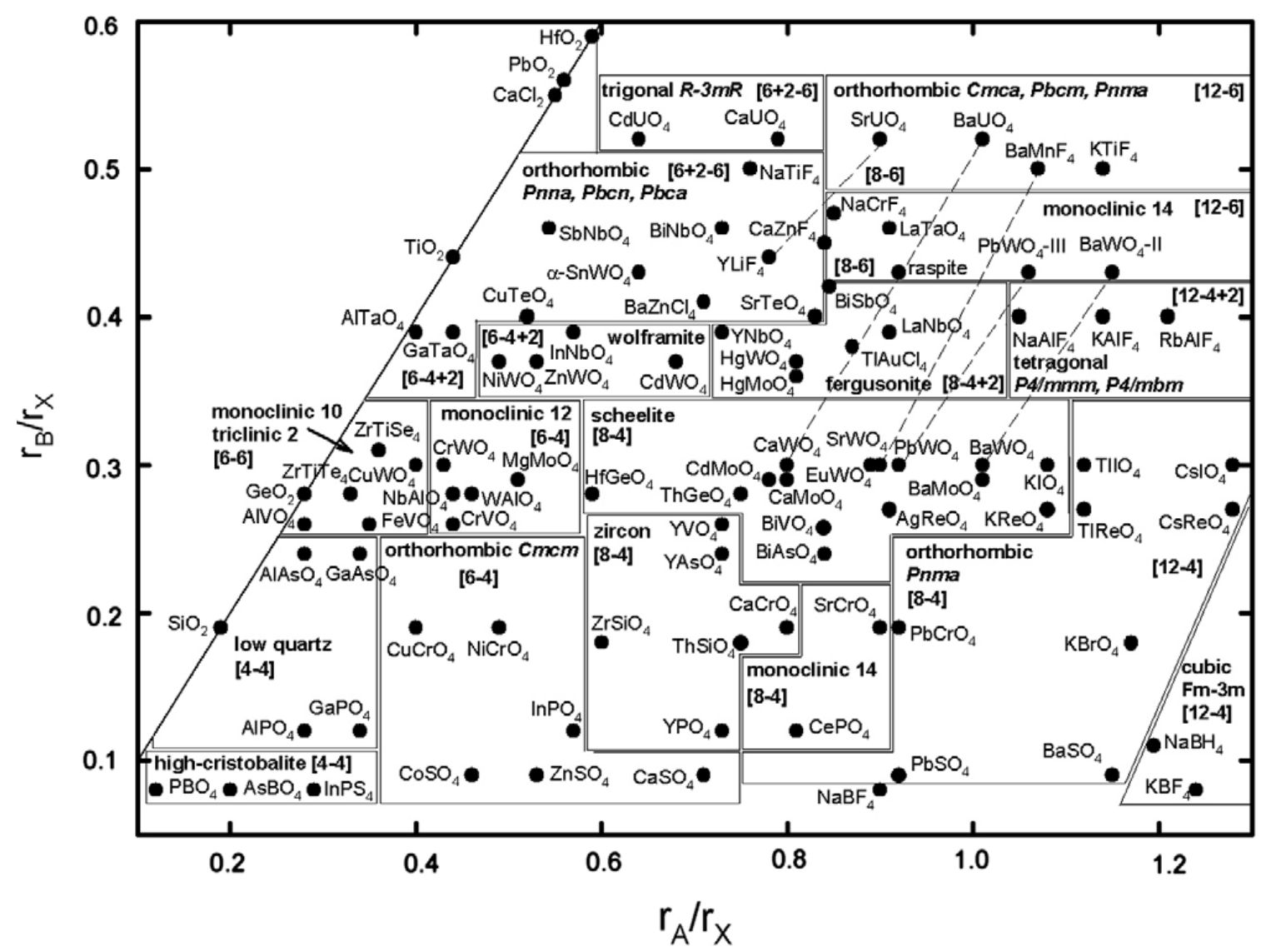

Fig. 1.1. Updated Bastide's diagram for $A B X_{4}$ compounds. The dashed lines show the evolution of the ionic radii ratios with increasing pressure in a number of scheelite-structured compounds.

The double tungstates and molybdates compounds with scheelite-type structure have received much attention in recent years for the consideration as promising self-doubling solid-state laser host materials and phosphors as well [1.2-1.9]. The composition of these compounds can be written as $\mathrm{AB}\left(\mathrm{XO}_{4}\right)_{2}$ (where $\mathrm{A}=$ alkali metal ion or $\mathrm{Ag}^{+}, \mathrm{B}=$ lanthanide trivalent ion, $\mathrm{Y}^{3+}$ or $\mathrm{Bi}^{3+}, \mathrm{X}=\mathrm{W}^{6+}$ or $\mathrm{Mo}^{6+}$ ) which crystallized in the scheelite-like structure formed by chains of alternate corner-sharing $\left(\mathrm{XO}_{4}\right)$ tetrahedral and edge-sharing $\left(\mathrm{A} / \mathrm{BO}_{8}\right)$ bisdisphenoid along the a-axis with the structure illustrated in Fig. 1.2. 


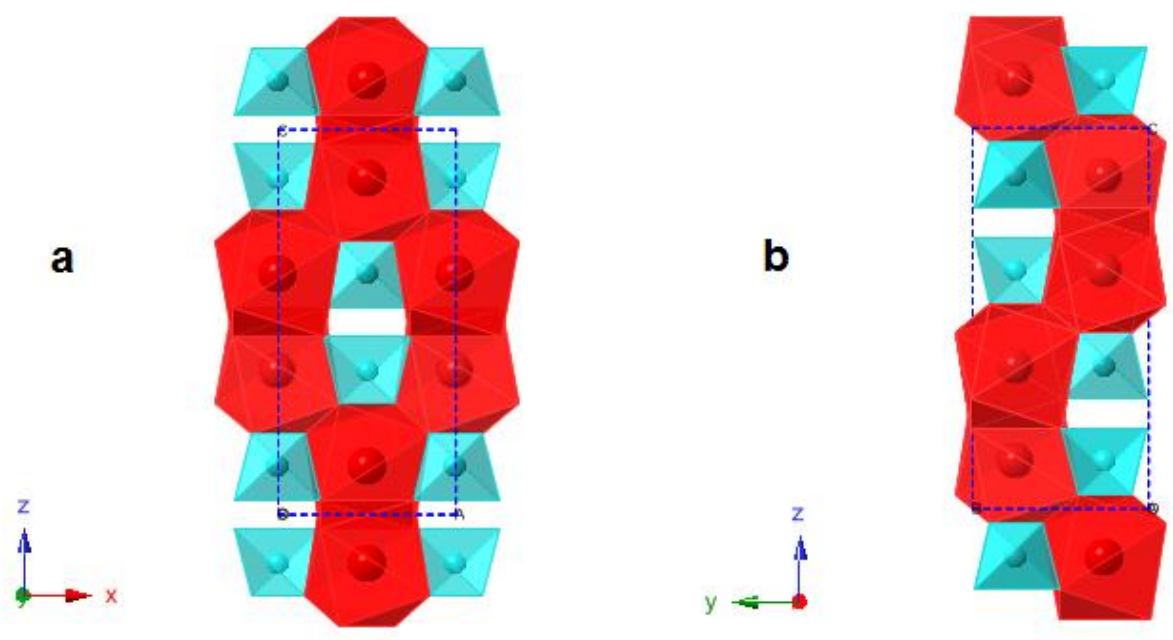

Fig. 1.2 Views along (010) (a) and (100) (b) directions of the structure for the scheelite-type double crystals $\mathrm{AB}\left(\mathrm{XO}_{4}\right)_{2}$.

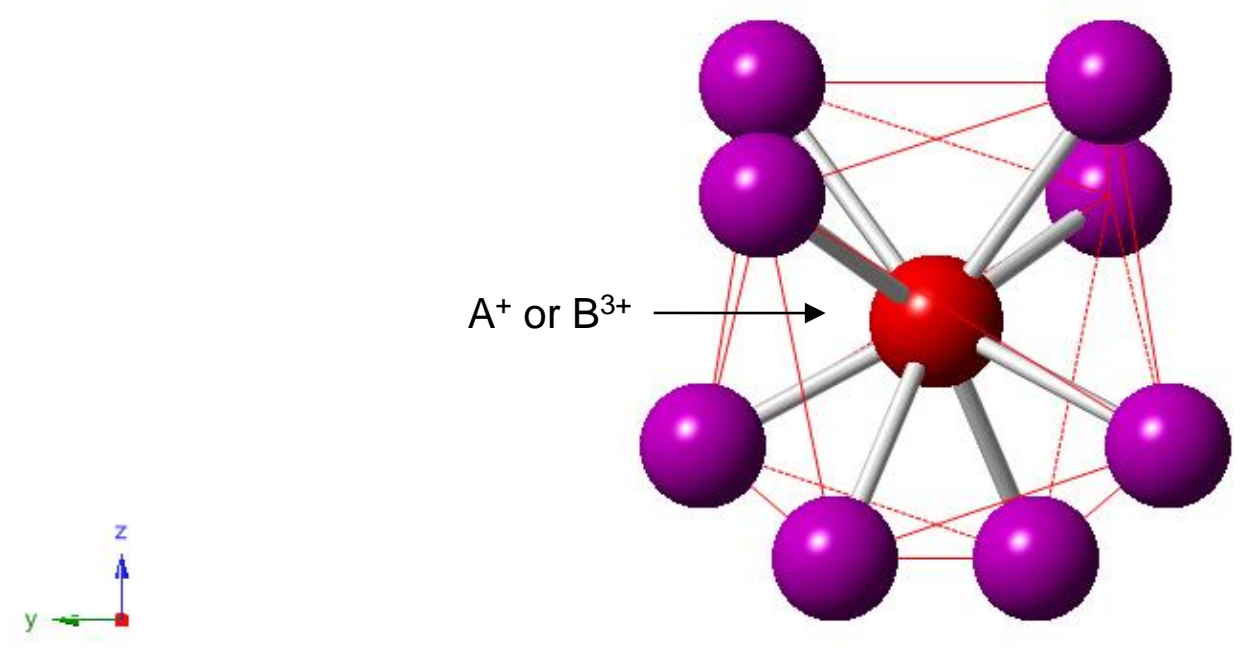

Fig. 1.3 View along (100) direction of the $\left(\mathrm{A} / \mathrm{BO}_{8}\right)$ bisdisphenoid.

Up to numerous crystalline hosts were investigated, scheelite-like double tungstates and molybdates occupy the especial place among these hosts, because of some advanced characterization by following features: 
(1) Big lanthanide impurity acceptance.

(2) High peak and integral absorption and strong anisotropy which leading to enormous optical cross-sections.

(3) Inhomogeneously-broadened lines of characteristic optical spectrum of rare-earth ions, due to structural disordering of the hosts. Broadened spectral bands of these crystals bring a number of advantages from the point of view of their application as active media in Laser Diode-pumped solid-state lasers:

(a) Substantial reduction of requirements to thermo stabilization of pumping Laser Diodes, because here, unlike in the most part of structurally ordered crystals, the emission line of Laser Diode hits into the band with the absorption coefficient, just slightly varying within wide spectral range.

(b) The possibility to obtain laser oscillation tunable within rather wide range.

(c) The possibility to obtain femtosecond laser pulses on these media.

(4) One additional special advantage of scheelite like double tungstates and molybdates crystals is the following: In scheelite-like structure, each $\mathrm{Ln}^{3+}$ ion is coordinated by eight neighbor $\mathrm{O}^{2-}$ ions and the $\mathrm{LnO}_{8}$ bisdisphenoid polyhedral is isolate from each other, as illustrated in Fig. 1.3, hence the distance between each $\mathrm{Ln}^{3+}$ ion is very large which leading to small energy transfer and concentration quenching.

Alkali-based double tungstates and molybdates are the best known groups and have received the most attentions [1.10-1.11]. But as known as that spectral characteristics of compounds are determined by their chemical composition and type of crystalline structure, our attentions were paid into the Ag-based system which is still not deeply investigated. Otherwise, complex tungstate-molybdates $\mathrm{AB}\left(\mathrm{XO}_{4}\right)_{2}$ have become the hot spot for the atoms Mo and $\mathrm{W}$, which have similar ionic radius, to substitute each other [1.12-1.17]. Thus in our work, researches around the silver-based double tungstates compounds and silver-based semi tungstates and semi molybdates compounds have been focused. 
Moreover, it is worth noting that cerium ions $\mathrm{Ce}^{3+}$ attracted much attentions because of the low cost and the spin and parity allowed $4 \mathrm{f}-5 \mathrm{~d}$ transitions which have a fast radiative life time of about 10-50 ns. And it has been found that the introduction of $\mathrm{Ce}^{3+}$ ions into $\mathrm{Er}^{3+}$ doped materials can efficiently depopulate $\mathrm{Er}^{3+}$ ions in the $\left.{ }^{4}\right|_{11 / 2}$ to the $\left.{ }^{4}\right|_{13 / 2}$ level by a phonon-assisted cross relaxation $\left.{ }^{4}\right|_{11 / 2}\left(\mathrm{Er}^{3+}\right)$ $+{ }^{2} \mathrm{~F}_{5 / 2}\left(\mathrm{Ce}^{3+}\right) \rightarrow{ }^{4} \mathrm{I}_{13 / 2}\left(\mathrm{Er}^{3+}\right)+{ }^{2} \mathrm{~F}_{7 / 2}\left(\mathrm{Ce}^{3+}\right)$ which help to reduce the back energy transfer and up-conversion loss [1.18-1.21]. However the $\mathrm{Ce}^{3+}$ ion is hard to exist in the scheelite-type structure hosts with alkaline cations because its relatively high instability in air. So the $\mathrm{Ce}^{3+}$ contained scheelite-type crystals are normally prepared by chemical methods or grown as monocrystals [1.22-1.24] instead of the easiest ceramic method. In our work, when we use $\mathrm{Ag}^{+}$to substitute the alkali cation, the scheelite-like crystal compounds $\mathrm{CeAg}\left(\mathrm{WO}_{4}\right)_{2}$ were well crystallized in air by ceramic method with wonderful thermal stabilization. Further, $\mathrm{Eu}^{3+}$ and $\mathrm{Tb}^{3+}$ ions were used as dopants for the investigation of its crystal field effect.

\subsection{Perovskites and related structures $\mathrm{Sr}_{2} \mathrm{LnSbO}_{6}$ compounds}

Last few years, as the search for new materials, it has increased the number of chemical species that have some rare earth in their composition. In general these new rare earth oxide ceramics with lanthanide elements and other metals, often have significant electrical, magnetic, luminescent or catalytic properties that confers potential applications in advanced technologies[1.25-1.29].

Among these materials, there is a special kind of compounds which related to the general formula as $A_{1+\times} B_{x} X_{3 x+1}$. They formed a big family that different members have been characterized to be correspond to it. It can take $x$ as different values between 1 and infinity.

In these structures $B$ is a cation of a transition element whose radius is between $0.5 \AA$ and $1.2 \AA$, and is coordinated by ion $\mathrm{X}(\mathrm{F}, \mathrm{Cl}, \mathrm{O})$ as octahedral. The cation A with more voluminous, which has a considerably larger radius between $1.0 \AA$ and $1.9 \AA$, present various coordination for each family member. 
At one of the extreme situations, it will have the perovskite type structure when $x$ becomes infinite value, which has the stoichiometry $\mathrm{ABX}_{3}$ and is common to a large number of compounds. This structure can be described as formed by octahedral $\left[\mathrm{BX}_{6}\right]$ linked by sharing all their vertices, and the cation $A$ is located in a cubo-octahedral formed by $X$ ions, presenting as shown in Fig. 1.4, as 12 coordination number. Ideal Perovskites have the structure adopt the cubic space group Pm̄̄m.

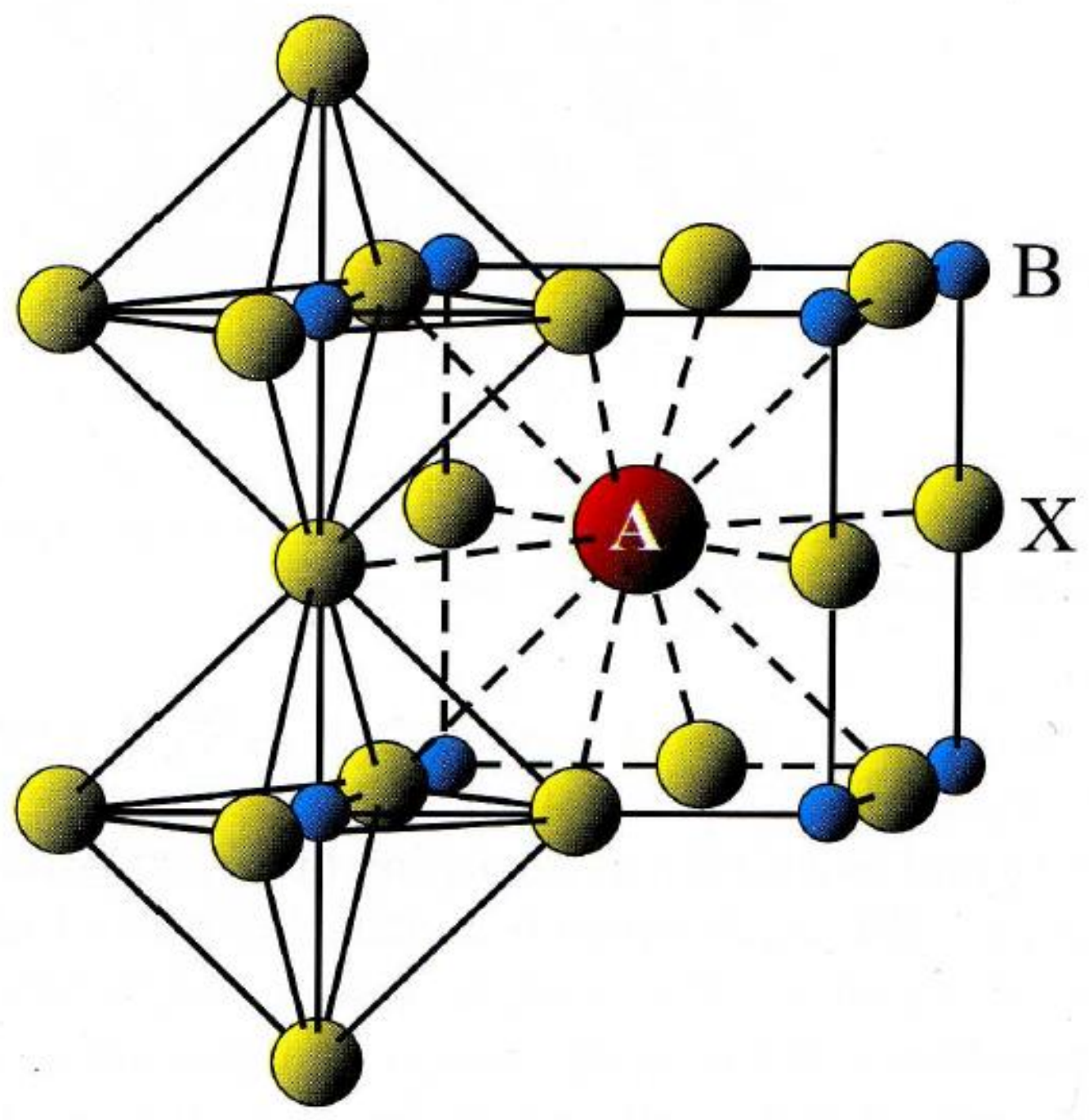

Fig. 1.4. The ideal $A B X_{3}$ single perovskite structure formed by the octahedral of the B-site and the cubo-octahedral (12-fold coordination) of the A-site cations. The spheres are the voluminous cation $A$ and the octahedrals are units $\left[B X_{6}\right]$ 
However, the perovskites $A B X_{3}$ have two characteristics: tilting of the octahedral $\left[\mathrm{BO}_{6}\right]$ and displacement of the $A$ cation. Because of the different tilting and displacement degree, the perovskites $\mathrm{ABX}_{3}$ can adopt orthorhombic, tetragonal, hexagonal crystal system and etc. The distortion degree of the structure can be represented by the tolerance factor:

$$
\tau=\left(r_{X}+r_{A}\right) /\left[\sqrt{2}\left(r_{X}+r_{B}\right)\right]
$$

where $r_{A}, r_{B}$ and $r_{X}$ were the radius of ion $\mathrm{A}, \mathrm{B}$ and $\mathrm{X}$ respectively. For ideal structures the factor $\tau$ is unity 1 .

The distortion of the simple ternary $\mathrm{ABX}_{3}$ perovskite $\mathrm{Pm} \overline{3} \mathrm{~m}$ structure can arise from various aspects:

1. Rotation or tilting of the octahedral $\left[\mathrm{BX}_{6}\right]$ because of the $A$-site cation being too large or too small for the 12-fold site.

2. Displacement of B-site cations from the center of the octahedral or the displacement of the A-site cation from the center of the cubo-octahedral..

3. Distortion of the octahedral due to Jahn-Teller effects.

4. Increased covalency of the A-O or B-O bonds.

Substitution derivatives of the simple ternary perovskite $A B X_{3}$ structure are collectively known as complex perovskites. Perovskites in which the substitution occurs at only one site $\mathrm{A}_{2} \mathrm{BB}^{\prime} \mathrm{X}_{6}$ are termed double perovskites. Double perovskites have been received much attention in recent years [1.30-1.33]. The ordering double perovskite has the similar structure with the simple ternary perovskite. The $B$ and $B^{\prime}$ cations occupy the B-site alternatively forming octahedral with its neighbor $X$ anions. The cation $A$ located in the interspaces between octahedrals. As similar as the simple ternary $A B X_{3}$ perovskite, the distortion degree of the structure can be also represented by the tolerance factor:

$$
\tau=\left(r_{X}+r_{A}\right) /\left[\sqrt{2}\left(r_{X}+\frac{1}{2}\left(r_{B}+r_{B^{\prime}}\right)\right)\right]
$$

where $r_{A}, r_{B}, r_{B^{\prime}}$ and $r_{X}$ were the radius of ion $\mathrm{A}, \mathrm{B}$ and $\mathrm{X}$ respectively. 
From the compositional point of view, the introducing of two cations B and B', with different oxidation states, increases the wealth of possible compounds, and gives rise to more various compositions as double perovskite $\mathrm{A}_{2} \mathrm{BB}^{\prime} \mathrm{X}_{6}$.

From the crystallographic point of view, the different possibilities and existence of order-disorder phenomena and possible different stacking of these layers makes the transformation from cubic structure, space group Fm3m, to the tetragonal, space group I $4 / \mathrm{mmm}$, ideally or derived from these. As the simple perovskite structure, a large number of compounds with $\mathrm{A}_{2} \mathrm{BB}^{\prime} \mathrm{X}_{6}$ stoichiometry, included in those reported publications, do not adopt to the ideal structure, although closely related to it. These deviations from ideality are mainly due to one or several cooperative effects that can be caused by:

- Phenomenon of order disorder among different cations, B and B', or vacant (cationic or anionic).

- Rotation or "tilt" of the BX ${ }_{6}$ octahedral in space.

- Displacement of the cations, parallel type (ferroelectric structure) or antiparallel type (antiferroelectric structure).

- Distortion of the octahedral.

From the magnetic point of view, compounds having the structure where in $A$ is a diamagnetic cation and cation $B$ and $\mathrm{B}^{\prime}$ only paramagnetic cation is of particular interest. In them, the possible magnetic interactions $B-X-B$ to $180^{\circ}$, super exchange type, which occur between the layers of simple perovskite type $A B X_{3}$ can be drastically reduced along the axis $\mathrm{c}$, in the case of order between the octahedral planes due to the presence of alternation of non magnetic layers $\mathrm{BX}_{6}$. As a result, the number of ions' neighbors which are capable of interacting is reduced from six, in the case of simple perovskite as Figure $1 \mathrm{a}$, to four in the case of the double ordering perovskite Figure $1 \mathrm{~b}$.

This situation would be different in the case of disordered double perovskite. It may appear different coupled magnetic effects depending on the cation $B$ of the six neighbors $\mathrm{BX}_{6}$ octahedral. 
In this present work we have studied the influence of the possible effects of order-disorder exerted on the structure, magnetic and optical properties of the $\mathrm{Sr}_{2} \mathrm{LnSbO}_{6}$ oxides ( $\mathrm{Ln}=\mathrm{La}-\mathrm{Lu}$ and $\mathrm{Y}$ ).

The synthesis conditions were determined by thermal analysis. Different $\mathrm{Sr}_{2} \mathrm{LnSbO}_{6}$ nominal composition samples were obtained and structural characterization was made by $\mathrm{X}$-ray diffraction.

The study of the magnetic properties, though not one of the most important objectives in this report, has been carried out from the measurement susceptibility in a wide temperature range: $4.2-300 \mathrm{~K}$. This study was realized by a magnetic susceptometer SQUID, which is a part of the Centers of Investigation Supporting (CAIs) of the UCM and is installed in the Department of Inorganic Chemistry of the Chemical Faculty of Complutense University.

The main objective of this work is the optical characterization of the emission fluorescence of these compounds which will be influenced mainly by the symmetry situation of lanthanide ion and the existence of cooperative phenomena between octahedral neighbors. For this, it was carried out the acquisition, installation and set-up of different laser sources (Ar-Kr laser and Nd-YAG), one closed loop cryostat and two $1 / 2$ meter optimized monochromators to record the emission fluorescence in range of UV-Visible and Infrared. The whole system is positioned on an optical bench with air-cushion to avoid vibration. 


\section{References}

[1.1] D. Errandonea, F. J. Manjón, Presure effects on the structure and electronic properties of ABX scintillating crystals. Progress Mater. Sci. 53 (2008) 711-773.

[1.2] P. Boutinaud, M. Bettinelli, F. Diaz, Intervalence charge transfer in $\mathrm{Pr}^{3+}$ - and $\mathrm{Tb}^{3+}$-doped double tungstate crystals $\mathrm{KRE}\left(\mathrm{WO}_{4}\right)_{2}(\mathrm{RE}=\mathrm{Y}, \mathrm{Gd}, \mathrm{Yb}, \mathrm{Lu})$. Opt. Mater. 32 (2010) 1659-1663.

[1.3] Z. Wang, H. Liang, Q. Wang, L. Luo, M. Gong, Luminescent properties of $\mathrm{Tb}^{3+}$ activated double molybdates and tungstates. Mater. Sci. Eng. B 164 (2009) 120-123.

[1.4] Y. Du, H. Jiao, D. He, Hydrothermal Synthesis and Luminescence of AgGdo.9Eu0.1(WO4)2 Phosphor. Acta Chim. Sinica 6921 (2011) 2550-2554.

[1.5] C. Colón, A. Alonso-Medina, F. Fernández, R. Sáez-Puche, V. Volkov, C. Cascales, and C. Zaldo, Correlation between Polymorphism and Optical Bandwidths in AgNd(WO4)2. Chem. Mater. 1726 (2005) 6635-6643.

[1.6] E. Tomaszewicz, H. Fuks, J. Typek, B. Sawicki, M. Oboz, T. Groń, T. Mydlarz, Preparation, thermal stability and magnetic properties of new $\mathrm{AgY}_{1-\mathrm{x}} \mathrm{Gd}_{x}\left(\mathrm{WO}_{4}\right)_{2}$ ceramic materials. Ceram. Int. 41 (2015) 5734-5748.

[1.7] K. Kavi Rasu, D. Balaji, S. Moorthy Badu, Spectroscopic properties of Eu+2: $\mathrm{KLa}\left(\mathrm{WO}_{4}\right)_{2}$ novel red phosphors, J. Lumin. 170 (2016) 547-555.

[1.8] G. Benoît, J. Véronique, A. Arnaud, G. Alain, Luminescence properties of tungstates and molybdates phosphors: Illustration on $A \operatorname{Ln}\left(\mathrm{MO}_{4}\right)_{2}$ compounds $(A$ = alkaline cation, $\mathrm{Ln}=$ lanthanides, $\mathrm{M}=\mathrm{W}, \mathrm{Mo}$ ). Solid State Sci. 13 (2011) 460-467.

[1.9] D. Balaji, K. Kavirasu, A. Durairajan, S. Moorthy Babu, Photoluminescence properties of novel $\mathrm{Sm}^{3+}$ and $\mathrm{Dy}^{3+}$ co-activated $\mathrm{CsGd}\left(\mathrm{WO}_{4}\right)_{2}$ phosphors. J. Alloys Compd. 637 (2015) 350-360. 
[1.10] M. Rico, J. Liu, U. Griebner, V. Petrov, M.D. Serrano, F. Esteban-Betegón, C. Cascales, C. Zaldo, Tunable laser operation of ytterbium in disordered single crystals of $\mathrm{Yb}: \mathrm{NaGd}\left(\mathrm{WO}_{4}\right)_{2}$. Opt. Express 12 (22) (2004)5362-5367.

[1.11] J. Liu, J.M. Cano-Torres, C. Cascales, F. Esteban-Betegón, M.D. Serrano, V. Volkov, C. Zaldo, M. Rico, U. Griebner, V. Petrov, Growth and continuous-wave laser operation of disordered crystals of $\mathrm{Yb}^{3+}: \mathrm{NaLa}\left(\mathrm{WO}_{4}\right)_{2}$ and $\mathrm{Yb}^{3+}: \mathrm{NaLa}\left(\mathrm{MoO}_{4}\right)_{2}$. Phys. Stat. Sol.(a)202(4) (2005)R29-R31.

[1.12] A. Xie, X. Yuan, Y. Shi, F. Wang, J. Wang, Photoluminescence Characteristics of Energy Transfer Between $\mathrm{Eu}^{3+}$ and $\mathrm{Bi}^{3+}$ in $\mathrm{LiEu}_{1-\mathrm{BBi}}$ (WO4)0.5(MoO4)1.5. J. Am. Ceram. Soc. 92 (10) (2009) 2254-2258.

[1.13] C. Chiu, C. Liu, S. Huang, T. Chen, White-Light-Emitting Diodes Using Red-Emitting $\mathrm{LiEu}\left(\mathrm{WO}_{4}\right)_{2-x}\left(\mathrm{MoO}_{4}\right)_{\times}$Phosphors. J. Electrochem. Soc. 154 (7) (2007) 181-184.

[1.14] B. Yan, L. Lin, J. Wu, F. Lei, Photoluminescence of Rare Earth Phosphors $\mathrm{Na} 0.5 G_{0.5} \mathrm{WO}_{4}: \mathrm{RE}^{3+}$ and $\mathrm{Na}_{0.5} \mathrm{Gd}_{0.5}\left(\mathrm{Mo}_{0.75} \mathrm{~W}_{0.25}\right)_{4} \mathrm{O}_{4} \mathrm{RE}^{3+}(\mathrm{RE}=\mathrm{Eu}, \mathrm{Sm}, \mathrm{Dy})$. J. Fluoresc. 21 (2011) 203-211.

[1.15] Z. Lu, T. Wanjun, Synthesis and luminescence properties of Eu ${ }^{3+}$-activated $\mathrm{NaLa}\left(\mathrm{MoO}_{4}\right)\left(\mathrm{WO}_{4}\right)$ phosphor. Ceram. Int. 38 (2012) 837-840.

[1.16] Y. Chen, F. Cao, Y. Tian, L. Xiao, L. Li, Optimized photoluminescence by charge compensation in a novel phosphor system. Physica B 405 (2010) 435-438.

[1.17] F. Cao, Y. Tian, Y. Che, L. Xiao, Q. Wu, Luminescence investigation of red

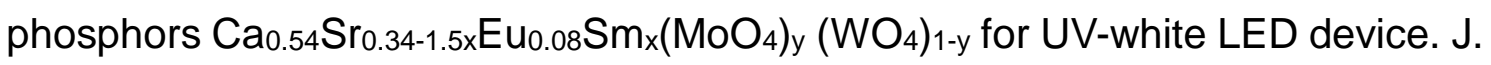
Lumin. 129 (2009) 585-588.

[1.18] L. Bonelli, F. Cornacchia, M. Tonelli, D. A. Lis, K. A. Subbotin, V. A. Smirnov, E. V. Zharikov, Spectroscopic properties of Er:NaLa $\left(\mathrm{WO}_{4}\right)_{2}$ crystals and effect of Ce codoping onto the excited state energy transformation in this crystal. J. Lumin. 135 (2013) 178-186. 
[1.19] E. Sani, A. Toncelli, M. Tonelli, D. A. Lis, E. V. Zharikov, K. A. Subbotin, V. A Smirnov, Effect of cerium codoping in $\mathrm{Er}^{3+}, \mathrm{Ce}^{3+}: \mathrm{NaLa}\left(\mathrm{MoO}_{4}\right)_{2}$ crystals. J. Appl. Phys. 97 (12) (2005) 123531-1-123531-6.

[1.20] Y. H. Tsang, D. J. Binks, B. D. O. Richards, A. Jha, Spectroscopic and lasing studies of $\mathrm{Ce}^{3+}: \mathrm{Er}^{3+}: \mathrm{Yb}^{3+}: \mathrm{YVO}_{4}$ crystals. Laser Phys. Lett. 8 (10) (2011) 729-735.

[1.21] Y. J. Chen, J. H. Huang, Y. Q. Zou, Y. F. Lin, Z. D. Luo, Y. D Huang, Diode-pumped $\mathrm{Er}^{3+}: \mathrm{Yb}^{3+}: \mathrm{NaCe}_{0,43} \mathrm{Gd}_{0,57}\left(\mathrm{WO}_{4}\right)_{2}$ pulse laser passively Q-switched with a $\mathrm{Co}^{2+}: \mathrm{Mg}_{0,4} \mathrm{Al}_{2,4} \mathrm{O}_{4}$ saturable absorber at $1.53 \mu \mathrm{m}$. Laser Phys. 24 (2014) 045810.

[1.22] J. Yan, X. Xiao, J. Yu, D. Mao, G. Lu, White light emission materials of self-assembled rare earth molybdates $\mathrm{NaRe}\left(\mathrm{MoO}_{4}\right)_{2}$ micro-particles: the controllable synthesis, growth mechanism and luminescent properties. Cryst. Res. Technol. 50 (7) (2015) 580-593.

[1.23] H. Fuks, S. M. Kaczmarek, G. Leniec, L. Macalik, B. Macalik, J. Hanuza, EPR and vibrational studies of some tungstates and molybdates single crystals. Opt. Mater. 32 (2010) 1560-1567.

[1.24] J. H. Huang, Y. J. Chen, X. H. Gong, Y. F. Lin, Z. D. Luo, Y. D. Huang, Spectral Properties and 1.5-1.6 $\mu \mathrm{m}$ Laser Operation of Er:Yb:NaCe(WO4)2 Crystal. Laser Phys. 22 (1) (2012) 146-151.

[1.25] C. Li, J. Lin, Rare earth fluoride nano-/microcrystals: synthesis, surface modification and application. J. Mater. Chem. 20 (2010) 6831-6847.

[1.26] D. Bloch, R. Lemaire, Metallic Alloys and Exchange-Enhanced Paramagnetism. Application to Rare-Earth-Cobalt Alloys. Phys. Rev. B 2 (1970) 2648.

[1.27] V Moizan, V Nazabal, J Troles, $P$ Houizot, JL Adam, J. Doualan, R. Moncorgé, F. Smektala, G. Gadret, S. Pitois, G. Canat, Er ${ }^{3+}$-doped GeGaSbS glasses for mid-IR fibre laser application: Synthesis and rare earthspectroscopy. Opt. Mater. 31 (2008) 39-46. 
[1.28] G. Tyler, Rare earth elements in soil and plant systems-A review. Plant and Soil 267 (2004) 191- 206.

[1.29] K. Kawano, K. Arai, H. Yamada, N. Hashimoto, R. Nakata, Application of rare-earth complexes for photovoltaic precursors. Sol. Energy Mater. Sol. Cells 48 (1-4) (1997) 35-41.

[1.30] R. Mukherjee, S. Saha, A. Dutta, T. P. Sinha, Dielectric and Raman spectroscopic studies of $\mathrm{A}_{2} \mathrm{ErSbO}_{6}(\mathrm{~A}=\mathrm{Ba}, \mathrm{Sr}$ and $\mathrm{Ca})$. J. Alloy. Compd. 651 (2015) 222-229.

[1.31] P. J. Saines, J. R. Spencer, B. J. Kennedy, M. Avdeev, Structures and crystal chemistry of the double perovskites $\mathrm{Ba}_{2} \mathrm{LnB}^{\prime} \mathrm{O}_{6}\left(\mathrm{Ln}=\right.$ lanthanide $\mathrm{B}^{\prime}=\mathrm{Nb}^{5+}$ and $\left.\mathrm{Ta}^{5+}\right)$ : Part I. Investigation of $\mathrm{Ba}_{2} \mathrm{LnTaO}_{6}$ using synchrotron $\mathrm{X}$-ray and neutron powder diffraction. J. Solid State Chem. 180 (2007) 2991-3000.

[1.32] P. J. Saines, J. R. Spencer, B. J. Kennedy, Y. Kubota, C. Minakata, H. Hano, K. Kato, M. Takata. Structures and crystal chemistry of the double perovskites $\mathrm{Ba}_{2} \mathrm{LnB}^{\prime} \mathrm{O}_{6}\left(\mathrm{Ln}=\right.$ lanthanide and $\mathrm{B}^{\prime}=\mathrm{Nb}$ and $\left.\mathrm{Ta}\right)$ : Part II Temperature dependence of the structures of Ba2LnB'O6. J. Solid State Chem. 180 (2007) 3001-3007.

[1.33] H. Karunadasa, Q. Huang, B. G. Ueland, P. Schiffer, R. J. Cava, $\mathrm{Ba}_{2} \mathrm{LnSbO}_{6}$ and $\mathrm{Sr}_{2} \mathrm{LnSbO}_{6}(\mathrm{Ln}=\mathrm{Dy}, \mathrm{Ho}, \mathrm{Gd})$ double perovskites: Lanthanides in the geometrically frustrating fcc lattice. PNAS 100 (14) (2003) 8097-8102. 


\section{CHAPTER 2 ---- INSTRUMENTAL TECHNIQUES AND METHODS}

\section{1.-Introduction of Varies Preparation Techniques of Samples.}

\subsubsection{Ceramic method Synthesis}

Varieties technique methods could be used for the preparation of ceramic samples. Among them, the most widely used method is ceramic method. The ceramic method can prepare polycrystallinesolids easily just from a mixture of solid starting materials like oxides. The selection of chemical reactants depends on the reaction conditions and expected nature of the product. The reactants should be dried thoroughly prior to weighting. As increase in surface area enhances the reaction rate, fine grained materials should be used if possible. The advantages of ceramic method can be concluded to its simple produce process, easy controllable reaction parameters and less limits of raw materials which make it can be used in wide applications. The disadvantages are that majorities solid phase reactions are carried out at high temperature. It is necessary to heat them to much higher temperatures than the room temperature, can upto $1500^{\circ} \mathrm{C}$, in order for the reaction to occur at an appreciable rate which increase the cost of preparation and resulting sinterized materials with large particle size.However the ceramic method is still the most suitable industrial process for large-scale production.

\subsubsection{Molten Salt Synthesis}

Molten salt synthesis is one of the methods of preparing ceramic powders, involves the use of a low melting point molten salt as the medium for preparing complex oxides from their constituent materials (oxides and carbonates). Ceramic powders are prepared from solid, liquid, and gas phases by various methods. Molten salt synthesis is a modified powder metallurgical method. Salt with a low melting point is added to the reactants and heated above the melting point of the salt. Different from the flux method, which uses small amount of salt as an additive to enhance the reaction rate, a large amount of salt is used as the 
solvent to control powder characteristics such as particle size and shape in molten salt synthesis. The appearance of liquid phase in the reaction process will enhance the rates of solid state reactions as well. Typical examples of salts used in molten salt synthesis are chlorides and sulfates. The melting points of $\mathrm{NaCl}$ and $\mathrm{KCl}$ are $801^{\circ} \mathrm{C}$ and $770^{\circ} \mathrm{C}$ respectively, and that of $0.5 \mathrm{NaCl}-0.5 \mathrm{KCl}$ (eutectic composition) is $650^{\circ} \mathrm{C}$. For example, $0.635 \mathrm{Li}_{2} \mathrm{SO}_{4}-0.365 \mathrm{Na}_{2} \mathrm{SO}_{4}$ is the most commonly used salt among sulfates because of its low melting temperature, which is $594^{\circ} \mathrm{C}$, whereas that of $\mathrm{Na}_{2} \mathrm{SO}_{4}-\mathrm{K}_{2} \mathrm{SO}_{4}$ is $823^{\circ} \mathrm{C}$ [2.1].

The procedure of the molten salt method is analogous as that of a conventional powder metallurgical method and is easily scaled up for the fabrication of large quantities of materials despite that the reacted mass need to be washed with an appropriate solvent (typically as water) to remove the salt after cooled down. The complex oxide powder is obtained after drying. Molten salt synthesis is suitable for the synthesis of anisotropic particles. Its biggest advantage is that by introducing a template it can control the shape of the particles and further the direction of arrangement of particles. In addition the molten salt synthesis method can also greatly reduce the calcination temperature, thereby reducing the cost of production.

\subsubsection{Chemical Co-precipitation Method}

Chemical co-precipitation is a method that makes use of soluble metal salts, formulated as a solution by a certain percentage, then added a precipitating agent (such as $\mathrm{OH}^{-}, \mathrm{C}_{2} \mathrm{O}_{4}{ }^{2-}, \mathrm{CO}_{2}{ }^{2-}$, etc.) or let the relevant metal ions be hydrolyzed at a certain temperature so that the various metal ions can precipitate as a constituent element in the same time. The properties of the precipitate can be controlled by adjusting the concentration and $\mathrm{pH}$ of the solution. The precipitate was then calcined to obtain a homogeneous mixture of the various constituent oxides. The process of chemical co-precipitation is simple and easy for scale production, but it is easily result in deviation of the stoichiometric composition and loss of chemical homogeneity. Hence for different reaction system, looking for proper precipitants to achieve the homogeneous mixing of constituent element at atomic size is the problem that should be paid particular attention. 


\subsubsection{Hydrothermal Synthesis}

Hydrothermal synthesis can be defined as a method of synthesis of crystals that depends on the solubility of minerals in hot water under high pressure. It is known that the solubility of hydroxide in water is greater than the corresponding solubility of oxide in water, so that the oxide can be precipitated while the hydroxide dissolved in water at the same time. The crystal growth is performed in an apparatus consisting of a steel pressure vessel called autoclave, in which a nutrient is supplied along with water. Advantages of hydrothermal synthesis over other method of crystal growth include the ability to create crystalline phases which are not stable at the melting point and also materials which have a high vapor pressure near their melting points. Otherwise, the method is particularly suitable for the growth of large good-quality crystals while maintaining relative low temperature and free of expensive alkoxides by controlling over their composition. Disadvantages of the method include the need of expensive autoclaves, and the impossibility of observing the crystal as it grows.

\subsubsection{Sol-gel Method}

Sol - gel method is a promising wet-chemical technique which developed rapidly over the past decades for the fabrication of ceramic materials. It is a synthesis method that metal organic compounds, metal inorganic compounds, or mixtures of those both evolve towards the formation of a gel-like biphasic system containing both liquid phase and solid phase through hydrolysis and condensation process to obtain oxides or other compounds. The process involves conversion of monomers into a colloidal solution (sol) which acts as the precursor for an integrated network (gel) of either discrete particles or network polymers.

No matter that the precursor (starting material) is an inorganic salt or a metal alkoxide, the main process of sol - gel method is that the precursor is dissolved in a solvent (water or organic solvent) forming a homogeneous solution. The solvent and solute generate alcoholysis or hydrolysis reaction, and then the 
reaction products gather into about $1 \mathrm{~nm}$ particles and form a sol. The sol will be evaporated and dried into a gel. The most basic reaction process is as follows:

(1) Solvation

Ionizable precursor (metal metal cation $\mathrm{M}^{\mathrm{z}+}$ ) attract water molecules to form a solvent unit $\mathrm{M}\left(\mathrm{H}_{2} \mathrm{O}\right) \mathrm{n}^{\mathrm{z}}$ ( $\mathrm{z}$ is the valence of $\mathrm{M}$ ions). The solvent unit have a strong trend to release $\mathrm{H}^{+}$ions in order to maintain its coordination number.

$\mathrm{M}\left(\mathrm{H}_{2} \mathrm{O}\right) \mathrm{n}^{\mathrm{z}+}=\mathrm{M}\left(\mathrm{H}_{2} \mathrm{O}\right){ }_{\mathrm{n}-1}(\mathrm{OH})^{(\mathrm{z}-1)+}+\mathrm{H}^{+}$

(2) Hydrolytic Reaction

Non-ionizable molecular precursors such as metal alkoxides $M(O R)_{n}$ ( $n$ is the valence of the metal $M, R$ represents an alkyl group) react with water:

$\mathrm{M}(\mathrm{OR})_{\mathrm{n}}+\mathrm{xH} \mathrm{H}_{2} \mathrm{O}=\mathrm{M}(\mathrm{OH})_{x}(\mathrm{OR})_{n-x}+x \mathrm{ROH}$

The reaction can be undergone continuously until the generation of $M(O H)$ n.

(3) Polycondensation Reaction

It can be divided into

Dehydration condensation:

$-\mathrm{M}-\mathrm{OH}+\mathrm{HO}-\mathrm{M}=\mathrm{M}-\mathrm{O}-\mathrm{M}-+\mathrm{H}_{2} \mathrm{O}$

And loss alcohol condensation:

$-\mathrm{M}-\mathrm{OR}+\mathrm{HO}-\mathrm{M}=\mathrm{M}-\mathrm{O}-\mathrm{M}-+\mathrm{ROH}$

Sol-gel synthesis can obtain a fine powder with homogeneous nano-scale particles which will improve the density of ceramic materials, reduce the sintering temperature and shorten the producing cycle.

\section{2. - Sample Preparation of $\mathrm{AgCe}\left(\mathrm{WO}_{4}\right)_{2}$ with $\mathrm{Eu}^{3+}$ and $\mathrm{Tb}^{3+}$ ions as dopants}

$\mathrm{Ce}^{3+}$ ions attracted much attentions because of the low cost and the spin and parity allowed $4 f-5 d$ transitions which have a fast radiative life time of about 10-50 ns. And it has been found that the introduction of $\mathrm{Ce}^{3+}$ ions into $\mathrm{Er}^{3+}$ doped materials can efficiently depopulate $\mathrm{Er}^{3+}$ ions in the ${ }^{4} I_{11 / 2}$ to the ${ }^{4} I_{13 / 2}$ level by a phonon-assisted cross relaxation ${ }^{4} \mathrm{I}_{11 / 2}\left(\mathrm{Er}^{3+}\right)+{ }^{2} \mathrm{~F}_{5 / 2}\left(\mathrm{Ce}^{3+}\right){ }^{4} \mathrm{I}_{13 / 2}\left(\mathrm{Er}^{3+}\right)+{ }^{2} \mathrm{~F}_{7 / 2}\left(\mathrm{Ce}^{3+}\right)$ 
which help to reduce the back energy transfer and up-conversion loss [2.2-2.5].Alkali-based double tungstates and molybdates are the best known groups [2.6-2.12], however the $\mathrm{Ce}^{3+}$ ion is hard to exist in the scheelite-type structure hosts with alkaline cations because its relatively high instability in air. So the $\mathrm{Ce}^{3+}$ contained scheelite-type crystals are normally prepared by chemical methods or grown as monocrystals [2.13-2.15] instead of the easiest ceramic method. Additionally, as known as that spectral characteristics of compounds are determined by their chemical composition and type of crystalline structure, our attentions were paid into the Ag-based system which is still not deeply investigated.

Analytical grade $\mathrm{Ag}_{2} \mathrm{O}, \mathrm{CeO}_{2}, \mathrm{WO}_{3}$ were used as starting materials for the synthesis of $\mathrm{Ag}_{(1+x)} \mathrm{Ce}_{(1-x)}\left(\mathrm{WO}_{4}\right)_{2}$ polycrystalline powders by ceramic method in air with the stoichiometric amounts.

$$
(1-\mathrm{x}) \mathrm{CeO}_{2}+1 / 2(1+x) \mathrm{Ag}_{2} \mathrm{O}+2 \mathrm{WO}_{3} \rightarrow \mathrm{AgCe}\left(\mathrm{WO}_{4}\right)_{2}
$$

Stoichiometric amounts of Analytical grade $\mathrm{EuCl}_{3} \cdot 6 \mathrm{H}_{2} \mathrm{O}$ and $\mathrm{Tb}\left(\mathrm{NO}_{3}\right)_{3} \cdot 5 \mathrm{H}_{2} \mathrm{O}$ were used as dopants by mixing with $\mathrm{Ag}_{2} \mathrm{O}, \mathrm{CeO}_{2}, \mathrm{WO}_{3}$ for the synthesis of $\mathrm{AgCe}_{1-\mathrm{x}} \mathrm{M}_{\mathrm{x}}\left(\mathrm{WO}_{4}\right)_{2}(\mathrm{M}=\mathrm{Eu}$ or $\mathrm{Tb})$. The mixtures were ground and heated at $750{ }^{\circ} \mathrm{C}$ in ceramic crucible in air atmosphere for 4 hours at first. After cooling to room temperature, the samples were reground in an agate mortar and heated again at $800{ }^{\circ} \mathrm{C}$ for $12 \mathrm{~h}$ to complete the reaction, and then quenched to room temperature in air.

In order to determine the treatment temperatures and decomposition temperatures of the different mixtures of starting products, thermal gravimetric (TG) and differential thermal analysis (DTA) were firstly made in still air using a simultaneous TG/DTA in TA equipment, Q-600 model. The compounds were heated and cooled at a $10^{\circ} \mathrm{C} / \mathrm{min}$ rate from room temperature to $1000{ }^{\circ} \mathrm{C}$ using $\mathrm{Al}_{2} \mathrm{O}_{3}$ as the reference.

\section{3. - Sample Preparation of $\mathrm{AgLn}\left(\mathrm{WO}_{4}\right)\left(\mathrm{MoO}_{4}\right)$.}

Lately, complex tungstate-molybdates $\mathrm{AB}\left(\mathrm{XO}_{4}\right)_{2}$ have become the hot spot for the atoms Mo and $\mathrm{W}$, which have similar ionic radius, to substitute each other 
[2.16-2.21]. Hence, the Ag-based scheelite system with both W and Mo atoms were investigated.

Analytical grade $\mathrm{Ag}_{2} \mathrm{O}, \mathrm{WO}_{3},\left(\mathrm{NH}_{4}\right)_{6} \mathrm{Mo}_{7} \mathrm{O}_{24} \cdot 4 \mathrm{H}_{2} \mathrm{O}$ and rare earth oxides $\mathrm{Ln}_{2} \mathrm{O}_{3}$ ( $\mathrm{Ln}=\mathrm{La}, \mathrm{Nd}, \mathrm{Sm}, \mathrm{Eu}, \mathrm{Gd}$, Dy, Ho, Er, Tm, Yb, Lu and Y), $\mathrm{CeO}_{2}, \mathrm{Pr}_{6} \mathrm{O}_{11}$ and $\mathrm{Tb}_{4} \mathrm{O}_{7}$ were used as starting materials. $\mathrm{AgLn}\left(\mathrm{WO}_{4}\right)\left(\mathrm{MoO}_{4}\right)$ polycrystalline powders were prepared by ceramic method in air using stoichiometric amounts. The mixtures were ground and heated at $700{ }^{\circ} \mathrm{C}$ in ceramic crucible in air atmosphere for 12 hours at first. After cooling to room temperature, the samples were reground in an agate mortar and heated again at $750{ }^{\circ} \mathrm{C}$ for $12 \mathrm{~h}$ to complete the reaction, and then quenched to room temperature in air.

\section{4. - Sample Preparation of $\mathrm{Sr}_{2} \mathrm{LnSbO}_{6}$ double perovskites}

Samples were prepared from stoichiometric amounts of sesquioxide antimony $\mathrm{Sb}_{2} \mathrm{O}_{3}$ with purity of $99.998 \%$, strontium carbonate $\mathrm{Sr}\left(\mathrm{CO}_{3}\right)_{2}$ and corresponding $\mathrm{Ln}_{2} \mathrm{O}_{3}$ ( $\mathrm{Ln}=$ oxides $\mathrm{Y}, \mathrm{La}, \mathrm{Nd}, \mathrm{Sm}, \mathrm{Eu}, \mathrm{Gd}$, Dy, Ho, Er, Tb, Yb and Lu), CeO2, $\mathrm{Pr}_{6} \mathrm{O}_{11}$ and $\mathrm{Tb}_{4} \mathrm{O}_{7}$ with purity of $99.997 \%$, by ceramic method after heated at $1200^{\circ} \mathrm{C}$ in air in $\mathrm{Al}_{2} \mathrm{O}_{3}$ ceramic crucible according to the following reactions:

$$
\begin{aligned}
& 1 / 2 \mathrm{Ln}_{2} \mathrm{O}_{3}+1 / 2 \mathrm{Sb}_{2} \mathrm{O}_{3}+2 \mathrm{SrCO}_{3} \stackrel{\text { aire } / 1200^{\circ} \mathrm{C}}{\longrightarrow} \operatorname{LnSbSr}_{2} \mathrm{O}_{6} \\
& 1 / 6 \mathrm{Pr}_{6} \mathrm{O}_{11}+1 / 2 \mathrm{Sb}_{2} \mathrm{O}_{3}+2 \mathrm{SrCO}_{3} \stackrel{\text { aire } / 1200^{\circ} \mathrm{C}}{\longrightarrow} \operatorname{PrSbSr}_{2} \mathrm{O}_{6} \\
& 1 / 3 \mathrm{Yb}_{3} \mathrm{O}_{4}+1 / 2 \mathrm{Sb}_{2} \mathrm{O}_{3}+2 \mathrm{SrCO}_{3} \stackrel{\text { aire } / 1200^{\circ} \mathrm{C}}{\longrightarrow} \mathrm{YbSbSr}_{2} \mathrm{O}_{6}
\end{aligned}
$$

In order to determine the treatment temperatures and decomposition temperatures of the different mixtures of starting products, we are first conducted several tests of thermal gravimetric analysis. Also, the possible loss of starting materials by volatilization is studied with this technique, with the purpose of introducing a possible excess of the volatile component.

The initial mixtures of the starting oxides were ground and homogenized in an agate mortar before treating the reaction temperature, from room temperature to estimated $1200^{\circ} \mathrm{C}$ for 96 hours in recrystallized alumina crucibles. It was performed various interruptions that proceeded to grind the samples in order to 
homogenize the reaction products. At the same time the degree of reaction was monitored by analyzing the different phases by X-ray diffraction. The obtained samples are homogeneous and with clear colors.

Before this treatment, the different oxides of the lanthanides used, $\mathrm{Ln}_{2} \mathrm{O}_{3}, \mathrm{Yb}_{3} \mathrm{O}_{4}$ and $\operatorname{Pr}_{6} \mathrm{O}_{11}$, were treated at $1000^{\circ} \mathrm{C}$ for 12 hours in order to remove moisture and carbonates and hydroxycarbonates which inevitably accompany these oxides.

\section{5. - Structure Characterization.}

\subsubsection{Simultaneous Thermo gravimetric and Differential Thermal Analysis} (SDT).

Experiences of simultaneous thermo gravimetric and differential thermal analysis (SDT) were performed using a TA-Q600 instrument (as seen in Fig.2.1) that records the weight and heat flow at the same time (DSC) on the same sample, in the range from room temperature to $1500{ }^{\circ} \mathrm{C}$. The gravimetric sensitivity is $0.1 \mu \mathrm{g}$, the thermal sensitivity is $0.0001{ }^{\circ} \mathrm{C}$ and provides a calorimetric accuracy of $\pm 2 \%$.
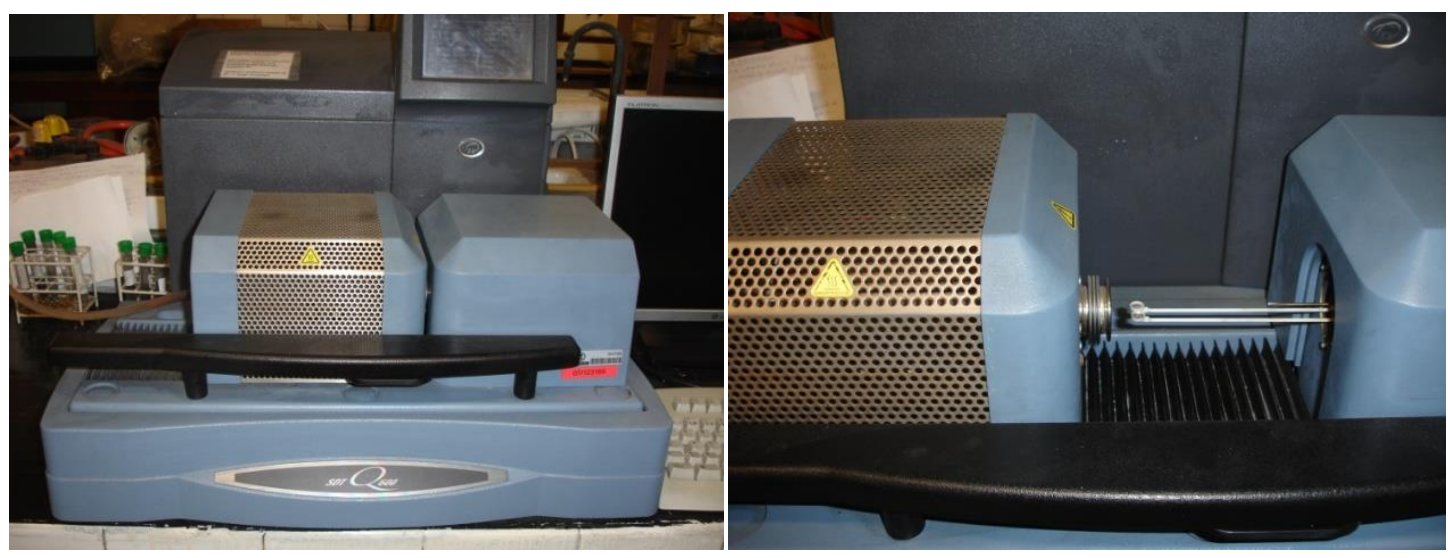

Fig. 2.1 Appearance of the TA Instrument SDT Q600 

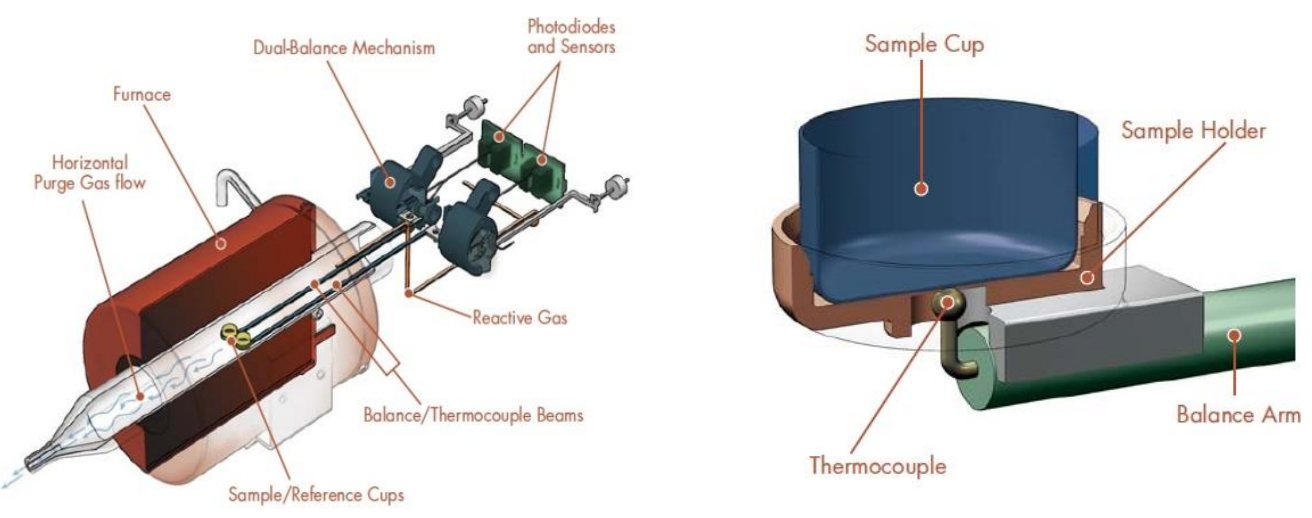

Fig. 2.2 Explode views of the TA Instrument SDT Q600

The horizontal balance arm is located within the oven and is necessary to calibrate without samples to compensate the expansion effects of the arm itself. The thermo couple Pt / Pt-Rhodium has been calibrated with reference to melting temperatures of zinc, lead and indium. A sapphire crystal was used for calorimeter calibration. The equipment was designed with dynamic gas flow which permits the use of different atmospheres. The explode view features were presented in the Fig. 2.2 for better understanding.

In the realization of experiment, different samples from 10 to $20 \mathrm{mg}$ were introduced in a sample holder of platinum or recrystallized alumina, and then heated between room temperature and $1300{ }^{\circ} \mathrm{C}$ at a heating rate of $10^{\circ} \mathrm{C}$ per minute.

\subsubsection{X-ray Diffraction.}

The products were obtained in powder form and its characterization was carried out using the Debye-Scherrer technique.

Generator KRISTALLOFLEX SIEMENS K810 and goniometer D-5000 equipped with a graphite monochromator were used. The radiation used in all cases was the copper $K_{\alpha}, \lambda=1.5418 \AA$.

The working conditions were $40 \mathrm{KV}$ and $32 \mathrm{~mA}$. The intensity measurement was performed by scanning in steps from $2 \theta=10^{\circ}$ to $2 \theta=120^{\circ}$, with increments of 
$0.05^{\circ}$ in $2 \theta$ and pulse time was 5 s per step, which gives a scanning speed of 1 degree/100s.

With the Rietveld method, powder diffraction technique is no longer restricted only to identify crystalline phases or refined cell parameters or even the microstructural analysis (particle size and micro strains), it is possible to refine the structure from the full profile of the diffraction pattern. It is a method based on the analysis of direct observation. The full profile of the diffraction pattern was obtained as a set of "number of accounts", Yiobs, for each angular position20i ( $\mathrm{i}=$ $1, \ldots N)$.

All of the information contained in the powder diagram is parameterized in a model which is adjusted so that the difference between the experimental data and the calculated fitting model differ as little as possible.

The model to calculate the number of accounts at position $i$ is depend on a set of parameters that can be divided into two main subsets:

(1) Parameters of pure structural position: atomic, occupation factors and temperature factors.

(2) Parameters of instrumental profile or dependent on the used particular sample: zero error of the diffractometer, parameters of profile form, parameters of defining the width at half maximum, cell parameters, scaling factor, parameters of preferred orientation, parameters describing the substance, etc.

If we arrange these parameters in a vector $\alpha=\left(\alpha_{1}, \alpha_{2}, \ldots, \alpha_{p}\right)$, the number of calculated accounts for the position $\mathrm{i}$ is $\mathrm{Y}_{\text {ical }}\left(\alpha_{1}\right)$. The Rietveld method then determine the vector $\alpha_{m}$ that minimizes the expression:

$$
\chi_{p}^{2}=\sum_{i} W_{i}\left(Y_{i o b s}-Y_{\text {icalc }}(\alpha)\right)
$$

where $W$ is the inverse of the variance associated with the observation $i$ (For sufficiently high counting rates and the process follows a Poisson statistical distribution ( $\alpha^{2}=Y_{\text {iobs}}$ ). The condition of minimum $\chi_{p}^{2}$ which respected to the parameter $\alpha$ implies that the gradient of $\partial \chi_{p}^{2} / \partial \alpha$ is annulled. Starting from an 
initial set of parameters $\alpha_{0}$ (next to the structure to refine) and then in a Taylor series around the point of $Y_{\text {ical }}$ function can, through an iterative process, obtain the variations of $\alpha_{i}$ parameters in each cycle that improve the value of $\chi_{p}^{2}$. The vector $\alpha_{n}=\alpha_{0}+\delta \alpha$, where $\delta$ is a damping factor which is closest to the initial value $\alpha 0$.

The discrepancy indices currently used in the literature are as followed:

$$
\begin{aligned}
& \chi_{p}^{2}=\sum_{i} W_{i}\left(Y_{\text {iobs }}-Y_{\text {icalc }}(\alpha)\right) \\
& R_{p}=100 \sum_{i}\left|\left(Y_{\text {iobs }}-Y_{\text {icalc }}(\alpha)\right)\right| /\left|\sum_{i} Y_{\text {iobs }}\right| \\
& R_{w p}=100\left[\sum_{i} W_{i}\left(Y_{\text {iobs }}-Y_{\text {icalc }}(\alpha)\right)^{2} / \sum_{i} W_{i} Y_{\text {iobs }}^{2}\right]^{1 / 2} \\
& R_{E}=100\left[(N-P) / \sum_{i} W_{i} Y_{\text {iobs }}^{2}\right]^{1 / 2} \\
& \text { G.o.f. }=\chi_{v}^{2}=\left(R_{\text {wp }} / R_{E}\right)=\sum_{i} W_{i}\left(Y_{\text {iobs }}-Y_{\text {icalc }}\right)^{2} /(N-P) \\
& R_{\text {Bragg }}=100 \sum_{k}\left|I_{\text {kobs }}-I_{\text {kcalc }}\right| / \sum_{k}\left|I_{\text {kobs }}\right|
\end{aligned}
$$

In principle, the only indicative value which is known as the statistical behavior is $\chi_{V}^{2}$ which is verified in the Poisson distribution law for statistical counts. The other according indices only have intrinsic meaning when systematic errors do not exist.

In general, in the form of giving the overall adjusted results by the Rietveld method, it requires the presentation of a complete pattern of the difference between observed and calculated diffract gram profiles $Y_{\text {iobs }}-Y_{\text {icalc }}$ at each point of the diffraction pattern and signaling the positions of the Bragg reflections. This pattern adds the information which is not contained in the discrepancy index values which is defined previously. 
The systematic use of the Rietveld method have been applied for a long time, and with better results, in the neutron diffraction and in the X-ray diffraction because of the great simplicity of neutron-matter interaction: the factors of atomic diffusion are constants comparing with diffusion angles, contrast between elements of atomic number, decrease of preferential orientations, and decrease of systematic errors from instrument.

The accuracy in the refinement of a structure by the Rietveld method is much less than that commonly obtained by diffraction with single crystals. Deviations are usually between five and twenty times greater than those corresponding to the results of single crystal.

The order of magnitude of the different rates between the model and experimental data, for the profile functions, give better results as followed:

$12 \leq R_{p} \leq 20 ; 13 \leq R w_{p} \leq 25 ; 3 \leq R_{B} \leq 12$

J. Rodriguez Carvajal [2.22] intends to adopt, as a criterion for deciding the goodness of a given model, the value of the indices Rв and Rwp. According to him, we consider that a model is correct when the orders of magnitude of these indices are those indicated in the above expression.

\subsubsection{Infrared Spectroscopy (FTIR).}

Infrared spectroscopy is the spectroscopy that deals with the electromagnetic spectrum in the infrared region of the light, which have a longer wavelength and lower frequency than visible light. A basic IR spectrum is a graph of infrared light absorbance or transmittance on the vertical axis versus frequency (wavenumber, normally use units $\mathrm{cm}^{-1}$ ) or wavelength on the horizontal axis. The laboratory instrument that uses this technique is a Fourier transform infrared (FTIR) spectrometer.

The infrared spectrum can be divided into three regions; the near infrared, mid infrared and far infrared, which correspond to the region $14000-4000 \mathrm{~cm}^{-1}$, $4000-400 \mathrm{~cm}^{-1}$ and $400-10 \mathrm{~cm}^{-1}$ respectively. 
Photon energies associated with the infrared region are normally not large enough to excite electrons, but may induce vibrational excitation of covalently bonded atoms and groups. Infrared spectroscopy exploits the fact that molecules absorb specific frequencies that are characteristic of their structure. These absorptions are resonant frequencies which match the transition energy of the bond or group that vibrates. The energies are determined by the shape of the molecular potential energy surfaces, the masses of the atoms, and the associated vibronic coupling.

In order to be "IR active" for a vibrational mode in a molecule, it must be associated with changes in the dipole. A molecule can vibrate in many ways, each way is called as a vibrational mode. For molecules with $n$-atoms, there are $3 n$ degrees of freedom, six of which are translations and rotations of the molecule itself. So it leaves $3 \mathrm{~N}-6$ degrees of vibrational modes for nonlinear molecules, whereas linear molecules have $3 \mathrm{~N}-5$ degrees of vibrational modes. Take $\mathrm{H}_{2} \mathrm{O}$ molecule as an example, it will have $3 \times 3-6=3$ degrees of vibrational freedom as a non-linear molecule.

The exact frequency at which a vibration occurs is determined by the strengths of the involved bonds and the mass of the component atoms. In practice, infrared spectra do not normally display separate absorption signals for each of the $3 n-6$ fundamental vibrational modes. The number of observed absorptions may be increased by additive and subtractive interactions leading to combination tones and overtones of the fundamental vibrations. Furthermore, the number of observed absorptions may be decreased as well by molecular symmetry, spectrometer limitations, and spectroscopic selection rules. One selection rule that influences the intensity of infrared absorptions, is that a change in dipole moment should occur for a vibration to absorb infrared energy. For example, absorption bands associated with $\mathrm{C}=\mathrm{O}$ bond stretching are usually very strong because a large change in the dipole takes place in this mode.

In our case, for the study by infrared spectroscopy, different samples were pressed into pullets in potassium bromide and subsequently its transmittance was measured in a FTIR spectrophotometer Perkin Elmer "Spectrum GX" as shown in Fig. 2.3. Its main characteristics are: 
Measurement range: $1000-27000 \mathrm{~nm}\left(10000 \mathrm{a}^{3} 37 \mathrm{~cm}^{-1}\right)$.

Lamps: Filament to $1350 \mathrm{~K}$, stabilized voltage, air cooled.

Detector:FR-DTGS (fast response deuterated triglycine sulfate).

Signal/Noise: 45000:1.

Resolution: 0.2 to $64 \mathrm{~cm}^{-1}$

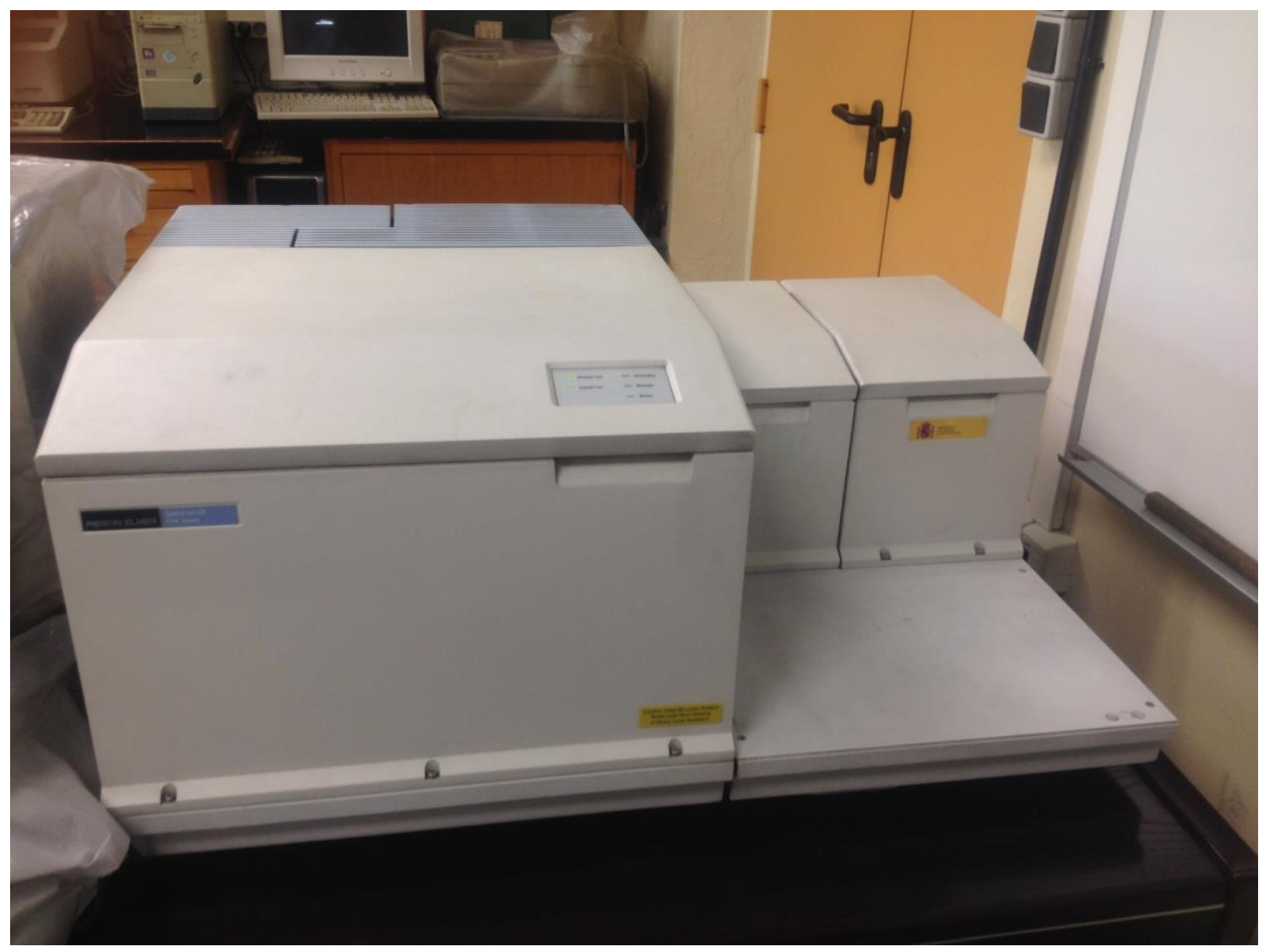

Fig. 2.3 FTIR spectrophotometer Perkin Elmer "Spectrum GX"

Instrumental accessories:

- The equipment is installed a wheel with filters, one of which contains an ampoule of methane, for the realization of the internal checking of equipment (accessory AVI).

REFL1302J50of Perkin-Elmer and calibration: Internal.

- The equipment is externally calibrated using a polystyrene standard. REF0186-2082of Perkin-Elmer. 


\subsubsection{Raman Spectroscopy}

Raman spectroscopy, based on the Raman scattering or inelastic scattering which found by C. V. Raman, is a spectroscopic technique used to observe vibrational, rotational, and other low-frequency modes in a system.[2.23] Raman spectroscopy is commonly used in chemistry to provide an analytical tool for molecular finger printing as well as monitoring changes in molecular bond structure.

In the theory of quantum particle interpretation, light is thought of as a photon which strikes the molecule and then in elastically scatters. In this interpretation the number of scattered photons is proportional to the size of the bond. The Raman effect is described as inelastic scattering of a photon off of a molecular bond. When a photon excites the molecule into a virtual energy state for a short period, three different potential results will come. Firstly, the molecule can relax back down to the ground state and emit a photon of equal energy to that of the incident photon which is an elastic process and is referred to Rayleigh scattering. Secondly, the molecule can relax to a real phonon state and emit a photon with less energy than the incident photon which is called Stokes shifted Raman scattering. Thirdly, the molecule is already in a real excited phonon state before being excited to a higher virtual state, and then relaxes back down to the ground state emitting a photon with more energy than the incident photon which is called Anti-Stokes Raman scattering. Due to the fact that most molecules will be found in the ground state at room temperature, there is a much lower probability that a photon will be Anti-Stokes scattered. As a result, most Raman measurements are performed considering only the Stokes shifted light.

With further investigation of the quantum interpretation of the Raman effect, The intensity of the Raman scattering $P_{\mathrm{s}}$ is equal to the intensity of the incident photons $l_{0}$ and a value known as the Raman cross-section $\sigma_{\mathrm{R}}$ as shown as following:

$$
\begin{aligned}
& P \mathrm{~s} \propto I \mathrm{o} / \lambda^{4} \\
& \sigma_{R} \propto 1 / \lambda^{4}
\end{aligned}
$$


It is obvious that there is a linear relationship between the intensity of the Raman scattering and the intensity of the incident light as well as a linear relationship between the intensity of the Raman scattering and the inverse of the wavelength to the fourth power. The intensity of the Raman scattering is proportional to the electric dipole-electric dipole polarizability change.

Raman spectroscopy provides fast, simple, repeatable and the most important non-invasive test for both qualitative and quantitative analysis. It does not require specific sample preparation. Samples can be measured directly or through transparent containers such as glass, quartz, and plastic by the optic fiber probe. Moreover, as the Raman scattering of water is very weak, Raman spectroscopy is an ideal tool for studying biological samples in aqueous solutions and chemical compounds. In comparison to other vibrational spectroscopy methods, such as FT-IR and NIR, Raman has several major advantages. Raman can cover a wide range from 50 to 4000 wavenumbers at the same time. Both the organic and inorganic substances can be analyzed. On the contrary, if the infrared spectrum needs to cover the same range, the gratings, beam splitters, filters and detectors must be changed. Otherwise, because the diameter of the laser beam is normally $0.2-2 \mathrm{~mm}$ at its focal point, and the conventional Raman requires only a small amount of the sample. This is a great advantage in comparison with infrared spectroscopy Furthermore, the objective lens of Raman microscope can focus the laser beam to 20 microns or less, which make it possible to analyze smaller samples or micro zones. Similar to FT-IR, Raman spectroscopy is highly selective, which allows it to identify and differentiate molecules and chemical species which are very analogous. Raman spectra are clear and sharp, which are more suitable for quantitative research, database searching, and qualitative studies with the use of difference analysis. In the chemical structural analysis, the intensity of independent Raman interval can be related with the number of functional groups. Resonance Raman effect can be used to selectively enhance vibrations of a specific chromophore in large biological molecules. The Raman scattering intensity of these chromophores can be selectively enhanced 1000-10000 times.

In our present work, the Raman measurements were carried out at room temperature over the wavenumbers range of $50-1100 \mathrm{~cm}^{-1}$. The instrument 
system was presented in Fig. 2.4. The samples were excited with a laser $\mathrm{Ar} / \mathrm{Kr}$ at $488.0 \mathrm{~nm}$. The scattered radiation was collected using a Notch filter to be subsequently driven (through an optical fiber) to a half-meter Spectrometer (Jobin-Yvon iHR550) equipped with a CCD.

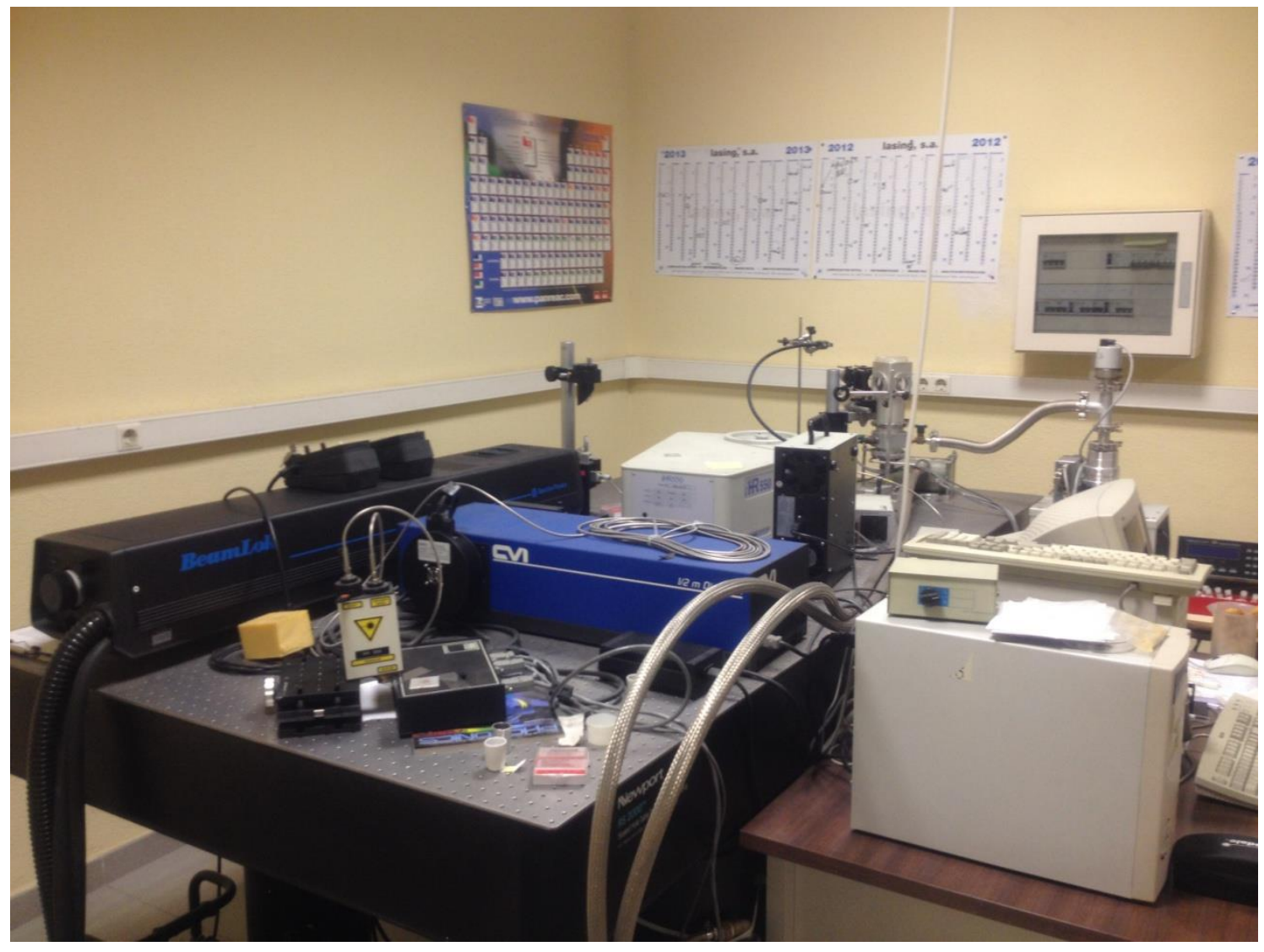

Fig. 2.4 Experimental system for the Raman spectra analysis.

\section{6. - Magnetic Measurements.}

\subsubsection{Magnetic susceptibility.}

When a substance is subjected to the action of a magnetic field intensity $\mathrm{H}$, it will induced a magnetic field $B$ in the same time and acquire a magnetization $M$, where the relationship between Band $\mathrm{H}$ is given by:

$$
B=H+4 \pi M
$$

The magnetization is related to the external applied field $\mathrm{H}$ by:

$$
\mathrm{M}=\chi \mathrm{H}
$$


where $\chi$ is the magnetic susceptibility per unit volume.

The magnetization $\mathrm{M}$ may be due to different types of contributions which originate in different magnetic field interactions depending on the matter. These interactions can be classified into three groups:

a) Diamagnetic, universal property of matter.

It is a consequence of Lenz's law of electromagnetism. All moving electrical charge creates a magnetic field and within an external magnetic field the induced field is applied contrary to sense. This type of contribution is characterized in that the magnetization is negative and proportional to the applied field.

b) Paramagnetic, property due to the existence of unpaired electrons in a material.

The mechanism of interaction is that a magnetic dipole in a magnetic field tends to order and align in the same direction. The magnetization according to this phenomenon is positive and proportional to the applied field.

c) Contributions due to cooperative effects: ferromagnetism and anti-ferromagnetism.

Materials exhibiting these effects are characterized by a strong interaction with the applied magnetic field and the magnetization that is a complex function thereof.

As given above, the magnetization $\mathrm{H}$ can be written as a sum of contributions:

$$
\mathrm{M}=\chi \mathrm{H}=\chi_{\mathrm{d}} \mathrm{H}+\chi_{\mathrm{p}} \mathrm{H}+\mathrm{M}_{\mathrm{c}}(3)
$$

Moreover, the energy of a magnetized body is given by:

$$
W=\frac{1}{2} H M
$$

The force acting on the magnetic moment due to the action of an external magnetic field $\mathrm{H}$ is the gradient of the energy. 


\subsubsection{SQUID}

SQUID (superconducting quantum interference device) is a very sensitive magnetometer used to measure extremely subtle magnetic fields, based on superconducting loops containing Josephson junctions. It contains two main types: DC SQUID (Direct Currency) and RF SQUID (Radio Frequency). RF SQUID can work with only one Josephson junction (superconducting tunnel junction), which might make them cheaper to produce, but with less sensitive.

Josephson junctions consist of two superconductors coupled by a weak link. The weak link can be an insulating barrier (known as superconductor-insulatorsuperconductor junction, or S-I-S), a short section of non-superconducting metal (S-N-S), or a physical constriction that weakens the superconductivity at the point of contact (S-S-S).

According to the classical theory, the insulating barrier between two superconducting materials should forbidden the across of electrons. Because the electric potential in the insulating layer is much lower than that in the superconductor, which forms a high barrier to the movement of electrons. Energy of electrons in the insulator layer is insufficient to make itself climb this barrier, so that it will not form any current at the macro level. However quantum mechanics point out that even for relatively high potential barrier, the electrons with low energy can pass through as well which seems like there is a tunnel there below the barrier. This phenomenon is called Josephson effect, also known as superconducting tunnel effect.

The system allows making measurements in a fully automatic mode. The apparatus is controlled by a computer. The equipment can detect changes in susceptibility of only $2 \cdot 10^{-10} \mathrm{emu} / \mathrm{g}$. Regarding to the magnetic moment, the sensitivity is found to be $10^{-6}$ emu for an applied field of $1.5 \mathrm{~T}$. The signal range corresponding to the force $F_{x}$ in arbitrary units is between 1 and $2 \cdot 10^{5}$ which causes the equipment very versatile and suitable for measuring compounds with very different characteristics. 


\section{7. - Fluorescence Properties}

\subsubsection{Photoluminescence Spectroscopy}

Photoluminescence is the emission of light which is caused by the irradiation of a substance after the absorption of photons (electromagnetic radiation). Photoluminescence is divided into two categories: fluorescence and phosphorescence, which differ in the time after irradiation over which the luminescence occurs.

A pair of electrons occupying the same electronic ground state has opposite spins and are said to be in a singlet spin state. When a sample absorbs an ultraviolet or visible photon, one of its valence electrons moves from the ground state to an excited state with a conservation of the electron's spin. Emission of a photon from the singlet excited state to the singlet ground state or between any two energy levels with the same spin is called fluorescence. The probability of fluorescence is very high and the average lifetime of an electron in the excited state is only $10^{-5}-10^{-8} \mathrm{~s}$, therefore, fluorescence decays rapidly once the source of excitation is removed.

In some cases an electron in a singlet excited state is transformed to a triplet excited state in which its spin is no longer paired with the ground state. Emission between a triplet excited state and a singlet ground state or between any two energy levels that differ in their respective spin states is called phosphorescence. Because the average lifetime for phosphorescence ranges from $10^{-4}-10^{4} \mathrm{~s}$, phosphorescence may continue for some time after removing the excitation source.

Photoluminescence generally has three main steps of process: light absorption, energy transfer and light emission. The light absorption and emission occur in the transition between energy levels, both through excited states. The energy transfer is due to the movement of the excited states. Ultraviolet radiation, visible light and infrared radiation can all cause photoluminescence.

Photoluminescence spectra are recorded by measuring the intensity of emitted radiation as a function of either the excitation wavelength or the emission 
wavelength. An excitation spectrum is obtained by monitoring emission at a fixed wavelength while varying the excitation wavelength. When corrected for variations in the source's intensity and the detector's response, a sample's excitation spectrum is nearly identical to its absorbance spectrum. The excitation spectrum provides a convenient means for selecting the best excitation wavelength for a quantitative or qualitative analysis.

In an emission spectrum a fixed wavelength is used to excite the sample and the intensity of emitted radiation is monitored as a function of wavelength. Although a molecule has only one single excitation spectrum, it has two emission spectra, one for fluorescence and another for phosphorescence.

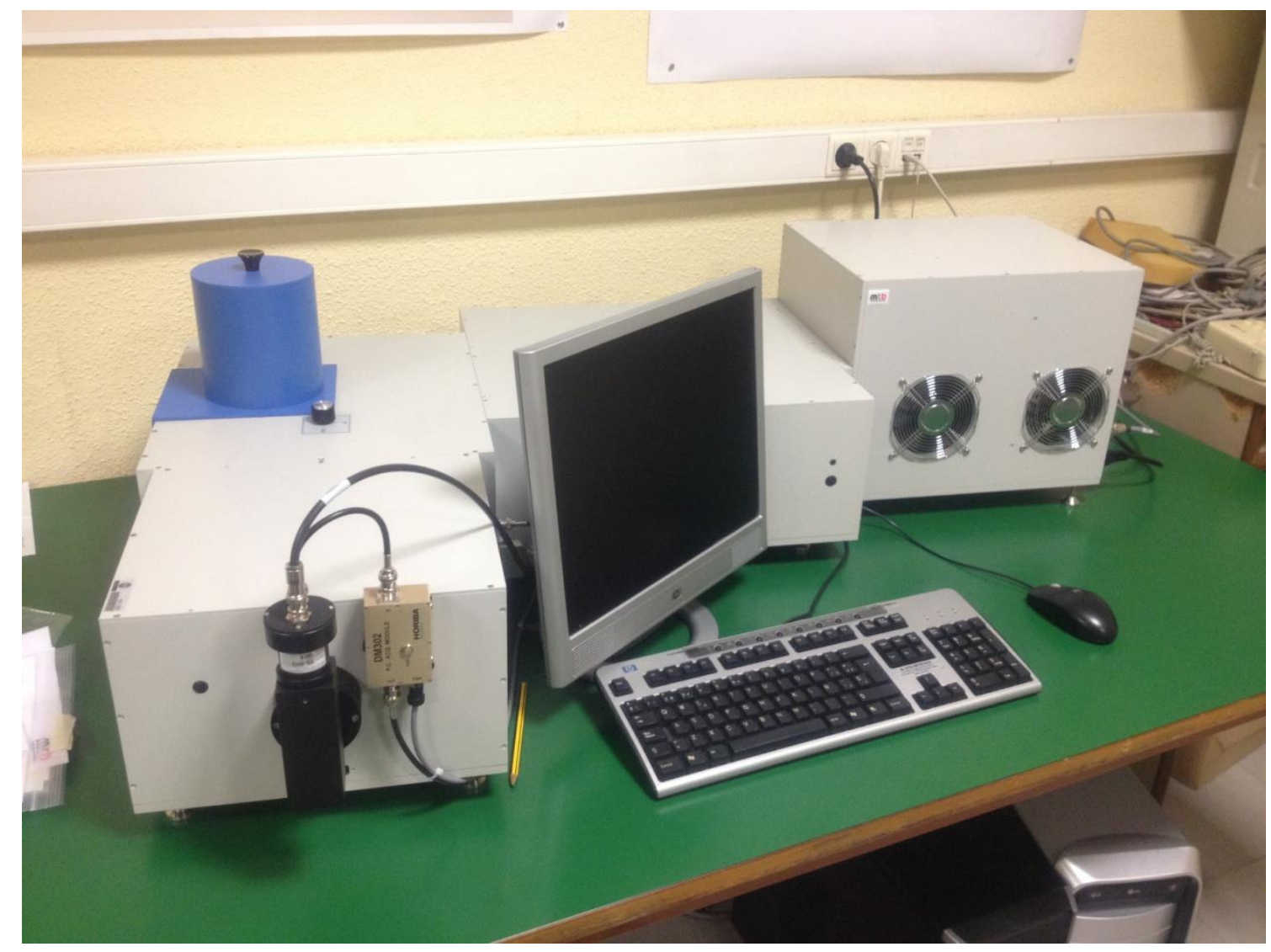

Fig. 2.5 Photoluminescence Spectroscopy instrument Horiba JobinYvon FL3-21. 


\subsubsection{Horiba JobinYvon FL3-21}

The basic design of an instrument for measuring fluorescence includes two wavelength selectors, one for selecting an excitation wavelength from the source and one for selecting the emission wavelength from the sample. In a fluorimeter the excitation and emission wavelengths are selected using absorption or interference filters. The excitation source for a fluorimeter is usually a low-pressure $\mathrm{Hg}$ vapor lamp that provides intense emission lines distributed throughout the ultraviolet and visible region $(254,312,365,405,436$, $546,577,691$, and $773 \mathrm{~nm}$ ). When a monochromator is used to select the excitation and emission wavelengths, the instrument is called a spectrofluorimeter. With a monochromator the excitation source is usually high-pressure Xe arc lamp, which has a continuous emission spectrum. Either instrumental design is appropriate for quantitative work, although only a spectrofluorimeter can be used to record an excitation or emission spectrum.

Horiba JobinYvon FL3-21 is one type instrument of the series Steady-State Fluorescence Spectrofluorometers Fluorolog $\AA-3$ produced by the company Horiba JobinYvon. The photo of the instrument Horiba JobinYvon FL3-21 was illustrated in Fig. 2.5. The Fluorolog®-3 spectrofluorometer is the ultimate in modular research system, designed to perform analyses over the ultraviolet and visible regions of the spectrum as well as far into the IR. The dimensions of Horiba JobinYvon FL3-21 is presented in the Fig.2.6.

The basic Fluorolog®-3 spectrofluorometer system consists of the following components:

1. A $450 \mathrm{~W}$ xenon short-arc as an excitation source was mounted vertically in an air-cooled housing as well as its power supply.

2. A single-grating excitation monochromator.

3. A T-format sample compartment with excitation reference detector.

4. A single-grating emission monochromator.

5. An emission photomultiplier tube with photon-counting detection. 
6. All necessary electronics and software to attach to the serial port of your compatible PC.

Both excitation and emission monochromators are Czerny-Turner design with kinematic gratings and all-reflective optics. Detectors Photodiode for excitation correction is from 240 to $1000 \mathrm{~nm}$. Standard emission detector is R928P photomultiplier tube for high sensitivity in photon-counting mode $(240-850 \mathrm{~nm})$. Software was used Windows based FluorEssence ${ }^{\mathrm{TM}}$ supplying all scanning, time-based, and accessory data-acquisition as well as complete control of all hardware.

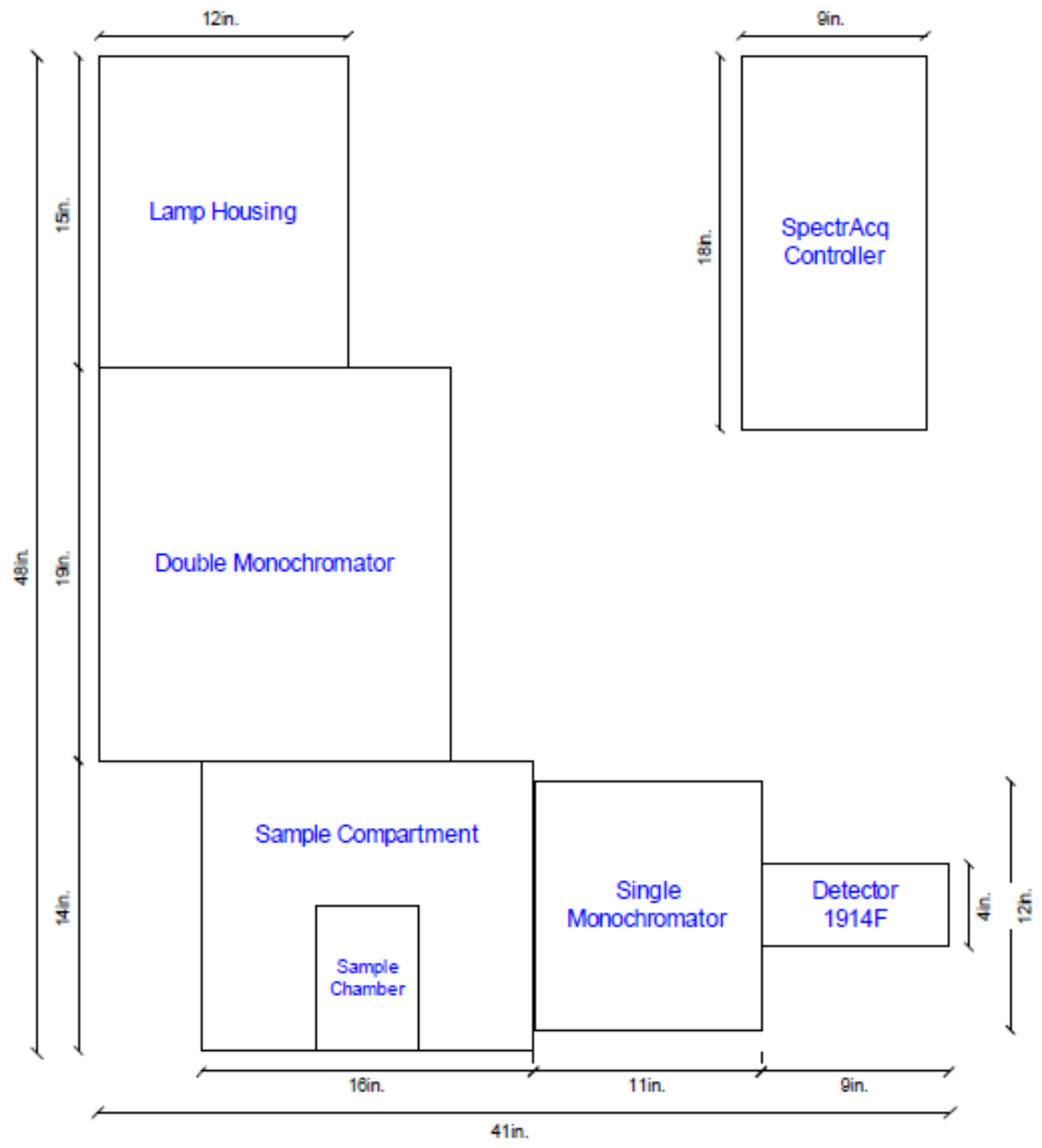

Fig.2.6 The dimensions of Horiba JobinYvon FL3-21. 
In order to measure the decay time of rare earth, our instrument equips spark sources and diodes for pulsed lifetime-acquisitions.

Lifetime MF2 (frequency-domain) has a lifetime range of $20 \mathrm{ps}$ to $10 \mathrm{~ms}$ and frequency range of $1 \mathrm{kHz}$ to $300 \mathrm{MHz}$; with 1 to 8 frequencies simultaneously (maximum 100 frequencies with sequential operation).

In the room temperature measurement, the samples were put in the Solid-sample holder 1933. The solid-sample holder is designed for solids including thin films, powders, pellets, microscope slides, and fibers. The holder consists of a base upon which a bracket, spring clip, and sample-block rest (see Fig.2.7).

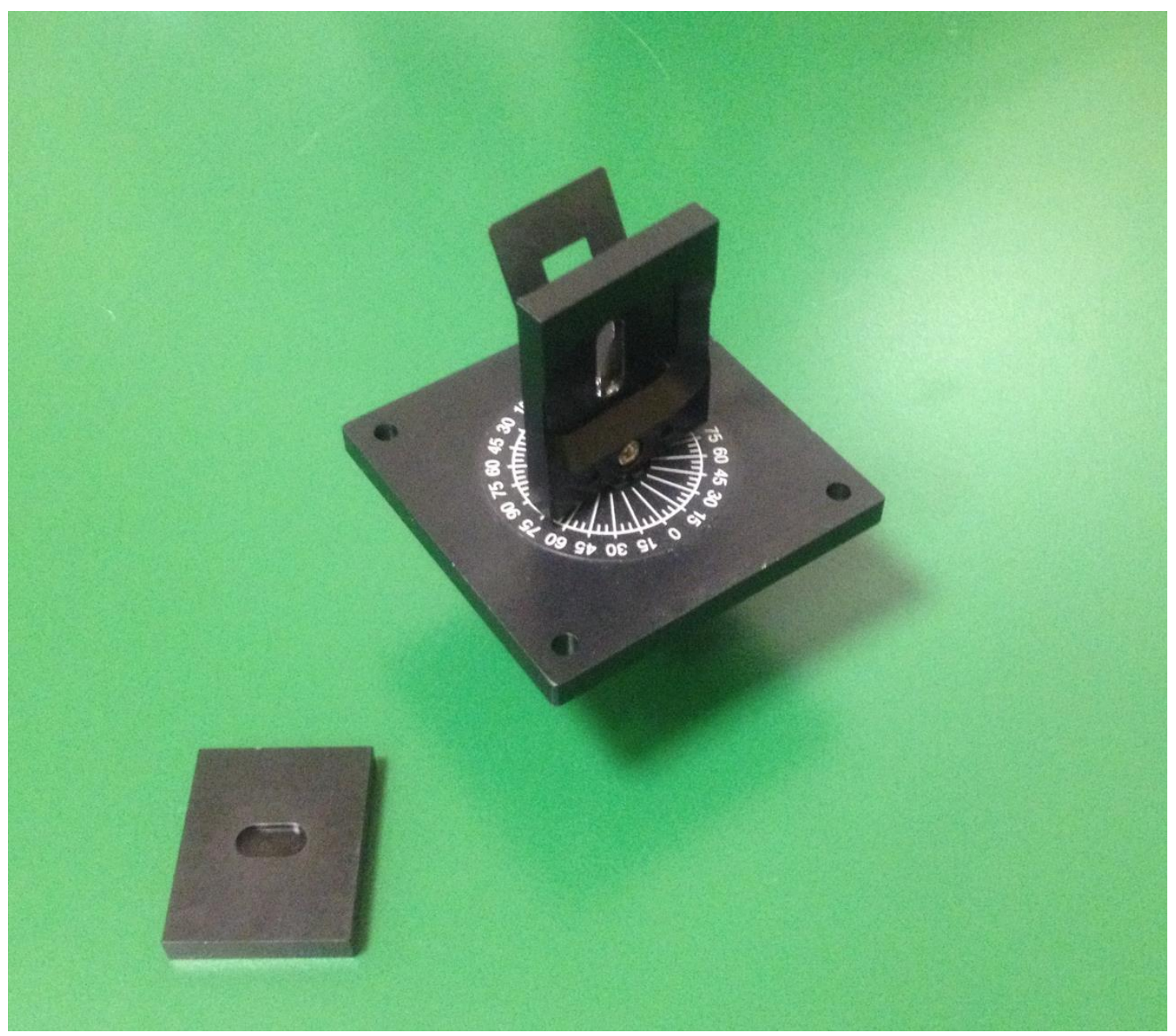

Fig.2.7 The Solid-sample holder 1933 
In order to measure delayed fluorescence, samples are often frozen at liquid-nitrogen temperature to preserve the fragile triplet state. in this case, the Liquid-nitrogen Dewar FL-1013 was used (as Fig. 2.8). The Dewar flask is used to freeze and maintain the temperature of the sample. The sample is placed in a quartz cell, and slowly immersed in the liquid-nitrogen-filled Dewar. The Dewar is on a pedestal within the Fluorolog®'s sample compartment.

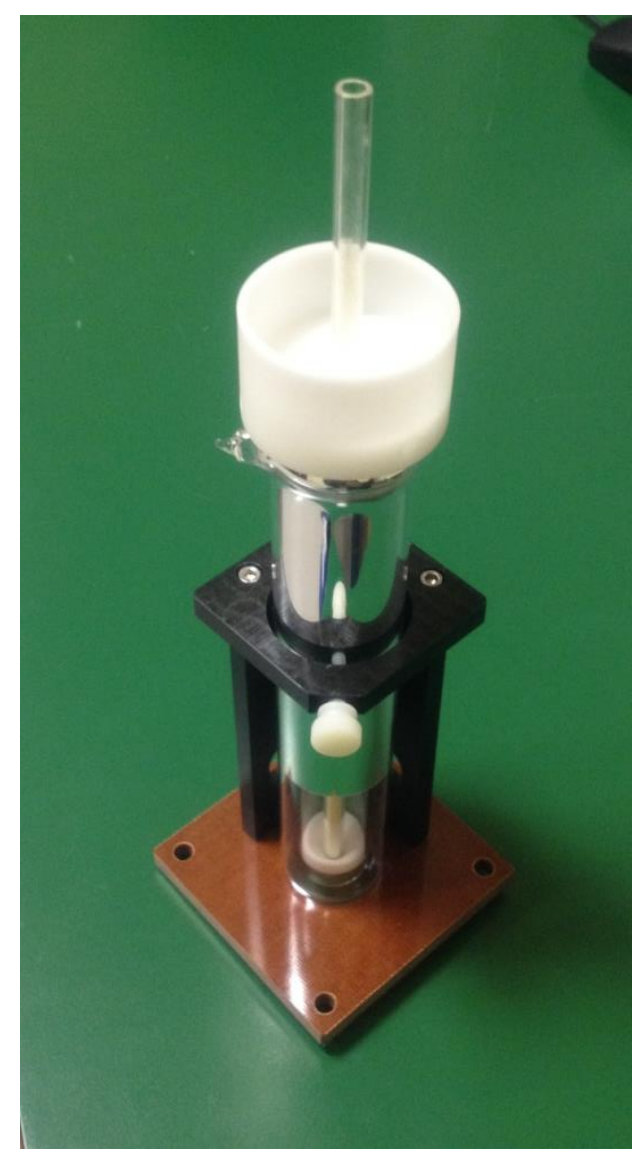

Fig. 2.8 Liquid-nitrogen Dewar FL-1013 


\subsubsection{Experimental Parameters}

The excitation and emission spectra were recorded on a Horiba JobinYvon FL3-21 spectra fluorometer at room temperature or at liquid nitrogen temperature with a $450 \mathrm{~W}$ xenon lamp as the excitation source. Data was collected in the spectra range of $250 \mathrm{~nm}$ to $800 \mathrm{~nm}$.

\section{References}

[2.1] Toshio Kimura, Molten Salt Synthesis of Ceramic Powders. Advances in Ceramics - Synthesis and Characterization, Processing and Specific Applications, Edited by Prof. Costas Sikalidis. 2011

[2.2] L. Bonelli, F. Cornacchia, M. Tonelli, D. A. Lis, K. A. Subbotin, V. A. Smirnov,

E. V. Zharikov, Spectroscopic properties of Er:NaLa(WO 4$)_{2}$ crystals and effect of Ce codoping onto the excited state energy transformation in this crystal. J. Lumin. 135 (2013) 178-186.

[2.3] E. Sani, A. Toncelli, M. Tonelli, D. A. Lis, E. V. Zharikov, K. A. Subbotin, V. A Smirnov, Effect of cerium codoping in $\mathrm{Er}^{3+}, \mathrm{Ce}^{3+}: \mathrm{NaLa}\left(\mathrm{MoO}_{4}\right)_{2}$ crystals. J. Appl. Phys. 97 (12) (2005) 123531-1-123531-6.

[2.4] Y. H. Tsang, D. J. Binks, B. D. O. Richards, A. Jha, Spectroscopic and lasing studies of $\mathrm{Ce}^{3+}: \mathrm{Er}^{3+}: \mathrm{Yb}^{3+}: \mathrm{YVO}_{4}$ crystals. Laser Phys. Lett. 8 (10) (2011) 729-735.

[2.5] Y. J. Chen, J. H. Huang, Y. Q. Zou, Y. F. Lin, Z. D. Luo, Y. D Huang, Diode-pumped $\mathrm{Er}^{3+}: \mathrm{Yb}^{3+}: \mathrm{NaCe}_{0,43} \mathrm{Gd}_{0,57}\left(\mathrm{WO}_{4}\right)_{2}$ pulse laser passively Q-switched with a $\mathrm{Co}^{2+}: \mathrm{Mg}_{0,4} \mathrm{Al}_{2,4} \mathrm{O}_{4}$ saturable absorber at $1.53 \mu \mathrm{m}$. Laser Phys. 24 (2014) 045810 .

[2.6] G. Li, S. Lan, L. Li, M. Li, W. Bao, H. Zou, X. Xu, S. Gan, Tunable luminescence properties of $\mathrm{NaLa}\left(\mathrm{MoO}_{4}\right)_{2}: \mathrm{Ce}^{3+}, \mathrm{Tb}^{3+}$ phosphors for near UV-excited white light-emitting-diodes. J. Alloys Compd. 513 (2012) 145-149. 
[2.7] J. Huang, J. Huang, Y. Lin, X. Gong, Y. Chen, Z. Luo, Y. Huang, Spectroscopic properties of Dy ${ }^{3+}$-doped $\mathrm{NaGd}\left(\mathrm{MoO}_{4}\right)_{2}$ crystal. J. Alloys Compd. 664 (2016) 266-271.

[2.8] L. Macalik, J. Hanuza, J. Sokolnicki, J. Legendziewicz, Optical properties of $\mathrm{Pr}^{3+}$ in lanthanum double molybdates and tungstates: $\mathrm{KLa}_{1-\mathrm{Pr}} \mathrm{Pr}_{\mathrm{x}}\left(\mathrm{MO}_{4}\right)_{2}(\mathrm{M}=\mathrm{Mo}$, W; $x$ 51). Spectrochim. Acta Part A 55 (1999) 251-262.

[2.9] F. B. Xiong, Z. W. Zhang, H. F. Lin, L. J. Wang, Y. C. Xu, W. Z. Zhu, Luminescent properties of deep red light-emitting phosphors $\mathrm{NaGd}\left(\mathrm{WO}_{4}\right)_{2}: \mathrm{Pr}^{3+}$ for blue LED. Opt. Mater. 42 (2015) 394-398.

[2.10] Y. Han, Y. Wang, S. Huang, F. Jin, S. Gai, N. Niu, L. Wang, P. Yang, Controlled synthesis and luminescence properties of doped $\mathrm{NaLa}\left(\mathrm{WO}_{4}\right)_{2}$ microstructures. J. Ind. Eng. Chem. 34 (2016) 269-277.

[2.11] Z. Wang, H. Liang, Q. Wang, L. Luo, M. Gong, Luminescent properties of $\mathrm{Tb}^{3+}$ activated double molybdates and tungstates. Mater. Sci. Eng. B 164 (2009) 120-123.

[2.12] Y. W. Wei, Y. J. Chen, Y. F. Lin, X. H. Gong, Z. D. Luo, Y. D. Huang, Spectral properties of $\mathrm{Tm}^{3+}$-doped $\mathrm{LiLa}\left(\mathrm{MoO}_{4}\right)_{2}$ crystal. J. Alloys Compd. 484 (2009) 529-534.

[2.13] J. Yan, X. Xiao, J. Yu, D. Mao, G. Lu, White light emission materials of self-assembled rare earth molybdates $\mathrm{NaRe}\left(\mathrm{MoO}_{4}\right)_{2}$ micro-particles: the controllable synthesis, growth mechanism and luminescent properties. Cryst. Res. Technol. 50 (7) (2015) 580-593.

[2.14] H. Fuks, S. M. Kaczmarek, G. Leniec, L. Macalik, B. Macalik, J. Hanuza, EPR and vibrational studies of some tungstates and molybdates single crystals. Opt. Mater. 32 (2010) 1560-1567.

[2.15] J. H. Huang, Y. J. Chen, X. H. Gong, Y. F. Lin, Z. D. Luo, Y. D. Huang, Spectral Properties and 1.5-1.6 $\mu \mathrm{m}$ Laser Operation of Er:Yb:NaCe(WO4)2 Crystal. Laser Phys. 22 (1) (2012) 146-151. 
[2.16] A. Xie, X. Yuan, Y. Shi, F. Wang, J. Wang, Photoluminescence Characteristics of Energy Transfer Between $\mathrm{Eu}^{3+}$ and $\mathrm{Bi}^{3+}$ in $\mathrm{LiEu}_{1-x} \mathrm{Bi}_{x}$ (WO4)0.5(MoO4)1.5. J. Am. Ceram. Soc. 92 (10) (2009) 2254-2258.

[2.17] C. Chiu, C. Liu, S. Huang, T. Chen, White-Light-Emitting Diodes Using Red-Emitting $\mathrm{LiEu}\left(\mathrm{WO}_{4}\right)_{2-x}\left(\mathrm{MoO}_{4}\right)_{\times}$Phosphors. J. Electrochem. Soc. 154 (7) (2007) 181-184.

[2.18] B. Yan, L. Lin, J. Wu, F. Lei, Photoluminescence of Rare Earth Phosphors Na0.5Gd0.5WO4: $\mathrm{RE}^{3+}$ and Na0.5Gd0.5(Mo0.75W0.25)O4: $\mathrm{RE}^{3+}$ (RE = Eu, Sm, Dy). J. Fluoresc. 21 (2011) 203-211.

[2.19] Z. Lu, T. Wanjun, Synthesis and luminescence properties of Eu ${ }^{3+}$-activated $\mathrm{NaLa}\left(\mathrm{MoO}_{4}\right)\left(\mathrm{WO}_{4}\right)$ phosphor. Ceram. Int. 38 (2012) 837-840.

[2.20] Y. Chen, F. Cao, Y. Tian, L. Xiao, L. Li, Optimized photoluminescence by charge compensation in a novel phosphor system. Physica B 405 (2010) 435-438.

[2.21] F. Cao, Y. Tian, Y. Che, L. Xiao, Q. Wu, Luminescence investigation of red

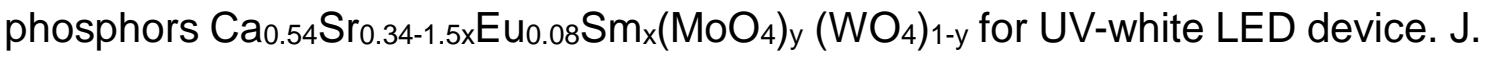
Lumin. 129 (2009) 585-588.

[2.22] J. Rodriguez-Carvajal, T. Roisnel, FullProf. 98 and WinPLOTR: New Windows 95/NT Applications for Diffraction. Commission for Powder Diffraction, International Union of Crystallography. Newsletter 20 (1998) 35.

[2.23] D. J. Gardiner, P. R. Graves, Practical Raman Spectroscopy, Springer Verlag. 1989. 


\section{CHAPTER 3 ----- RESULTS DISCUSSIONS}

\section{1. - $\mathrm{AgCe}\left(\mathrm{WO}_{4}\right)_{2}: \mathrm{Eu}^{3+}, \mathrm{Tb}^{3+}$}

\subsubsection{Thermal Behavior of the Mixture Precursors of $\mathrm{AgCe}\left(\mathrm{WO}_{4}\right)_{2}$}

To investigate the reaction process of the composition, the measurements of TG-DTA and X-ray diffraction have been used. The precursor of $\mathrm{CeAg}\left(\mathrm{WO}_{4}\right)_{2}$ and Eu0.01 $\mathrm{Ce}_{0.99 \mathrm{Ag}}\left(\mathrm{WO}_{4}\right)_{2}$ were first examined by means of TG-DTA measurement respectively in the temperature range from room temperature to $1000^{\circ} \mathrm{C}$. As we can see from the Fig. 3.1, the curves of them in the TG-DTA performed very alike except for some temperature shifts at the endothermic/exothermic peaks. The temperature decreases of the peaks in $\mathrm{Eu}_{0.01} \mathrm{Ce}_{0.99} \mathrm{Ag}\left(\mathrm{WO}_{4}\right)_{2}$ can be well explained by the colligative properties due to the dopants.

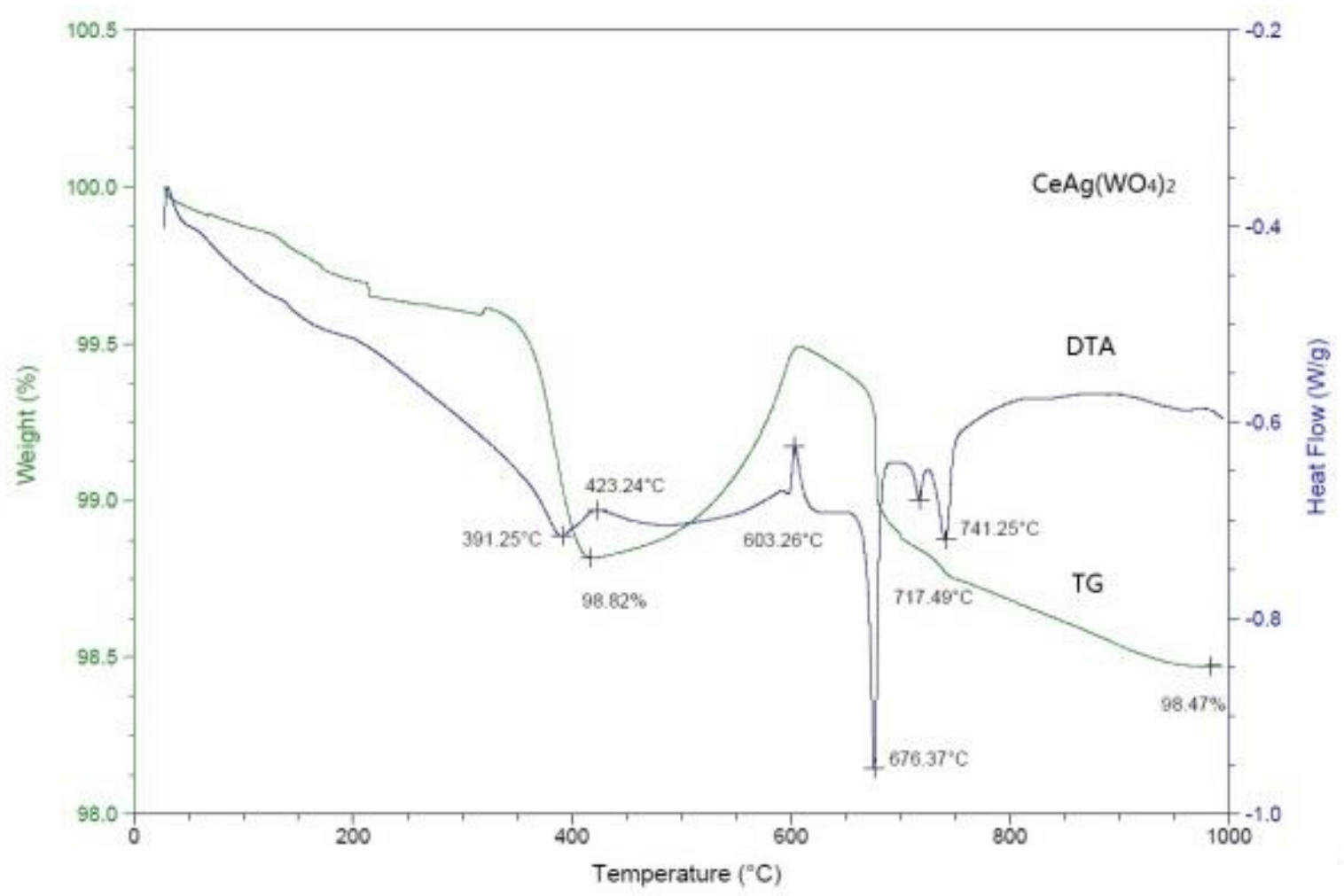

(a) 


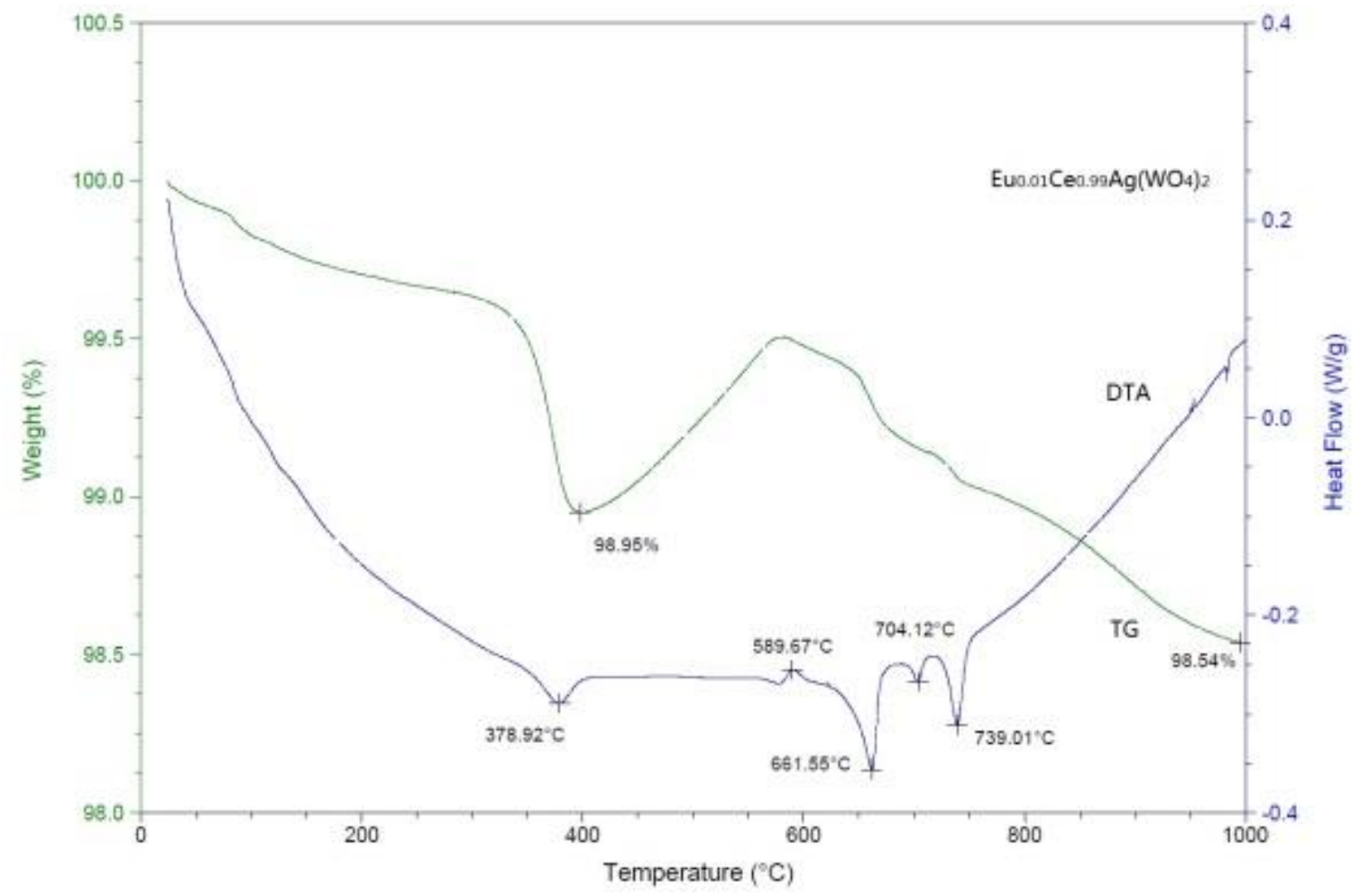

(b)

Fig. 3.1. The TG-DTA curves of $\mathrm{CeAg}\left(\mathrm{WO}_{4}\right)_{2}(\mathrm{a})$ and $\mathrm{Eu} 0.01 \mathrm{Ce}_{0.99} \mathrm{Ag}\left(\mathrm{WO}_{4}\right)_{2}$ (b) composites.

Here we just take the testing results of $\mathrm{CeAg}\left(\mathrm{WO}_{4}\right)_{2}$ for further discussing. The weight loss before $300{ }^{\circ} \mathrm{C}$ is attributed to the water loss of $\mathrm{EuCl}_{3} \cdot 6 \mathrm{H}_{2} \mathrm{O}$ in the mixture. The first big exothermic peak was found around $400{ }^{\circ} \mathrm{C}$ which can be attributed to the reaction of $\mathrm{Ag}_{2} \mathrm{O}, \mathrm{CeO}_{2}$ and $\mathrm{WO}_{3}$. In this step, the $\mathrm{Ag}_{2} \mathrm{O}, \mathrm{CeO}_{2}$ and $\mathrm{WO}_{3}$ were deoxidized to $\mathrm{Ag}, \mathrm{Ce}_{4} \mathrm{O}_{7}$ and $\mathrm{W}_{3} \mathrm{O}_{8}$ respectively causing weight loss with releasing the oxygen. The reaction functions are as below:

$$
\begin{aligned}
& \mathrm{Ag}_{2} \mathrm{O} \rightarrow 2 \mathrm{Ag}+1 / 2 \mathrm{O}_{2} \uparrow \\
& 4 \mathrm{CeO}_{2} \rightarrow \mathrm{Ce}_{4} \mathrm{O}_{7}+1 / 2 \mathrm{O}_{2} \uparrow \\
& 3 \mathrm{WO}_{3} \rightarrow \mathrm{W}_{3} \mathrm{O}_{8}+1 / 2 \mathrm{O}_{2} \uparrow
\end{aligned}
$$

Then the followed endothermic peak and weight gain indicate that there were oxidation reactions. Affected by the redox property of $\mathrm{Ag}$, the highly air instable trivalent $\mathrm{Ce}^{3+}$ ion has been obtained as formed as $\mathrm{Ce}_{2}\left(\mathrm{WO}_{4}\right)_{3}$ (JCPDS No: 85-0143). And the phase $\mathrm{Ag}_{2} \mathrm{~W}_{2} \mathrm{O}_{7}$ (JCPDS No: 32-1030) has been also found in 
the compounds. This process is very important in the whole reaction, and it is the reason that why it's impossible to obtain the equivalent $\mathrm{MCe}\left(\mathrm{WO}_{4}\right)_{2}$ compounds when $\mathrm{M}$ was $\mathrm{K}, \mathrm{Na}$ or $\mathrm{Rb}$. And it is worth noting that the reaction $\mathrm{Ag}+\mathrm{CeO}_{2} \rightarrow$ $\mathrm{Ag}_{2} \mathrm{O}+\mathrm{Ce}_{2} \mathrm{O}_{3}$ cannot occur in isolation under the same temperature neither without the attendance of cation $\mathrm{W}$ in the compounds.

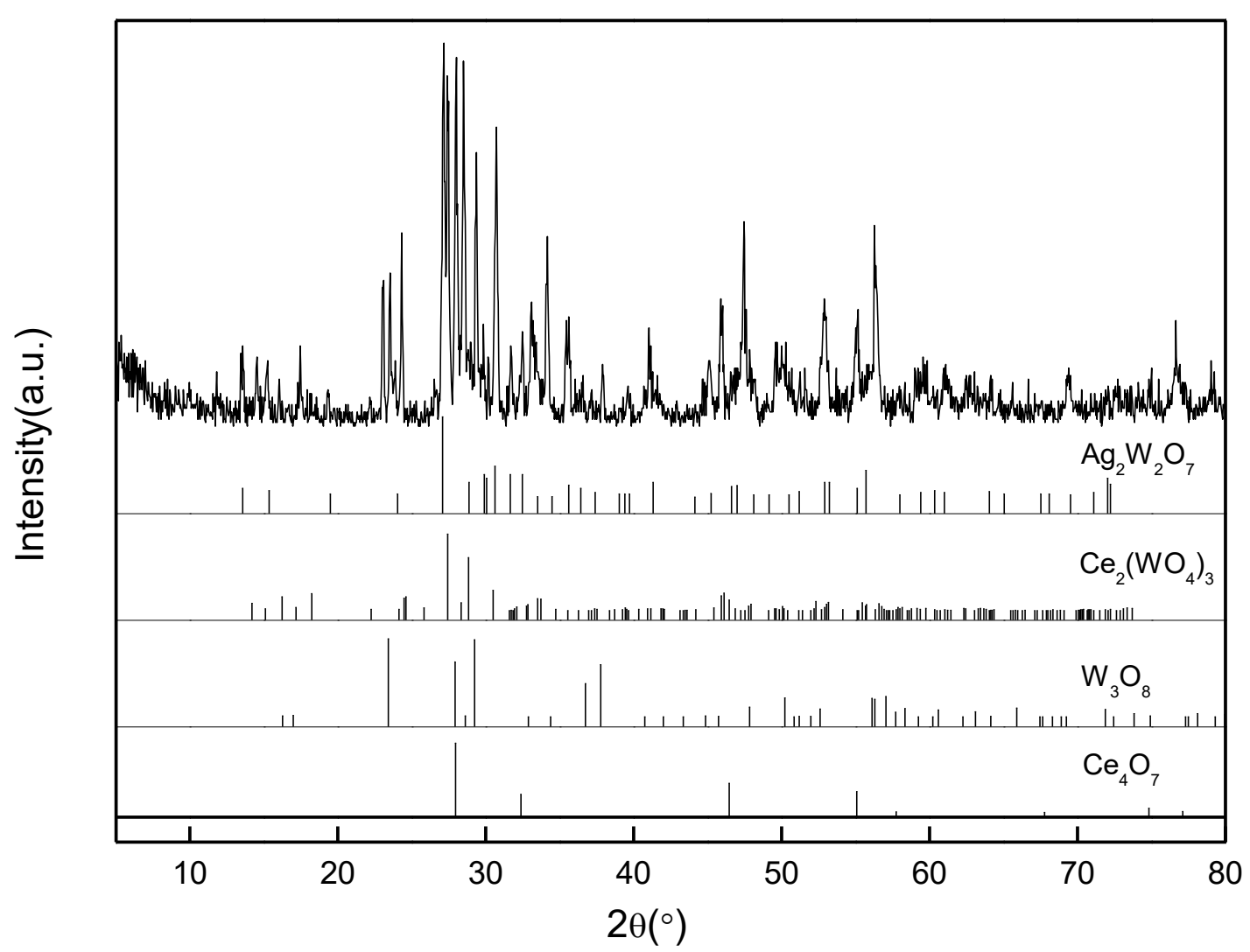

Fig. 3.2. The $X R D$ analysis of stoichiometric mixtures $\mathrm{Ag}_{2} \mathrm{O}, \mathrm{CeO}_{2}$ and $\mathrm{WO}_{3}$ as precursor of $\mathrm{AgCe}\left(\mathrm{WO}_{4}\right)_{2}$ after heated at $580{ }^{\circ} \mathrm{C}$.

The XRD pattern of stoichiometric mixtures $\mathrm{Ag}_{2} \mathrm{O}, \mathrm{CeO}_{2}$ and $\mathrm{WO}_{3}$ after heated at $580{ }^{\circ} \mathrm{C}$ was shown in Fig. 3.2. The existence of $\mathrm{Ce}_{4} \mathrm{O}_{7}$ (JCPDS No: 65-7999) and $\mathrm{W}_{3} \mathrm{O}_{8}$ (JCPDS No: 81-2263) at this temperature can also confirm the reaction (2) and (3) in the first step. The reaction function at the temperature range of $400{ }^{\circ} \mathrm{C}$ - $600{ }^{\circ} \mathrm{C}$ can be written as follow: 


$$
\mathrm{Ce}_{4} \mathrm{O}_{7}+8 / 3 \mathrm{~W}_{3} \mathrm{O}_{8}+2 \mathrm{Ag}+4 / 3 \mathrm{O}_{2} \uparrow \rightarrow 2 \mathrm{Ce}_{2}\left(\mathrm{WO}_{4}\right)_{3}+\mathrm{Ag}_{2} \mathrm{~W}_{2} \mathrm{O}_{7}
$$

When the temperature reached $680{ }^{\circ} \mathrm{C}$, another exothermic peak appeared indicating the reaction between $\mathrm{Ce}_{2}\left(\mathrm{WO}_{4}\right)_{3}$ and $\mathrm{Ag}_{2} \mathrm{~W}_{2} \mathrm{O}_{7}$. The XRD measurement was undergone under this temperature and the result was shown in Fig. 3.3. Despite the rest of the $\mathrm{Ce}_{2}\left(\mathrm{WO}_{4}\right)_{3}, \mathrm{Ag}_{2} \mathrm{~W}_{2} \mathrm{O}_{7}$ and $\mathrm{W}_{3} \mathrm{O}_{8}$, the $\mathrm{CeAg}\left(\mathrm{WO}_{4}\right)_{2}$ phase was first observed in this step. The combination equation of $\mathrm{Ce}_{2}\left(\mathrm{WO}_{4}\right)_{3}$ and $\mathrm{Ag}_{2} \mathrm{~W}_{2} \mathrm{O}_{7}$ can be described as below:

$$
C e_{2}\left(W_{4}\right)_{3}+\mathrm{Ag}_{2} \mathrm{~W}_{2} \mathrm{O}_{7} \rightarrow 2 \mathrm{CeAg}\left(\mathrm{WO}_{4}\right)_{2}+\mathrm{WO}_{3}
$$

Then the rest of $\mathrm{WO}_{3}$ repeated the step (3) and went further reaction as the step (4) and (5) until it all transformed into $\mathrm{CeAg}\left(\mathrm{WO}_{4}\right)_{2}$. The whole process completed at around $750{ }^{\circ} \mathrm{C}$ and single phase $\mathrm{CeAg}\left(\mathrm{WO}_{4}\right)_{2}$ was obtained.

Thus we can conclude that on the purpose of pure and well crystallized $\mathrm{CeAg}\left(\mathrm{WO}_{4}\right)_{2}$, a temperature beyond $750{ }^{\circ} \mathrm{C}$ should be used.

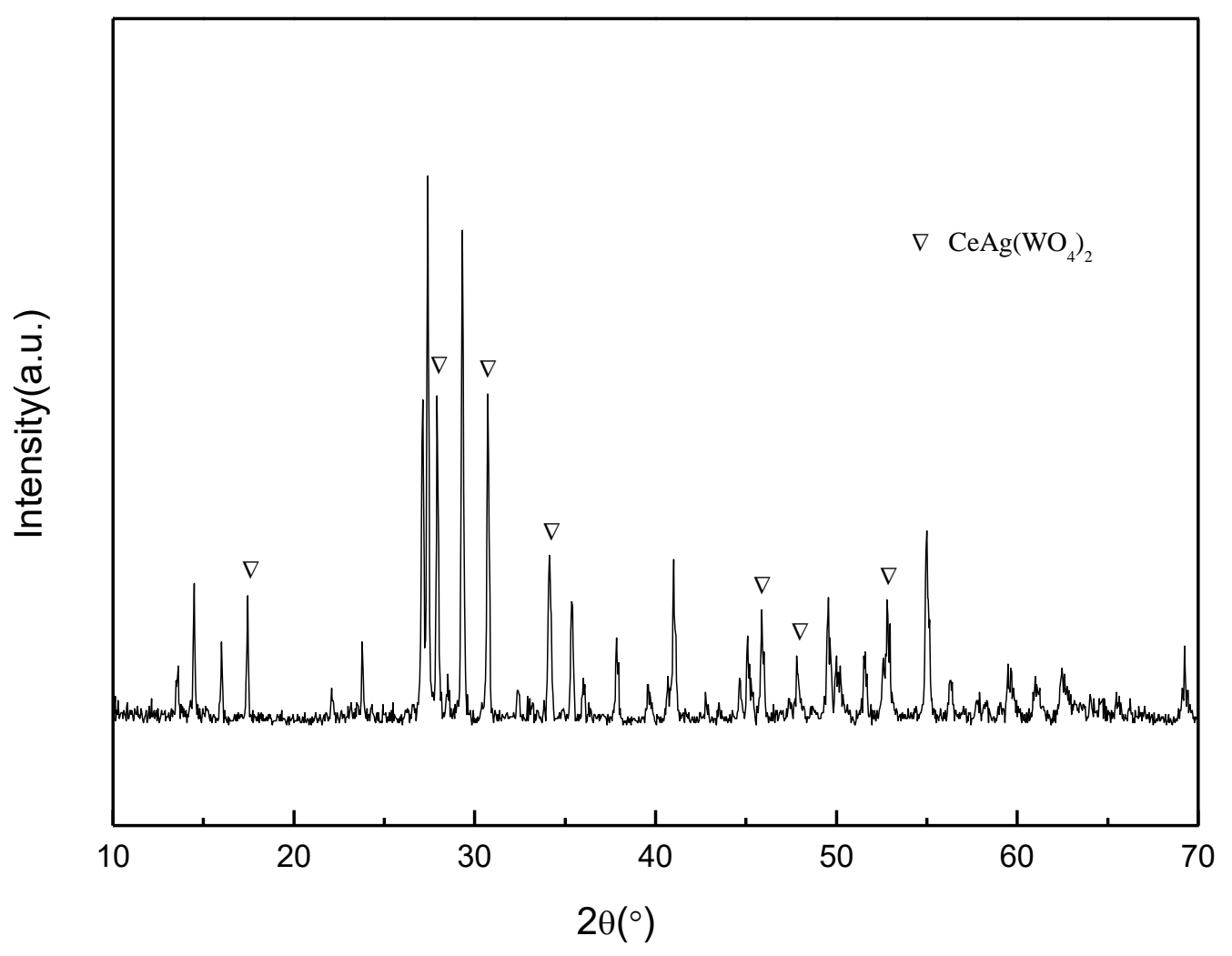

Fig.3.3. The XRD pattern of stoichiometric mixtures $\mathrm{Ag}_{2} \mathrm{O}, \mathrm{CeO}_{2}$ and $\mathrm{WO}_{3}$ as precursor of $\mathrm{AgCe}\left(\mathrm{WO}_{4}\right)_{2}$ after heated at $680^{\circ} \mathrm{C}$. 


\subsubsection{High Temperature X-ray Diffraction}

In order to investigate the stability and phase transition property while heat treated, the high temperature X-ray diffraction was introduced in. The pure tetragonal phase of Eu0.01 $\mathrm{Ce} 0.99 \mathrm{Ag}\left(\mathrm{WO}_{4}\right)_{2}$ was first well-prepared and then be heated up to $900{ }^{\circ} \mathrm{C}$ from room temperature. The X-ray diffraction data were collected while heated and were presented in Fig. 3.4. The main phases at all temperatures nearly maintain the same indicating that there is no big phase transition in the structure of $\mathrm{Eu}_{0.01} \mathrm{Ce}_{0.99} \mathrm{Ag}\left(\mathrm{WO}_{4}\right)_{2}$. They also maintain the tetragonal phase in Space Group I 41/a. But the unexpected phases appearing at the temperature range of $550{ }^{\circ} \mathrm{C}-660{ }^{\circ} \mathrm{C}$ manifest the existence of decomposition.

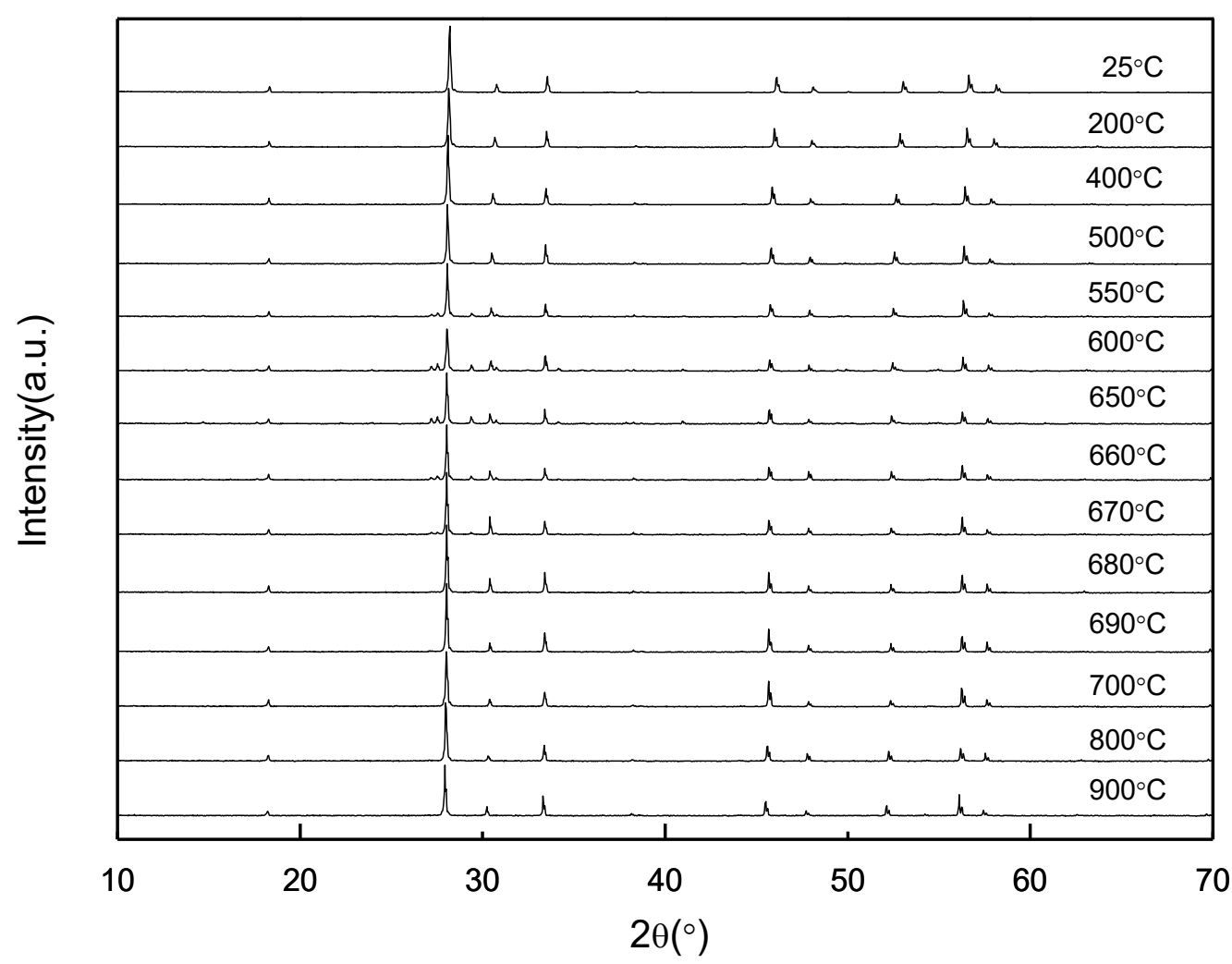

Fig.3.4. X-ray diffraction patterns of $\mathrm{Eu}_{0.01} \mathrm{Ce}_{0.99} \mathrm{Ag}\left(\mathrm{WO}_{4}\right)_{2}$ during high temperature from $25^{\circ} \mathrm{C}$ to $900{ }^{\circ} \mathrm{C}$.

For further investigation of the structural distortions and decomposition reactions, the XRD patterns of Eu $u_{0.01} \mathrm{Ce}_{0.99} \mathrm{Ag}\left(\mathrm{WO}_{4}\right)_{2}$ at all temperatures were refined and as it can be observed as an example in Fig. 3.5 which present the refinement 
result of $\mathrm{Eu}_{0.01} \mathrm{Ce}_{0.99} \mathrm{Ag}\left(\mathrm{WO}_{4}\right)_{2}$ while heat treated at $600{ }^{\circ} \mathrm{C}$. In the refine plot, the observed and calculated profiles were fine fitted. The green lines show the Bragg positions of $\mathrm{Eu}_{0.01} \mathrm{Ce}_{0.99} \mathrm{Ag}\left(\mathrm{WO}_{4}\right)_{2}, \mathrm{Ag}_{2} \mathrm{~W}_{2} \mathrm{O}_{7}$ and $\mathrm{Ce}_{2}\left(\mathrm{WO}_{4}\right)_{3}$ respectively from above to blow. It is confirmed that the decomposition process did occur in this temperature range. The lattice parameters were calculated to be $a=b=5.3899 \AA$ and $\mathrm{c}=11.8136 \AA$ for $\mathrm{Eu}_{0.01} \mathrm{Ce} 0.99 \mathrm{Ag}\left(\mathrm{WO}_{4}\right)_{2}$ under $600{ }^{\circ} \mathrm{C}$ heat treated. The lattice parameters of $\mathrm{Eu}_{0.01} \mathrm{Ce}_{0.99} \mathrm{Ag}\left(\mathrm{WO}_{4}\right)_{2}$ under various temperatures were plotted in Fig. 3.6. The parameters a and $c$ accumulated as the increasing of temperature and maintained in linear approximately. The nonlinear increasing around $700{ }^{\circ} \mathrm{C}$ can be explained by the vacancies due to the composition deviation caused by the decomposition process.

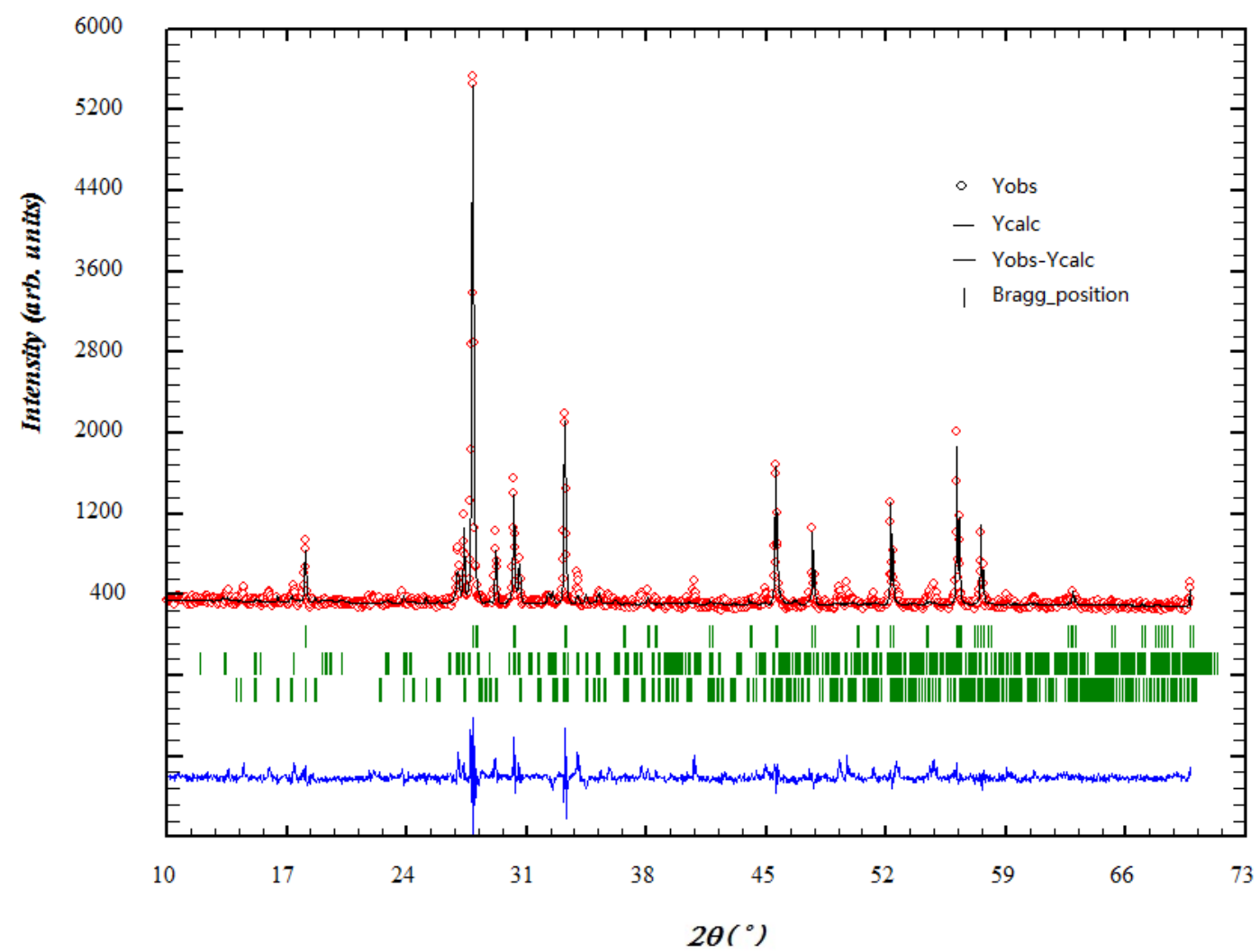

Fig.3.5. Observed (open symbols) and calculated (straight line) X-ray powder diffraction pattern for Eu0.01 $\mathrm{Ce}_{0.99} \mathrm{Ag}\left(\mathrm{WO}_{4}\right)_{2}$ while heated at $600{ }^{\circ} \mathrm{C}$. The short vertical lines below the patterns mark the positions of Bragg reflections of Eu0.01 $\mathrm{Ce}_{0.99} \mathrm{Ag}\left(\mathrm{WO}_{4}\right)_{2}, \mathrm{Ag}_{2} \mathrm{~W}_{2} \mathrm{O}_{7}$ and $\mathrm{Ce}_{2}\left(\mathrm{WO}_{4}\right)_{3}$ respectively from above to blow. The bottom continuous blue line is the difference between the observed and the calculated intensity. 


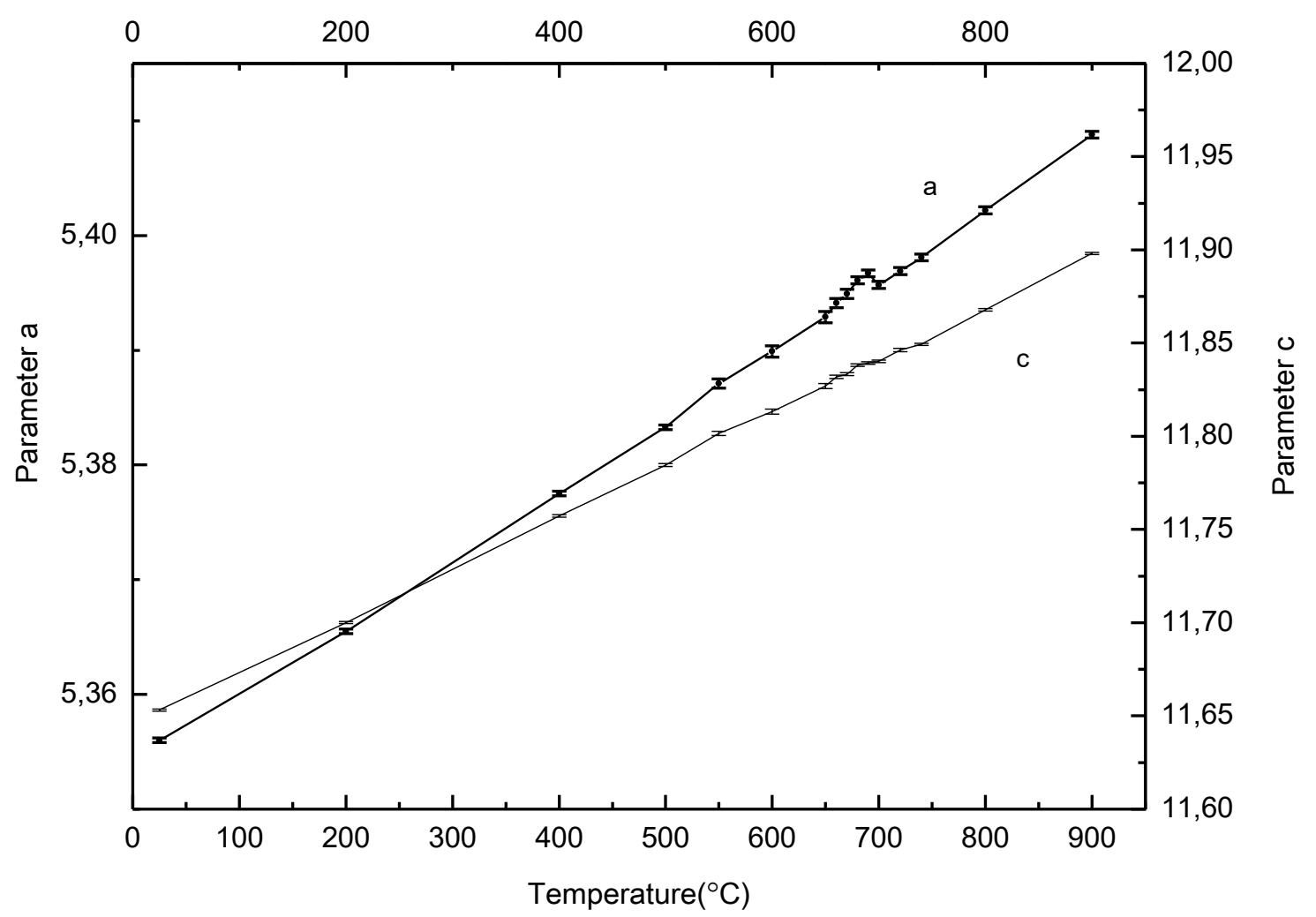

Fig. 3.6. The lattice parameters a and $c$ with errors of $\mathrm{Eu}_{0.01} \mathrm{Ce} \mathrm{e}_{.99} \mathrm{Ag}\left(\mathrm{WO}_{4}\right)_{2}$ from $25^{\circ} \mathrm{C}$ to $900{ }^{\circ} \mathrm{C}$.

\subsubsection{Structural Study by X-ray Diffraction.}

The X-ray diffraction analysis was carried out to test the purity and structure of the samples and the results were refined by using the Rietveld profile refinement method. The Fig. 3.7 gives the XRD patterns of Eu0.01 $\mathrm{Ce}_{0.99} \mathrm{Ag}\left(\mathrm{WO}_{4}\right)_{2}$ (1), Eu0.05 $\mathrm{Ce}_{0.95} \mathrm{Ag}\left(\mathrm{WO}_{4}\right)_{2}$ (2), Eu0.2 $\mathrm{Ce}_{0.8 \mathrm{Ag}}\left(\mathrm{WO}_{4}\right)_{2}$ (3), Eu0.5 $\mathrm{Ce}_{0.5} \mathrm{Ag}\left(\mathrm{WO}_{4}\right)_{2}$ (4), Eu0.7 $\mathrm{Ce}_{0.3} \mathrm{Ag}\left(\mathrm{WO}_{4}\right)_{2}$ (5). And the refined result of Eu0.01 $\mathrm{Ce} 0.99 \mathrm{Ag}\left(\mathrm{WO}_{4}\right)_{2}$ was shown in Fig. 3.8 for example. 


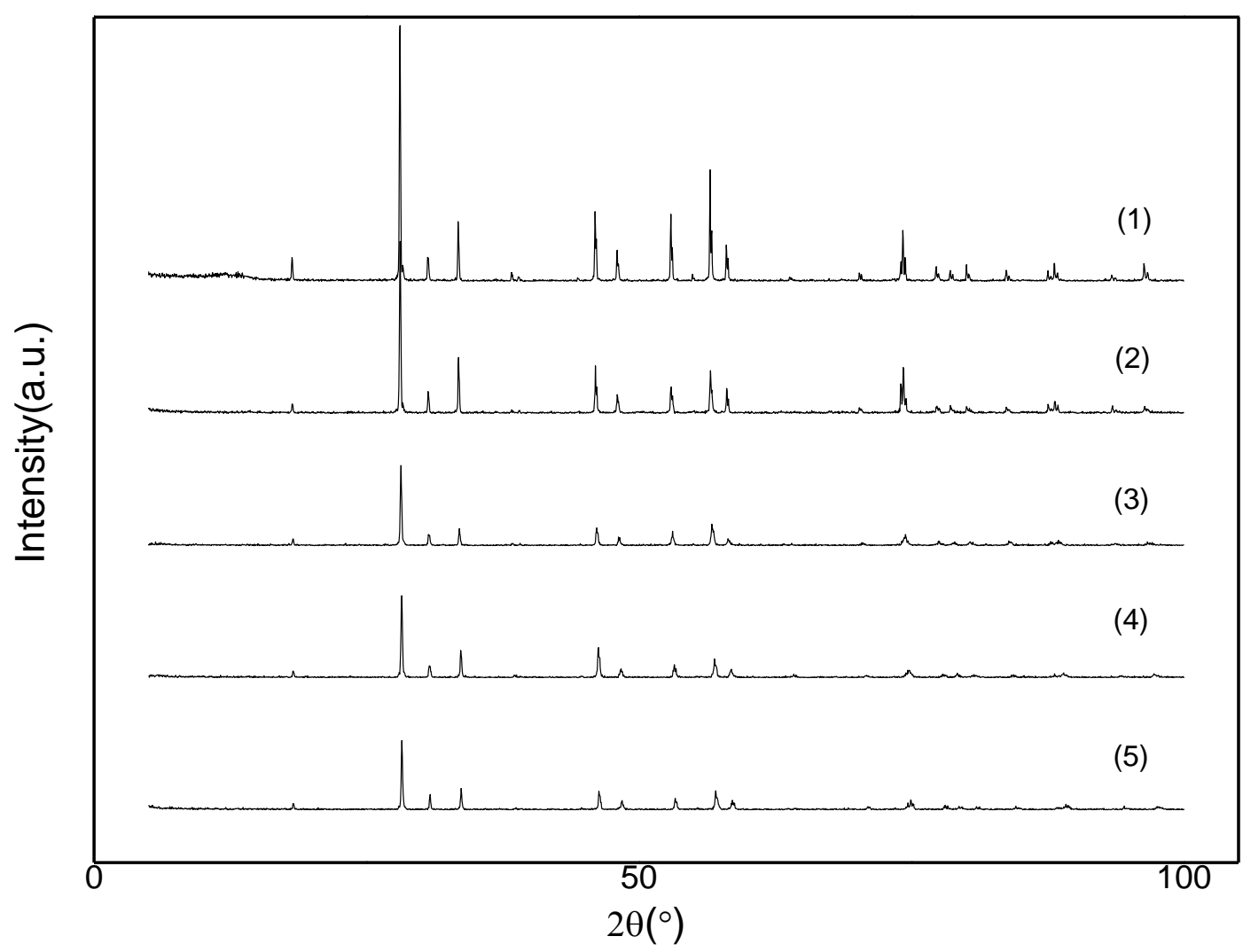

Fig.3.7. XRD patterns of $\mathrm{Eu}_{0.01} \mathrm{Ce}_{0.99} \mathrm{Ag}\left(\mathrm{WO}_{4}\right)_{2}$ (1), $\mathrm{Eu}_{0.05} \mathrm{Ce}_{0.95} \mathrm{Ag}\left(\mathrm{WO}_{4}\right)_{2}$ (2), $\mathrm{Eu}_{0.2} \mathrm{Ce} \mathrm{e}_{0.8} \mathrm{Ag}\left(\mathrm{WO}_{4}\right)_{2}$ (3), $\mathrm{Eu} 0.5 \mathrm{Ce} 0.5 \mathrm{Ag}\left(\mathrm{WO}_{4}\right)_{2}$ (4), $\mathrm{Eu} 0.7 \mathrm{Ce} 0.3 \mathrm{Ag}\left(\mathrm{WO}_{4}\right)_{2}$ (5).

All the compounds have scheelite type isostructural and performed in the tetragonal space group as I 41/a (No. 88). In the structure, $W^{6+}$ occupies the tetrahedral site as $\mathrm{WO}_{4}{ }^{2-}$ anion, and the $\mathrm{Ag}^{+}, \mathrm{Ce}^{3+}$ and $\mathrm{Eu}^{3+}$ share the $\left(\mathrm{RO}_{8}\right)$ sites performed as distorted bisdisphenoids. As increasing of the $\mathrm{Eu}^{3+}$ concentration, the characteristic diffraction peaks have no rather shift indicating that the doped $\mathrm{Eu}^{3+}$ did not influence the host structure much. This can be explained as the analogous of the radius of $\mathrm{Ce}^{3+}$ ion and $\mathrm{Eu}^{3+}$ ion: $r\left(\mathrm{Ce}^{3+}\right) \approx r\left(\mathrm{Eu}^{3+}\right)$. The lattice parameters and crystallographic positional parameters after refined for these five phases are presented in Table 3.1 respectively. Structures of the compounds will be further discussed by FTIR and Raman measurement later. 


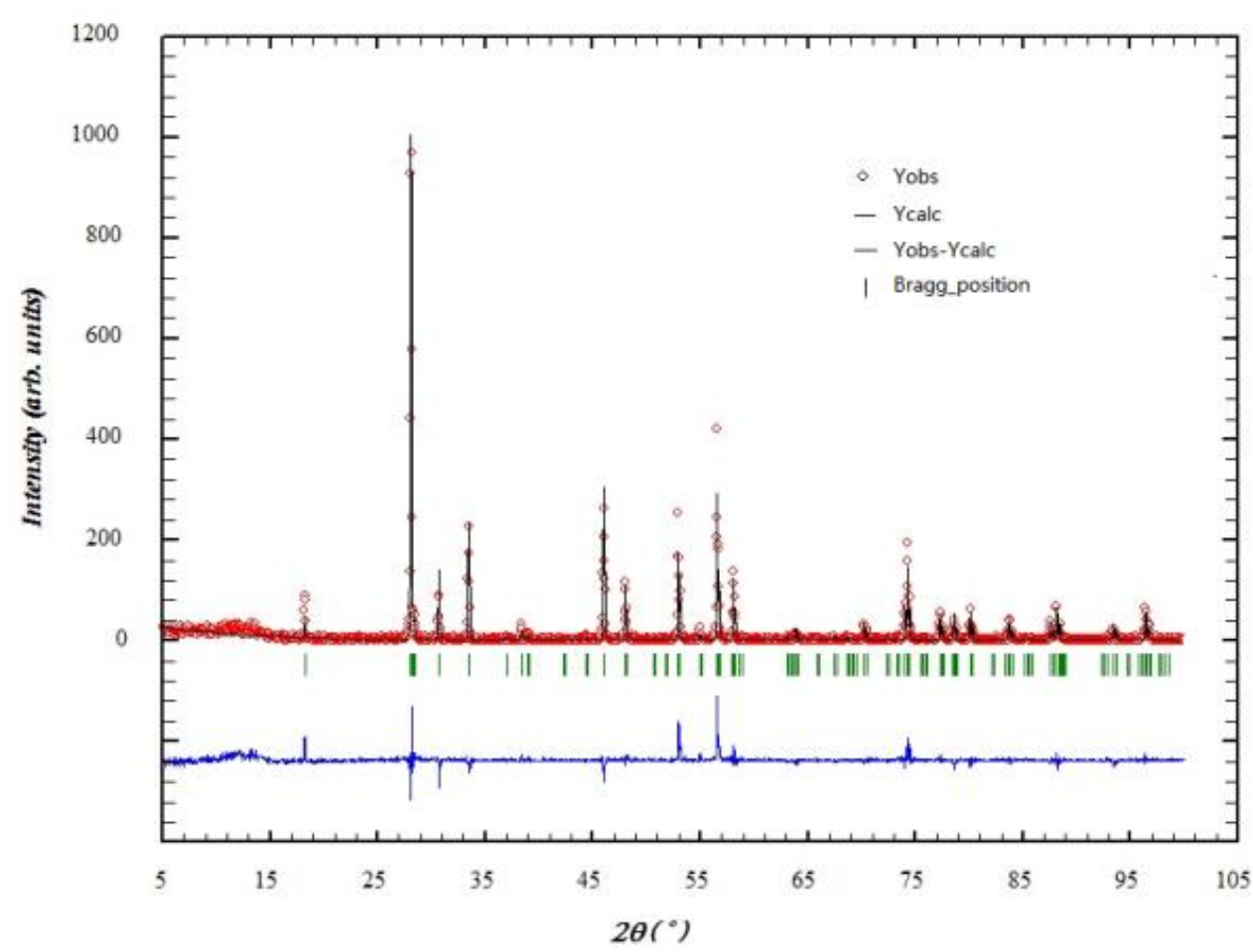

Fig. 3.8. Observed (open symbols) and calculated (straight line) X-ray powder diffraction pattern for $\mathrm{Eu}_{0.01} \mathrm{Ce}_{0.99} \mathrm{Ag}\left(\mathrm{WO}_{4}\right)_{2}$. The short vertical lines below the patterns mark the positions of Bragg reflections. The bottom continuous blue line is the difference between the observed and the calculated intensity.

Table 3.1. Lattice parameters and crystallographic positional parameters for $\mathrm{Eu}_{x} \mathrm{Ce}_{(1-x)} \mathrm{Ag}\left(\mathrm{WO}_{4}\right)_{2}$.

\begin{tabular}{|c|c|c|c|c|c|c|c|c|}
\hline $\mathrm{x}$ & $\mathrm{a}(\AA)$ & $\mathrm{c}(\AA)$ & $\mathrm{V}\left(\AA^{3}\right)$ & $\mathrm{Ox}$ & $\mathrm{Oy}$ & $\mathrm{Oz}$ & $\mathrm{R}_{\text {bragg }}$ & $\mathrm{R}_{\mathrm{f}}$ \\
\hline 0.01 & $5.3541(2)$ & $11.6491(6)$ & $333.94(2)$ & $0.744(7)$ & $0.882(6)$ & $0.037(3)$ & 16.9 & 17.9 \\
\hline 0.05 & $5.3526(2)$ & $11.6452(10)$ & $333.65(3)$ & $0.734(6)$ & $0.883(6)$ & $0.051(2)$ & 20.5 & 22.9 \\
\hline 0.2 & $5.3403(5)$ & $11.6266(15)$ & $331.57(6)$ & $0.753(7)$ & $0.875(6)$ & $0.058(3)$ & 17.6 & 19.1 \\
\hline 0.5 & $5.3143(5)$ & $11.5851(15)$ & $327.19(6)$ & $0.710(11)$ & $0.904(16)$ & $0.017(8)$ & 20.1 & 19.7 \\
\hline 0.7 & $5.2990(4)$ & $11.5513(13)$ & $324.35(5)$ & $0.659(10)$ & $1.051(14)$ & $0.048(5)$ & 18.4 & 22.2 \\
\hline
\end{tabular}




\subsubsection{Vibrational Study by FTIR and Raman Spectral.}

Because of the imprecision of the X-ray diffraction while measure the positions of light $\mathrm{O}$ atoms in the compounds, the analysis of FT-IR and Raman were introduced in. The FT-IR and Raman spectra of the $\left.\mathrm{Eu}_{x} \mathrm{Ce}_{(1-x)}\right) \mathrm{Ag}\left(\mathrm{WO}_{4}\right)_{2}$ (x from 0.00 to 0.50 ) samples are shown in Fig.3.9.

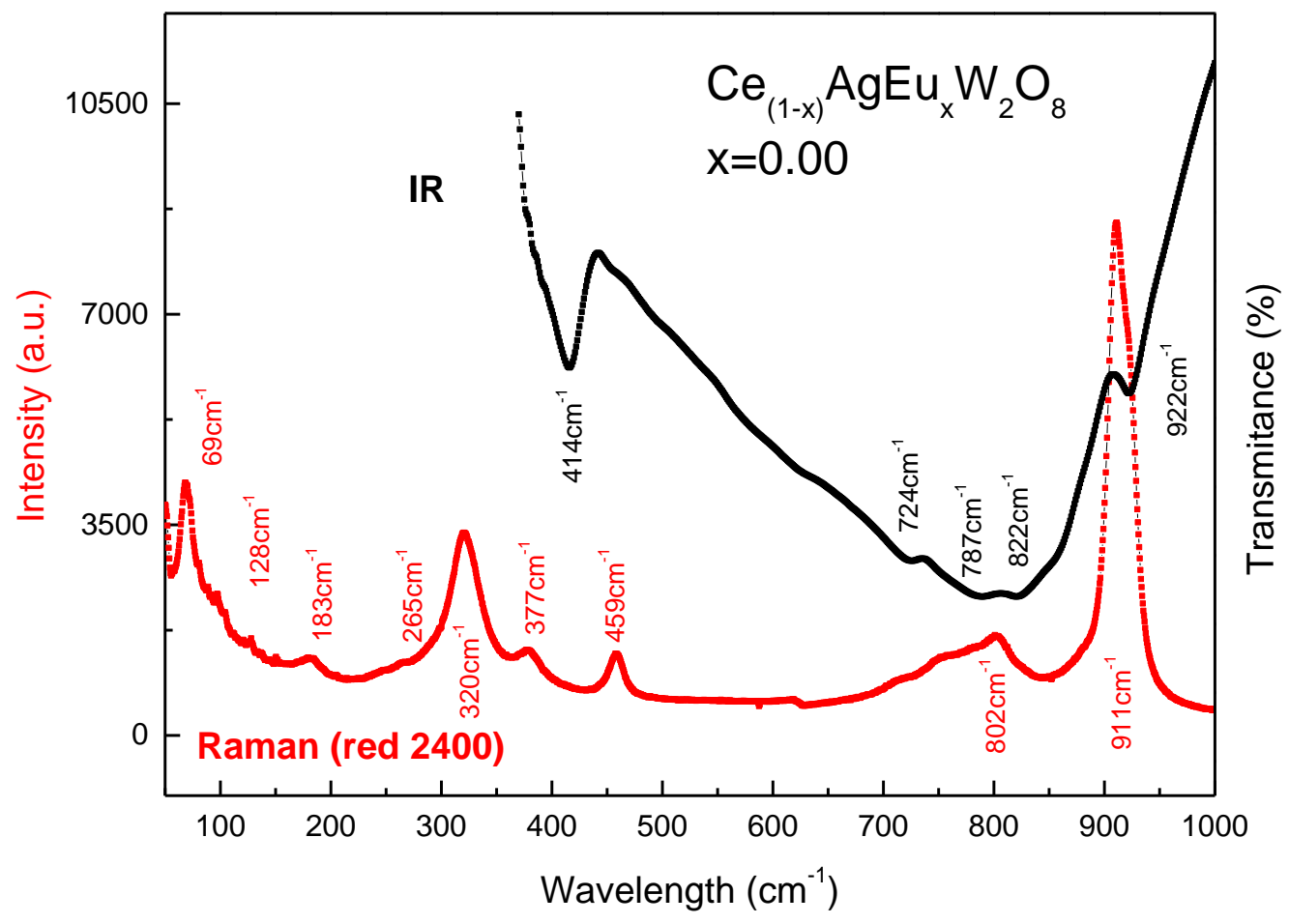

Fig.3.9 a The FT-IR and Raman spectra of $\mathrm{Eu}_{x} \mathrm{Ce}(1-x) \mathrm{Ag}\left(\mathrm{WO}_{4}\right)_{2}($ when $\mathrm{x}=0$ ) samples. 

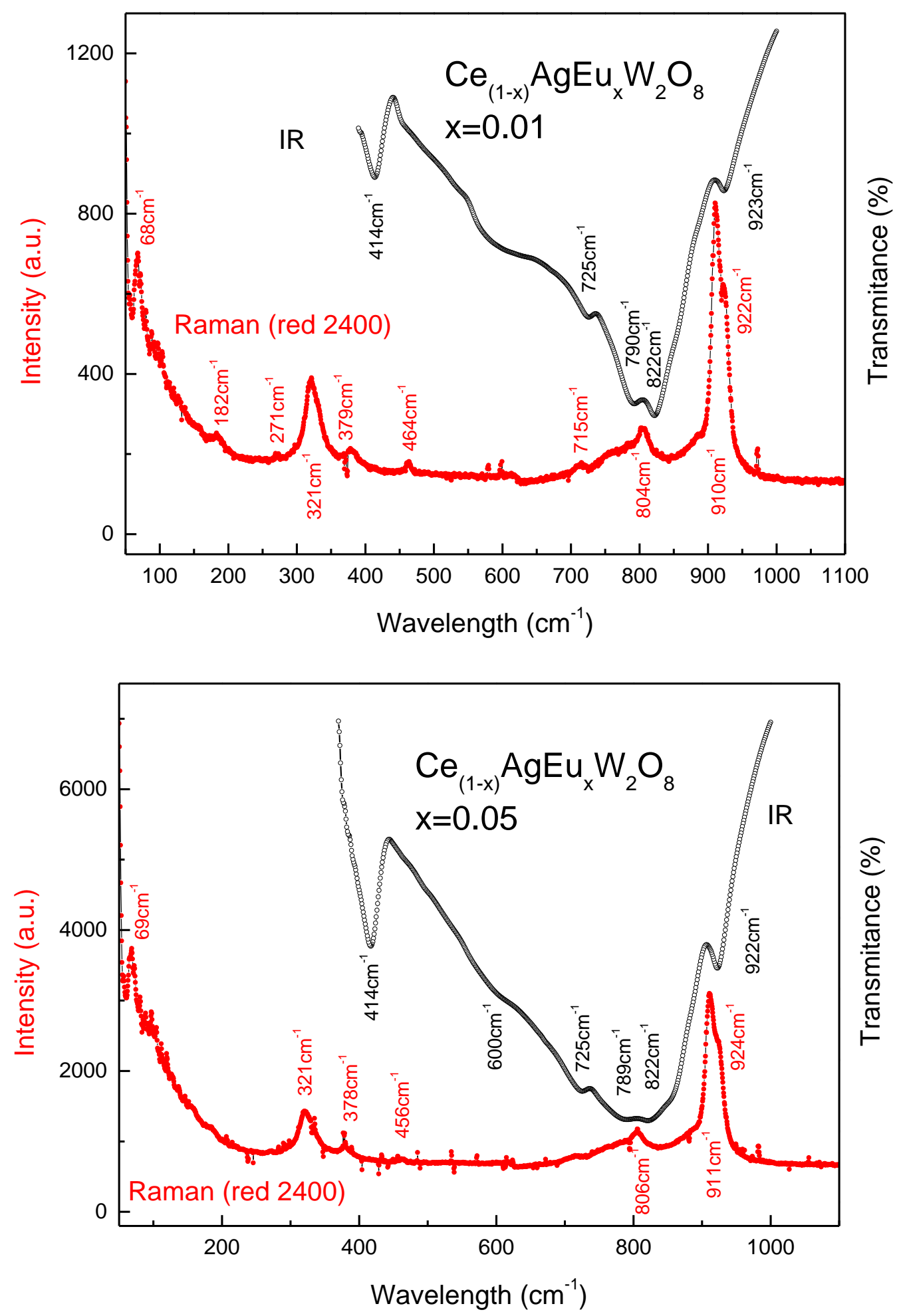

Fig.3.9. $b$ The FT-IR and Raman spectra of $\mathrm{Eu}_{x} \mathrm{Ce}_{(1-x)} \mathrm{Ag}\left(\mathrm{WO}_{4}\right)_{2}($ when $\mathrm{x}=0.01$ and 0.05$)$ samples. 

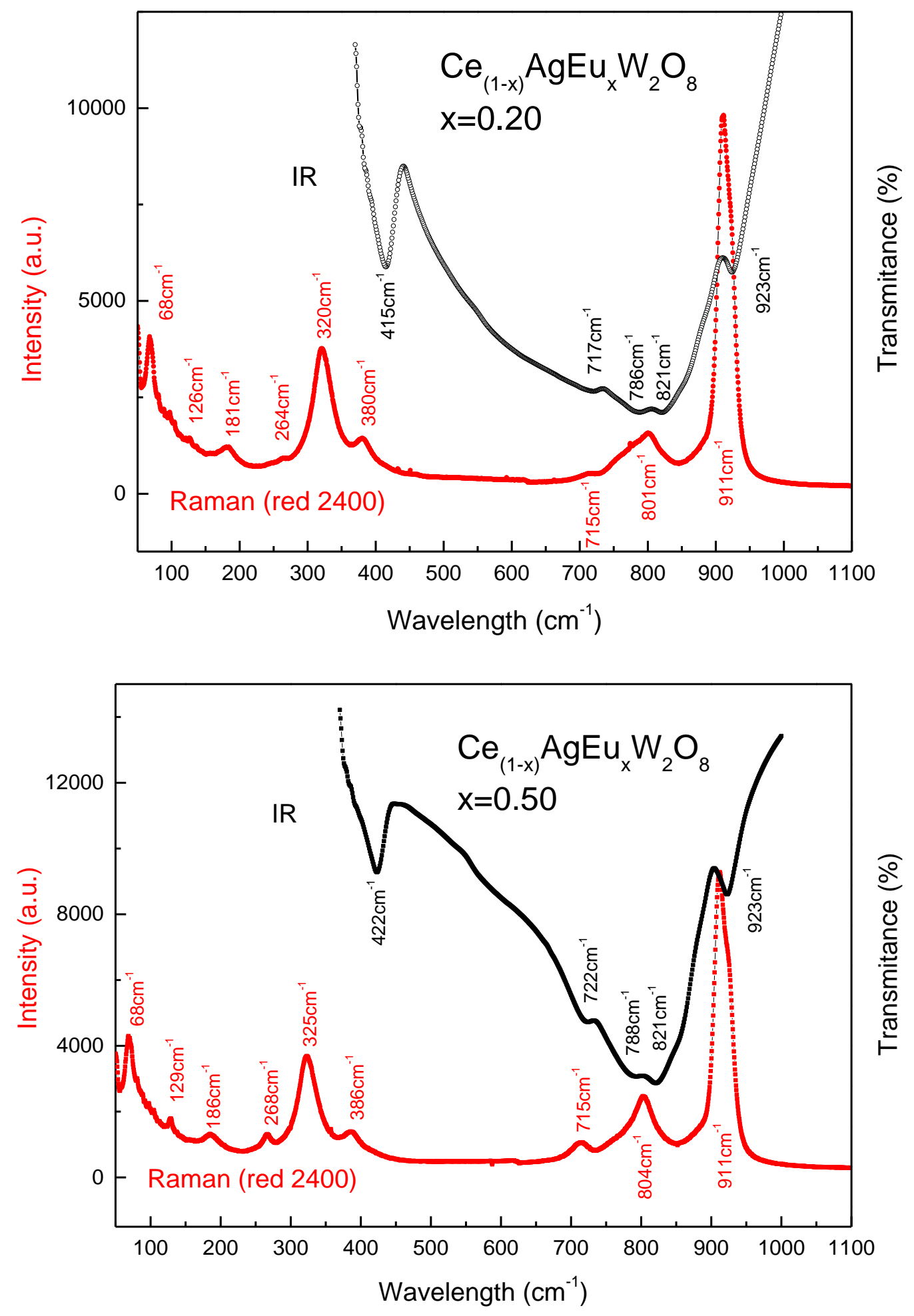

Fig.3.9. The FT-IR and Raman spectra of $\mathrm{Eu}_{x} \mathrm{Ce}_{(1-x)} \mathrm{Ag}\left(\mathrm{WO}_{4}\right)_{2}$ (when $\mathrm{x}=0.20$ and $0.50)$ samples. 
The IR spectra of $\mathrm{Eu}_{x} \mathrm{Ce}_{(1-x)} \mathrm{Ag}\left(\mathrm{WO}_{4}\right)_{2}(\mathrm{x}$ from 0.00 to 0.5$)$ in the region of $370-$ $1000 \mathrm{~cm}^{-1}$ were recorded. The $\mathrm{WO}_{4}^{2-}$ groups which having $\mathrm{S}_{4}$ site symmetry show three absorption bands in the region of $370-1000 \mathrm{~cm}^{-1}$ around 925, 800 and $400 \mathrm{~cm}^{-1}$ which correspond to the $\mathrm{v}_{1}, \mathrm{v}_{3}$ and $\mathrm{v}_{2}$ vibration modes respectively [3.1,3.2]. All these compounds have similar IR spectra patterns and are analogous with those $\mathrm{AgLn}\left(\mathrm{MoO}_{4}\right)_{2}$ compounds [3.3]. The v3 mode splits into three components around 724, 791 and $821 \mathrm{~cm}^{-1}$ for $\mathrm{Eu}_{x} \mathrm{Ce}_{(1-x)} \mathrm{Ag}\left(\mathrm{WO}_{4}\right)_{2}$ when $\mathrm{x}=0.01$ as example. The $\mathrm{v}_{1}$ mode has only one peak at $922 \mathrm{~cm}^{-1}$, and $\mathrm{v}_{2}$ mode has one peak at $413 \mathrm{~cm}^{-1}$. It is confirmed that the compounds $\mathrm{Eu} \mathrm{Ce}_{(1-\mathrm{x})} \mathrm{Ag}\left(\mathrm{WO}_{4}\right)_{2}(\mathrm{x}$ from 0.00 to 0.5 ) all crystallized the scheelite-related structure with $\mathrm{WO}_{4}^{2-}$ tetrahedral. The dopants did not transform the host structure and the results are coincident with the obtained by XRD analysis.

Using the Factor Group Analysis (FGA), the primitive unit cell containing 12 atoms gives rise to $3 \mathrm{~N}=36$ freedom degrees which are divided into 26 vibration species. The 26 vibration species can be described as $\Gamma=3 A_{g}+5 B_{g}+5 E_{g}+5 A_{u}$ $+3 B_{u}+5 E_{u}$, where the $E$ vibrations are doubly degenerate. Acoustic modes $\Gamma \mathrm{T}=$ $A_{u}+E_{u}$, translatory lattice modes $\Gamma^{\prime}{ }_{T}=2 B_{g}+2 E_{g}+A_{u}+E_{u}$, rotatory lattice modes $\Gamma L=A_{g}+E_{g}+B_{u}+E_{u}$ and internal vibrations $\Gamma_{i}=2 A_{g}+3 B_{g}+2 E_{g}+3 A_{u}+2 B_{u}+$ $2 \mathrm{E}_{u}$ [3.4-3.6]. The assignments of observed vibrational modes in $\mathrm{Eu}_{x} \mathrm{Ce}_{(1-x)} \mathrm{Ag}\left(\mathrm{WO}_{4}\right)_{2}$ ( $x$ from 0.00 to 0.5 ) were listed in Table 3.2. For the samples, the number of bands is nearly the same and is analogous as observed for scheelite-related $\mathrm{NaY}\left(\mathrm{WO}_{4}\right)_{2}$ crystal [3.5], which proves that the structures of all these samples are isomorphic. The line with highest intensity appears at $911 \mathrm{~cm}^{-1}$ and it is assigned to symmetric stretching vibrations of the $\left(\mathrm{WO}_{4}\right)$.

It was reported that the scheelite crystals, where $\mathrm{XO}_{4}$ - ions form isolated tetrahedral, exhibit the energy gap in the region of $450-700 \mathrm{~cm}^{-1}[3.5,3.7]$. This was observed in our spectra as well. Meanwhile in our compounds the different proportion of cerium and europium ions did not significantly affect the spectra, except slight shifts of the lines (see Table 3.2). The selection rules corresponding to the $C_{4 h}^{6}$ symmetry group is perfectly verified and therefore we can conclude that there is no appreciable distortion of the tetragonal structure. 
Table 3.2. The observed bands $\left(\mathrm{cm}^{-1}\right)$ and symmetry of Raman modes for $\mathrm{Eu}_{\times} \mathrm{Ce}_{(1-x)} \mathrm{Ag}\left(\mathrm{WO}_{4}\right)_{2}$. A band with wavenumbers in parentheses is a very weak band.

\begin{tabular}{llllll}
\hline $\mathrm{X}=0.00$ & $\mathrm{X}=0.01$ & $\mathrm{X}=0.05$ & $\mathrm{X}=0.20$ & $\mathrm{X}=0.50$ & Assignments \\
\hline$(922)$ & $(922)$ & 924 & & $(923)$ & \\
911 & 910 & 911 & 911 & 911 & $\mathrm{v}_{\mathrm{s}}\left(\mathrm{WO}_{4}\right)$ \\
802 & 804 & 806 & 801 & 804 & $\mathrm{Vas}_{\mathrm{s}}\left(\mathrm{WO}_{4}\right)$ \\
& 715 & & $(715)$ & 715 & \\
459 & 464 & $(456)$ & weak & weak & \\
377 & 379 & 378 & 380 & 386 & $\delta_{\mathrm{as}}\left(\mathrm{WO}_{4}\right)$ \\
320 & 321 & 321 & 320 & 325 & $\delta_{\mathrm{s}}\left(\mathrm{WO}_{4}\right)$ \\
$(265)$ & $(271)$ & & $(264)$ & 268 & \\
183 & 182 & & 181 & 186 & $\mathrm{~T}^{\prime}\left(\mathrm{Ag}^{+}\right)$and $\mathrm{R}\left(\mathrm{WO}_{4}\right)$ \\
$(128)$ & & & $(126)$ & 129 & $\mathrm{~T}^{\prime}\left(\mathrm{Ce}^{3+}, \mathrm{Eu} \mathrm{u}^{3+}\right)$ and \\
& & & & & $\mathrm{T}^{\prime}\left(\mathrm{WO}_{4}\right)$ \\
69 & 68 & 69 & 68 & 68 & \\
\hline
\end{tabular}

\subsubsection{Magnetic Properties}

In order to prepare the silver cerium tungstate in where the cerium may have mixed valence which may generate variations in their properties, especially electrical properties, attempts have been made to substitute the $\mathrm{Ce}^{3+}$ with the stoichiometric ion $\mathrm{Ag}^{+}$in the compounds, hoping for the valence pass from $\mathrm{Ce}^{3+}$ to $\mathrm{Ce}^{4+}$ due to charge compensation. X-ray diffraction analysis showed that the obtained different samples exhibit the same original crystal structure without obvious distortions and changes. As a suitable technique for measuring the electron state of cerium, magnetic characterization has been performed.

Magnetic susceptibility measurements for the compounds $\mathrm{Ce}_{(1-x)} \mathrm{Ag}_{(1+x)}\left(\mathrm{WO}_{4}\right)_{2}$ reveal a paramagnetic behavior down to temperatures of $2 \mathrm{~K}$, see Fig. 3.10. Considering that only $\mathrm{Ce}^{3+}$ has paramagnetic behavior, this gives evidence that existed trivalent $\mathrm{Ce}^{3+}$ ions in the $\mathrm{Ce}_{(1-\mathrm{x})} \mathrm{Ag}_{(1+x)}\left(\mathrm{WO}_{4}\right)_{2}$ compounds. Moreover, as 
the increase of $x$ value in $\mathrm{Ce}_{(1-x)} \mathrm{Ag}_{(1+x)}\left(\mathrm{WO}_{4}\right)_{2}$, no sudden decrease of the magnetic susceptibility $x$ was observed which indicated that the trivalent $\mathrm{Ce}^{3+}$ ions did not convert to tetravalent $\mathrm{Ce}^{4+}$ ions for charge compensation. The downwards or upwards deviation from the Curie-Weiss behavior observed for the compounds can be fully explained taking into account the splitting of the ground term of the $\mathrm{Ce}^{3+}$ cation under the influence of the crystal field without considering any magnetic phenomena as for example magnetic frustration or cooperative magnetic interactions [3.8].

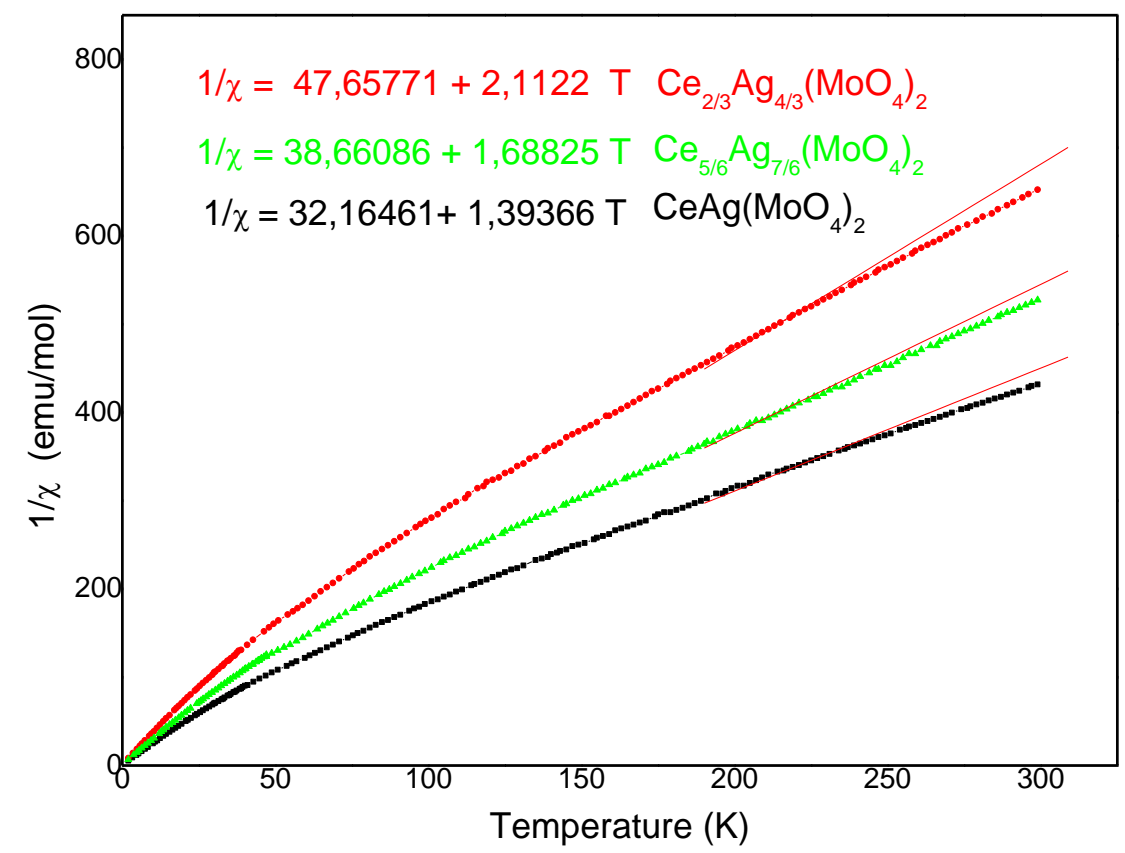

Fig. 3.10 Temperature dependence of the magnetic susceptibility for the $\mathrm{Ce}_{(1-x)} \mathrm{Ag}_{(1+\mathrm{x})}\left(\mathrm{WO}_{4}\right)_{2}$ tungstate.

\subsubsection{Fluorescence Properties of $\mathrm{AgCe}\left(\mathrm{WO}_{4}\right)_{2}: \mathrm{Eu}^{3+}$}

The $\mathrm{Eu}^{3+}$ was thought to be used as dopant by substituting the location of $\mathrm{Ce}^{3+}$ ions. The excitation spectra (monitored at $615 \mathrm{~nm}$ ) and emission spectra (excited at $465 \mathrm{~nm})$ of $\mathrm{AgCe}_{1-\mathrm{x}} \mathrm{Eu}_{\mathrm{x}}\left(\mathrm{WO}_{4}\right)_{2}(\mathrm{x}=0,0.01,0.05,0.2,0.5,0.7,0.8,0.85$ and 1) were shown in Fig. 3.11.

It is well known that the luminescence photon energy of $\mathrm{Ce}^{3+}$ ions depends strongly on the structure of the host crystal through the crystal field splitting of the 
$5 d$ state, and varies from near UV to the visible region[3.9]. In our case, as shown in the excitation spectrum of $\mathrm{AgCe}_{1-\mathrm{x}} \mathrm{Eu}_{\mathrm{x}}\left(\mathrm{WO}_{4}\right)_{2}$ ( $\mathrm{x}$ value from 0 to 0.7 ), the broad band between 400 and $500 \mathrm{~nm}$ can be attributed to the $4 \mathrm{f} \rightarrow 5 \mathrm{~d}$ transition of $\mathrm{Ce}^{3+}$ [3.10] which overlaps with the charge transfer of $\mathrm{O}^{2-}-\mathrm{W}^{6+}$. The peak at about 561 $\mathrm{nm}$ can be assigned to the behavior of $\mathrm{Ag}^{+}$. No efficient bands, which can be attributed to the appearance of $\mathrm{Ce}^{3+}$ ions, were observed in the emission spectrum,

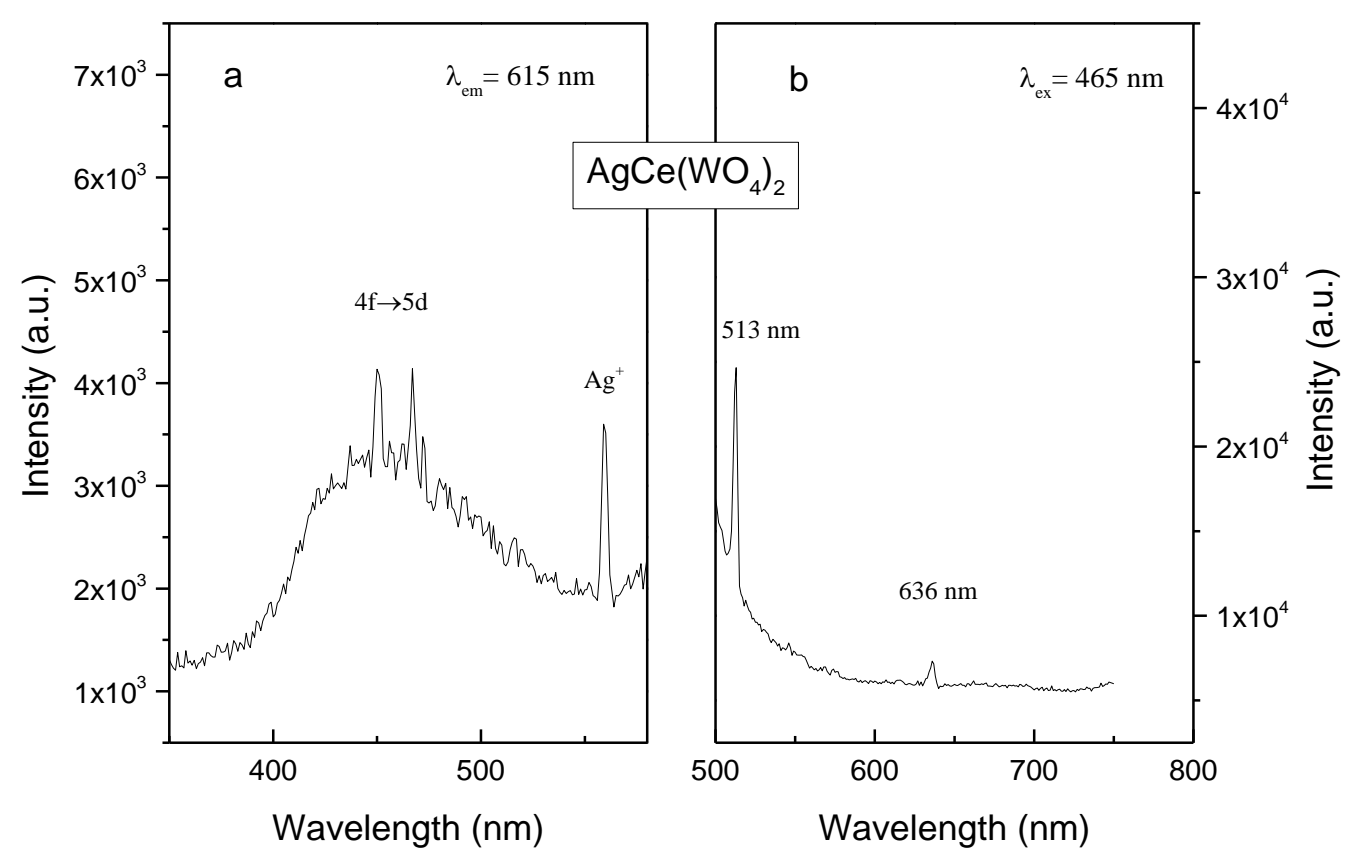




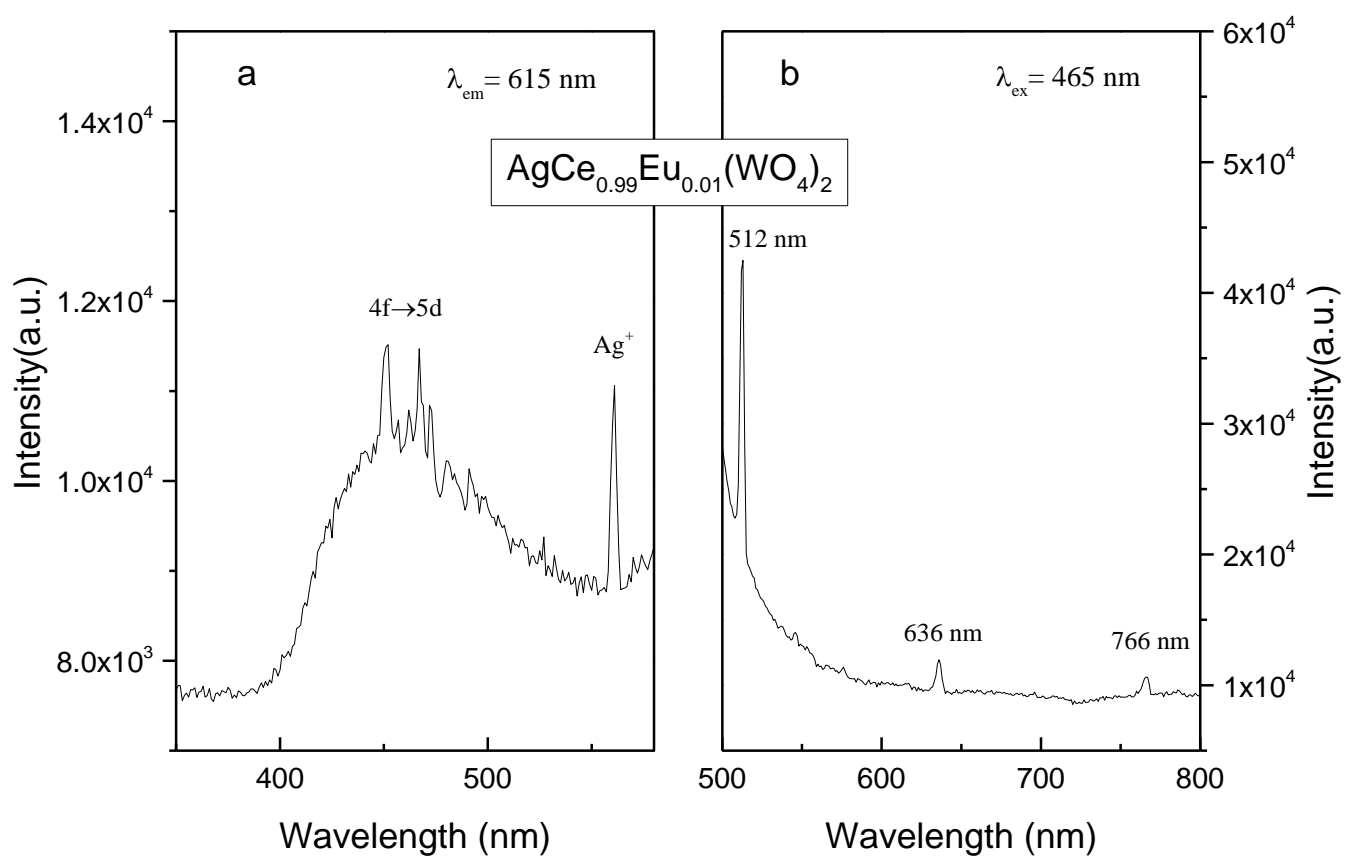

Fig. $3.11 \mathrm{a}$. Photo luminescent excitation spectra (monitored at $615 \mathrm{~nm}$ ) and emission spectra (excited at $465 \mathrm{~nm})$ of $\mathrm{AgCe}_{1-\mathrm{x}} \mathrm{Eu}_{\mathrm{x}}\left(\mathrm{WO}_{4}\right)_{2}(\mathrm{x}=0$ and 0.01$)$

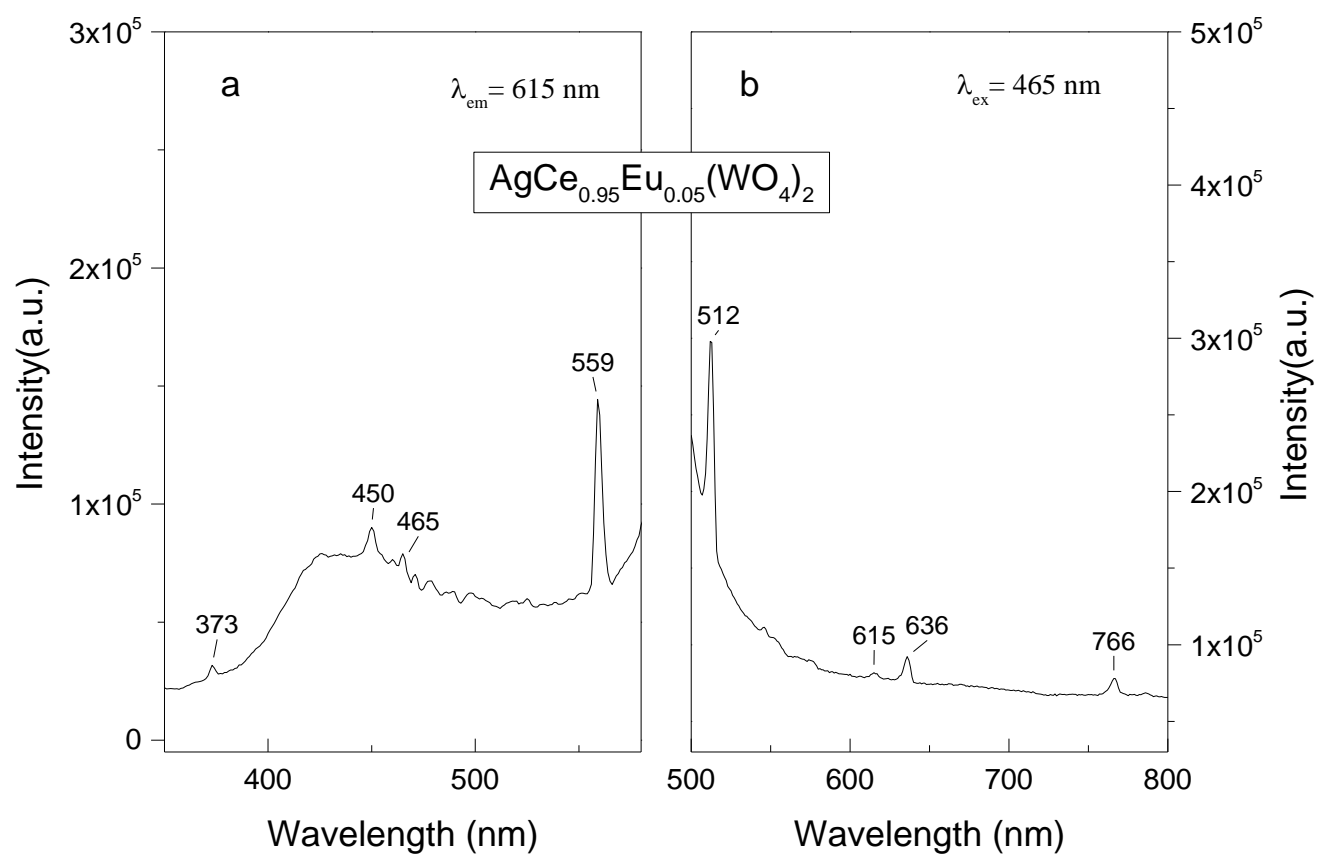




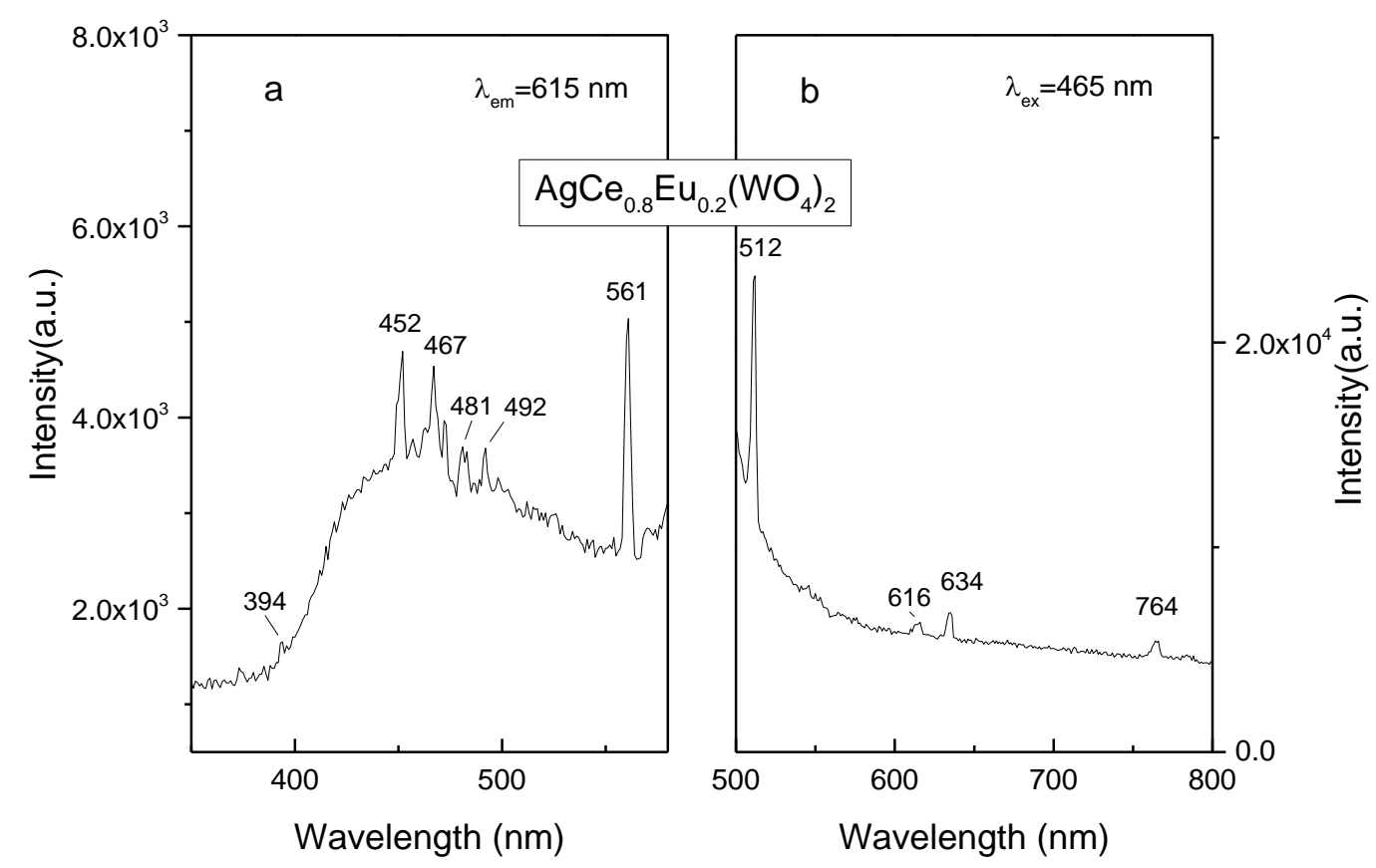

Fig. 3.11 b. Photo luminescent excitation spectra (monitored at $615 \mathrm{~nm}$ ) and emission spectra (excited at $465 \mathrm{~nm}$ ) of $\mathrm{AgCe}_{1-\mathrm{x}} \mathrm{Eu}_{x}\left(\mathrm{WO}_{4}\right)_{2}(\mathrm{x}=0.05$ and 0.2).

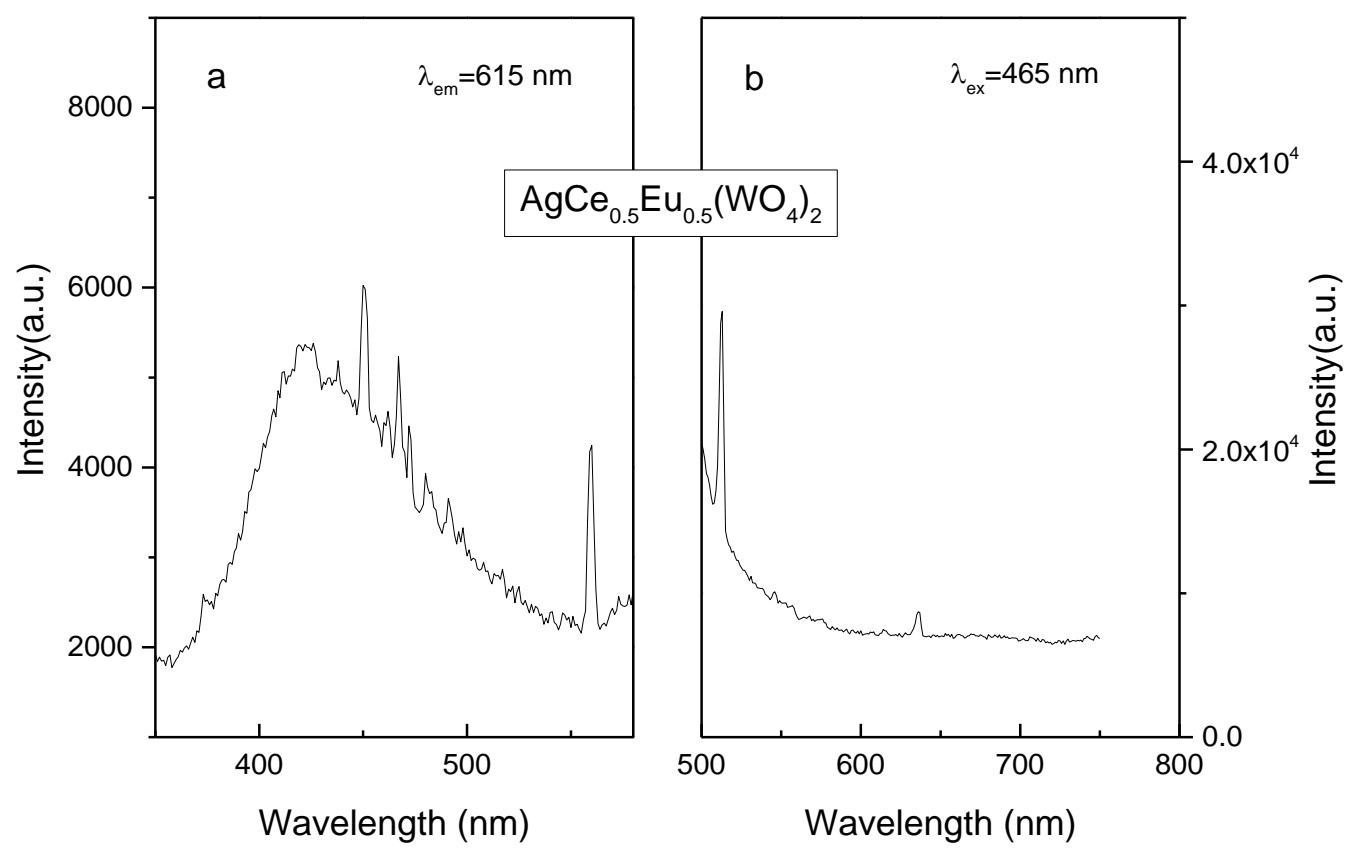




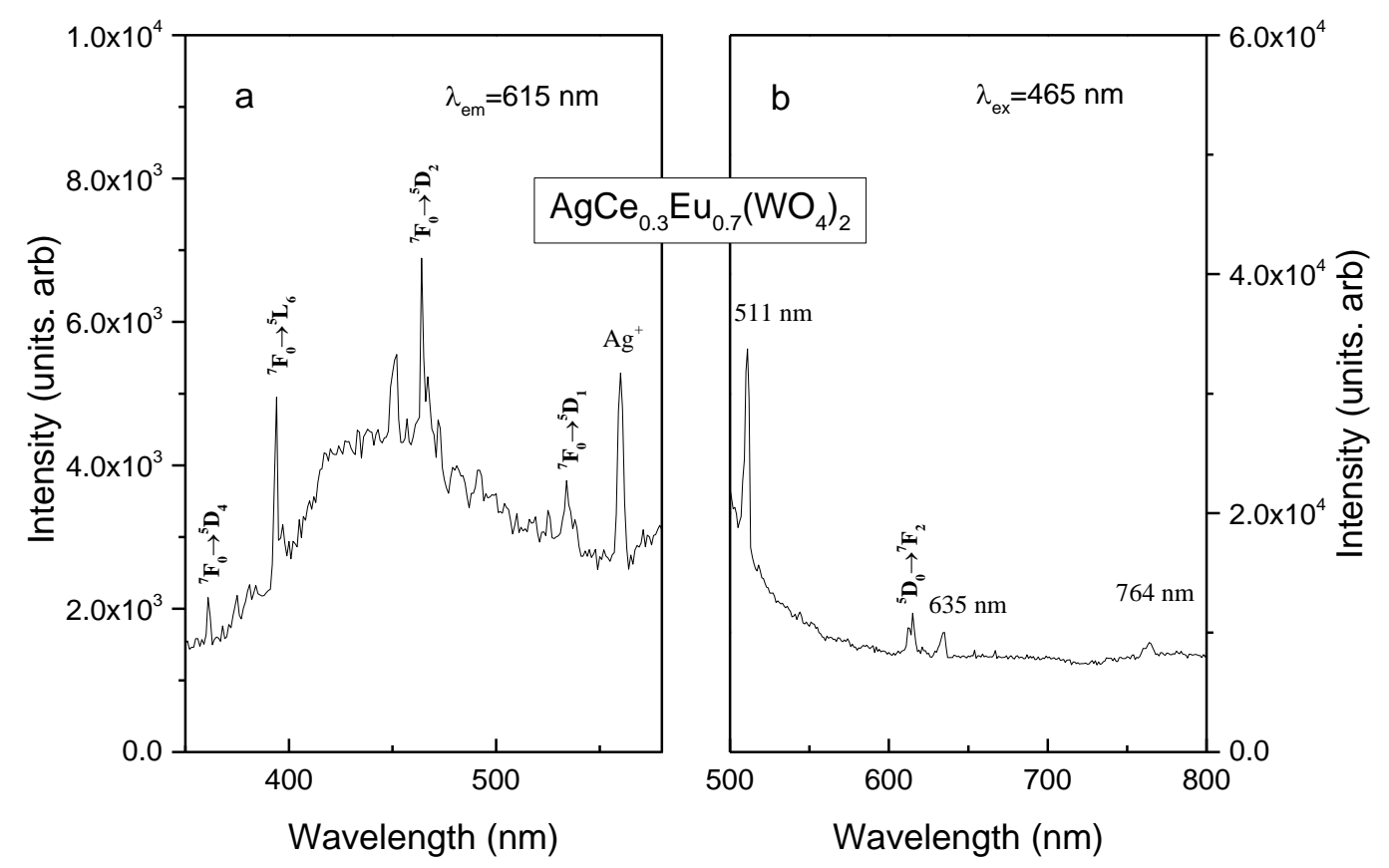

Fig. 3.11 c. Photo luminescent excitation spectra (monitored at $615 \mathrm{~nm}$ ) and emission spectra (excited at $465 \mathrm{~nm}$ ) of $\mathrm{AgCe}_{1-\mathrm{x}} \mathrm{Eu}_{\mathrm{x}}\left(\mathrm{WO}_{4}\right)_{2}(\mathrm{x}=0.5$ and 0.7$)$.

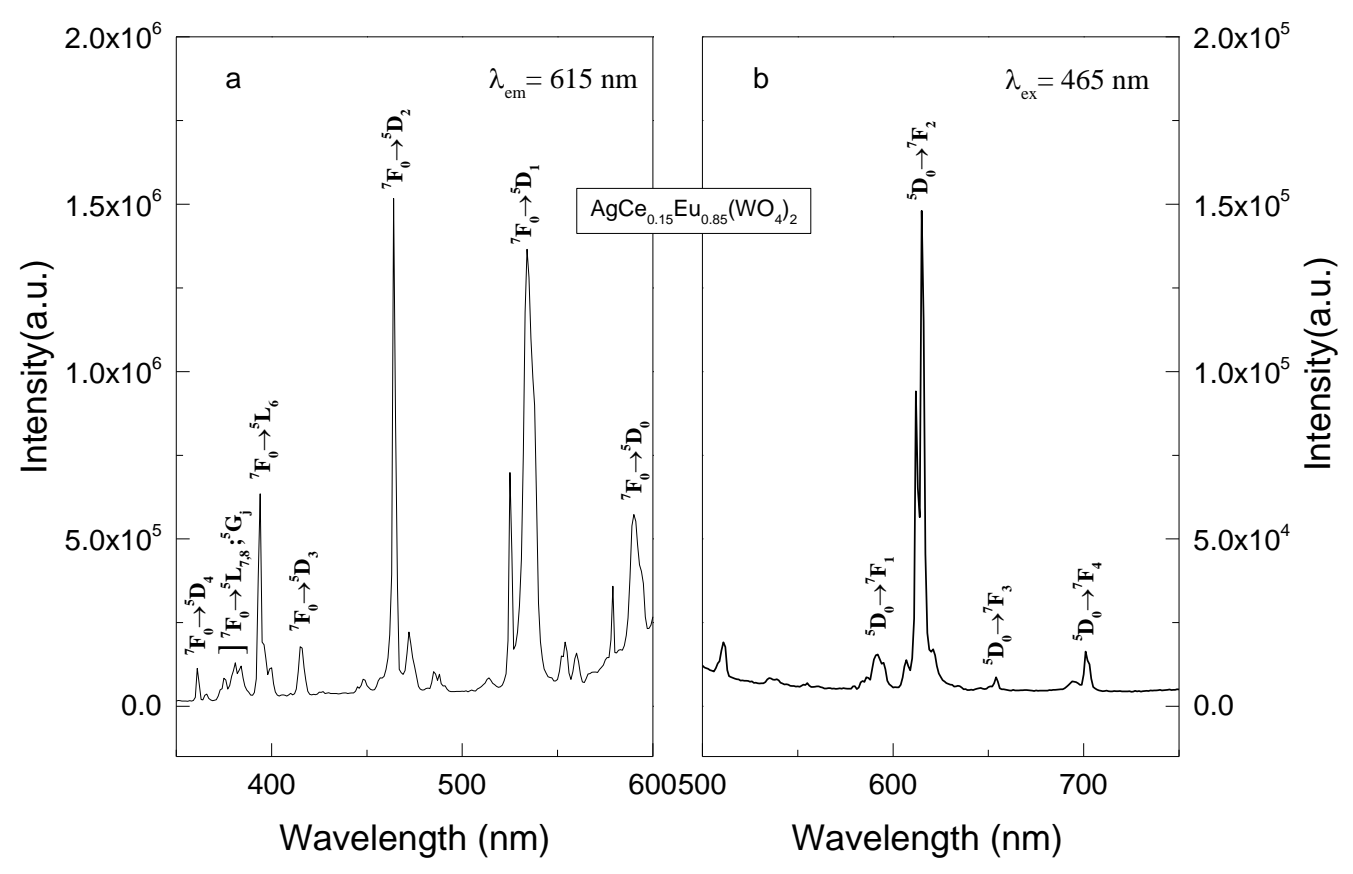




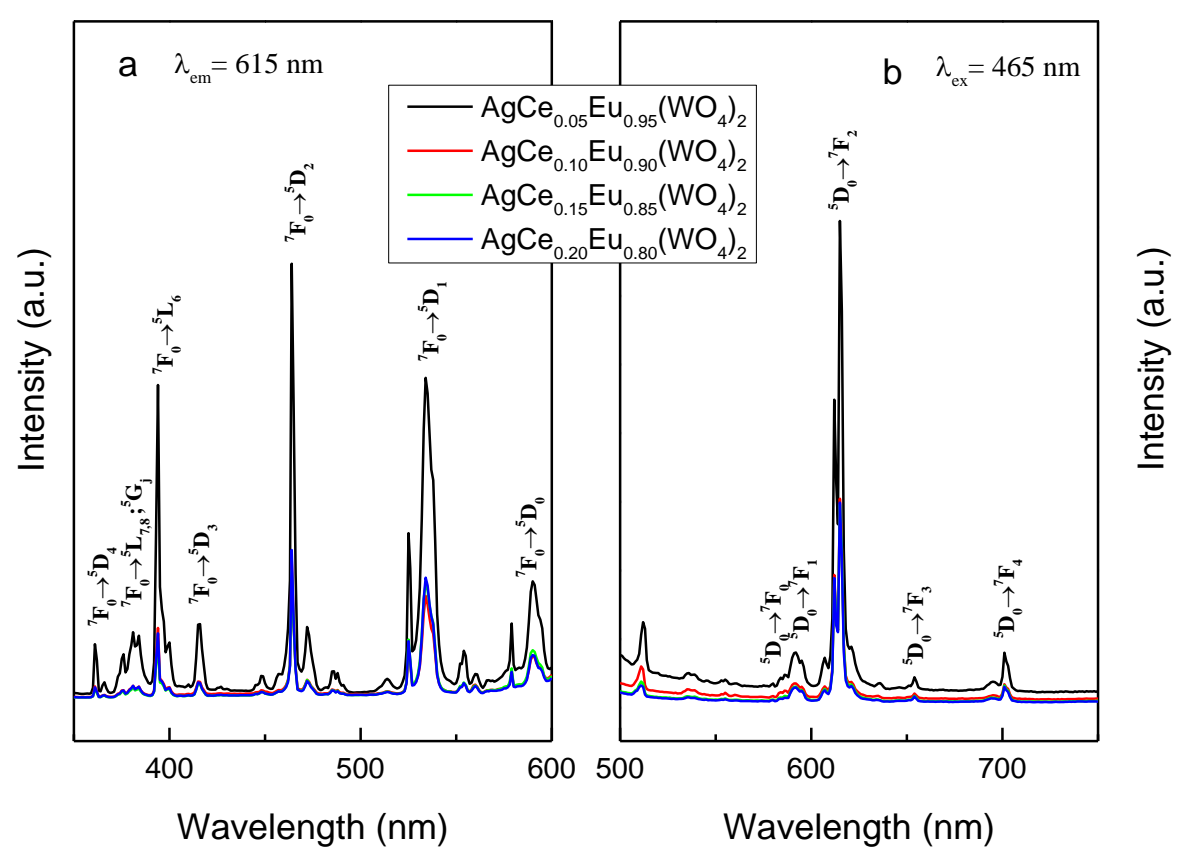

Fig. $3.11 \mathrm{~d}$. Photo luminescent excitation spectra (monitored at $615 \mathrm{~nm}$ ) and emission spectra (excited at $465 \mathrm{~nm}$ ) of $\mathrm{AgCe}_{1-\mathrm{x}} \mathrm{Eu}_{\mathrm{x}}\left(\mathrm{WO}_{4}\right)_{2}$ ( $\mathrm{x}$ values from 0.8 to 0.95).

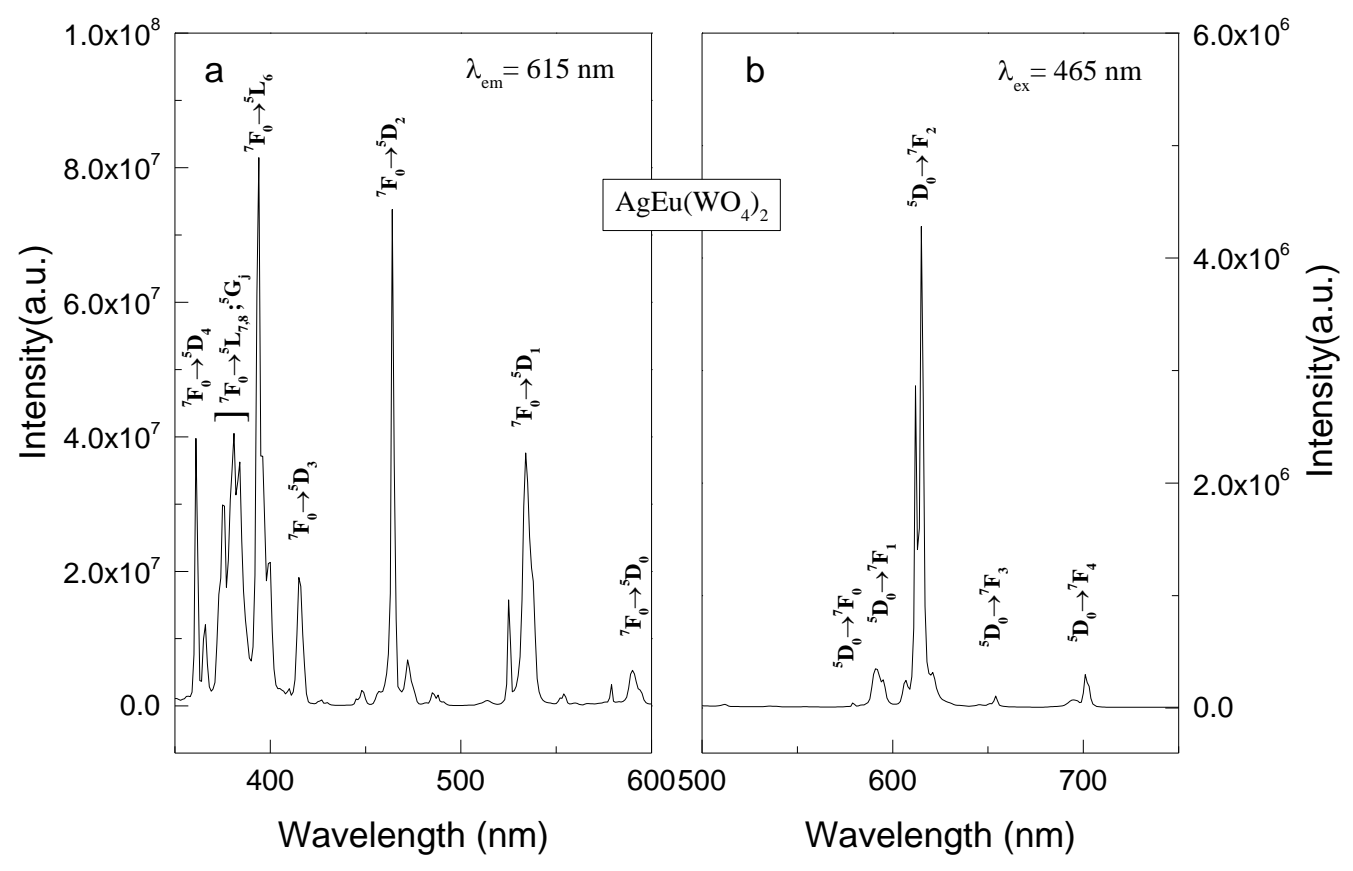

Fig. 3.11 e. Photo luminescent excitation spectra (monitored at $615 \mathrm{~nm}$ ) and emission spectra (excited at $465 \mathrm{~nm})$ of $\mathrm{AgCe}_{1-\mathrm{x}} \mathrm{Eu}_{\mathrm{x}}\left(\mathrm{WO}_{4}\right)_{2}(\mathrm{x}=1)$. 
In the $\mathrm{AgCe}_{1-\mathrm{x}} \mathrm{Eu}_{\mathrm{x}}\left(\mathrm{WO}_{4}\right)_{2}$ compounds, the specific bands of $\mathrm{Eu}^{3+}$ were almost disappeared when the $\mathrm{Eu}^{3+}$ concentration is below than $70 \%$.Both excitation spectrum and emission spectrum maintain similar as the compounds $\mathrm{AgCe}$ $\left(\mathrm{WO}_{4}\right)_{2}$ without any $\mathrm{Eu}^{3+}$ ions involved in. In the excitation spectrum the broad band between 400 and $500 \mathrm{~nm}$ can be also attributed to the $4 \mathrm{f} \rightarrow 5 \mathrm{~d}$ transition of $\mathrm{Ce}^{3+}[3.10]$ and the charge transferofO'- $-\mathrm{W}^{6+}$. The peak at about $561 \mathrm{~nm}$ can be assigned to the behavior of $\mathrm{Ag}^{+}$. The similar situation can be seen in the emission spectra. The most intensity peaks were found at about $512 \mathrm{~nm}, 636 \mathrm{~nm}$ and 766 $\mathrm{nm}$ instead of $615 \mathrm{~nm}$ or $702 \mathrm{~nm}(615 \mathrm{~nm}$ and $702 \mathrm{~nm}$ were coincident with the well-known ${ }^{5} \mathrm{D}_{0} \rightarrow{ }^{7} \mathrm{~F}_{2}$ and ${ }^{5} \mathrm{D}_{0} \rightarrow{ }^{7} \mathrm{~F}_{4}$ transitions of $\mathrm{Eu}^{3+}$ respectively) [3.11-3.14].

With the increase of dopants concentration, specific bands of $\mathrm{Eu}^{3+}$ appeared despite of the unknown peaks. When the concentration of $\mathrm{Eu}^{3+}$ reached $70 \%$, efficient transitions ${ }^{7} \mathrm{~F}_{0} \rightarrow{ }^{5} \mathrm{D}_{4},{ }^{7} \mathrm{~F}_{0} \rightarrow{ }^{5} \mathrm{~L}_{6},{ }^{7} \mathrm{~F}_{0} \rightarrow{ }^{5} \mathrm{D}_{2}$ and ${ }^{7} \mathrm{~F}_{0} \rightarrow{ }^{5} \mathrm{D}_{1}$ of Eu $\mathrm{Eu}^{3+}$ were found at about $361 \mathrm{~nm}, 394 \mathrm{~nm}, 464 \mathrm{~nm}$ and $534 \mathrm{~nm}$ respectively in the excitation spectrum. And the ${ }^{5} \mathrm{D}_{0} \rightarrow{ }^{7} \mathrm{~F}_{2}$ transition was observed at around $615 \mathrm{~nm}$ in the emission spectrum.

When the $\mathrm{Eu}^{3+}$ concentration is higher than $70 \%$, the specific bands of $\mathrm{Eu}^{3+}$ became much more efficient with tremendous high intensity. It has been observed that the efficient excitation and emission spectrum of $\mathrm{Eu}^{3+}$ disappeared with the increase of $\mathrm{Ce}^{3+}$ concentration. Otherwise, the efficiency of the excitation band of $\mathrm{Eu}^{3+}$ to activate its well-known emission band at $615 \mathrm{~nm}\left({ }^{5} \mathrm{D}_{0}\right.$ $\rightarrow{ }^{7} \mathrm{~F}_{2}$ transition) and decreased with increasing concentration of $\mathrm{Ce}^{3+}$ and formed differently in according with the same wavelength. The effect is more obviously with moving towards the UV.

The X-ray diffraction data (see Table 3.3) for relations $\mathrm{Ce}^{3+} / \mathrm{Eu}^{3+}$ greater than 95 / 5 suggested that the $\mathrm{Eu}^{3+}$ located in the $\mathrm{Ce}^{3+}$ sites and does not distort the crystal structure. However the europium bands have nearly completely disappeared in this compound. Hence, it can be conclude that the $\mathrm{Eu}^{3+}$ cannot be used as local structure probe in the $\mathrm{AgCe}\left(\mathrm{WO}_{4}\right)_{2}$ compound because the emission spectra of $\mathrm{Eu}^{3+}$ was quenched by the $\mathrm{Ce}^{3+}$ presence .

Table 3.3. Lattice parametersfor $\mathrm{AgCe}\left(\mathrm{WO}_{4}\right)_{2}, \quad \mathrm{AgCe}_{0.95} \mathrm{Eu}_{0.05}\left(\mathrm{WO}_{4}\right)_{2}$ and $\mathrm{AgCe}_{0.95} \mathrm{~Tb}_{0.05}\left(\mathrm{WO}_{4}\right)_{2}$. 


\begin{tabular}{l|ccc}
\hline Empirical Formula & $\mathrm{AgCe}\left(\mathrm{WO}_{4}\right)_{2}$ & $\mathrm{AgCe}{ }_{0.95} \mathrm{Eu}_{0.05}\left(\mathrm{WO}_{4}\right)_{2}$ & $\mathrm{AgCe}_{0.95} \mathrm{~Tb}_{0.05}\left(\mathrm{WO}_{4}\right)_{2}$ \\
\hline Formula Weight & 743.67 & 744.26 & 744.61 \\
Crystal System & Tetragonal & Tetragonal & Tetragonal \\
Space Group & $\mid 41 / \mathrm{a}$ & $\mid 41 / \mathrm{a}$ & I $41 / \mathrm{a}$ \\
Unit Cell & $\mathrm{a}=\mathrm{b}=5.3539(2)$ & $\mathrm{a}=\mathrm{b}=5.3527(3)$ & $\mathrm{a}=\mathrm{b}=5.3498(3)$ \\
Dimensions & $\mathrm{c}=11.6460(7)$, & $\mathrm{c}=11.6452(10)$, & $\mathrm{c}=11.6369(9)$, \\
& $\mathrm{\alpha}=\beta=\mathrm{\gamma}=90^{\circ}$ & $\mathrm{\alpha}=\beta=\mathrm{\gamma}=90^{\circ}$ & $\mathrm{\alpha}=\beta=\mathrm{\gamma}=90^{\circ}$ \\
Volume & $333.82(3) \AA^{3}$ & $333.65(4) \AA^{3}$ & $333.04(4) \AA^{3}$ \\
RBragg & 16.9 & 20.5 & 21.4 \\
Rf & 18.6 & 22.9 & 23.5 \\
\hline
\end{tabular}

\subsubsection{Fluorescence Properties of $\mathrm{AgCe}\left(\mathrm{WO}_{4}\right)_{2}: \mathrm{Tb}^{3+}$}

For the destination of investigating the crystal field of $\mathrm{AgCe}\left(\mathrm{WO}_{4}\right)_{2}$, another local structure probe $\mathrm{Tb}^{3+}$ was used. As can be seen in the Table 3.3, the presence of $\mathrm{Tb}^{3+}$ did not distort the crystal structure neither. The excitation spectra (monitored at $545 \mathrm{~nm}$ ) and emission spectra (excited at $486 \mathrm{~nm}$ ) of $\mathrm{AgCe}_{0.95} \mathrm{~Tb}_{0.05}\left(\mathrm{WO}_{4}\right)_{2}$ under room temperature and liquid nitrogen temperature - $77 \mathrm{~K}$ were illustrated in Fig. 3.12.

The emission spectra of $\mathrm{AgCe} 0.95 \mathrm{~Tb}_{0.05}\left(\mathrm{WO}_{4}\right)_{2}$ under both room temperature and $77 \mathrm{~K}$ were observed as similar as which have been reported in the $\mathrm{NaLa}\left(\mathrm{WO}_{4}\right)_{2}: \mathrm{Tb}^{3+}$ and $\mathrm{NaLa}\left(\mathrm{WO}_{4}\right)\left(\mathrm{MoO}_{4}\right): \mathrm{Tb}^{3+}$ system [3.13,3.15]. The emission peaks located at 545,583 , and $624 \mathrm{~nm}$ can be observed, which are attributed to the ${ }^{5} \mathrm{D}_{4} \rightarrow{ }^{7} \mathrm{~F}_{5},{ }^{5} \mathrm{D}_{4} \rightarrow{ }^{7} \mathrm{~F}_{4}$ and ${ }^{5} \mathrm{D}_{4} \rightarrow{ }^{7} \mathrm{~F}_{3}$ transitions of $\mathrm{Tb}^{3+}$ respectively. And the green emission of ${ }^{5} \mathrm{D}_{4} \rightarrow{ }^{7} \mathrm{~F}_{5}$ transition is dominant in the emission spectra. The excitation spectrum of $\mathrm{AgCe}_{0.95} \mathrm{~Tb}_{0.05}\left(\mathrm{WO}_{4}\right)_{2}$ was unlike as reported in the literatures. In the literatures, several sharp peaks were observed ranged from 300 to $450 \mathrm{~nm}$ corresponding to the intra configurational $4 \mathrm{f}-4 \mathrm{f}$ transitions of $\mathrm{Tb}^{3+}$ in the excitation spectra monitored at $545 \mathrm{~nm}$ [3.16-3.17]. However no such sharp 
peaks were observed in the excitation spectra of $\mathrm{AgCe} 0.95 \mathrm{~Tb}_{0.05}\left(\mathrm{WO}_{4}\right)_{2}$ in our work. The most intense band centered at $486 \mathrm{~nm}$ is attributed to the ${ }^{7} \mathrm{~F}_{6} \rightarrow{ }^{5} \mathrm{D}_{4}$ transition of $\mathrm{Tb}^{3+}$.

Otherwise, as observed in the emission spectra of $\mathrm{AgCe} 0.95 \mathrm{~Tb}_{0.05}\left(\mathrm{WO}_{4}\right)_{2}$ under low temperature, ${ }^{5} \mathrm{D}_{4} \rightarrow{ }^{7} \mathrm{~F}_{5}$ transition was split into three peaks and ${ }^{5} \mathrm{D}_{4} \rightarrow{ }^{7} \mathrm{~F}_{4}$ and ${ }^{5} D_{4} \rightarrow{ }^{7} F_{3}$ transitions were split into several more little peaks which can give more information about the structure of $\mathrm{AgCe} 0.95 \mathrm{~Tb}_{0.05}\left(\mathrm{WO}_{4}\right)_{2}$. Thus the $\mathrm{Tb}^{3+}$ is qualified as a local structure probe which can further help us to determine the crystal field energy level of the $\mathrm{AgCe}\left(\mathrm{WO}_{4}\right)_{2}$.

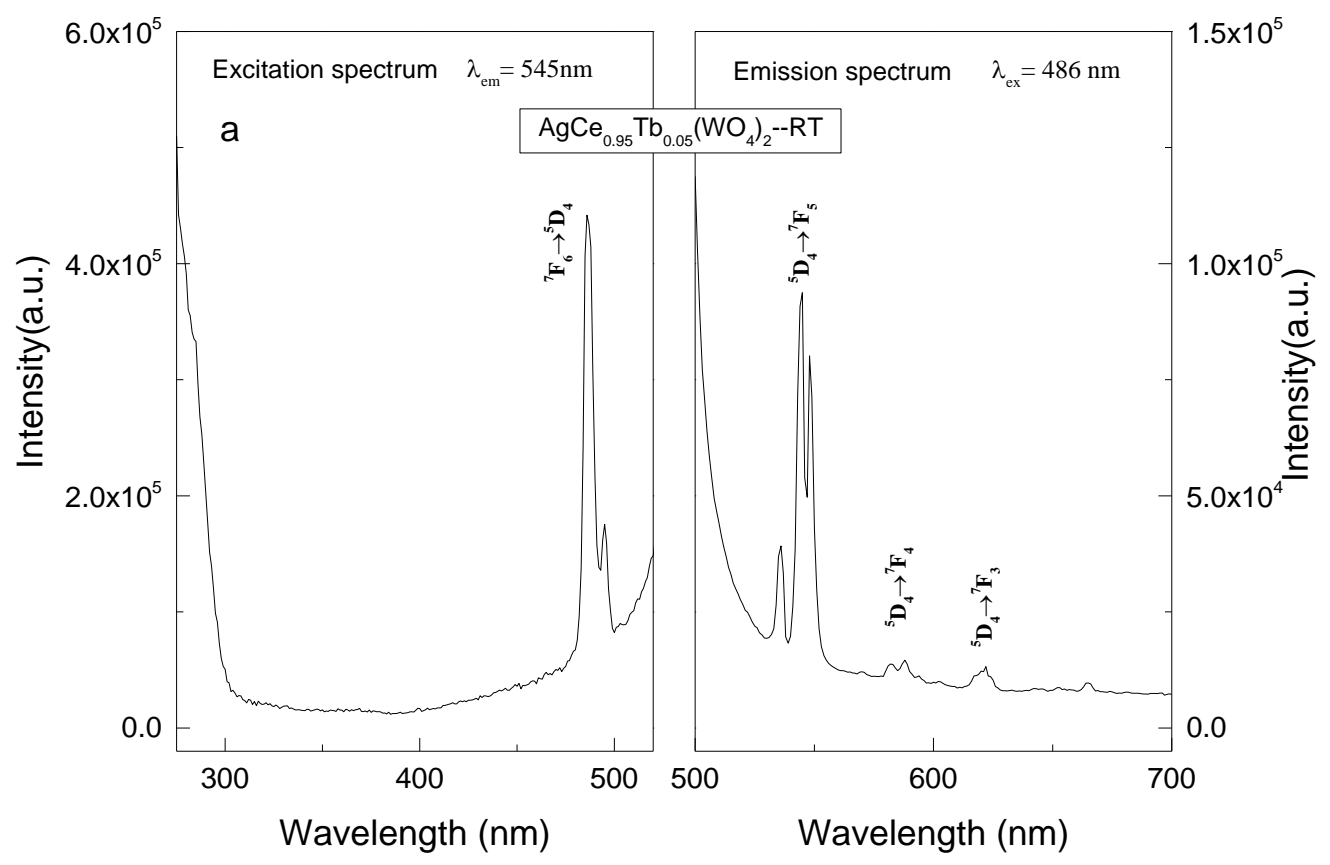




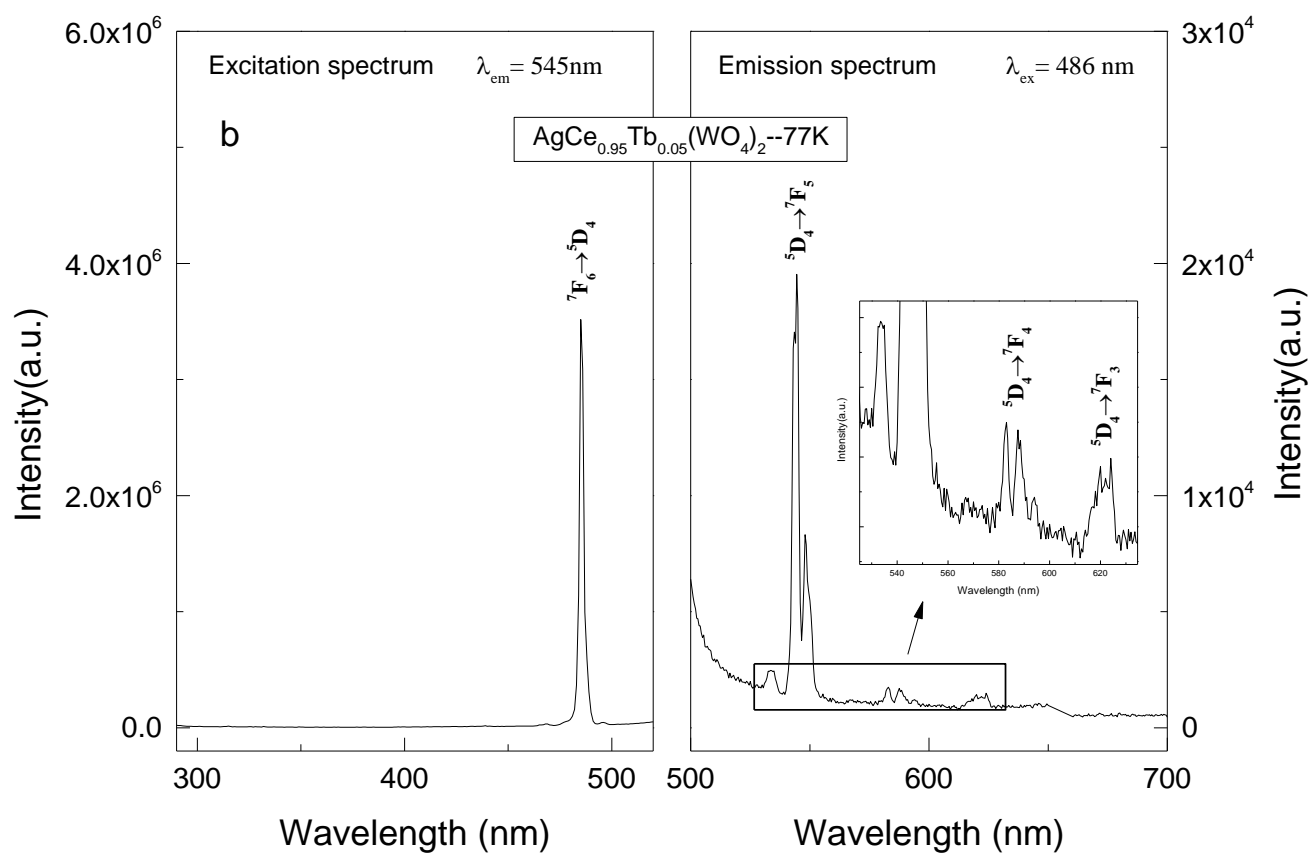

Fig. 3.12. Photo luminescent excitation spectra (monitored at $545 \mathrm{~nm}$ ) and emission spectra (excited at $486 \mathrm{~nm}$ ) of $\mathrm{AgCe}_{0.95} \mathrm{~Tb}_{0.05}\left(\mathrm{WO}_{4}\right)_{2}$ at room temperature - RT (a) and liquid nitrogen temperature - 77K (b).

\section{2. - $\mathrm{AgLn}\left(\mathrm{WO}_{4}\right)\left(\mathrm{MoO}_{4}\right)$}

\subsubsection{Structural study by X-ray diffraction.}

After identification of the scheelite phase for all the $\mathrm{AgLn}\left(\mathrm{WO}_{4}\right)\left(\mathrm{MoO}_{4}\right)(\mathrm{Ln}=\mathrm{La}$ to Lu and $Y$ ) derivatives the Rietveld profile analysis for this polymorphic familly was performed in the tetragonal S.G. I 41/a. The compounds were well crystallized and the lattice parameters for these phases are given in Table 3.4, where the refinement factors are also included. It can be observed a decrease in the lattice parameters with the increase in the atomic number of the rare earth according to the well-known lanthanide contraction that take place in going from La to Lu.

The refinement was performed in the tetragonal Space Group I 41/a(No. 88) and the starting values for the unit cell and positional parameters were those reported 
for the $\mathrm{AgNd}\left(\mathrm{WO}_{4}\right)_{2}$ [3.18]. It has been found that the silver and lanthanide atoms randomly occupy the $2 \mathrm{a}$ site and also molybdate and tungstate are randomly distributed in the structure. The $(1 / 2 \mathrm{Ag}+1 / 2 \mathrm{Ln}),(1 / 2 \mathrm{~W}+1 / 2 \mathrm{Mo})$ and $\mathrm{O}$ atoms occupy the $4 a(1 / 2,1 / 4,3 / 8), 4 b(0,1 / 4,5 / 8)$ and $16 f(x, y, z)$ sites, respectively. The crystallographic positional parameters for $\mathrm{AgLn}\left(\mathrm{WO}_{4}\right)\left(\mathrm{MoO}_{4}\right)$ after refinement are listed in Table 3.4.

It is worth noting that the $\mathrm{AgLn}\left(\mathrm{WO}_{4}\right)\left(\mathrm{MoO}_{4}\right)$ derivatives forLn $=\mathrm{Ce}, \mathrm{Pr}$ and $\mathrm{Tb}$ have been obtained despite the relativelyhigh instability of these trivalent ions. This behaviour couldbe explained from the redox properties of $\mathrm{Ag}_{2} \mathrm{O}$ in the solidstate reaction at high temperature, which stabilises the trivalentvalence state. 
Table3.4 Lattice parameters and crystallographic positional parameters for $\operatorname{AgLn}\left(\mathrm{WO}_{4}\right)\left(\mathrm{MoO}_{4}\right)$

\begin{tabular}{lllllllll}
\hline & $\mathrm{a}(\AA)$ & $\mathrm{c}(\AA)$ & $\mathrm{V}\left(\AA^{3}\right)$ & $\mathrm{O}_{x}$ & $\mathrm{O}_{\mathrm{y}}$ & $\mathrm{O}_{z}$ & $\mathrm{R}_{\text {Bragg }}$ & $\mathrm{R}_{F}$ \\
\hline $\mathrm{La}$ & $5.3694(2)$ & $11.7756(6)$ & $339.49(3)$ & $0.725(5)$ & $0.612(5)$ & $0.037(2)$ & 9.81 & 15.3 \\
$\mathrm{Ce}$ & $5.3425(3)$ & $11.7294(8)$ & $334.78(3)$ & $0.725(4)$ & $0.610(4)$ & $0.041(2)$ & 7.07 & 9.79 \\
$\mathrm{Pr}$ & $5.3246(3)$ & $11.6894(8)$ & $331.41(3)$ & $0.718(4)$ & $0.613(4)$ & $0.038(2)$ & 8.18 & 13.7 \\
$\mathrm{Nd}$ & $5.3142(2)$ & $11.6097(7)$ & $327.87(3)$ & $0.719(6)$ & $0.602(5)$ & $0.037(2)$ & 7.12 & 8.5 \\
$\mathrm{Sm}$ & $5.2852(1)$ & $11.5512(4)$ & $322.66(2)$ & $0.735(3)$ & $0.603(2)$ & $0.040(1)$ & 4.73 & 7.13 \\
$\mathrm{Eu}$ & $5.2730(1)$ & $11.5259(3)$ & $320.47(1)$ & $0.732(3)$ & $0.601(2)$ & $0.040(1)$ & 4.55 & 6.08 \\
$\mathrm{Gd}$ & $5.2457(4)$ & $11.542(1)$ & $317.60(4)$ & $0.726(4)$ & $0.617(3)$ & $0.045(2)$ & 6.41 & 9.73 \\
$\mathrm{~Tb}$ & $5.2463(1)$ & $11.4831(4)$ & $316.05(2)$ & $0.732(3)$ & $0.597(2)$ & $0.040(1)$ & 4.8 & 6.14 \\
$\mathrm{Dy}$ & $5.2312(2)$ & $11.4702(5)$ & $313.88(2)$ & $0.733(3)$ & $0.599(2)$ & $0.042(1)$ & 4.37 & 7.16 \\
$\mathrm{Ho}$ & $5.2009(6)$ & $11.454(2)$ & $309.81(7)$ & $0.716(5)$ & $0.608(5)$ & $0.045(2)$ & 10.3 & 10.7 \\
$\mathrm{Er}$ & $5.2044(3)$ & $11.4453(9)$ & $310.01(4)$ & $0.733(5)$ & $0.595(4)$ & $0.041(2)$ & 6.91 & 10.3 \\
$\mathrm{Tm}$ & $5.1919(6)$ & $11.447(2)$ & $308.58(6)$ & $0.742(8)$ & $0.594(6)$ & $0.047(3)$ & 14 & 13.7 \\
$\mathrm{Yb}$ & $5.1805(6)$ & $11.420(2)$ & $306.49(7)$ & $0.731(8)$ & $0.589(7)$ & $0.048(3)$ & 14.5 & 15.3 \\
$\mathrm{Lu}$ & $5.1700(7)$ & $11.418(2)$ & $305.20(8)$ & $0.729(9)$ & $0.592(8)$ & $0.050(3)$ & 17.7 & 16.6 \\
$\mathrm{Y}$ & $5.2172(2)$ & $11.4655(7)$ & $312.08(3)$ & $0.737(3)$ & $0.597(3)$ & $0.042(1)$ & 6.17 & 6.83 \\
\hline
\end{tabular}

\subsubsection{Vibrational study by FTIR and Raman spectral.}

Because of the imprecision of the X-ray diffraction while measure the positions of $\mathrm{O}$ atoms in the compounds, the analysis of FT-IR and Raman were introduced in. The FT-IR and Raman spectra of the $\mathrm{AgLn}\left(\mathrm{WO}_{4}\right)\left(\mathrm{MoO}_{4}\right)$ samples are shown in Fig.3.13. 

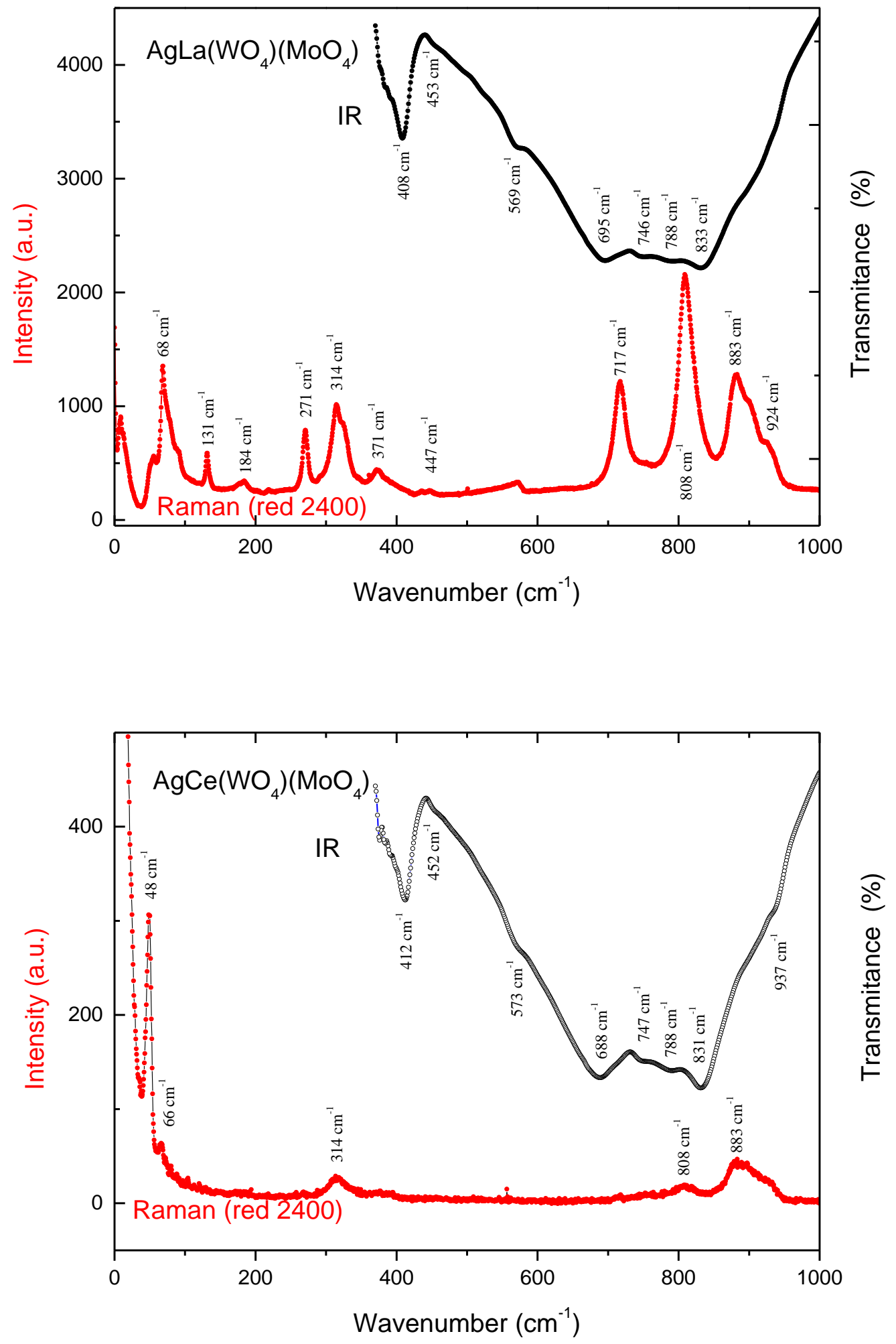

Fig. 3.13 a. The FT-IR and Raman spectra of $\mathrm{AgLn}\left(\mathrm{WO}_{4}\right)\left(\mathrm{MoO}_{4}\right)(\mathrm{Ln}=\mathrm{La}$ and Ce) samples. 

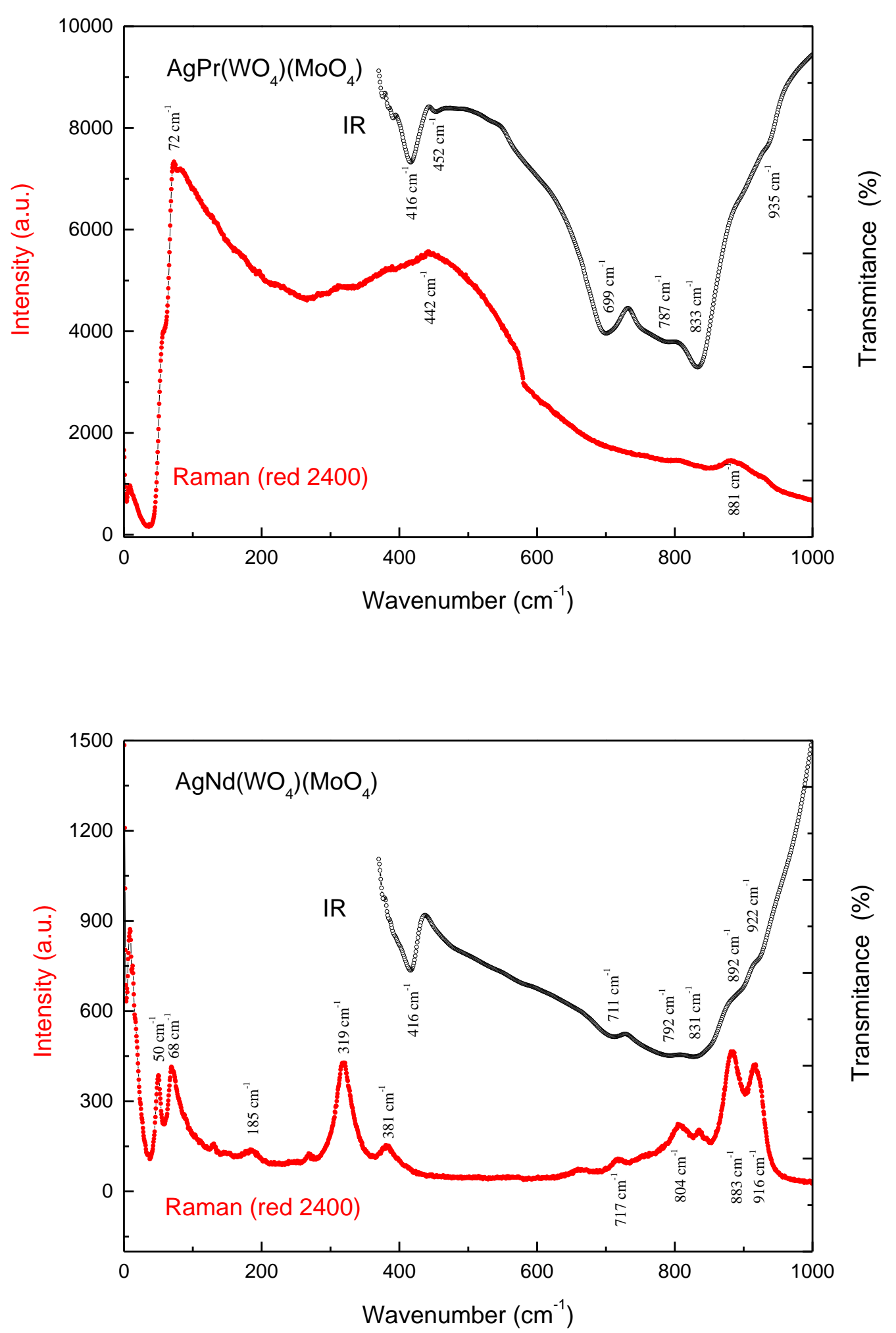

Fig. 3.13 b. The FT-IR and Raman spectra of $A g L n\left(\mathrm{WO}_{4}\right)\left(\mathrm{MoO}_{4}\right)(\mathrm{Ln}=\mathrm{Pr}$ and Nd) samples. 

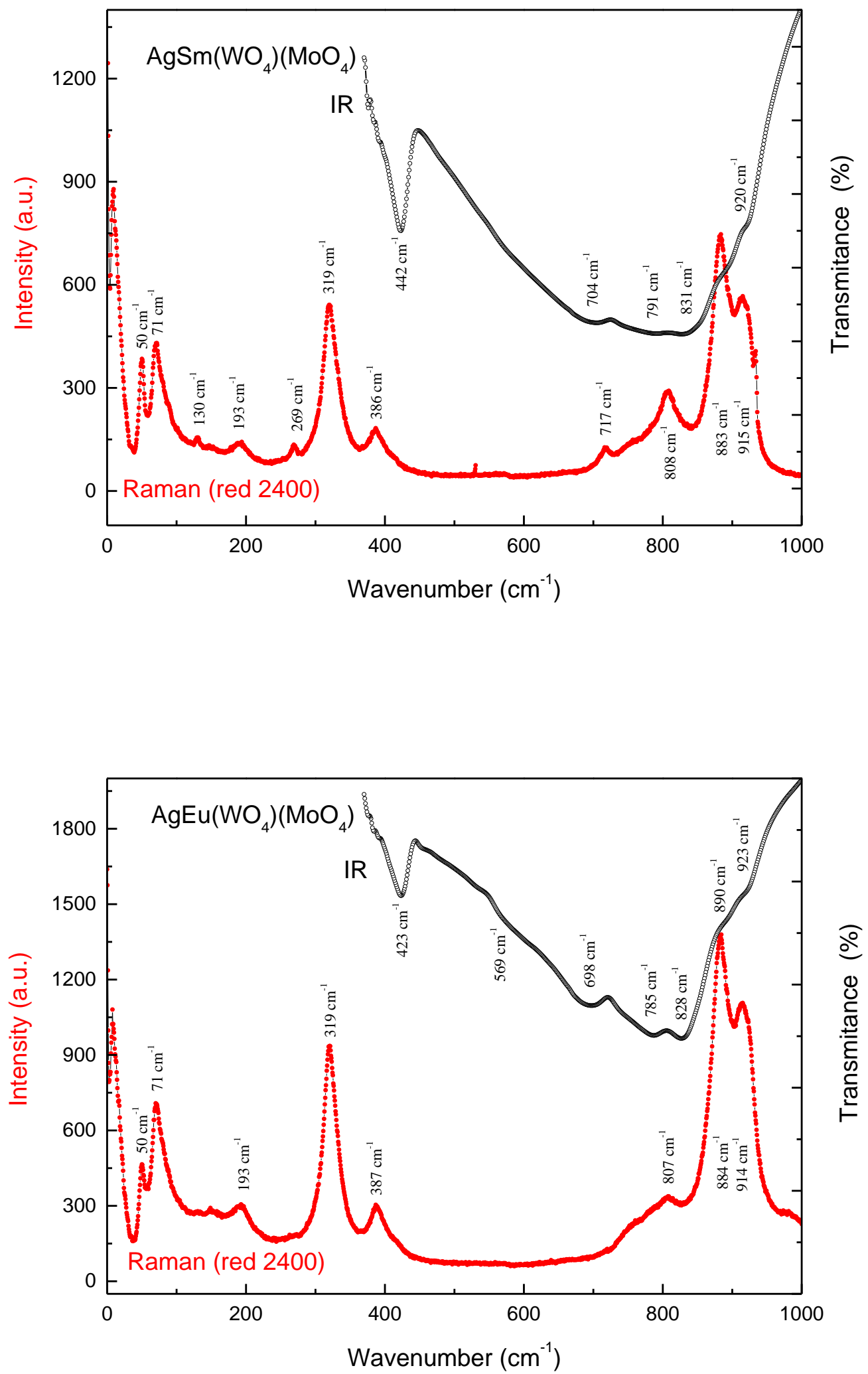

Fig. 3.13 c. The FT-IR and Raman spectra of $\mathrm{AgLn}\left(\mathrm{WO}_{4}\right)\left(\mathrm{MoO}_{4}\right)(\mathrm{Ln}=\mathrm{Sm}$ and Eu) samples. 

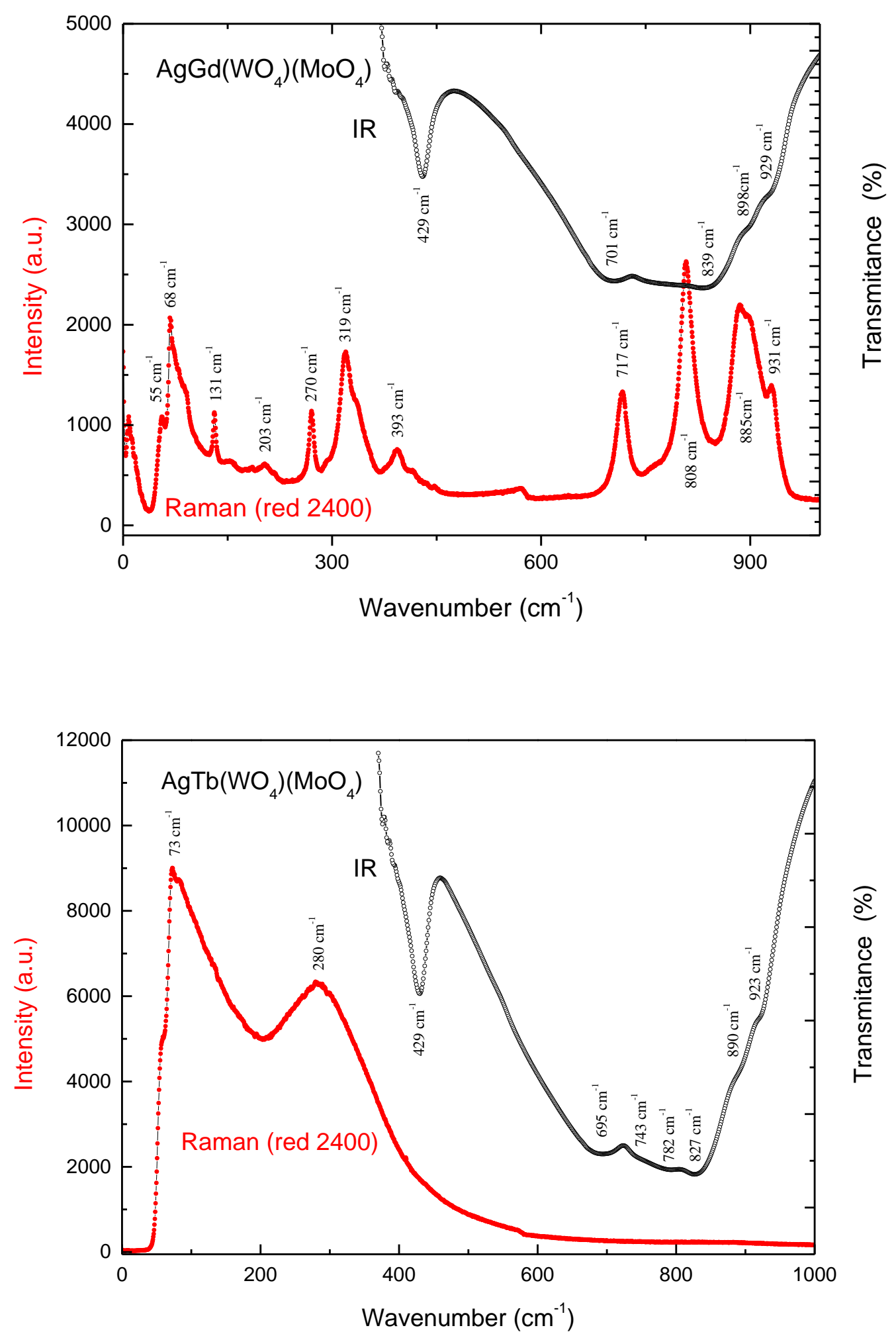

Fig. $3.13 \mathrm{~d}$. The FT-IR and Raman spectra of $\mathrm{AgLn}\left(\mathrm{WO}_{4}\right)\left(\mathrm{MoO}_{4}\right)(\mathrm{Ln}=\mathrm{Gd}$ and Tb) samples. 

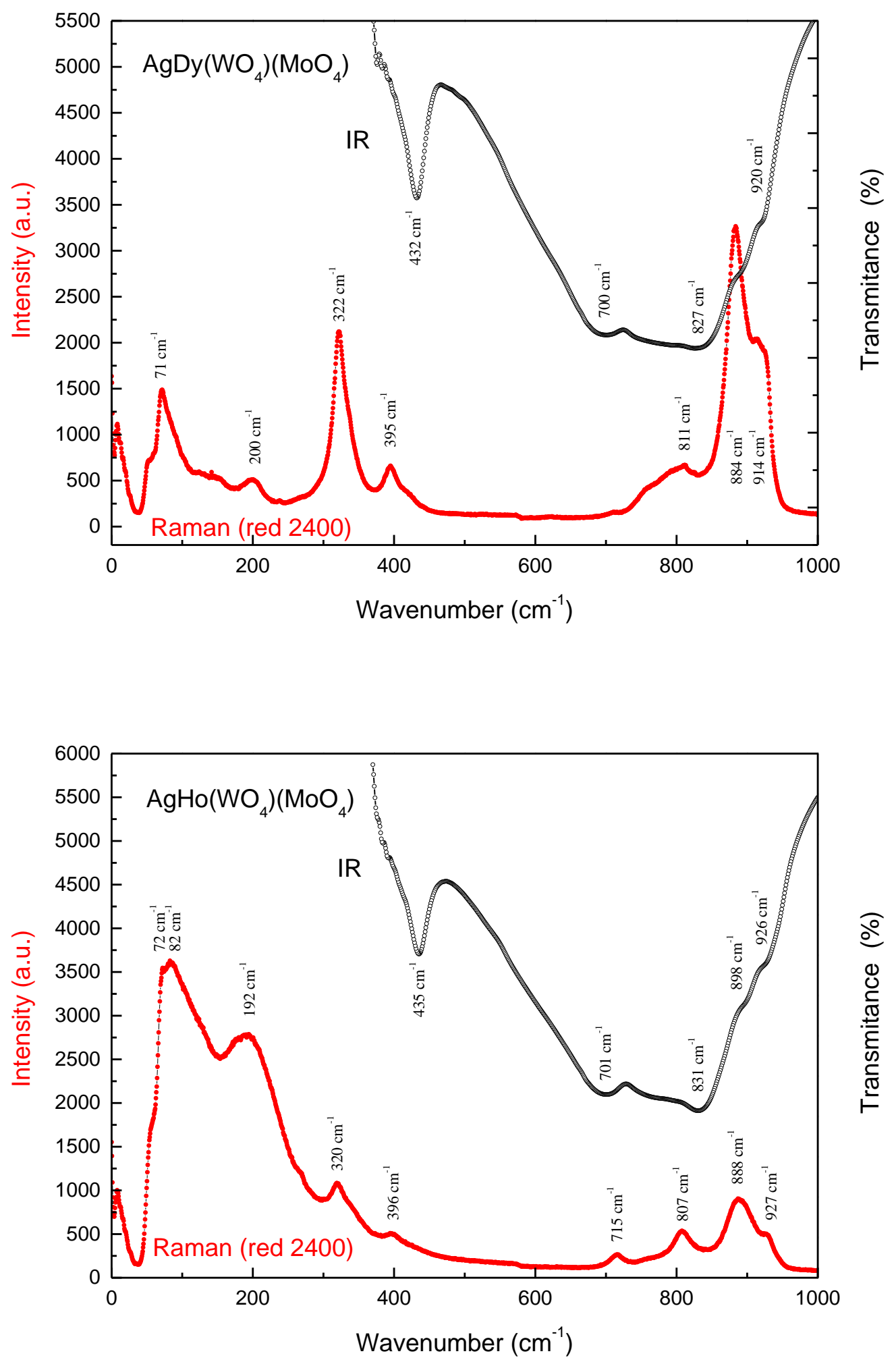

Fig. 3.13 e. The FT-IR and Raman spectra of $\mathrm{AgLn}\left(\mathrm{WO}_{4}\right)\left(\mathrm{MoO}_{4}\right)(\mathrm{Ln}=\mathrm{Dy}$ and Ho) samples. 

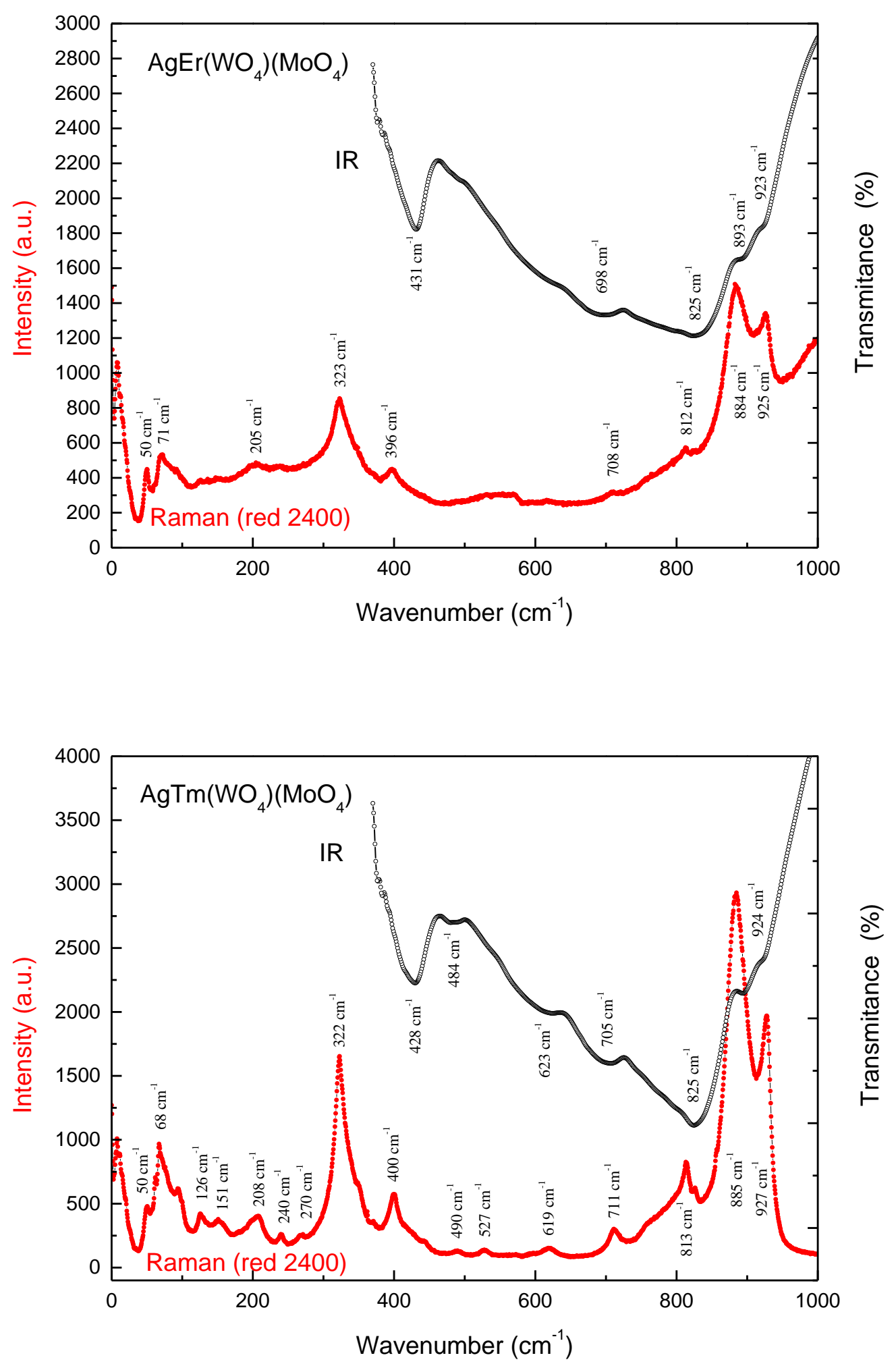

Fig. $3.13 \mathrm{f}$. The FT-IR and Raman spectra of $\mathrm{AgLn}\left(\mathrm{WO}_{4}\right)\left(\mathrm{MoO}_{4}\right)(\mathrm{Ln}=\mathrm{Er}$ and Tm) samples. 

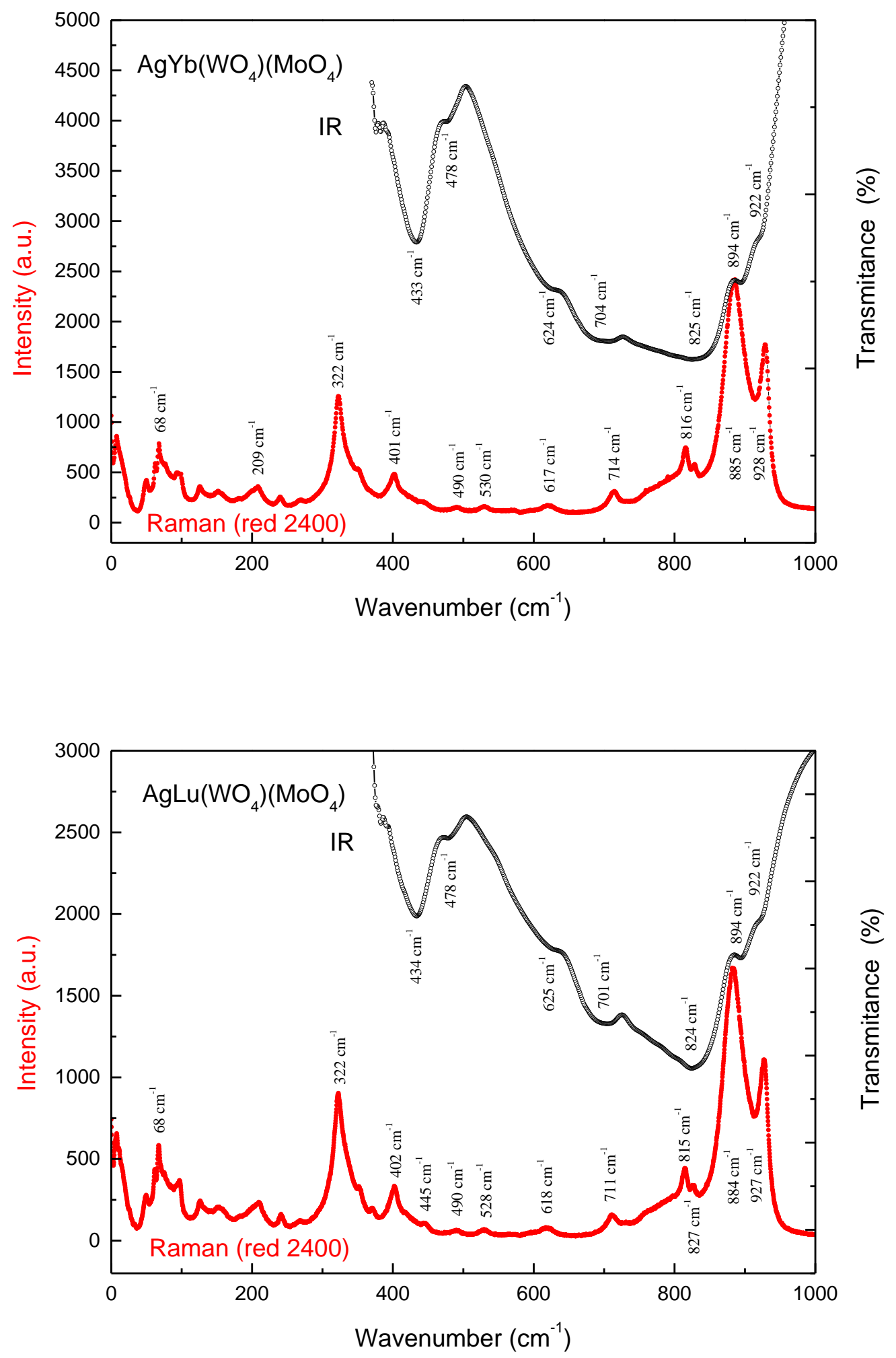

Fig. $3.13 \mathrm{~g}$. The FT-IR and Raman spectra of $\mathrm{AgLn}\left(\mathrm{WO}_{4}\right)\left(\mathrm{MoO}_{4}\right)(\mathrm{Ln}=\mathrm{Yb}$ and Lu) samples. 


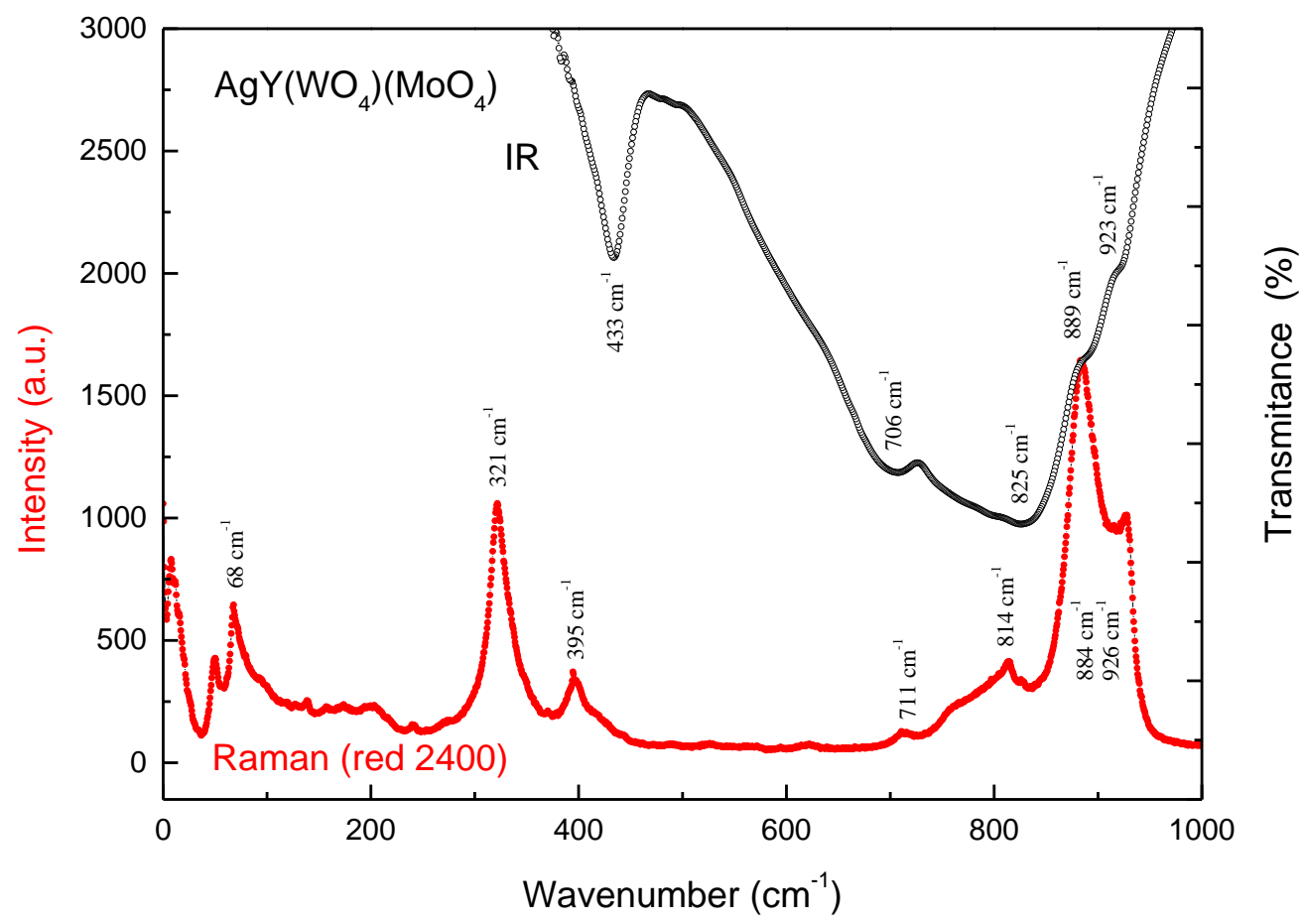

Fig. $3.13 \mathrm{~h}$. The FT-IR and Raman spectra of $\mathrm{AgLn}\left(\mathrm{WO}_{4}\right)\left(\mathrm{MoO}_{4}\right)(\mathrm{Ln}=\mathrm{Y})$ samples.

The IR spectra of $\mathrm{AgLn}\left(\mathrm{WO}_{4}\right)\left(\mathrm{MoO}_{4}\right)$ in the region of $370-1000 \mathrm{~cm}^{-1}$ were recorded. The $\mathrm{WO}_{4}{ }^{2-} / \mathrm{MoO}_{4}{ }^{2-}$ groups which having $\mathrm{S}_{4}$ site symmetry show three absorption bands in the region of $370-1000 \mathrm{~cm}^{-1}$ around $925 \mathrm{~cm}^{-1}, 800 \mathrm{~cm}^{-1}$ and $420 \mathrm{~cm}^{-1}$ which correspond to the $\mathrm{v}_{1}, \mathrm{v}_{3}$ and $\mathrm{v}_{4}$ vibration modes respectively [3.20-3.21]. All these compounds have similar IR spectra patterns and are analogous with those reported in $\mathrm{AgLn}\left(\mathrm{MoO}_{4}\right)_{2}$ compounds [3.3]. Take $\mathrm{AgLn}\left(\mathrm{WO}_{4}\right)\left(\mathrm{MoO}_{4}\right)$ when $\mathrm{Ln}=\mathrm{La}$ for example, the $\mathrm{v}_{3}$ mode splits into four components around 833, 788, 746 and $695 \mathrm{~cm}^{-1}$. The $\mathrm{v}_{1}$ mode splits into two peaks at around 934 and $897 \mathrm{~cm}^{-1}$, the sharp peak at $408 \mathrm{~cm}^{-1}$ and one weak peak at $453 \mathrm{~cm}^{-1}$ can be assigned to $\mathrm{v}_{4}$ mode. However, the peak at around 569 $\mathrm{cm}^{-1}$ was not assigned.

It reveals in our previous works that the $\mathrm{AgLn}\left(\mathrm{WO}_{4}\right)\left(\mathrm{MoO}_{4}\right)$ compounds present tetragonal symmetry, of space group $\mathrm{C}_{4 \mathrm{~h}}^{6}$ (I 41/a) [3.19]. The $\mathrm{Ag}^{+}$and $\mathrm{Ln}^{3+}$ ions are distributed randomly in sites of symmetry $S_{4}$. The equivalent $\mathrm{WO}_{4}{ }^{2-} / \mathrm{MoO}_{4}{ }^{2-}$ ions located in the $S_{4}$ sites of symmetry as well. The eight oxygen atoms are 
equivalent, and occupy a site of symmetry $C_{1}$. Based on the Factor Group Analysis (FGA), the primitive unit cell containing 12 atoms gives rise to $3 \mathrm{~N}=36$ freedom degrees which are divided into 26 vibration species [3.4-3.6, 3.22]. The 26 vibration species can be described as $\Gamma=3 A_{g}+5 B_{g}+5 E_{g}+5 A_{u}+3 B_{u}+5 E_{u}$, where the $E$ vibrations are doubly degenerate. $1 A_{u}+1 B_{g}+1 E_{g}+1 E_{u}$ resulted from contributions of both $\mathrm{Ag}$ and $\mathrm{Ln}, 1 \mathrm{~A}_{u}+1 \mathrm{~B}_{g}+1 \mathrm{E}_{g}+1 \mathrm{E}_{u}$ from contributions of $W$, and $3 A_{g}+3 A_{u}+3 B_{g}+3 B_{u}+3 E_{g}+3 E_{u}$ from contributions of the oxygen $O$ atoms. The optical branches are presented as $\Gamma_{\text {opt }}=3 A_{g}+4 A_{u}+5 B_{g}+3 B_{u}+5 E_{g}$ $+4 \mathrm{E}_{\mathrm{u}}$, while the acoustic branches are $\Gamma_{\text {acous }}=1 \mathrm{~A}_{\mathrm{u}}+1 \mathrm{E}_{\mathrm{u}}$; translatory lattice modes $\Gamma_{T^{\prime}}=2 B_{g}+2 E_{g}+A_{u}+E_{u}$; rotatory lattice modes $\Gamma_{L}=A_{g}+E_{g}+B_{u}+E_{u}$ and internal vibrations $\Gamma_{i}=2 A_{g}+3 B_{g}+2 E_{g}+3 A_{u}+2 B_{u}+2 E_{u}$. Its distribution among $\mathrm{n}(\mathrm{T})$ acoustic, $\mathrm{n}\left(\mathrm{T}^{\prime}\right)$ translational, $\mathrm{n}(\mathrm{L})$ librational and $\mathrm{n}$ (int) internal modes is presented in Table 3.5.The $A_{g}, B_{g}$ and $E_{g}$ modes are Raman active; the $A u$ and Eu modes are IR active and the three Bu modes are silent. The assignments of observed vibrational modes in $\mathrm{AgLn}\left(\mathrm{WO}_{4}\right)\left(\mathrm{MoO}_{4}\right)(\mathrm{Ln}=\mathrm{La}$ to $\mathrm{Lu}$ and $\mathrm{Y})$ were listed in Table 3.6.

In all cases the Raman spectra show several strong modes (as example 926, 884, 814, 395, 321, $68 \mathrm{~cm}-1$ in the Yttrium sample) and others weaker features. These modes are analogous as observed for scheelite-related $\mathrm{NaY}\left(\mathrm{WO}_{4}\right)_{2}$ single crystal obtained by Macalik et al. [3.5]. The author found the modes at 919, 335 and $224 \mathrm{~cm}^{-1}$ to the $\mathrm{Ag}_{\mathrm{g}}$ phonons, at 811, 416, 339, 216 and $67 \mathrm{~cm}^{-1}$ to the $\mathrm{Bg}_{\mathrm{g}}$ phonons and at $807,411,175,123$ and $84 \mathrm{~cm}^{-1}$ to the $E_{g}$ phonons. In our case the corresponding $\mathrm{A}_{\mathrm{g}}$ modes were split into two components at 926 and $884 \mathrm{~cm}^{-1}$ and seem compatible with those observed bands in the IR spectra. The modes at 814,717 and $395 \mathrm{~cm}^{-1}$ can be assigned as an overlap of $B_{g}+E_{g}$. The modes at 321 and $68 \mathrm{~cm}^{-1}$ can be assigned as $A_{g}+B_{g}$ and $B_{g}$ respectively. It was reported that the scheelite crystals, where $\mathrm{XO}_{4}$ - ions form isolated tetrahedral, exhibit the energy gap in the region of $450-700 \mathrm{~cm}^{-1}$ [3.23]. This was observed in our most samples as well (weak peaks were observed between 450 to700 $\mathrm{cm}^{-1}$ in the Raman spectra of samples $\mathrm{Ln}=\mathrm{Tm}, \mathrm{Yb}, \mathrm{Lu})$. The stretching $\mathrm{V}_{\mathrm{s}}$, Vas and bending $\delta_{\text {as }}, \delta_{\mathrm{s}}$ vibrations are observed for the yttrium sample at 926-884, 814-717, 395 and $321-241 \mathrm{~cm}^{-1}$, respectively. 
In $\mathrm{AgPr}\left(\mathrm{WO}_{4}\right)\left(\mathrm{MoO}_{4}\right)$ and $\mathrm{AgTb}\left(\mathrm{WO}_{4}\right)\left(\mathrm{MoO}_{4}\right)$ samples, Raman spectra are different from the others. Several attempts to assign bands to different modes of distortions of the tetragonal cell have been inconclusive and the long range Raman Spectra was measured as shown in Fig.3.14 and Fig.3.15. We suggest that additional information is needed on the crystal structure of both samples in order to conclude and assign unequivocally the observed vibrational bands. An alternative crystal structure should be searched by neutron diffraction technique. 
Table3.5 Factor group analysis for $\mathrm{AgLn}\left(\mathrm{WO}_{4}\right)\left(\mathrm{MoO}_{4}\right)-C_{4 h}^{6}$

\begin{tabular}{|c|c|c|c|c|c|c|c|c|c|c|c|c|c|c|c|}
\hline $\mathrm{C}_{4 \mathrm{~h}}$ & $\mathrm{E}$ & $\mathrm{C}_{4}$ & $\mathrm{C}_{2}$ & $\mathrm{C}_{4}{ }^{3}$ & $\mathrm{i}$ & $\mathrm{S}_{4}{ }^{3}$ & $\sigma_{\mathrm{h}}$ & $\mathrm{S}_{4}$ & $n(N)$ & $n(T)$ & $n\left(T^{\prime}\right)$ & $\mathrm{n}(\mathrm{L})$ & $n$ (int) & IR & Raman \\
\hline$A_{g}$ & 1 & 1 & 1 & 1 & 1 & 1 & 1 & 1 & 3 & 0 & 0 & 1 & 2 & \multirow[t]{2}{*}{$\mathrm{R}_{\mathrm{z}}$} & $x^{2}+y^{2}, z^{2}$ \\
\hline $\mathrm{B}_{\mathrm{g}}$ & 1 & -1 & 1 & -1 & 1 & -1 & 1 & -1 & 5 & 0 & 2 & 0 & 3 & & $x^{2}-y^{2}, x y$ \\
\hline \multirow[t]{2}{*}{$E_{g}$} & 1 & $\mathrm{i}$ & -1 & $-i$ & 1 & $\mathrm{i}$ & -1 & $-i$ & 5 & 0 & 2 & 1 & 2 & \multirow[t]{2}{*}{$\left(R_{x}, R_{y}\right)$} & \multirow[t]{6}{*}{$(x z, y z)$} \\
\hline & 1 & $-i$ & -1 & $\mathrm{i}$ & 1 & $-i$ & -1 & $\mathrm{i}$ & 5 & 0 & 2 & 1 & 2 & & \\
\hline$A_{u}$ & 1 & 1 & 1 & 1 & -1 & -1 & -1 & -1 & 5 & 1 & 1 & 0 & 3 & \multirow[t]{2}{*}{ z } & \\
\hline $\mathrm{Bu}_{\mathrm{u}}$ & 1 & -1 & 1 & -1 & -1 & 1 & -1 & 1 & 3 & 0 & 0 & 1 & 2 & & \\
\hline \multirow[t]{2}{*}{$E_{u}$} & 1 & $\mathrm{i}$ & -1 & $-i$ & -1 & $-i$ & 1 & $\mathrm{i}$ & 5 & 1 & 1 & 1 & 2 & \multirow[t]{2}{*}{$(x, y)$} & \\
\hline & 1 & $-i$ & -1 & $\mathrm{i}$ & -1 & $\mathrm{i}$ & 1 & $-\mathrm{i}$ & 5 & 1 & 1 & 1 & 2 & & \\
\hline & & & & & & & & & 36 & 3 & 9 & 6 & 18 & & \\
\hline
\end{tabular}


Table3.6 a The observed bands $\left(\mathrm{cm}^{-1}\right)$, their relative intensities and the band assignments of the Raman and Infrared spectra for $\mathrm{AgLn}\left(\mathrm{WO}_{4}\right)\left(\mathrm{MoO}_{4}\right)(\mathrm{RE}=\mathrm{La}$ to $\mathrm{Tb})$. A band with wavenumbers followed by $\left(^{*}\right)$ is an unassigned band. $\mathrm{A}$ band with wavenumbers in parentheses is a very weak band.

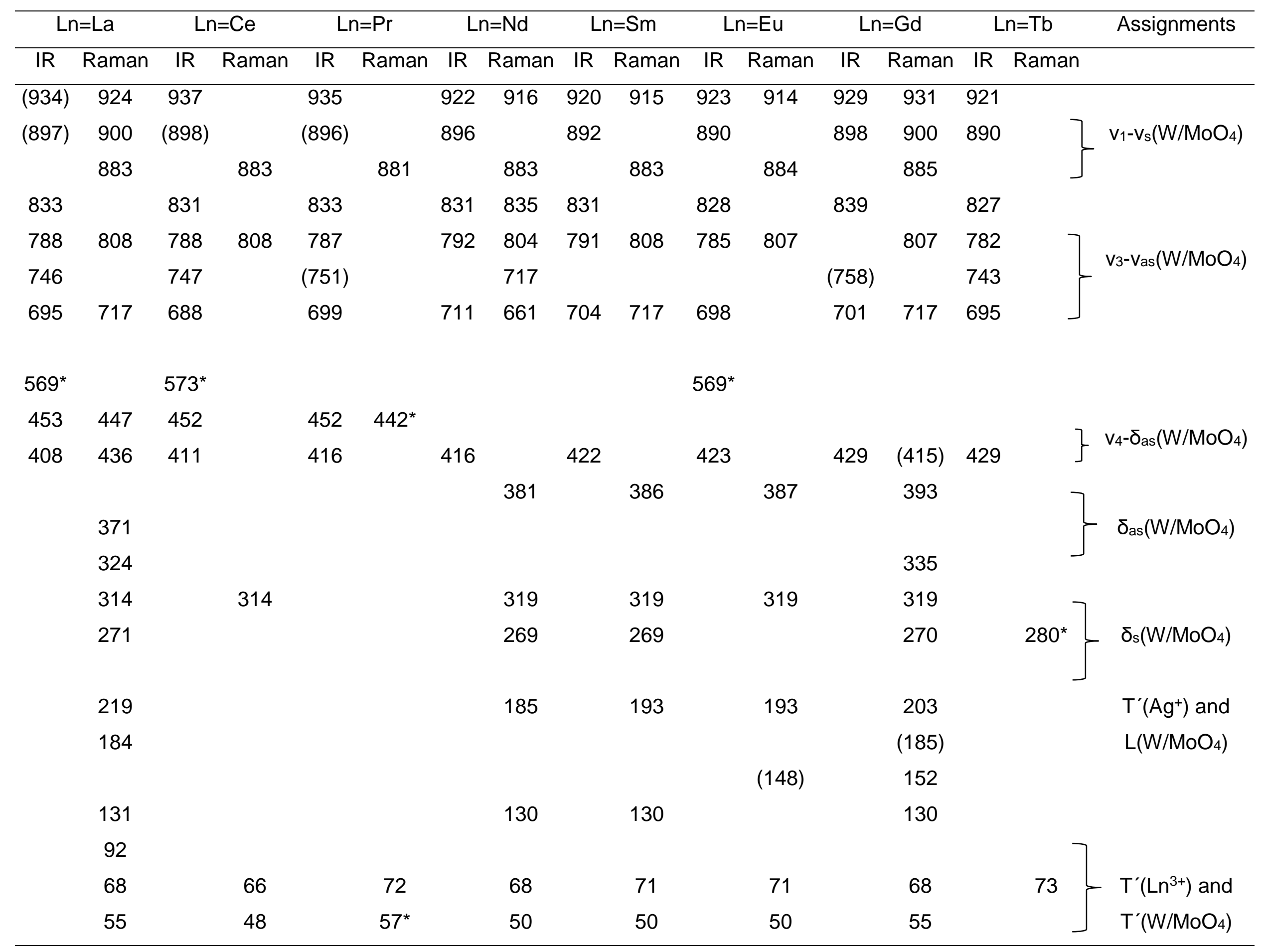


Table $3.6 \mathrm{~b}$ The observed bands $\left(\mathrm{cm}^{-1}\right)$, their relative intensities and the band assignments of the Raman and Infrared spectra for $\mathrm{AgLn}\left(\mathrm{WO}_{4}\right)\left(\mathrm{MoO}_{4}\right)(\mathrm{RE}=\mathrm{Dy}$ to $\mathrm{Lu}$ and $\mathrm{Y})$. A band with wavenumbers followed by $\left.{ }^{*}\right)$ is an unassigned band. $\mathrm{A}$ band with wavenumbers in parentheses is a very weak band.

\begin{tabular}{|c|c|c|c|c|c|c|c|c|c|c|c|c|c|c|}
\hline \multicolumn{2}{|c|}{ Ln=Dy } & \multicolumn{2}{|c|}{ Ln=Ho } & \multicolumn{2}{|c|}{$\mathrm{Ln}=\mathrm{Er}$} & \multicolumn{2}{|c|}{$\mathrm{Ln}=\mathrm{Tm}$} & \multicolumn{2}{|c|}{ Ln=Yb } & \multicolumn{2}{|c|}{$L n=L u$} & \multicolumn{2}{|c|}{$L n=Y$} & \multirow[t]{2}{*}{ Assignments } \\
\hline IR & Raman & IR & Raman & IR & Raman & IR & Raman & IR & Raman & IR & Raman & IR & Raman & \\
\hline 920 & 914 & 926 & 927 & 923 & 925 & 924 & 927 & 922 & 928 & 922 & 927 & 923 & 926 & 7 \\
\hline \multirow[t]{2}{*}{894} & & 898 & & 893 & & 894 & & 894 & & 894 & & & & $\mathrm{v}_{1}-\mathrm{v}_{\mathrm{s}}\left(\mathrm{W} / \mathrm{MoO}_{4}\right)$ \\
\hline & 884 & & 888 & & 884 & & 885 & & 885 & & 884 & 889 & 884 & 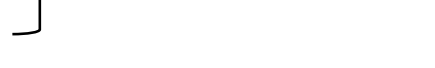 \\
\hline \multirow[t]{3}{*}{827} & & 831 & & 825 & & 825 & 826 & 825 & 828 & 824 & 827 & 825 & & \\
\hline & 811 & & 807 & & 812 & & 813 & & 816 & & 815 & & 814 & 7 \\
\hline & & (756) & & & & & & & & & & & & $\mathrm{V}_{3}-\mathrm{V}_{\mathrm{as}}\left(\mathrm{W} / \mathrm{MoO}_{4}\right)$ \\
\hline \multirow[t]{4}{*}{700} & & 701 & 715 & 698 & 708 & 705 & 711 & 704 & 714 & 701 & 711 & 706 & 711 & \rfloor \\
\hline & & & & & & $623^{*}$ & $619^{*}$ & $624^{*}$ & $617^{*}$ & $625^{\star}$ & $618^{*}$ & & & \\
\hline & & & & & & & $527^{*}$ & & $529^{*}$ & & $528^{*}$ & & & \\
\hline & & & & & & 484 & 490 & 478 & 491 & 479 & 490 & & & 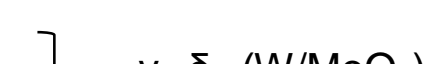 \\
\hline \multirow[t]{14}{*}{432} & & 435 & & 431 & & 428 & 441 & 433 & 443 & 434 & 445 & 433 & & 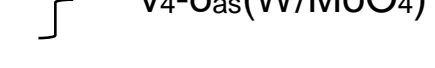 \\
\hline & 395 & & 396 & & 396 & & 400 & & 401 & & 402 & & 395 & 7 \\
\hline & & & & & & & & & & & 371 & & & $\delta_{a s}\left(\mathrm{~W} / \mathrm{MoO}_{4}\right)$ \\
\hline & & & & & & & 349 & & 351 & & 352 & & & 」 \\
\hline & 322 & & 320 & & 323 & & 322 & & 322 & & 322 & & 321 & 7 \\
\hline & & & & & & & 270 & & 269 & & & & & $\delta_{s}\left(\mathrm{~W} / \mathrm{MoO}_{4}\right)$ \\
\hline & & & & & & & 240 & & 239 & & 240 & & 241 & 」 \\
\hline & 200 & & 192 & & 205 & & 208 & & 209 & & 210 & & 202 & $\mathrm{~T}^{\prime}\left(\mathrm{Ag}^{+}\right)$and \\
\hline & & & & & & & & & & & & & (173) & $\mathrm{L}\left(\mathrm{W} / \mathrm{MoO}_{4}\right)$ \\
\hline & & & & & 125 & & 151 & & 151 & & 152 & & 157 & \\
\hline & & & 82 & & & & 126 & & 126 & & 126 & & 139 & $\neg$ \\
\hline & & & & & & & 94 & & 96 & & 97 & & & $\mathrm{~T}^{\prime}\left(\mathrm{Ln}^{3+}\right)$ and \\
\hline & 71 & & 72 & & 71 & & 68 & & 68 & & 68 & & 68 & $\mathrm{~T}^{\prime}\left(\mathrm{W} / \mathrm{MoO}_{4}\right)$ \\
\hline & 53 & & & & 50 & & 50 & & 50 & & 50 & & 50 & \\
\hline
\end{tabular}




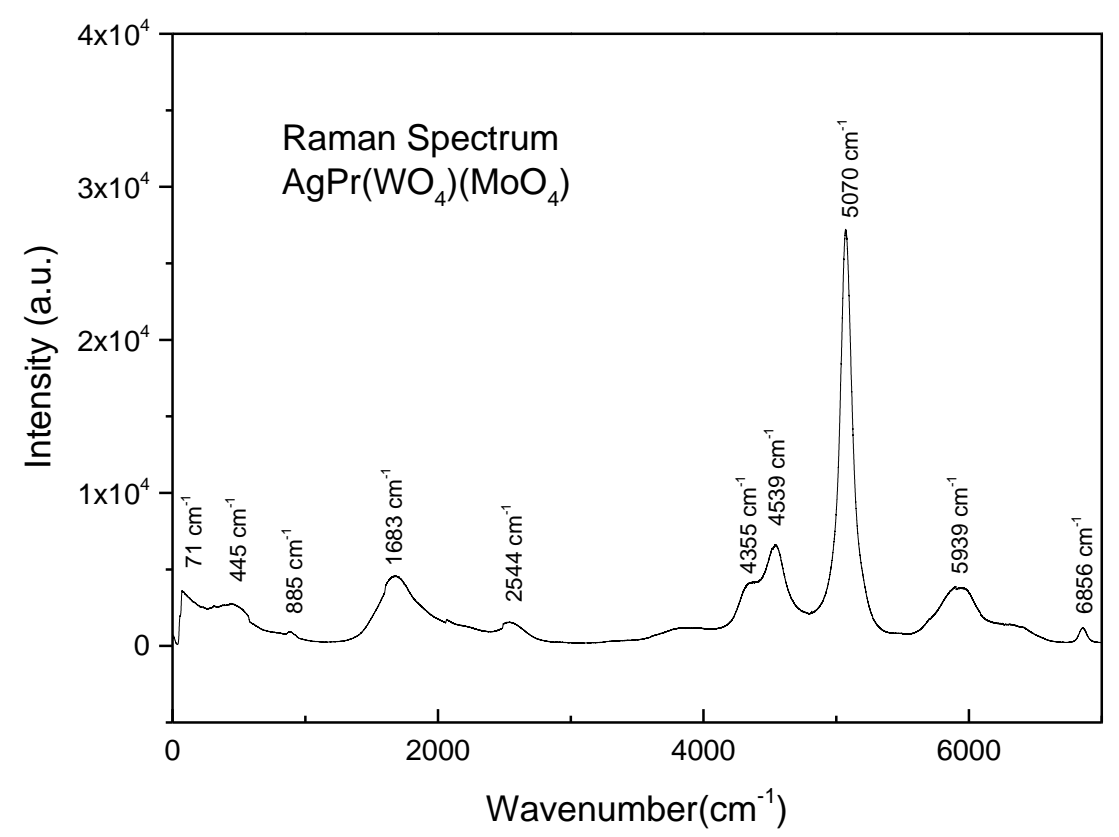

Fig. 3.14 Long range Raman spectrum of $\mathrm{AgPr}\left(\mathrm{WO}_{4}\right)_{2}$ compounds.

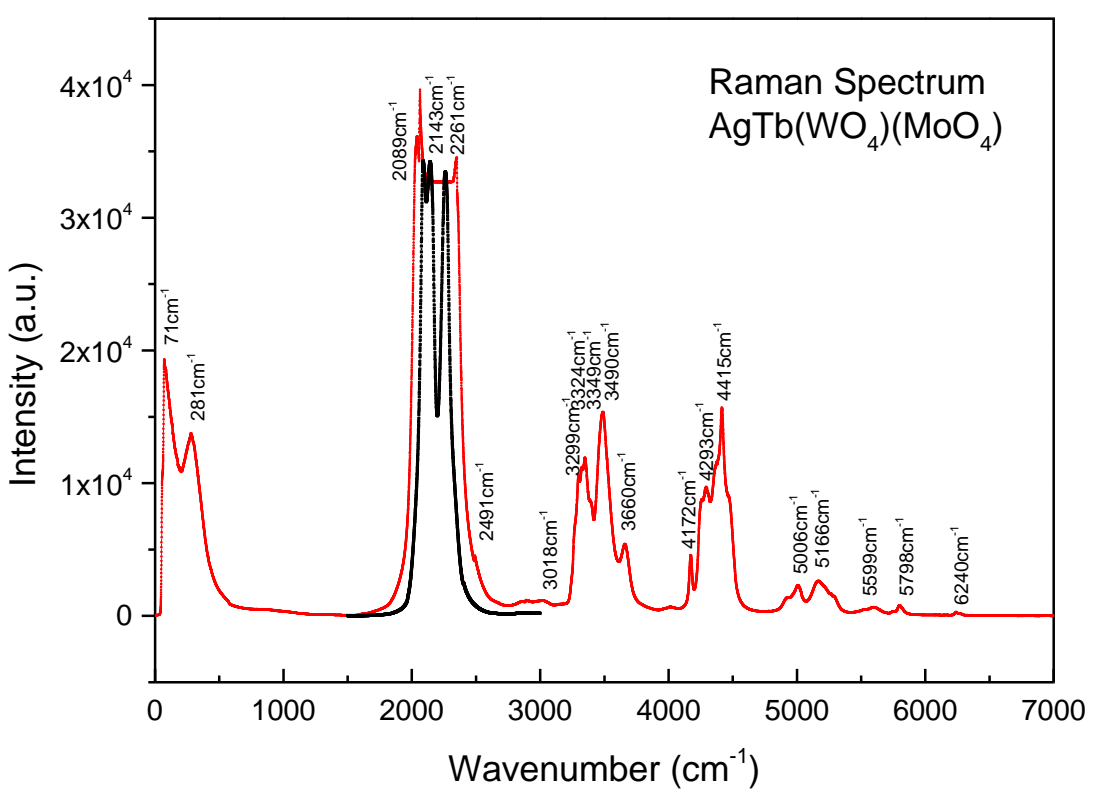

Fig. 3.15 Long range Raman spectrum of $\mathrm{AgTb}\left(\mathrm{WO}_{4}\right)_{2}$ compounds. The black line ranged from 1500 to $3000 \mathrm{~cm}^{-1}$ is measured with the same conditions except for smaller excitation intensity. 


\subsection{3. - Fluorescence Properties}

\subsubsection{1 $\mathrm{AgPr}\left(\mathrm{WO}_{4}\right)\left(\mathrm{MoO}_{4}\right)$}

Fig. 3.16 a presents the excitation spectra of $\mathrm{AgPr}\left(\mathrm{WO}_{4}\right)\left(\mathrm{MoO}_{4}\right)$ monitored at 648 $\mathrm{nm}$ corresponding to the ${ }^{3} \mathrm{P}_{0} \rightarrow{ }^{3} \mathrm{~F}_{2}$ transition. In this figure, the peaks located around 430-500 $\mathrm{nm}$ are assigned to the transitions from the ground ${ }^{3} \mathrm{H}_{4}$ to the excited ${ }^{3} \mathrm{P}_{2}$ (centered at $\left.449 \mathrm{~nm}\right),{ }^{3} \mathrm{P}_{1}+{ }^{1} \mathrm{I}_{6}(467 \mathrm{~nm}$ and $473 \mathrm{~nm}),{ }^{3} \mathrm{P}_{0}(486 \mathrm{~nm})$ manifolds, therefore, the $\operatorname{AgPr}\left(\mathrm{WO}_{4}\right)\left(\mathrm{MoO}_{4}\right)$ are suitable to excited by the blue LED chips. Meanwhile, some relative feeble peaks centered at $591 \mathrm{~nm}$ are assigned to the transition ${ }^{3} \mathrm{H}_{4} \rightarrow{ }^{1} \mathrm{D}_{2}$. The broadband around $350-430 \mathrm{~nm}$ are attributed to the tungstate / molybdate host absorption and the $\left[\mathrm{Pr}^{3+}-\mathrm{W}^{6+} / \mathrm{Mo}^{6+}\right]$ charge transfer (CT) band [3.24-3.26].

Fig.3.16 b shows the emission spectra of $\mathrm{AgPr}\left(\mathrm{WO}_{4}\right)\left(\mathrm{MoO}_{4}\right)$ excited at $449 \mathrm{~nm}$ and $486 \mathrm{~nm}$, corresponding to the $\mathrm{Pr}^{3+}$ excitation of the ${ }^{3} \mathrm{H}_{4} \rightarrow{ }^{3} \mathrm{P}_{2}$ and ${ }^{3} \mathrm{H}_{4} \rightarrow{ }^{3} \mathrm{P}_{0}$ transition respectively. Five emission bands are observed and marked at 497 $\mathrm{nm}\left({ }^{3} \mathrm{P}_{0} \rightarrow{ }^{3} \mathrm{H}_{4}\right), 531 \mathrm{~nm}\left({ }^{3} \mathrm{P}_{1} \rightarrow{ }^{3} \mathrm{H}_{5}\right), 556 \mathrm{~nm}\left({ }^{3} \mathrm{P}_{0} \rightarrow{ }^{3} \mathrm{H}_{5}\right), 598 \mathrm{~nm}\left({ }^{1} \mathrm{D}_{2} \rightarrow{ }^{3} \mathrm{H}_{4}\right), 618 \mathrm{~nm}$ $\left({ }^{3} \mathrm{P}_{0} \rightarrow{ }^{3} \mathrm{H}_{6}\right), 648 \mathrm{~nm}\left({ }^{3} \mathrm{P}_{0} \rightarrow{ }^{3} \mathrm{~F}_{2}\right)$ and $686 \mathrm{~nm}\left({ }^{3} \mathrm{P}_{0} \rightarrow{ }^{3} \mathrm{~F}_{3}\right)$ which are attributed to $4 \mathrm{f}-4 \mathrm{f}$ transitions within the $\mathrm{Pr}^{3+}$. It is also noticed that the emission lines maintain nearly the same when excited at different wavelength, which can be explained by a quick non-radiative relaxation process between ${ }^{3} \mathrm{P}_{2}$ and ${ }^{3} \mathrm{P} 0$ manifolds of $\mathrm{Pr}^{3+}$ when excited from the ground state. The intense red emission band around 618 $\mathrm{nm}$ and $648 \mathrm{~nm}$ make $\mathrm{AgPr}\left(\mathrm{WO}_{4}\right)\left(\mathrm{MoO}_{4}\right)$ an efficient red phosphor material which can be used as one of the components in the fabrication of white LED for blue light conversion. 


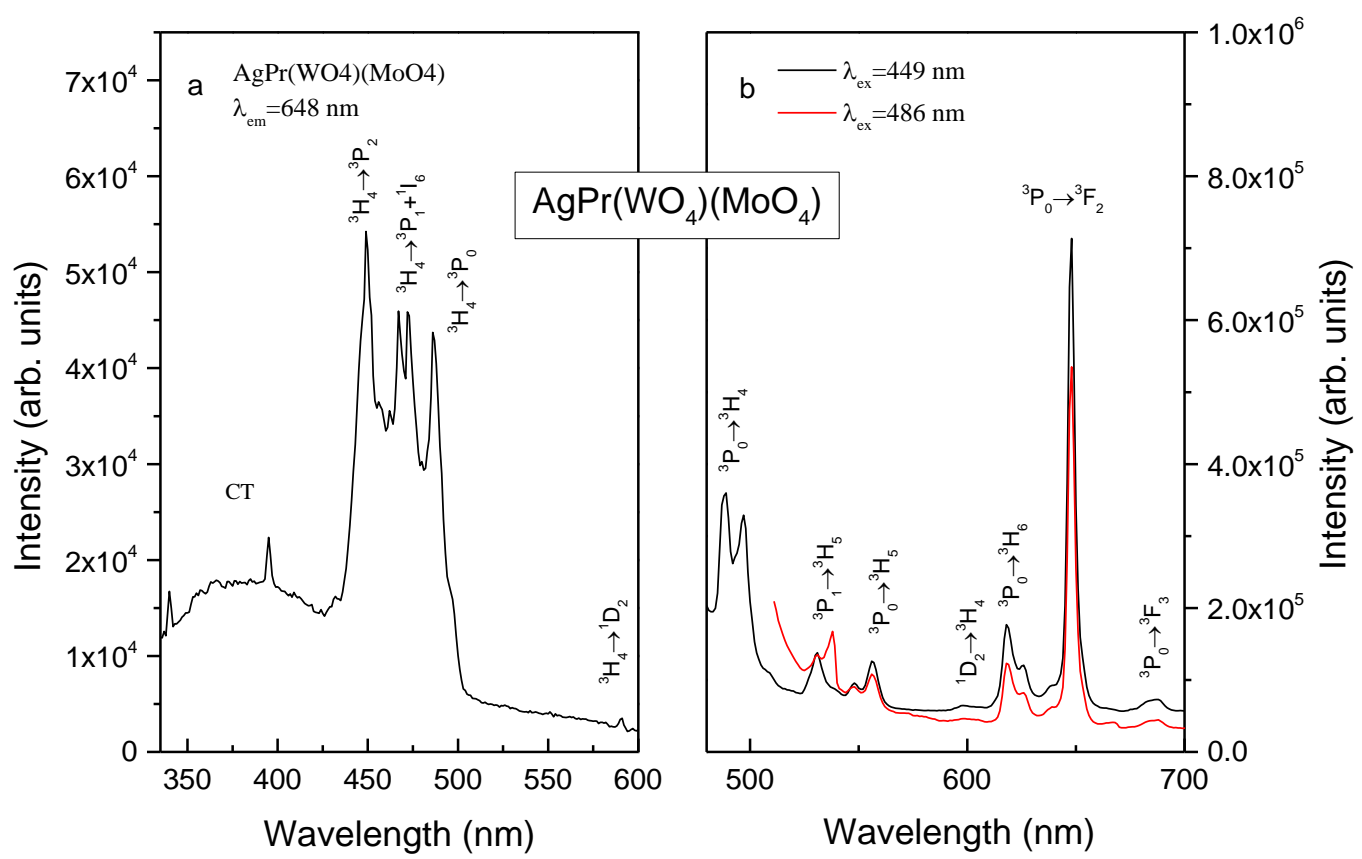

Fig. 3.15 Photoluminescence excitation spectrum (monitored at $648 \mathrm{~nm}$ ) and emission spectrum (excited at $449 \mathrm{~nm}$ and $486 \mathrm{~nm})$ of $\operatorname{AgPr}\left(\mathrm{WO}_{4}\right)\left(\mathrm{MoO}_{4}\right)$ compounds.

\subsubsection{2 $\mathrm{AgSm}\left(\mathrm{WO}_{4}\right)\left(\mathrm{MoO}_{4}\right)$}

The excitation spectra of $\mathrm{AgSm}\left(\mathrm{WO}_{4}\right)\left(\mathrm{MoO}_{4}\right)$ monitored at $599 \mathrm{~nm}$ and $645 \mathrm{~nm}$ emission both presented several sharp peaks at the same wavelength position as shown in Fig. 3.16 a. These sharp peaks ranged from $350 \mathrm{~nm}$ to $500 \mathrm{~nm}$ are ascribed to the $\mathrm{f}-\mathrm{f}$ transition of $\mathrm{Sm}^{3+}$ ions. Compared to other rare-earth ions, the assignment of exact position of $\mathrm{f}-\mathrm{f}$ transitions of $\mathrm{Sm}^{3+}$ ions are very difficult because large numbers of excitation transitions levels present with small energy differences. Hence, the bands at 363 nm, 376 nm, 392 nm, 404 nm, 420 nm, 439 nm, $450 \mathrm{~nm}, 463 \mathrm{~nm}, 467 \mathrm{~nm}, 472 \mathrm{~nm}, 480 \mathrm{~nm}$ and $490 \mathrm{~nm}$ can be assigned from ground state ${ }^{6} \mathrm{H}_{5 / 2}$ to various exited states ${ }^{4} \mathrm{~L}_{15 / 2},{ }^{6} \mathrm{P}_{7 / 2},{ }^{4} \mathrm{~K}_{11 / 2},{ }^{4} \mathrm{~F}_{7 / 2},{ }^{4} \mathrm{P}_{5 / 2}$, ${ }^{4} \mathrm{G}_{9 / 2}+{ }^{4}{ }_{15 / 2},{ }^{4} \mathrm{~F}_{5 / 2},{ }^{4}{ }_{13 / 2},{ }^{4}{ }_{11 / 2},{ }^{4} \mathrm{M}_{15 / 2},{ }^{4}{ }_{9 / 2}$ and ${ }^{4} \mathrm{G}_{7 / 2}$ respectively [3.27-3.31]. The most intense transition is observed at $404 \mathrm{~nm}$ corresponding to the ${ }^{6} \mathrm{H}_{5 / 2} \rightarrow{ }^{4} \mathrm{~F}_{7 / 2}$ transition which suggests that it can be effectivelyexcited by near-UV LED chips (350-420 nm). 
The emission spectra of $\mathrm{AgSm}\left(\mathrm{WO}_{4}\right)\left(\mathrm{MoO}_{4}\right)$ was excited under $404 \mathrm{~nm}$ $\left({ }^{6} \mathrm{H}_{5 / 2} \rightarrow{ }^{4} \mathrm{~F}_{7 / 2}\right.$ transition) and $467 \mathrm{~nm}\left(\left.{ }^{6} \mathrm{H}_{5 / 2} \rightarrow{ }^{4}\right|_{11 / 2}\right)$ as shown in Fig. $3.16 \mathrm{~b}$. The emission spectra excited by the ${ }^{6} \mathrm{H}_{5 / 2} \rightarrow{ }^{4} \mathrm{~F}_{7 / 2}$ transition presented stronger intensity as expected. The emission spectra consists of three strong bands at 563 $\mathrm{nm}, 599 \mathrm{~nm}, 645 \mathrm{~nm}$ in orange region corresponding to $\mathrm{f}-\mathrm{f}$ transitions ${ }^{4} \mathrm{G}_{5 / 2} \rightarrow$ ${ }^{6} \mathrm{H}_{5 / 2},{ }^{4} \mathrm{G}_{5 / 2} \rightarrow{ }^{6} \mathrm{H}_{7 / 2},{ }^{4} \mathrm{G}_{5 / 2} \rightarrow{ }^{6} \mathrm{H}_{9 / 2}$ of $\mathrm{Sm}^{3+}$ ions respectively. Among them, the strongest emission band is located at $645 \mathrm{~nm}$ due to the ${ }^{4} \mathrm{G}_{5 / 2} \rightarrow{ }^{6} \mathrm{H}_{9 / 2}$ transition, which is closer to the red range rather than the ${ }^{4} \mathrm{G}_{5 / 2} \rightarrow{ }^{6} \mathrm{H}_{7 / 2}$ transition (at $599 \mathrm{~nm}$ ) as observed in the $\mathrm{NaGd}\left(\mathrm{WO}_{4}\right)_{2}: \mathrm{Sm}^{3+}[3.27]$, $\mathrm{LiY}\left(\mathrm{MoO}_{4}\right)_{2}: \mathrm{Sm}^{3+}$ [3.28], $\mathrm{MMoO}_{4}$ $\left(\mathrm{M}=\mathrm{Ca}^{2+}, \mathrm{Ba}^{2+}\right.$ and $\left.\mathrm{Sr}^{2+}\right): \mathrm{Sm}^{3+}$ [3.31]. Therefore, $\mathrm{AgSm}\left(\mathrm{WO}_{4}\right)\left(\mathrm{MoO}_{4}\right)$ or $\mathrm{AgLn}\left(\mathrm{WO}_{4}\right)\left(\mathrm{MoO}_{4}\right): \mathrm{Sm}^{3+}$ will be a good potential red luminescent material.

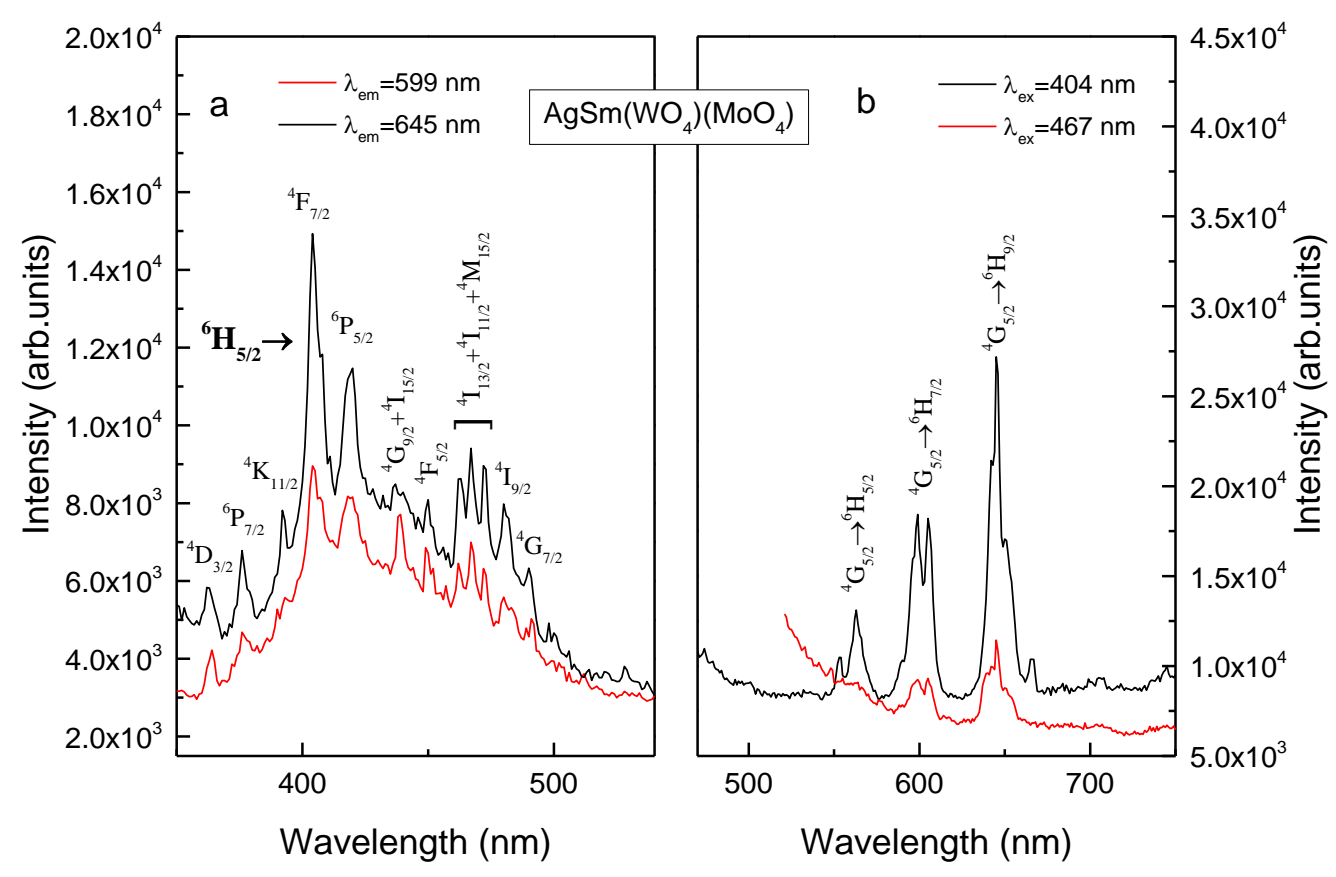

Fig. 3.16 Photoluminescence excitation spectrum (monitored at $599 \mathrm{~nm}$ and 645 $\mathrm{nm}$ ) and emission spectrum (excited at $404 \mathrm{~nm}$ and $467 \mathrm{~nm}$ ) of AgSm( $\left(\mathrm{WO}_{4}\right)\left(\mathrm{MoO}_{4}\right)$ compounds. 


\subsubsection{3 $\mathrm{AgEu}\left(\mathrm{WO}_{4}\right)\left(\mathrm{MoO}_{4}\right)$}

The photoluminescence excitation and emission spectra of $\mathrm{AgEu}\left(\mathrm{WO}_{4}\right)\left(\mathrm{MoO}_{4}\right)$ were illustrated in Fig. 3.17. The results were similar with those observed in the AgLn(WO4)2 double tungstate system by Shi et al. [3.32]. The photoluminescence excitation spectra, under monitored at $615 \mathrm{~nm}$, consists of several strong bands ranging from $350 \mathrm{~nm}$ to $600 \mathrm{~nm}$ which are attributed to intra-configurational $4 \mathrm{f}-4 \mathrm{f}$ transitions of $\mathrm{Eu}^{3+}$ in the lattice. The most intense bands at $394 \mathrm{~nm}, 464 \mathrm{~nm}$ and $534 \mathrm{~nm}$, which have been assigned to ${ }^{7} \mathrm{~F}_{0} \rightarrow{ }^{5} \mathrm{~L} 6$, ${ }^{7} F_{0} \rightarrow{ }^{5} D_{2}$ and ${ }^{7} F_{0} \rightarrow{ }^{5} D_{1}$ respectively, were further used to excite the photoluminescence emission spectra. Under excited at different wavelength, the emission bands are nearly the same and exhibit a characteristic $\mathrm{Eu}^{3+}$ emission except for some intensity varieties. The most intensity emission bands which give rise to red luminescence at $615 \mathrm{~nm}$ (corresponding to ${ }^{5} \mathrm{D}_{0} \rightarrow{ }^{7} \mathrm{~F}_{2}$ transition) were observed with excited by $464 \mathrm{~nm}$. Therefore, the similar situation like in the $\mathrm{AgPr}\left(\mathrm{WO}_{4}\right)\left(\mathrm{MoO}_{4}\right)$ compounds was found that the ${ }^{7} \mathrm{~F}_{0} \rightarrow{ }^{5} \mathrm{D}_{2}$ transition (at $464 \mathrm{~nm}$ ) matches very well with the blue GaN-based LED system and can be used as oneof the components red phosphor materials for the white LED fabrications. Furthermore, the excitation peak of ${ }^{7} \mathrm{~F}_{0} \rightarrow{ }^{5} \mathrm{~L}_{6}$ at $394 \mathrm{~nm}$ indicate that the $\mathrm{AgEu}\left(\mathrm{WO}_{4}\right)\left(\mathrm{MoO}_{4}\right)$ can be used in the ultraviolet LEDs.

It has known that the $\mathrm{Eu}^{3+}$ emission lines are hypersensitive to the environment of $\mathrm{Eu}^{3+}$ ions which can be used as a local structure probe [3.33-3.34]. In the photoluminescence emission spectra of $\mathrm{AgEu}\left(\mathrm{WO}_{4}\right)\left(\mathrm{MoO}_{4}\right)$, the strongest emission lines centered at $615 \mathrm{~nm}$ are attributed to the ${ }^{5} \mathrm{D}_{0} \rightarrow{ }^{7} \mathrm{~F}_{2}$ transition [3.35-3.36]. The intensity of lines originating from ${ }^{5} \mathrm{D}_{0} \rightarrow{ }^{7} \mathrm{~F}_{1}(591 \mathrm{~nm}),{ }^{5} \mathrm{D}_{0} \rightarrow{ }^{7} \mathrm{~F}_{3}$ $(654 \mathrm{~nm})$ and ${ }^{5} \mathrm{D}_{0} \rightarrow{ }^{7} \mathrm{~F}_{4}(701 \mathrm{~nm})$ is much weaker comparing to ${ }^{5} \mathrm{D}_{0} \rightarrow{ }^{7} \mathrm{~F}_{2}$ transition. ${ }^{5} \mathrm{D}_{0} \rightarrow{ }^{7} \mathrm{~F}_{2}$ is an electric dipole transition, which requires a low symmetry without inversion center on the respective $\mathrm{Eu}^{3+}$ sites. The transition ${ }^{5} \mathrm{D}_{0} \rightarrow{ }^{7} \mathrm{~F}_{0}$ shows only one feeble peak at $580 \mathrm{~nm}$ indicating the existence of one site symmetry not higher than $\mathrm{C}_{\mathrm{n}}, \mathrm{C}_{\mathrm{nv}}$ or $\mathrm{C}_{\mathrm{s}}$ for the $\mathrm{Eu}^{3+}$ ion environment. This is in agreement with the structure, where the sites of the rare earth ions have been recognized, whose symmetries are more or less distorted from $S_{4}$. The ${ }^{5} D_{0} \rightarrow{ }^{7} F_{1}$ magnetic dipole transition only split into two peaks corresponds well with our previous works that $\mathrm{AgEu}\left(\mathrm{WO}_{4}\right)\left(\mathrm{MoO}_{4}\right)$ compounds present $\mathrm{C}_{4 \mathrm{~h}}$ factor group. 


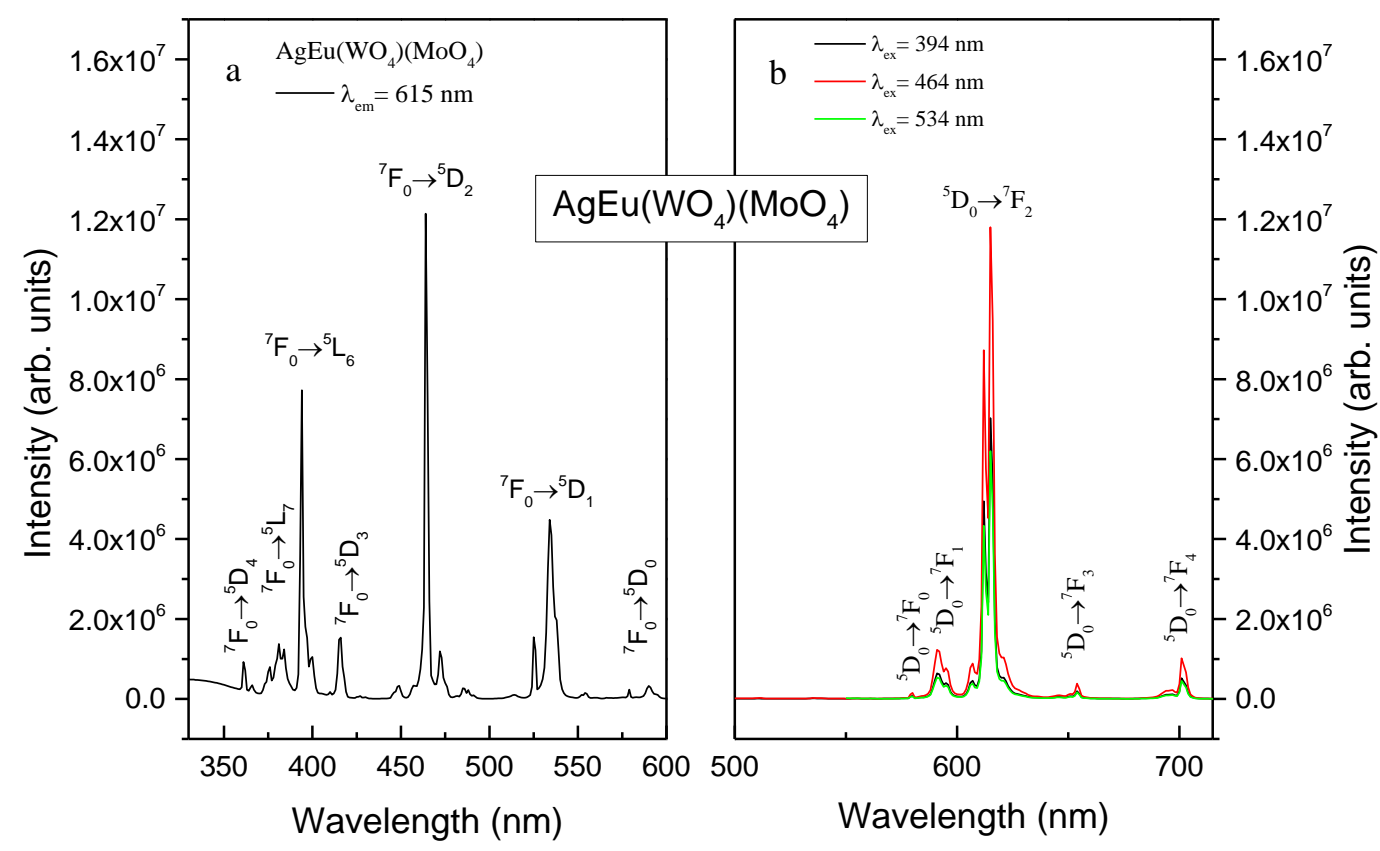

Fig. 3.17 Photoluminescence excitation spectrum (monitored at $615 \mathrm{~nm}$ ) and emission spectrum (excited at $394 \mathrm{~nm}, 464 \mathrm{~nm}$ and $534 \mathrm{~nm}$ ) of $\mathrm{AgEu}\left(\mathrm{WO}_{4}\right)\left(\mathrm{MoO}_{4}\right)$ compounds.

\subsubsection{AgTb $\left(\mathrm{WO}_{4}\right)\left(\mathrm{MoO}_{4}\right)$}

Fig. 3.18 a gives the excitation spectra of the $\operatorname{AgTb}\left(\mathrm{WO}_{4}\right)\left(\mathrm{MoO}_{4}\right)$ samples. The excitation spectra under the $548 \mathrm{~nm}$ monitoring exhibit a strong broad band ranging from 300 to $500 \mathrm{~nm}$ and a sharp strong band at $486 \mathrm{~nm}$. The intense broad band peaking at $348 \mathrm{~nm}$ can be ascribed to the charge transfer of $\mathrm{O}^{2-}-\mathrm{W}^{6+} / \mathrm{Mo}^{6+}$, which overlaps some $4 \mathrm{f}-4 \mathrm{f}$ transitions of $\mathrm{Tb}^{3+}$. The existence of this band and the spectral overlap in the excitation spectra indicate the energy transfer between the $\mathrm{WO}_{4}{ }^{2-}$ groups and $\mathrm{Tb}^{3+}$ ions. For $\mathrm{Tb}^{3+}$ ions with $4 f^{8}$ electrons configuration, the ground states are ${ }^{7} \mathrm{~F}_{6}$. The peak at the shoulder of the broad band $(377 \mathrm{~nm})$ and the intense peak centered at $486 \mathrm{~nm}$ can be assigned as transition of ${ }^{7} \mathrm{~F}_{6} \rightarrow{ }^{5} \mathrm{D}_{3}$ and ${ }^{7} \mathrm{~F}_{6} \rightarrow{ }^{5} \mathrm{D}_{4}$ respectively [3.37].

Fig. $3.18 \mathrm{~b}$ shows the emission spectra of the $\mathrm{AgTb}\left(\mathrm{WO}_{4}\right)\left(\mathrm{MoO}_{4}\right)$ samples excited at $377 \mathrm{~nm}$ and $486 \mathrm{~nm}$. Strong emission peaks located at 545, 588, 622 
and $652 \mathrm{~nm}$ can be observed, which are attributed to the ${ }^{5} \mathrm{D}_{4} \rightarrow{ }^{7} \mathrm{~F}_{5},{ }^{5} \mathrm{D}_{4} \rightarrow{ }^{7} \mathrm{~F}_{4},{ }^{5} \mathrm{D}_{4}$ $\rightarrow{ }^{7} \mathrm{~F}_{3}$ and ${ }^{5} \mathrm{D}_{4} \rightarrow{ }^{7} \mathrm{~F}_{2}$ transitions of $\mathrm{Tb}^{3+}$ respectively [3.38-3.39], despite the intensity of the peaks excited at $377 \mathrm{~nm}$ is much weaker than that excited at 486 $\mathrm{nm}$. And the green emission of ${ }^{5} \mathrm{D}_{4} \rightarrow{ }^{7} \mathrm{~F}_{5}$ transition is dominant in the emission spectra. The inset graph is the zoom-in zone of the emission spectra.

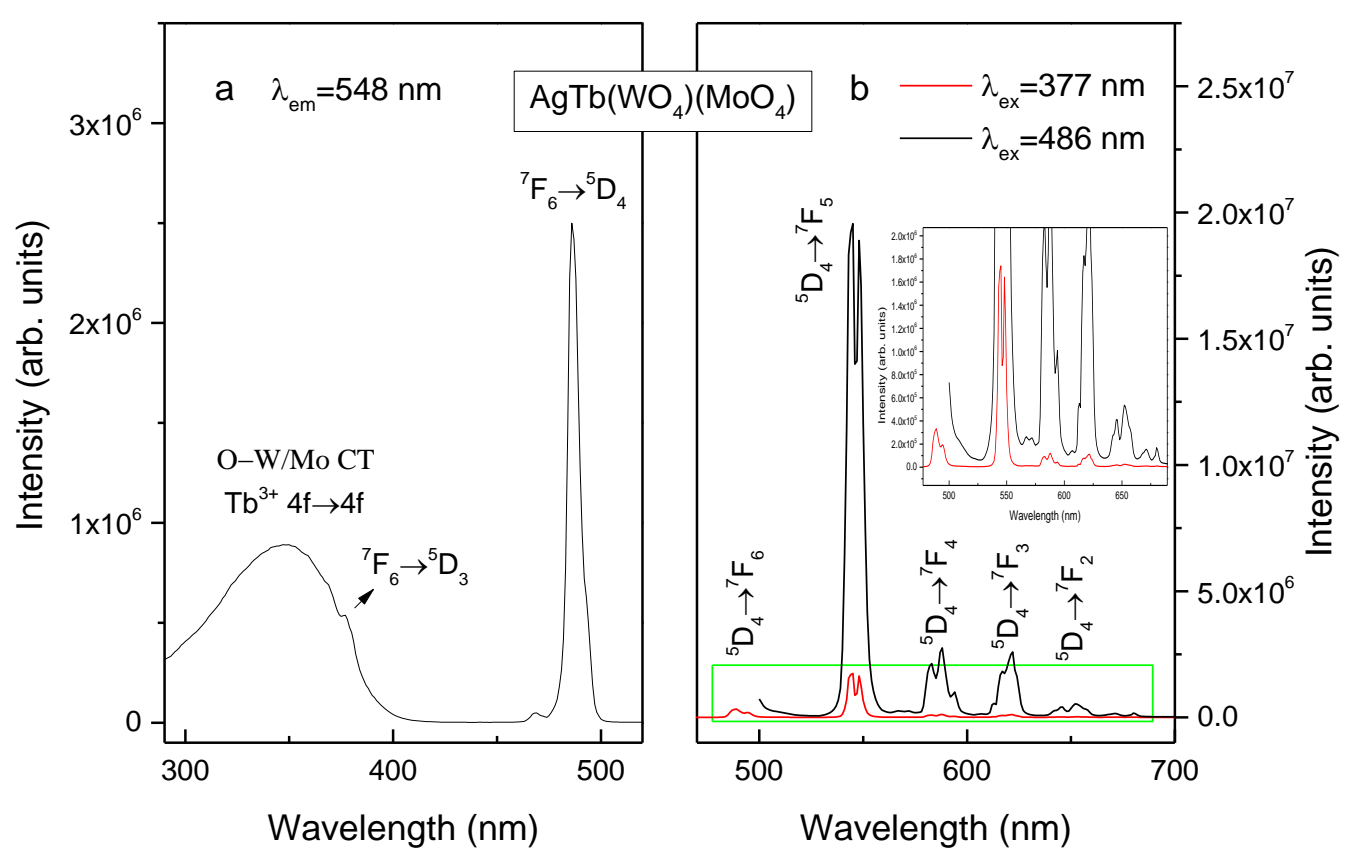

Fig. 3.18 Photoluminescence excitation spectrum (monitored at $548 \mathrm{~nm}$ ) and emission spectrum (excited at $377 \mathrm{~nm}$ and $486 \mathrm{~nm}$ ) of $\mathrm{AgTb}\left(\mathrm{WO}_{4}\right)\left(\mathrm{MoO}_{4}\right)$ compounds.

\subsubsection{5 $\mathrm{AgDy}\left(\mathrm{WO}_{4}\right)\left(\mathrm{MoO}_{4}\right)$}

The room temperature fluorescence spectra of excitation spectrum (monitored at $574 \mathrm{~nm}$ ) and emission spectrum (excited at $387 \mathrm{~nm}$ and $454 \mathrm{~nm}$ ) was presented in Fig. 3.19. Strong bands were observed which corresponding well with the energy transitions of Dy ${ }^{3+}$ [3.40-3.41]. Several sharp peaks from 310 to $500 \mathrm{~nm}$ in the excitation spectrum were assigned to the intra- $4 \mathrm{f}$ transitions of $D y^{3+}$ ions from the ground state ${ }^{6} \mathrm{H}_{15 / 2}$ to the excited state of ${ }^{6} \mathrm{P}_{7 / 2}(353 \mathrm{~nm}),{ }^{6} \mathrm{P}_{5 / 2}(366 \mathrm{~nm})$, ${ }^{4} \mathrm{~F}_{7 / 2}+\left.{ }^{4}\right|_{13 / 2}(387 \mathrm{~nm}),{ }^{4} \mathrm{G}_{11 / 2}(427 \mathrm{~nm}),\left.{ }^{4}\right|_{15 / 2}(454 \mathrm{~nm})$ and ${ }^{4} \mathrm{~F}_{9 / 2}(473 \mathrm{~nm})$. Three 
bands centered at $486 \mathrm{~nm}, 574 \mathrm{~nm}$ and $661 \mathrm{~nm}$ (feeble peaks) which correspond to the transitions ${ }^{4} \mathrm{~F}_{9 / 2} \rightarrow{ }^{6} \mathrm{H}_{15 / 2},{ }^{4} \mathrm{~F}_{9 / 2} \rightarrow{ }^{6} \mathrm{H}_{13 / 2}$ and ${ }^{4} \mathrm{~F}_{9 / 2} \rightarrow{ }^{6} \mathrm{H}_{11 / 2}$ respectively were marked under excitation of $387 \mathrm{~nm}$. It is worth noting that the strong excitation band of the $\left.{ }^{6} \mathrm{H}_{15 / 2} \rightarrow{ }^{4}\right|_{15 / 2}$ transition centered at $454 \mathrm{~nm}$ is coupled well with the emission wavelength of $\mathrm{GaN}$ laser diodes which means that the $\left.{ }^{4}\right|_{15 / 2}$ multiplet is a suitable pumped level for the yellow laser use.

It has been known that the transition ${ }^{4} \mathrm{~F}_{9 / 2} \rightarrow{ }^{6} \mathrm{H}_{15 / 2}$ (blue emission) is of magnetic dipole and ${ }^{4} \mathrm{~F}_{9 / 2} \rightarrow{ }^{6} \mathrm{H}_{13 / 2}$ (yellow emission) is of electric dipole (ED). Generally, when $\mathrm{Dy}^{3+}$ is locatedat a low symmetry (without inversion center), the yellow emission is dominant whereas the blue emission is stronger when Dy ${ }^{3+}$ is located at a high symmetry (with inversion center) [3.42-3.43]. It can be seen from Fig. $3.19 \mathrm{~b}$ that the strong yellow emission at $574 \mathrm{~nm}$ is the dominant band, which indicates that $\mathrm{Dy}^{3+}$ ions occupy the site without inversion symmetry. This result corresponds well with the previous IR-Raman research.

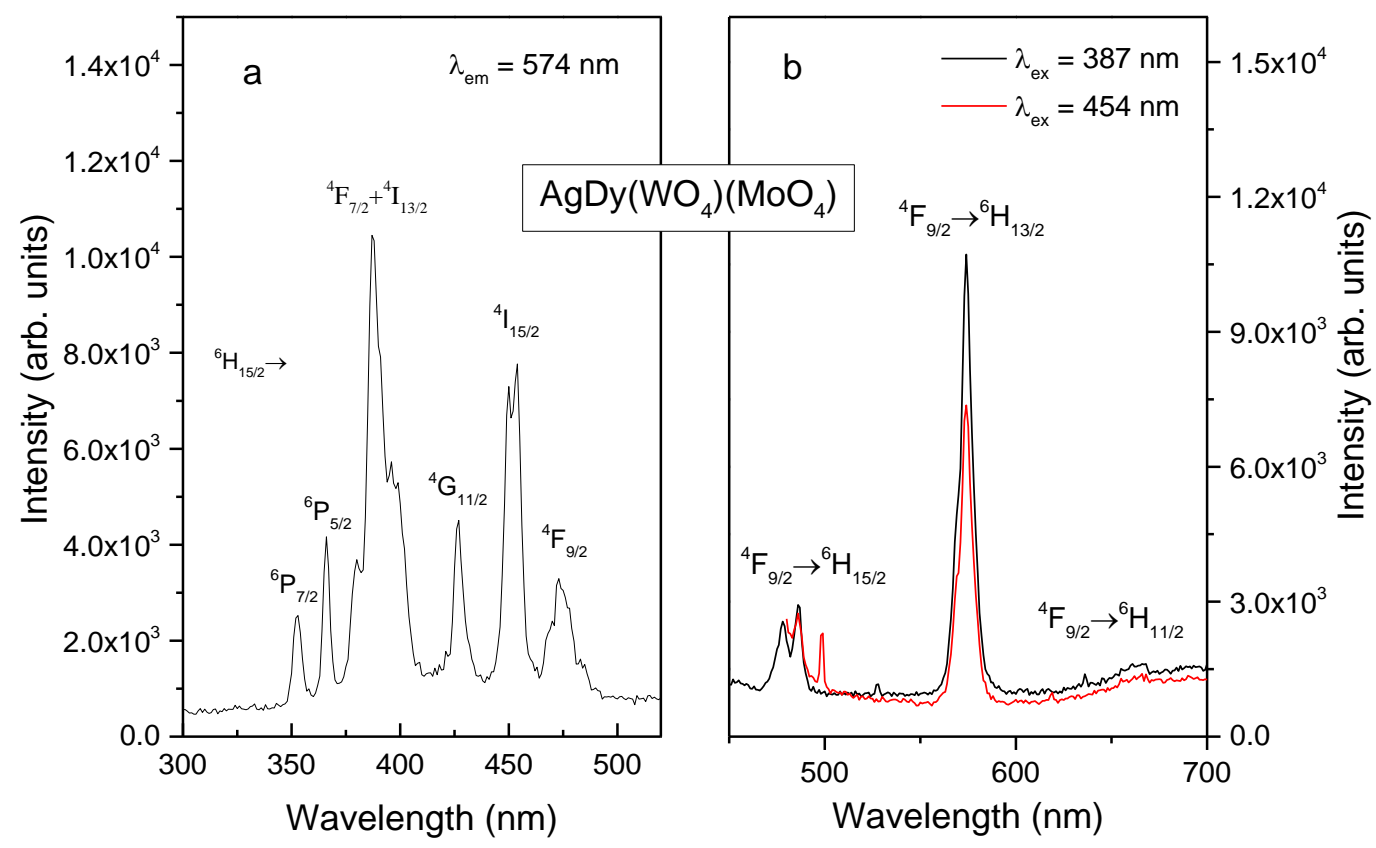

Fig. 3.19 Photoluminescence excitation spectrum (monitored at $574 \mathrm{~nm}$ ) and emission spectrum (excited at $387 \mathrm{~nm}$ and $454 \mathrm{~nm}$ ) of $\mathrm{AgDy}\left(\mathrm{WO}_{4}\right)\left(\mathrm{MoO}_{4}\right)$ compounds. 


\subsubsection{6 $\mathrm{AgHo}\left(\mathrm{WO}_{4}\right)\left(\mathrm{MoO}_{4}\right)$}

The room temperature fluorescence excitation spectrum of $\mathrm{AgHo}\left(\mathrm{WO}_{4}\right)\left(\mathrm{MoO}_{4}\right)$ was observed under monitored at $546 \mathrm{~nm}$ and $660 \mathrm{~nm}$ as presented in Fig. 3.20 a. The spectrum recorded between 350 and $530 \mathrm{~nm}$ exhibits sharp and well distinct excitation bands which are assigned to the $4 \mathrm{f}-4 \mathrm{f}$ transitions of $\mathrm{Ho}^{3+}$ ions. The mainly characterized intense peaks positioned at $360,418,449,467,486$ nm can be assigned to ${ }^{5} \mathrm{I}_{8} \rightarrow{ }^{5} \mathrm{G}_{5},{ }^{3} \mathrm{G}_{5},{ }^{5} \mathrm{G}_{6}+{ }^{5} \mathrm{~F}_{1},{ }^{3} \mathrm{~K}_{8}+{ }^{5} \mathrm{~F}_{2}$ and ${ }^{5} \mathrm{~F}_{3}$ transitions respectively.

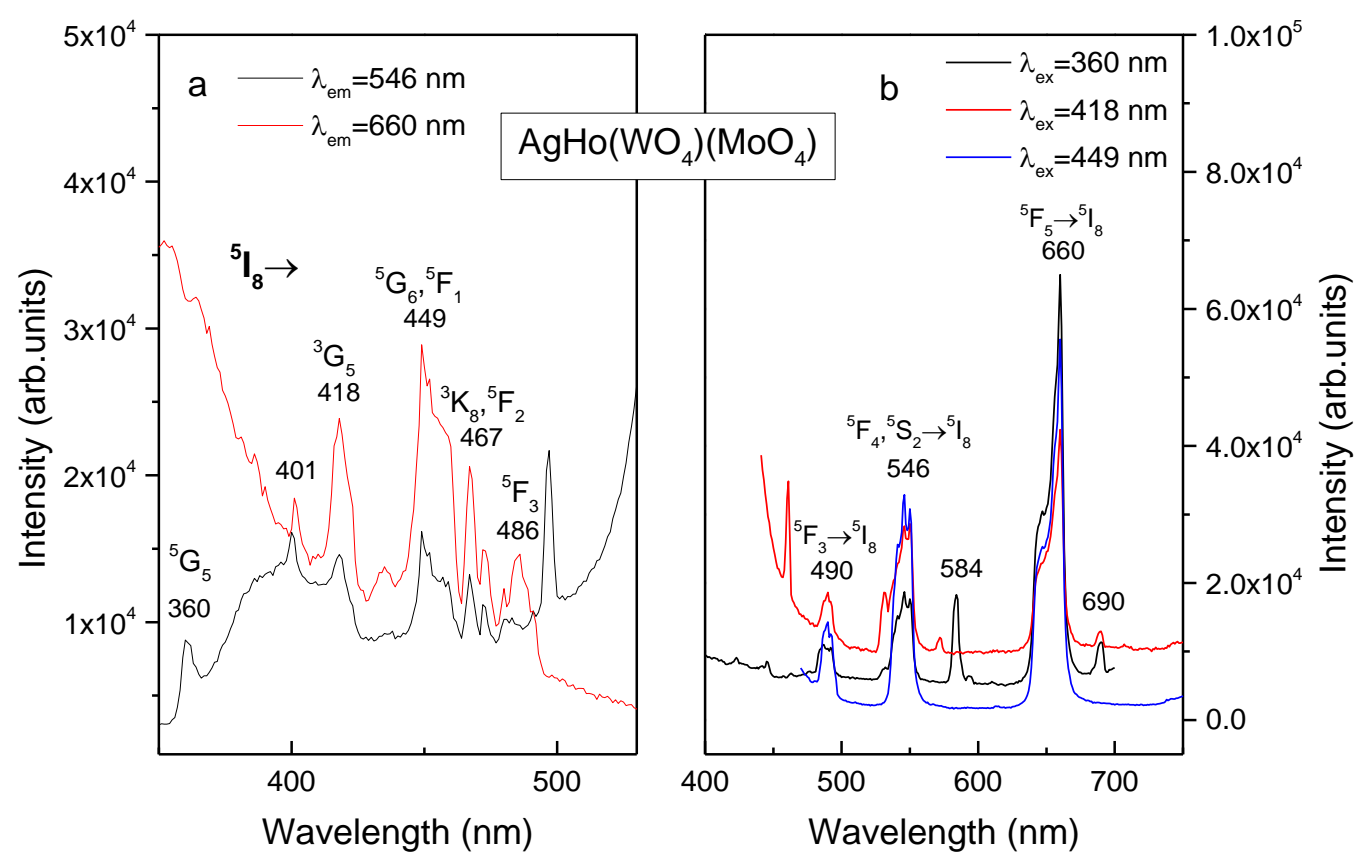

Fig. 3.20 Photoluminescence excitation spectrum (monitored at $546 \mathrm{~nm}$ and 660 $\mathrm{nm}$ ) and emission spectrum (excited at $360 \mathrm{~nm}, 418 \mathrm{~nm}$ and $449 \mathrm{~nm}$ ) of $\mathrm{AgHo}\left(\mathrm{WO}_{4}\right)\left(\mathrm{MoO}_{4}\right)$ compounds.

The band at $449 \mathrm{~nm}$ shows the highest intensity among all the excitation bands, so we used it as excitation to detect the emission spectra. For comparison, the bands at 360 and $418 \mathrm{~nm}$ were taken as excitation as well. Upon these three excitations, the recorded emission spectra in the spectral region $400-750 \mathrm{~nm}$ are analogous. According to the energy diagram of $\mathrm{Ho}^{3+}$, the emission peaks located 
at 490,546 and $660 \mathrm{~nm}$ are attributed to the blue $\left(\left.{ }^{5} \mathrm{~F}_{3} \rightarrow{ }^{5}\right|_{8}\right)$, the green $\left({ }^{5} \mathrm{~F}_{4}+\right.$ $\left.{ }^{5} \mathrm{~S}_{2} \rightarrow{ }^{5} l_{8}\right)$ and the red $\left({ }^{5} \mathrm{~F}_{5} \rightarrow{ }^{5} \mathrm{I}_{8}\right)$ emission. Normally the green emission from $\mathrm{Ho}^{3+}$ is of particular interest for utilizing as a green solid-state laser because the emission of the $f$-f transitions of ${ }^{5} F_{4}+{ }^{5} S_{2} \rightarrow{ }_{8} I_{8}$ are usually observed to be stronger than that of other $\mathrm{f}-\mathrm{f}$ transitions in most holmium host matrices including crystals or glasses [3.44-3.46]. However, as one can observe in Fig 3.20 b, the red emission at $660 \mathrm{~nm}$ is clearly dominant, and it can be excited by a broad region from UV to blue. This similar situation has been observed in some upconversion photoluminescence spectra of holmium doped alkali based scheelite type hosts, like $\mathrm{NaLa}\left(\mathrm{MoO}_{4}\right)_{2}$ and $\mathrm{NaY}\left(\mathrm{WO}_{4}\right)_{2}$ as well [3.47-3.49]. However, in some others as $\mathrm{NaLa}\left(\mathrm{WO}_{4}\right)_{2}$ host for example [3.50], green emission is still the dominant one.

\subsubsection{7 $\mathrm{AgEr}\left(\mathrm{WO}_{4}\right)\left(\mathrm{MoO}_{4}\right)$}

The room temperature fluorescence spectra of excitation spectrum (monitored at $557 \mathrm{~nm}$ ) and emission spectrum (excited at $377 \mathrm{~nm}$ ) was presented in Fig. 3.21. Several strong sharp bands were observed which corresponding well with the energy levels of $\mathrm{Er}^{3+}$ [3.51-3.52]. The peaks from 350 to $550 \mathrm{~nm}$ in the excitation spectrum were assigned to the intra- $4 \mathrm{f}$ transitions of $\mathrm{Er}^{3+}$ ions from the ground state ${ }^{4} I_{15 / 2}$ to the excited state of ${ }^{2} G_{9 / 2}(365 \mathrm{~nm}),{ }^{4} \mathrm{G}_{11 / 2}(377 \mathrm{~nm}),{ }^{2} \mathrm{H}_{9 / 2}(407 \mathrm{~nm})$, ${ }^{4} \mathrm{~F}_{5 / 2+}{ }^{4} \mathrm{~F}_{3 / 2}$ (around $450 \mathrm{~nm}$ ) and ${ }^{4} \mathrm{~F}_{7 / 2}(488 \mathrm{~nm}$ ). The emission spectrum was recorded under excited at $377 \mathrm{~nm}$ which shows the most intensity among the excitation peaks. Five distinct emission bands were exhibited: one violet luminescence band corresponding to the $\left.{ }^{2} \mathrm{H}_{9 / 2} \rightarrow{ }^{4}\right|_{15 / 2}$ transition of $\mathrm{Er}^{3+}$ at $408 \mathrm{~nm}$, two green bands corresponding to the ${ }^{2} \mathrm{H}_{11 / 2}+\left.{ }^{4} \mathrm{~S}_{3 / 2} \rightarrow{ }^{4}\right|_{15 / 2}$ centered around 531 and $557 \mathrm{~nm}$, two red emission bands at $658 \mathrm{~nm}\left(\left.{ }^{4} \mathrm{~F}_{9 / 2} \rightarrow{ }^{4}\right|_{15 / 2}\right)$ and $697 \mathrm{~nm}$ $\left(\left.\left.{ }^{4}\right|_{9 / 2} \rightarrow{ }^{4}\right|_{15 / 2}\right)$. Inside, the dominant emission is in the green associated with the $\left.{ }^{4} S_{3 / 2} \rightarrow{ }^{4}\right|_{15 / 2}$ transition. 


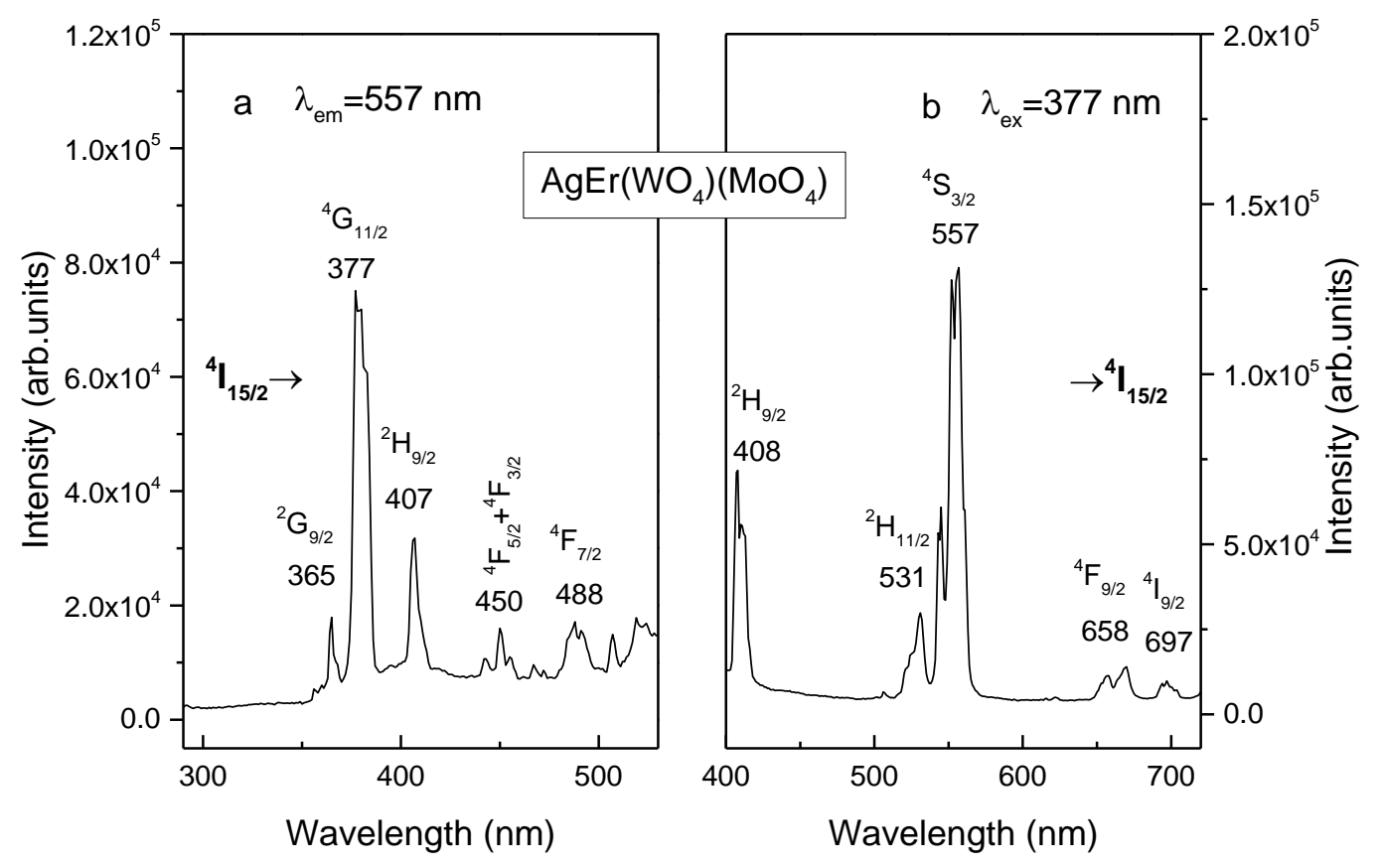

Fig. 3.21 Photoluminescence excitation spectrum (monitored at $557 \mathrm{~nm}$ ) and emission spectrum (excited at $377 \mathrm{~nm}$ ) of $\mathrm{AgEr}\left(\mathrm{WO}_{4}\right)\left(\mathrm{MoO}_{4}\right)$ compounds.

\subsubsection{AgTm( $\left(\mathrm{WO}_{4}\right)\left(\mathrm{MoO}_{4}\right)$}

Fig.3.22 gives the room temperature excitation spectrum of $\mathrm{AgTm}\left(\mathrm{WO}_{4}\right)\left(\mathrm{MoO}_{4}\right)$ monitored at 579 and $697 \mathrm{~nm}$. The broad band ranged from 350 to $500 \mathrm{~nm}$ can be attributed to the charge transfer of O-W/Mo, which overlaps the ${ }^{3} \mathrm{H}_{6} \rightarrow{ }^{1} \mathrm{G}_{4}$ transition of $\mathrm{Tm}^{3+}$ at around $470 \mathrm{~nm}$. The existence of CTB in the excitation spectrum suggests that the energy transfer from $\left[\mathrm{WO}_{4}\right] /\left[\mathrm{MoO}_{4}\right]$ groups to $\mathrm{Tm}^{3+}$ ion occurs in the $\mathrm{AgTm}\left(\mathrm{WO}_{4}\right)\left(\mathrm{MoO}_{4}\right)$ compounds. Many attempts have been made to obtain the emission spectrum of $\mathrm{AgTm}\left(\mathrm{WO}_{4}\right)\left(\mathrm{MoO}_{4}\right)$ by exciting at various wavelength, no efficient band was observed in visible range (until 750 $\mathrm{nm}$ ) however. It is because the emission bands from the high energy level ${ }^{1} \mathrm{G}_{4}$ of $\mathrm{Tm}^{3+}$ are mostly located in infrared range. The only transition ${ }^{1} \mathrm{G}_{4} \rightarrow{ }^{3} \mathrm{~F}_{4}$, which can be located at around $645 \mathrm{~nm}$ [3.53], did not be observed in our sample. 


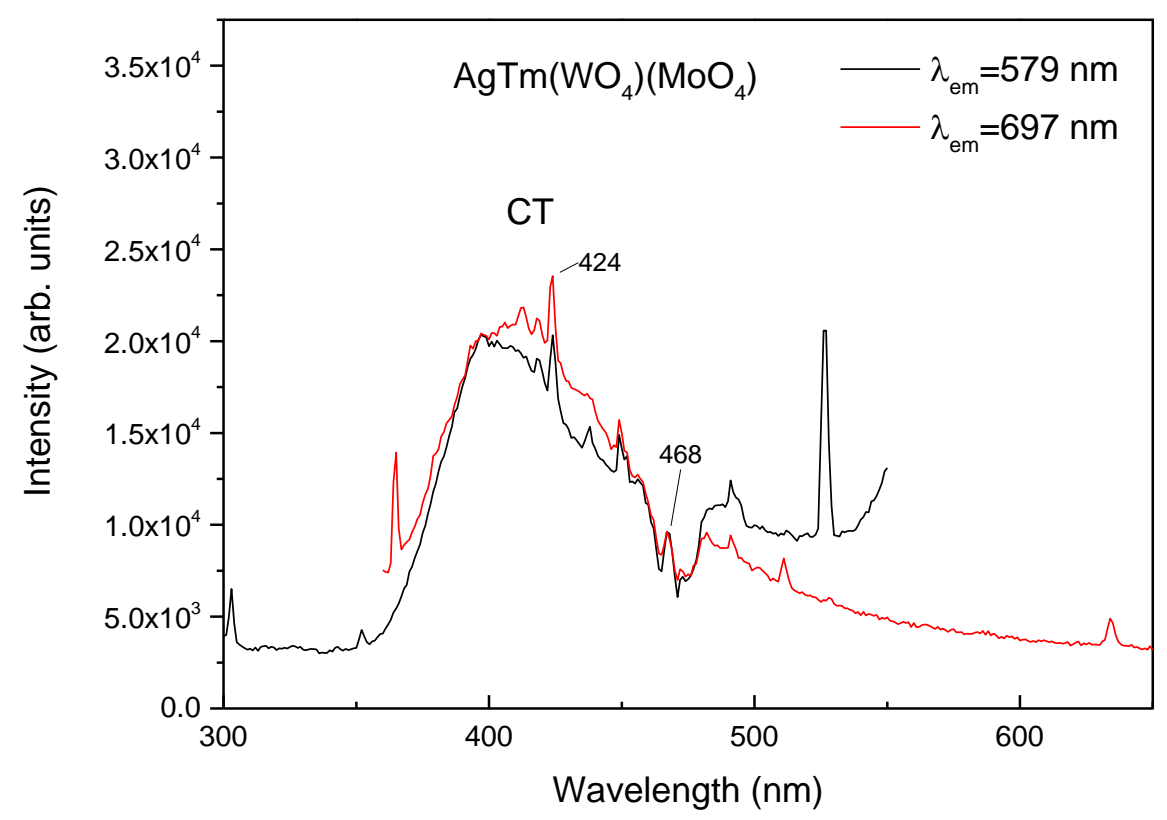

Fig. 3.22 Photoluminescence excitation spectrum (monitored at $579 \mathrm{~nm}$ and 697 $\mathrm{nm})$ of $\mathrm{AgTm}\left(\mathrm{WO}_{4}\right)\left(\mathrm{MoO}_{4}\right)$ compounds.

\section{3. - $\mathrm{Sr}_{2} \mathrm{LnSbO}_{6}$ double provskites.}

\subsubsection{Thermal behavior of the mixture precursors of $\mathrm{Sr}_{2} \mathrm{LnSbO}_{6}$}

In the preliminary study of the forming reaction of the samples $\mathrm{Sr}_{2} \mathrm{LnSbO}_{6}$, different processes, some of them simultaneously, corresponding to processes of dehydration, decarbonation, decomposition andoxidation of the different reagents were observed. And this is why we chose to perform thermal analysis of the initial reagents, in order to describe behaviors from the first complex ones to a sum of simpler processes. Since the samples are obtained by reacting in the air, it was decided to perform these analyzes in dynamic atmosphere of oxygen.

Fig. 3.23 presents the simultaneous diagrams thermal gravimetric analysis (TGA) and differential scanning calorimetry (DSC) corresponding to the different precursors of $\mathrm{Sr}_{2} \mathrm{LnSbO}_{6}$ samples: thermal decomposition of strontium carbonate $\left(\mathrm{SrCO}_{3}\right)$ and oxidation of antimony sesquioxide $\left(\mathrm{Sb}_{2} \mathrm{O}_{3}\right)$. 


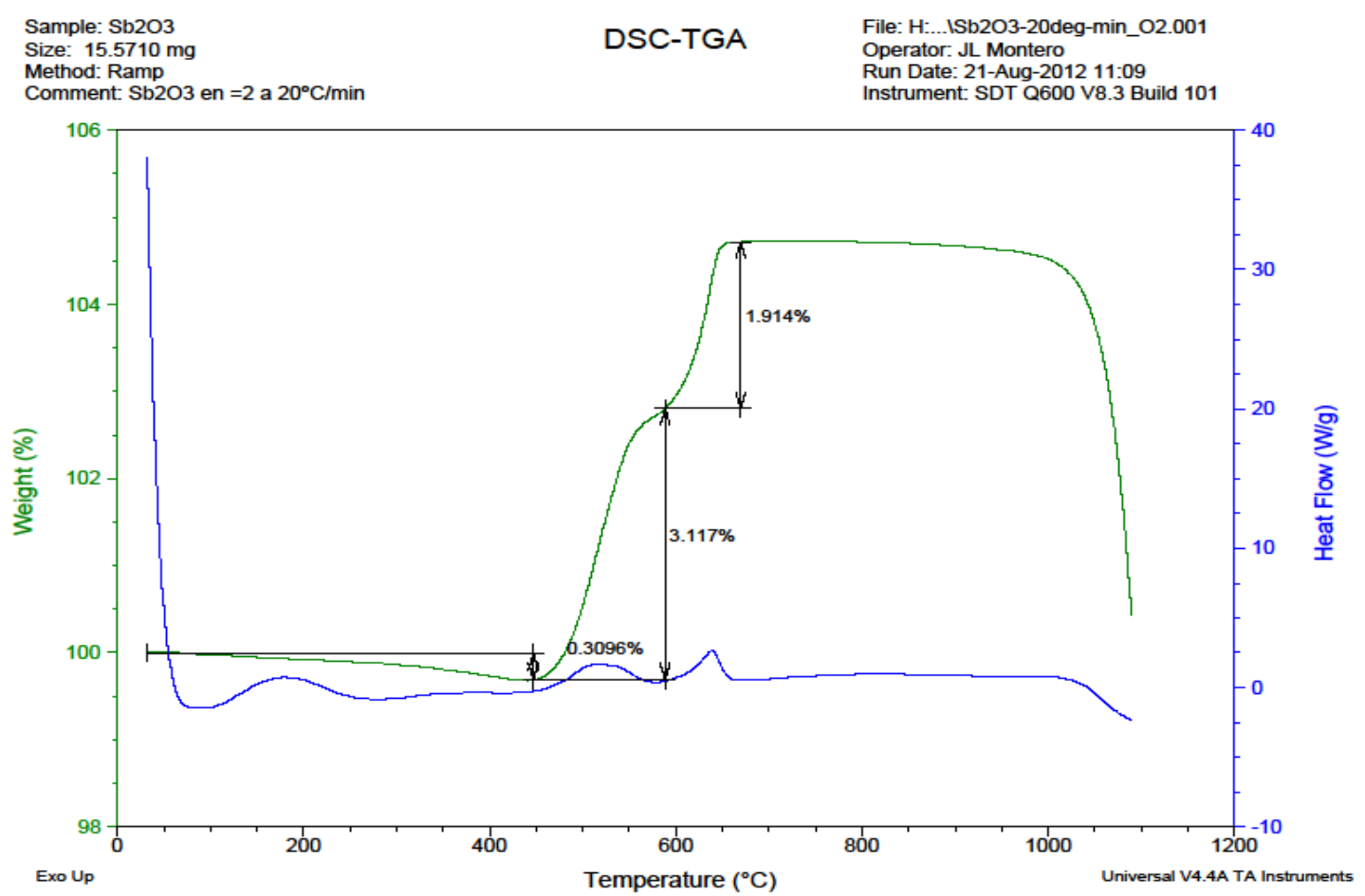

Fig. 3.23 Differential scanning calorimetry and thermal gravimetric analysis of $\mathrm{Sb}_{2} \mathrm{O}_{3}$ oxides.

The analysis results of the $\mathrm{Sb}_{2} \mathrm{O}_{3}$ sample were obtained by performing the heat treatment in an oxygen atmosphere. It displays initially a slow weight loss from $100^{\circ} \mathrm{C}$ to $450^{\circ} \mathrm{C}$, which is due to the loss of the reagent by volatilization $(0.3096 \%)$. And then two considerable weight increments appear at the temperatures of $500{ }^{\circ} \mathrm{C}$ and $600{ }^{\circ} \mathrm{C}$ respectively, due to the oxidation process of antimony sesquioxide, according to the reaction:

$$
\mathrm{Sb}_{2} \mathrm{O}_{3}+1 / 2 \mathrm{O}_{2} \rightarrow \mathrm{Sb}_{2} \mathrm{O}_{4}
$$

This oxidation process occurs in two exothermic stages rather than a single. Some authors suggest that it corresponds to the superposition of two processes, the oxidation and simultaneous volatilization of sesquioxide, probably because the antimony sesquioxideitself has a phase transition from orthorhombic to cubic, at the intermediate temperature of $570{ }^{\circ} \mathrm{C}$ and the oxidation process of the two crystalline phases occur at different temperatures:

$$
\mathrm{Sb}_{2} \mathrm{O}_{3} \text { (orthorhombic) } \rightarrow \mathrm{Sb}_{2} \mathrm{O}_{3} \text { (cubic) }
$$


It should be emphasized that the weight increase obtained in the two stages, $5.031 \%$, is less than the theoretical increase by incorporating an oxygen atom to the compound, which should be $5.49 \%$. This fact can interpret due to the volatilization loss of $\mathrm{Sb}_{2} \mathrm{O}_{3}$, which is still occurring during the oxidation process, and allows us to estimate the amount of reagent volatilized in the process, which turns out to be approximately $8.34 \%$, and it is consequently necessary to add an excess of this order in the synthesis reaction of $\mathrm{Sr}_{2} \mathrm{LnSbO}_{6}$ oxides.Probably this fact may explain why it is not possible to obtain different pure phases of $\mathrm{Sr}_{2} \mathrm{LnSbO}_{6}$, as its mechanism is one of the reagents in default case of oxides of rare earth, must appear non-volatile in default, which can be seen in varying amounts by X-ray diffraction.

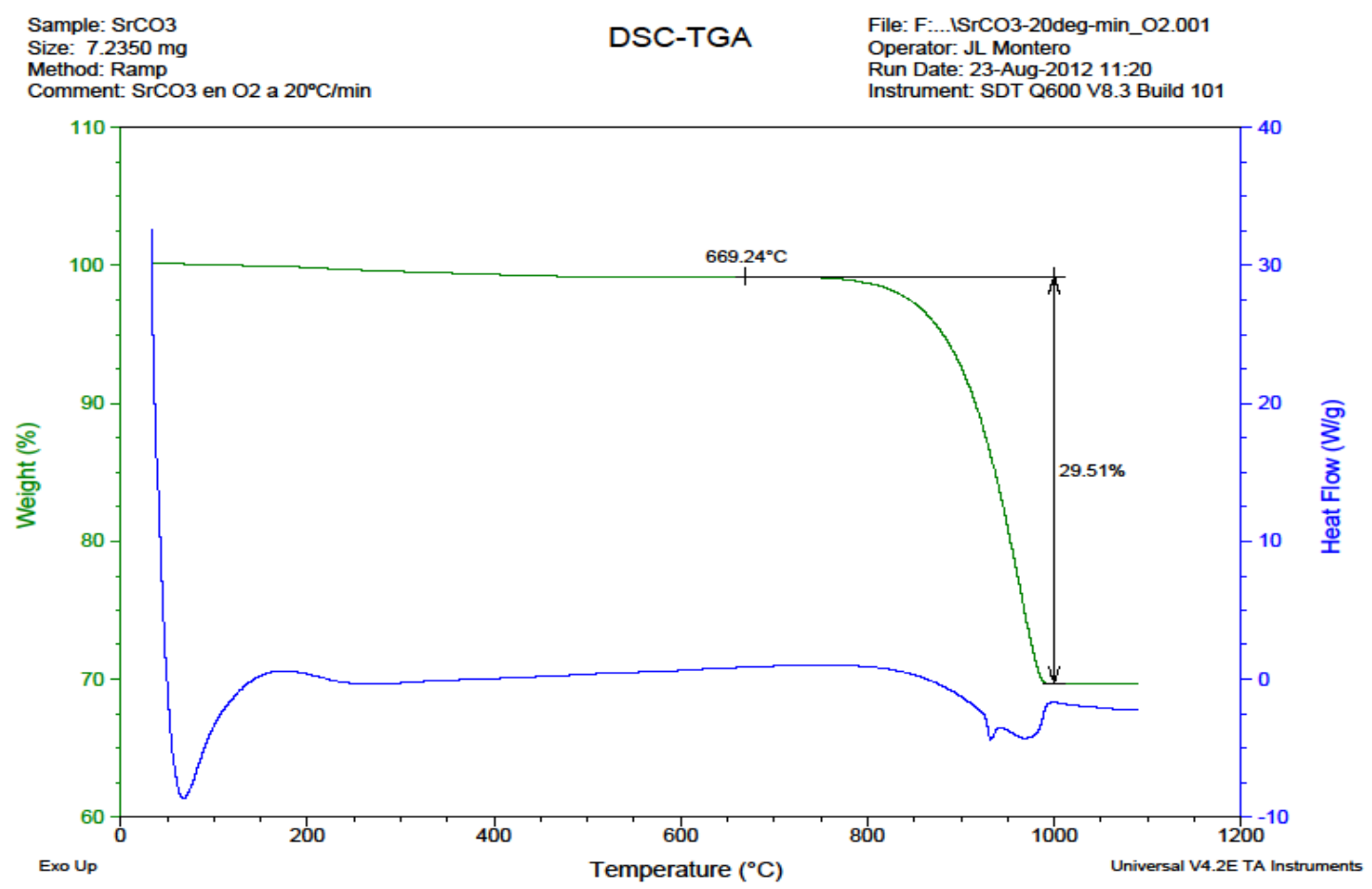

Fig. 3.24 Differential scanning calorimetry and thermal gravimetric analysis of $\mathrm{SrCO}_{3}$ oxides.

The analysis results of the $\mathrm{Sr}_{2} \mathrm{CO}_{3}$ sample were obtained by performing the heat treatment in an oxygen atmosphere.A significant weight loss at about $700{ }^{\circ} \mathrm{C}$ was observed, due to the thermal decomposition processof the strontium carbonate as the reaction: 


$$
\mathrm{Sr}_{2} \mathrm{CO}_{3} \rightarrow \mathrm{SrO}+\mathrm{CO}_{2} \uparrow
$$

In this case, the experimental weight loss (29.51\%)matches well with the theoreticalweight loss which is $29.80 \%$.

In the Figures 3.25 and 3.26, the simultaneous thermal gravimetric analysis (TGA) diagrams and differential scanning calorimetry (DSC) diagrams were presented corresponding to the mixture of the precursors of the sample $\mathrm{Sr}_{2} \mathrm{SmSbO}_{6}$ and $\mathrm{Sr}_{2} \mathrm{DySbO}_{6}$ which can be shown as:

$$
\mathrm{Sr}_{2} \mathrm{CO}_{3}+1 / 2 \mathrm{Ln}_{2} \mathrm{O}_{3}+1 / 2 \mathrm{Sb}_{2} \mathrm{O}_{3}
$$

where Ln equal to Sm and Dy respectively.

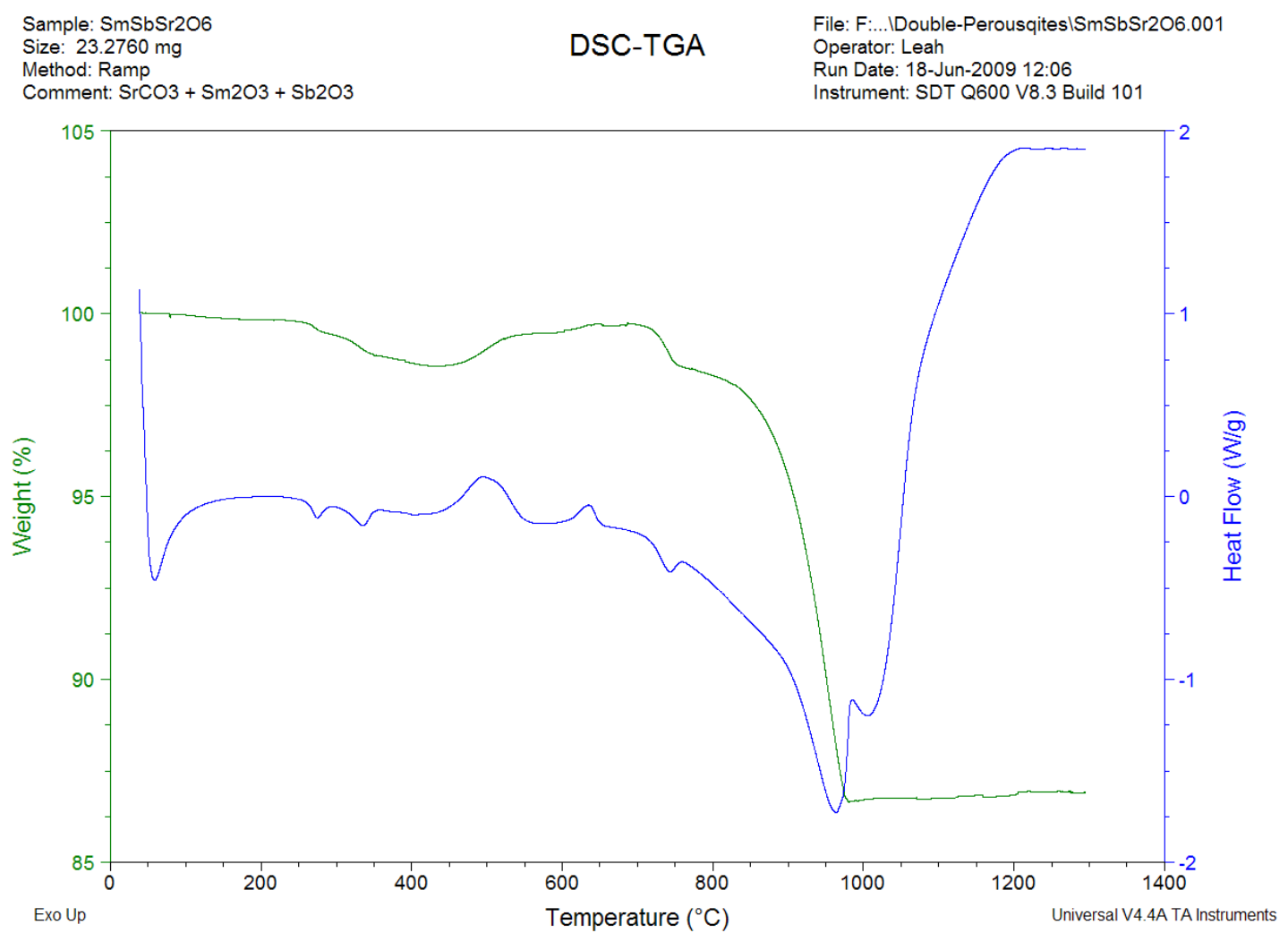

Fig.3.25 Thermal Gravimetric Analysis (TGA) of $\mathrm{Sr}_{2} \mathrm{SmSbO}_{6}$ synthesis process.

In the study of the process of the formation reaction of $\mathrm{Sr}_{2} \mathrm{SmSbO}_{6}$ it shows different processes, sum of simpler processes, each of the reagents undergoing 
in the heating process in an oxidizing atmosphere. Firstly, a weight loss occurs in two stages between 250 and $350^{\circ} \mathrm{C}$, corresponding to processes of dehydration and decarbonation of the corresponding rare earth oxides, as $\mathrm{Sm}_{2} \mathrm{O}_{3}$ in this case for example. Then the reactive mixture undergoes a weight increase between 500 and $600{ }^{\circ} \mathrm{C}$ which is similar to that already described for the process of oxidation of antimony sesquioxide. At temperature of $750{ }^{\circ} \mathrm{C}$ observed an endothermic process in which a weight loss equivalent to the increase experienced in the previous step occurs and can be attributed to the loss of an oxygen atom as well.In this case it is due to the process of forming the perovskite antimony and rare earth, following the reaction:

$$
1 / 2 \mathrm{Sm}_{2} \mathrm{O}_{3}+1 / 2 \mathrm{Sb}_{2} \mathrm{O}_{4} \rightarrow \mathrm{SbSmO}_{3}+1 / 2 \mathrm{O}_{2}
$$

Next, it can be observed at the temperature of $800{ }^{\circ} \mathrm{C}$ a new endothermic process in which produces a weight loss corresponding to the reduction like already observed in the process of decomposition of strontium carbonate $\mathrm{SrCO}_{3}$. And finally, at the temperature of $1025^{\circ} \mathrm{C}$ we can observe a final endothermic effect, in which have no mass variation and can be attributed to the formation of the double perovskiteof the corresponding rare earth. 


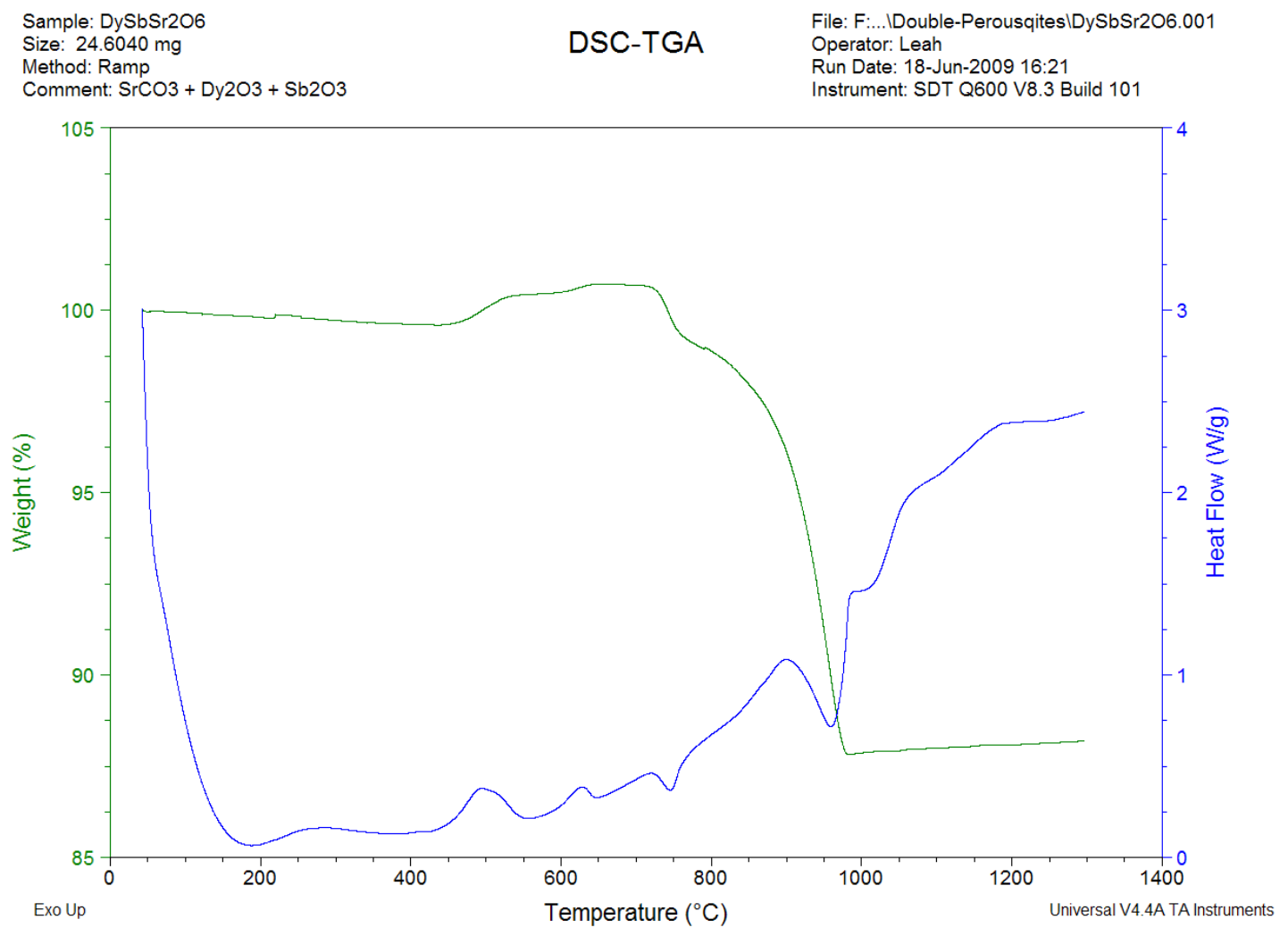

Fig.3.26 Thermal Gravimetric Analysis (TGA) of $\mathrm{Sr}_{2} \mathrm{DySbO}_{6}$ synthesis process.

The formation reaction of $\mathrm{Sr}_{2} \mathrm{DySbO}_{6}$ followed the analogous process. The weight loss firstly occurred in two stages between 200 and $400{ }^{\circ} \mathrm{C}$, corresponding to processes of dehydration and decarbonation of the corresponding rare earth oxides, as $\mathrm{Dy}_{2} \mathrm{O}_{3}$ in this case for example. Then the reactive mixture undergoes a weight increase between 500 and $600{ }^{\circ} \mathrm{C}$ which is similar to that already described for the process of oxidation of antimony sesquioxide. At temperature of $750{ }^{\circ} \mathrm{C}$ observed an endothermic process in which a weight loss equivalent to the increase experienced in the previous step occurs and can be attributed to the loss of an oxygen atom as well. In this case it is due to the process of forming the perovskite antimony and rare earth, following the reaction:

$$
1 / 2 \mathrm{Dy}_{2} \mathrm{O}_{3}+1 / 2 \mathrm{Sb}_{2} \mathrm{O}_{4} \rightarrow \mathrm{SbDyO}_{3}+1 / 2 \mathrm{O}_{2}
$$


Then, it can be observed at the temperature of $800{ }^{\circ} \mathrm{C}$ a new endothermic process in which produces a big weight loss corresponding to the reduction like already observed in the process of decomposition of strontium carbonate $\mathrm{SrCO}_{3}$. And at the temperature of $1025^{\circ} \mathrm{C}$ we can observe a final endothermic effect as observed in the $\mathrm{Sr}_{2} \mathrm{SmSbO}_{6}$ compound, in which have no mass variation and can be attributed to the formation of the double perovskite of the corresponding rare earth.

\subsubsection{Structural study by X-ray diffraction.}

The figures 3.27 presented X-ray Diffraction diagrams for $\mathrm{Sr}_{2} \mathrm{LnSbO}_{6}$ oxides. In all cases the experimental results have been adjusted using the Rietveld method. In these figures the differences between the experimental and calculated diffraction patterns are shown as well. The vertical segments represent the position of the reflections that correspond to the different values (hkl). In some cases the X-ray fitting diagrams are adjust with two phases, the double perovskite compound and as secondary phase of $\mathrm{Ln}_{2} \mathrm{O}_{3}$ oxide.

The X-ray diffraction study reveals that all the fourteen compounds have monoclinic symmetry and belongs to the space group $\mathrm{P} 21 / \mathrm{n}$ with lattice parameters $\mathrm{a}=\sqrt{2} \mathrm{a}_{\mathrm{p}}, \mathrm{b}=\sqrt{2} \mathrm{a}_{\mathrm{p}}, \mathrm{c}=2 \mathrm{a}_{\mathrm{p}}$ and $\beta \sim 90^{\circ}$, being $\mathrm{a}_{\mathrm{p}}$ the lattice parameter of the cubic aristotype, $Z=4$ and $Z B=1$.

Values corresponding to the cell parameters are shown in Table 3.7.

Fig. 3.28 shows the variation of crystal parameters with the rare earth cation ionic radii of the $\mathrm{Sr}_{2} \mathrm{LnSbO}_{6}$. As it expected there was a slight growth of lattice lengths as the ionic radius of the rare earth cation increases. The angular behavior is more erratic. This indicates the existence of distortions in the crystal lattice which will be discussed later with the help of spectroscopic data. 
PrSbSr2O6 Perovskita

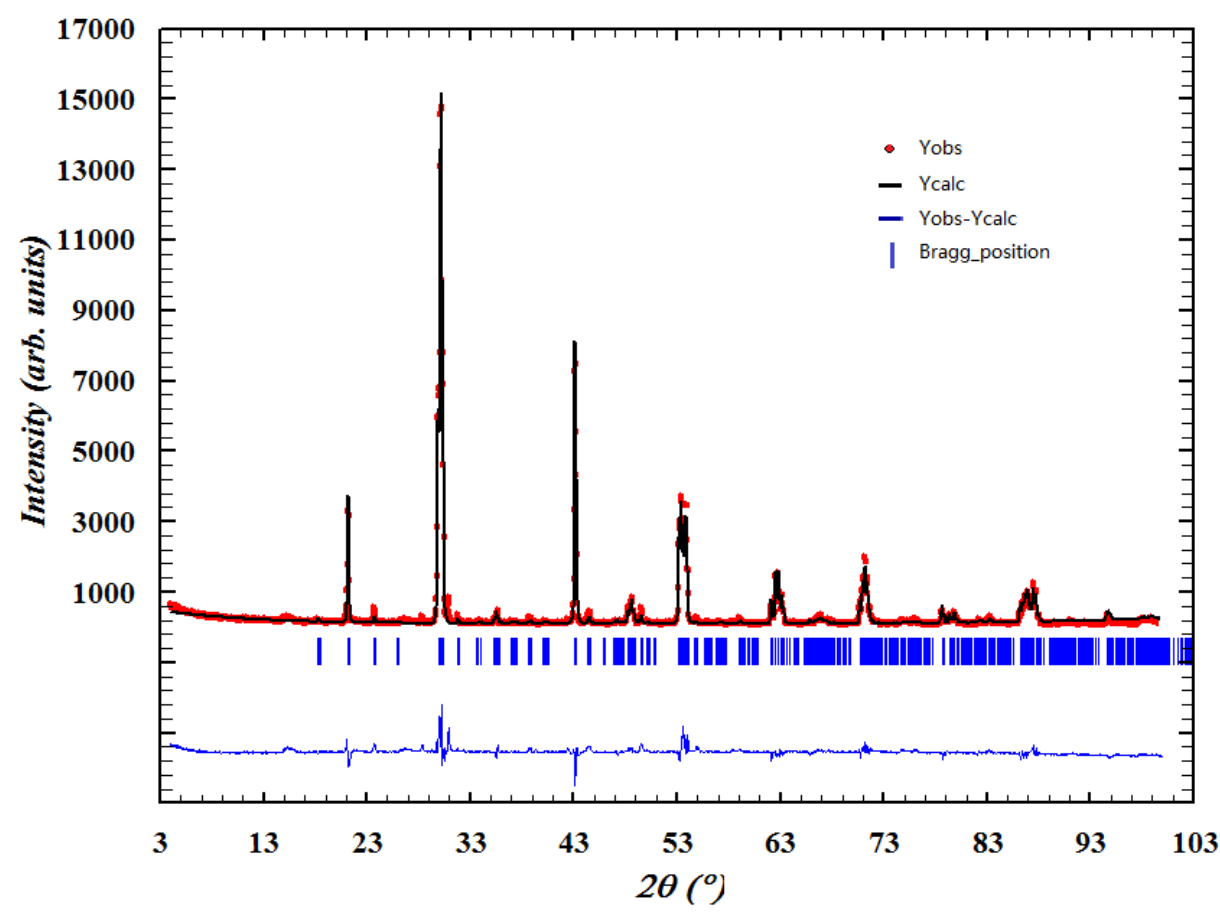

NdSbSr2O6 Perovskita

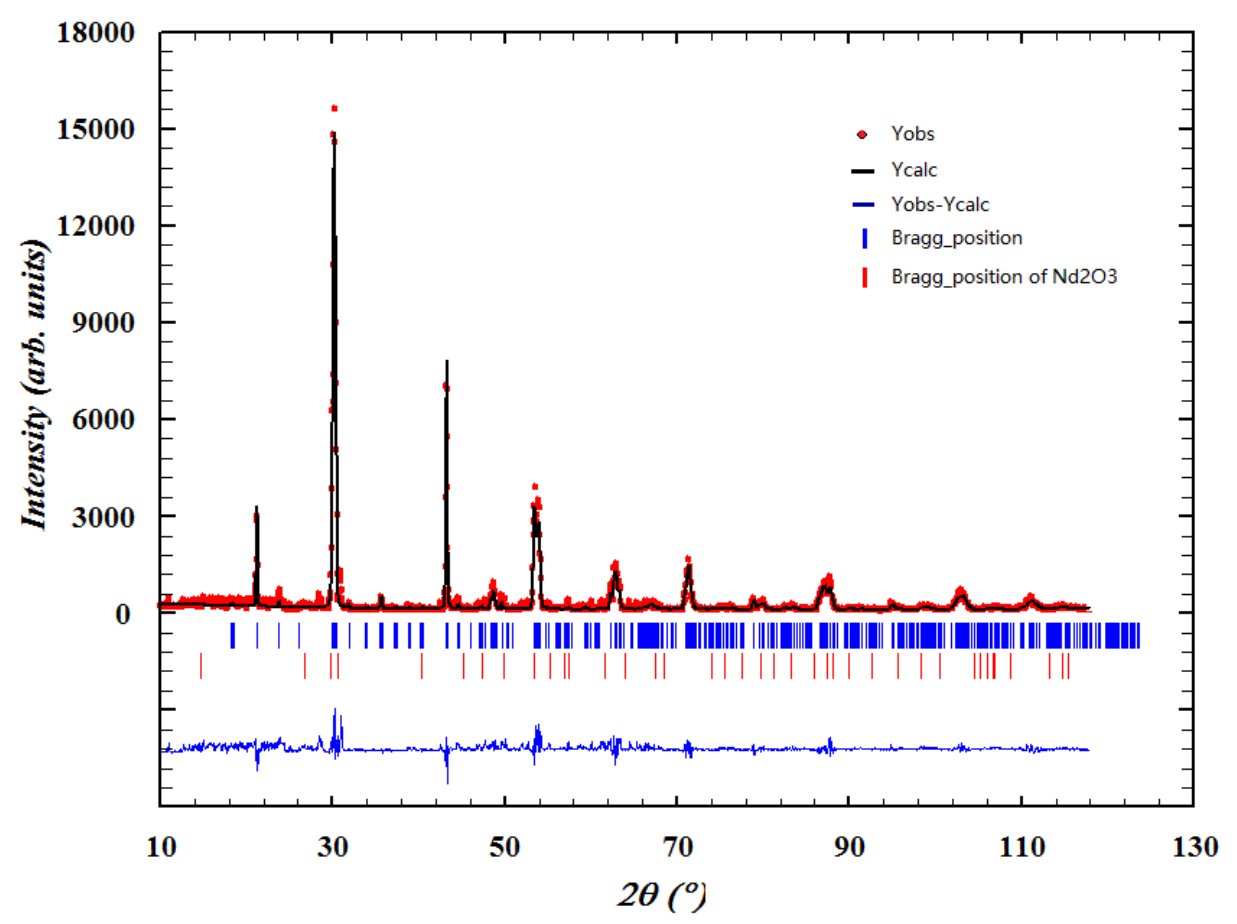




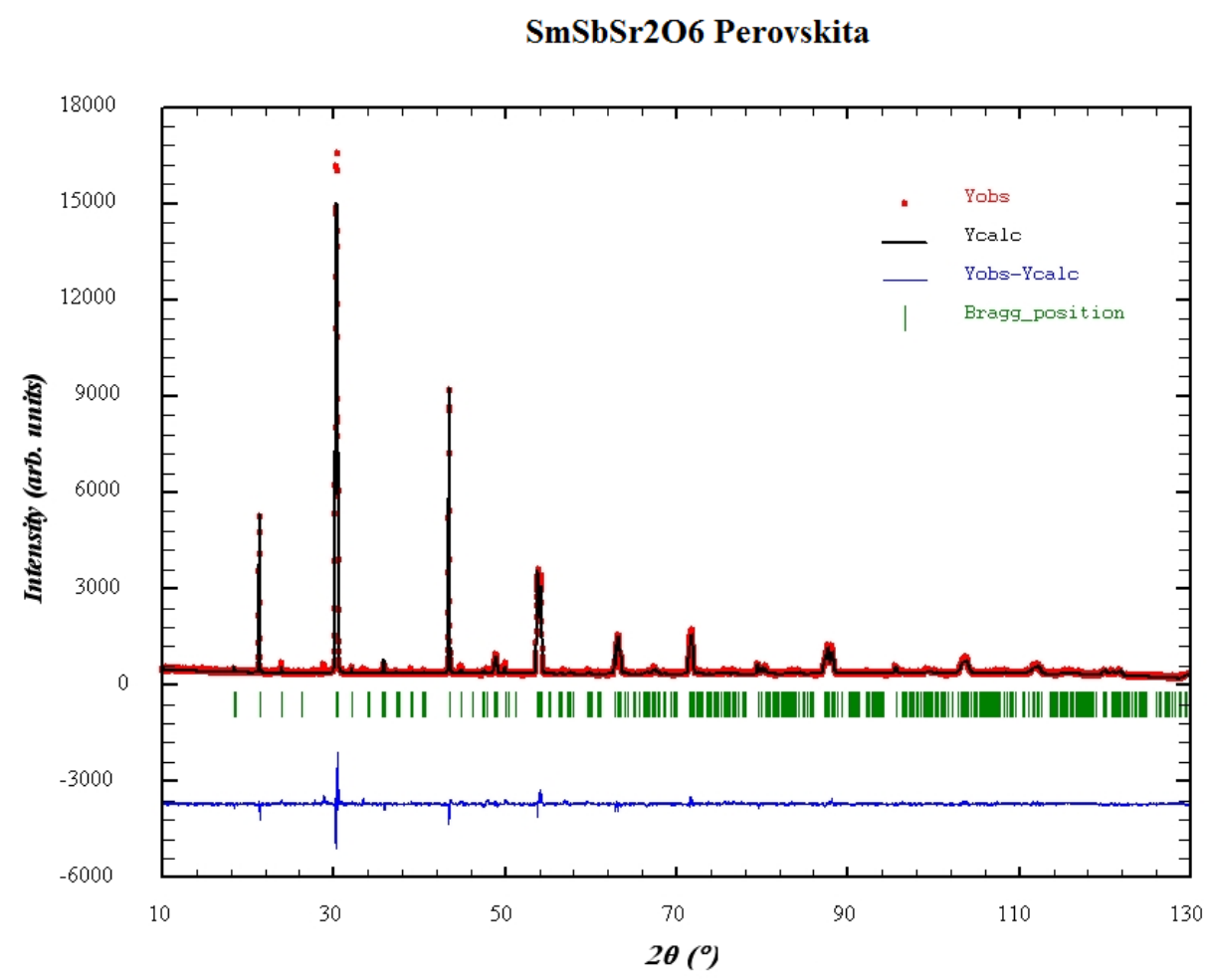

EuSbSr2O6 Perovskita

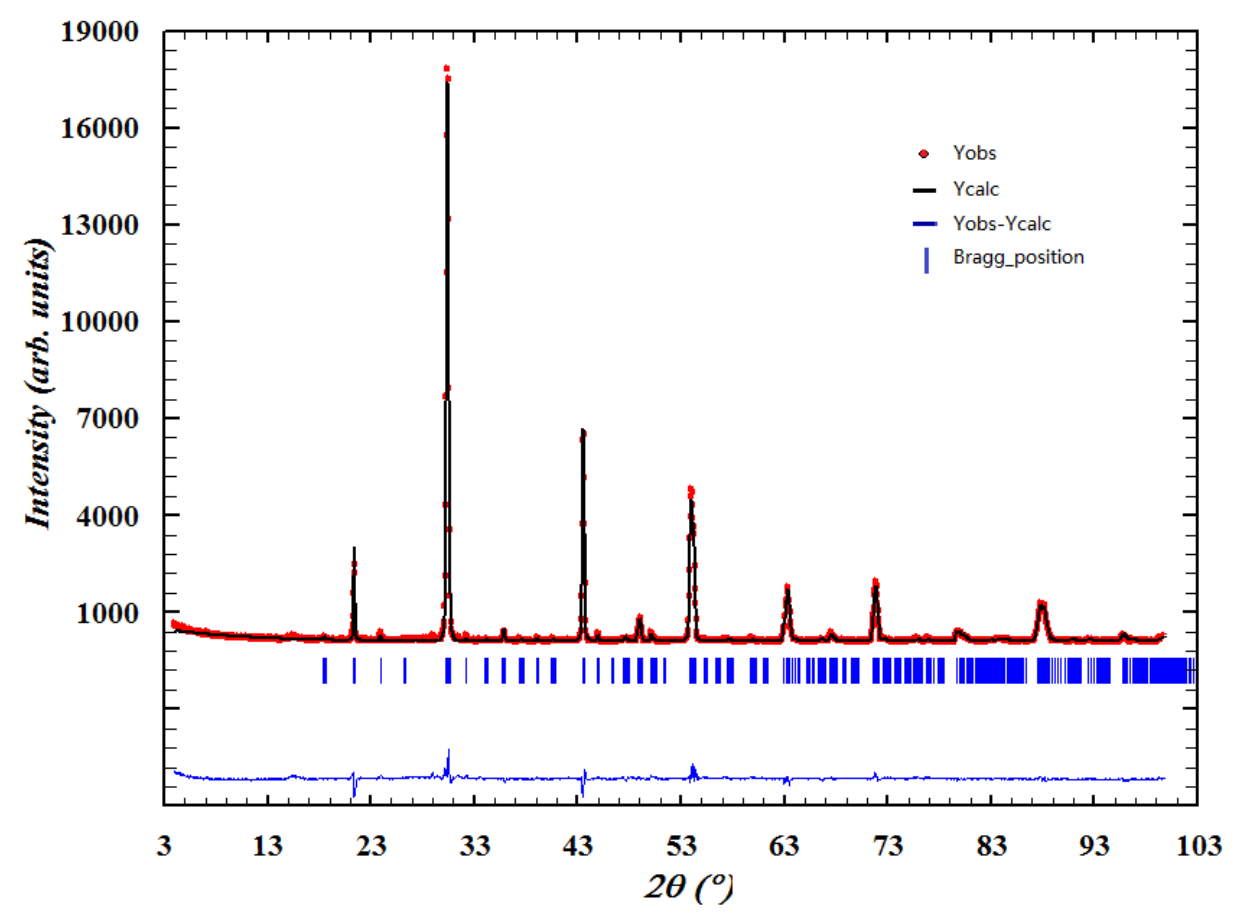




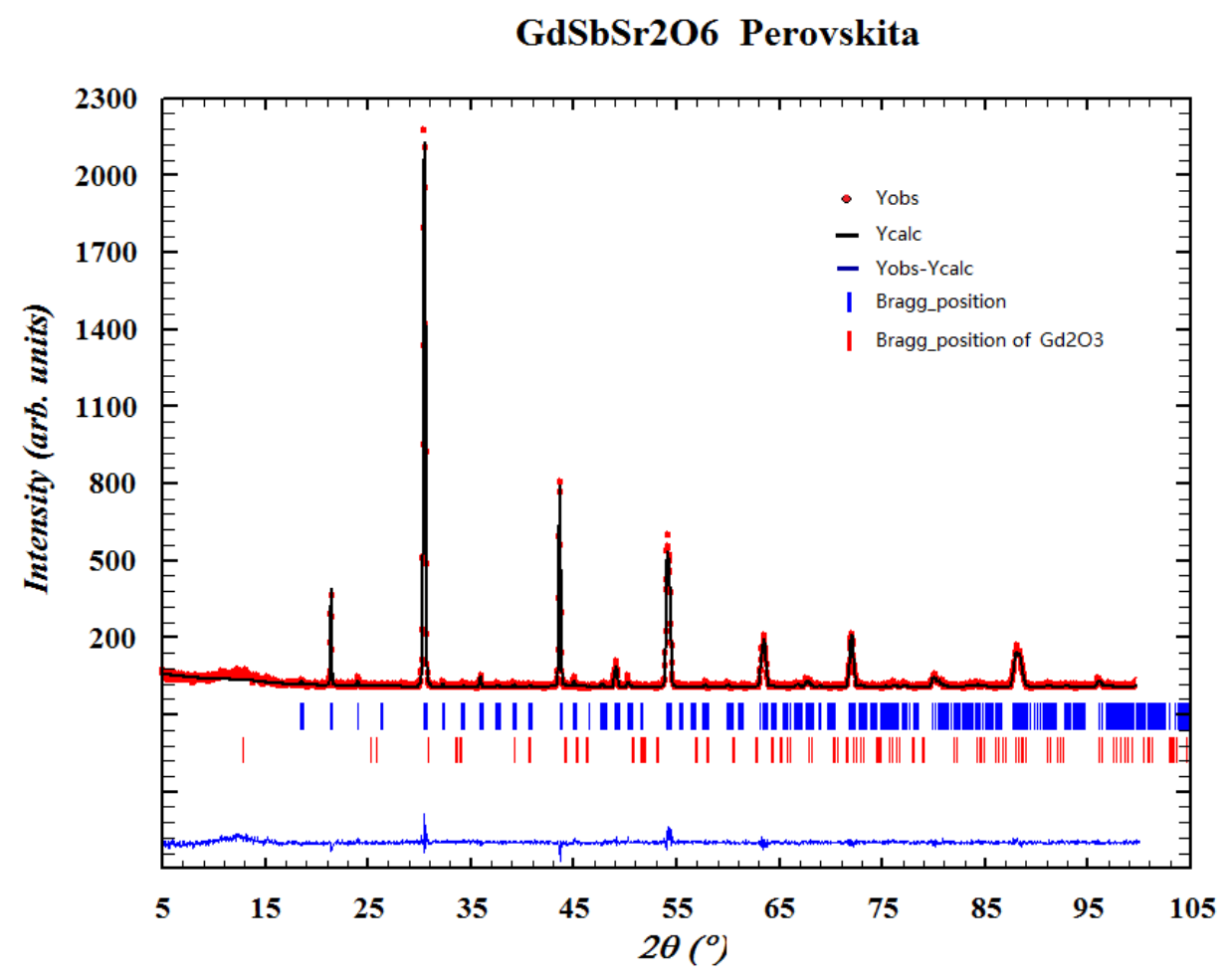

TbSbSr2O6 Perovskita

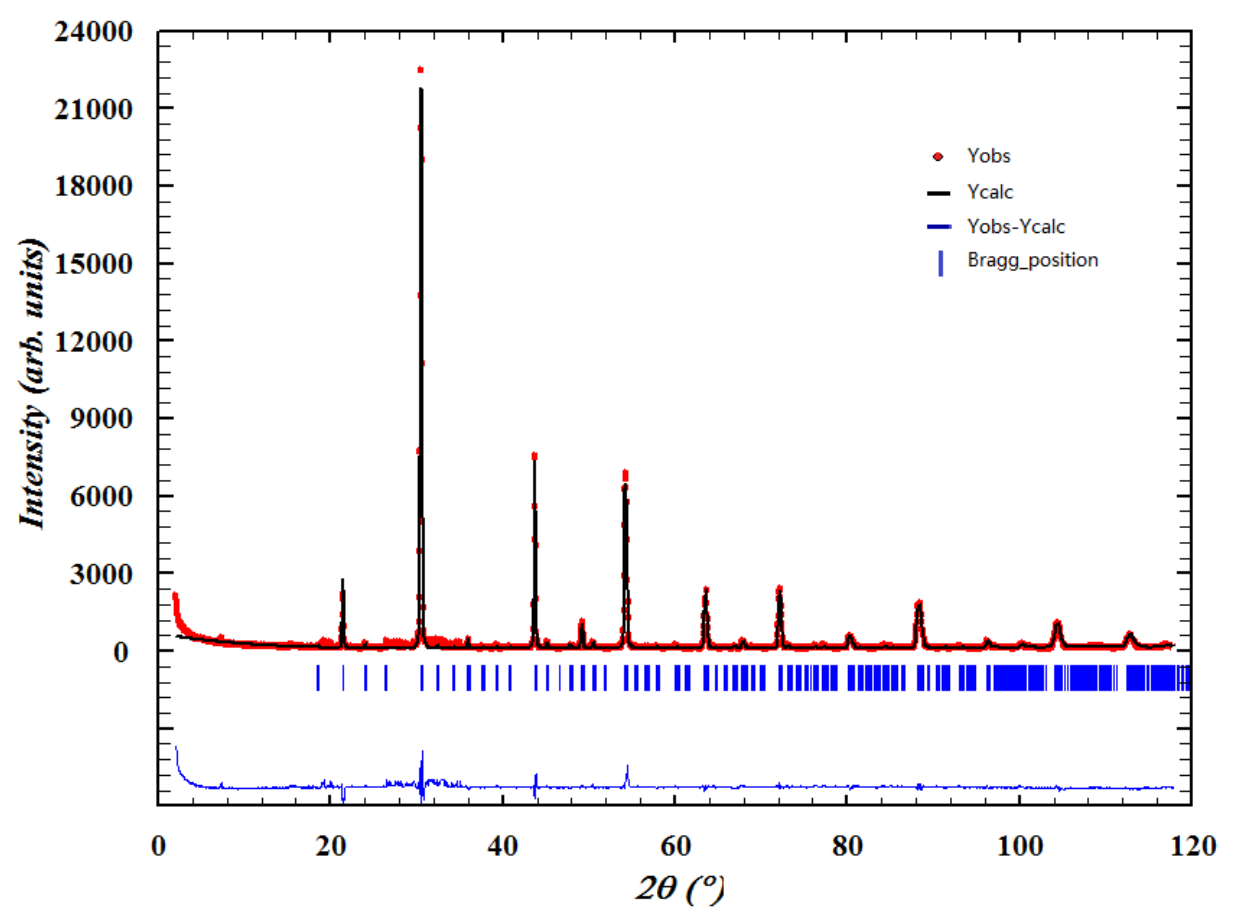


DySbSr206 Perovskita

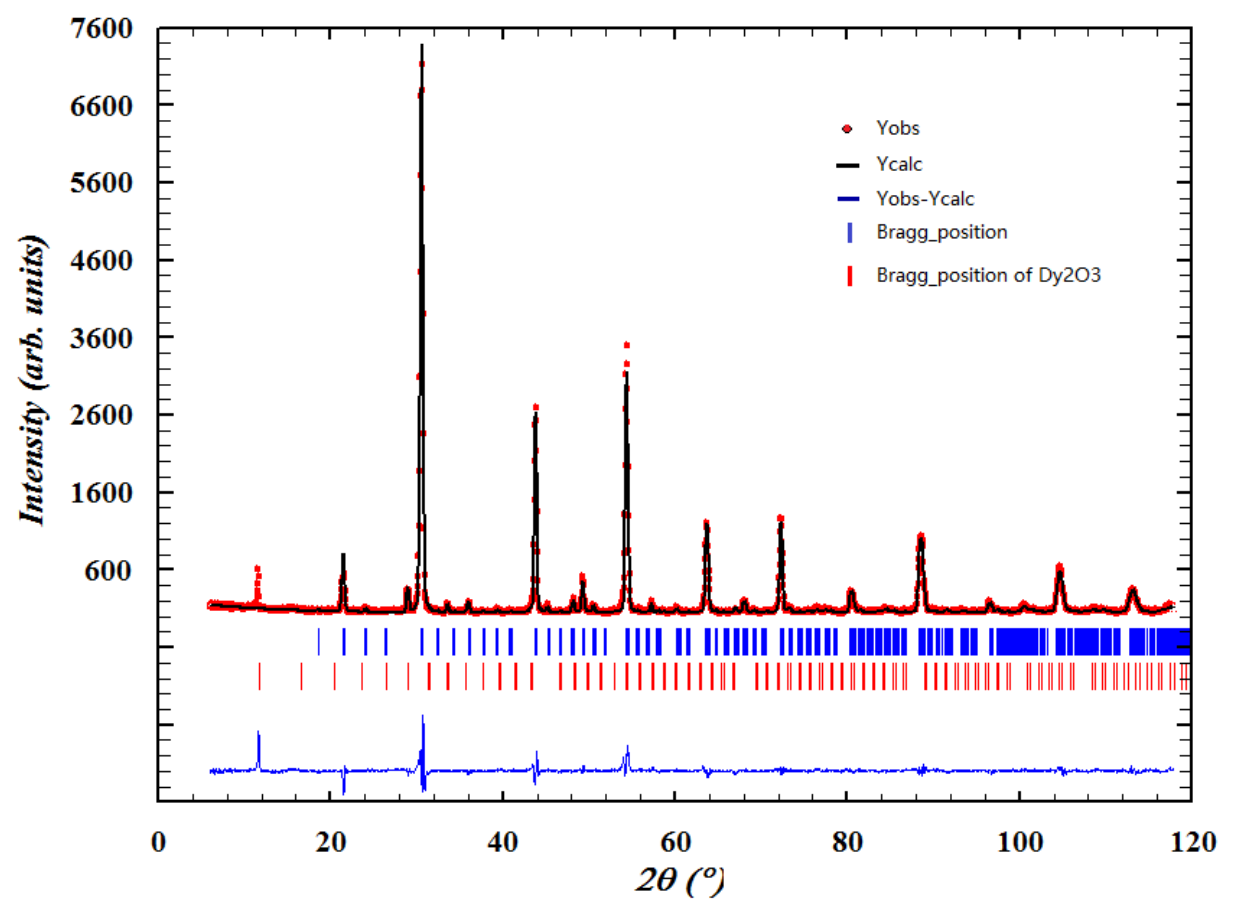

HoSbSr2O6 Perovskita

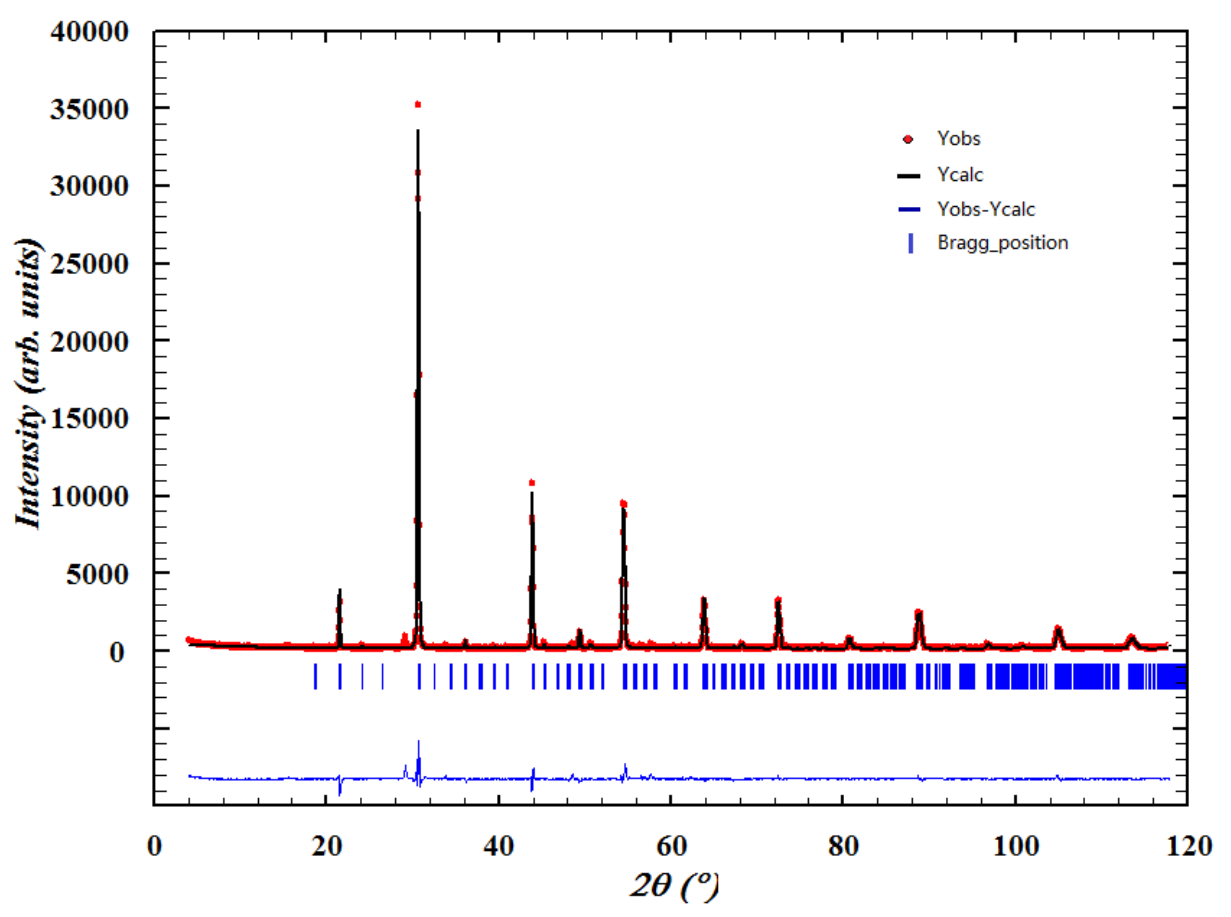


ErSbSr2O6 Perovskita

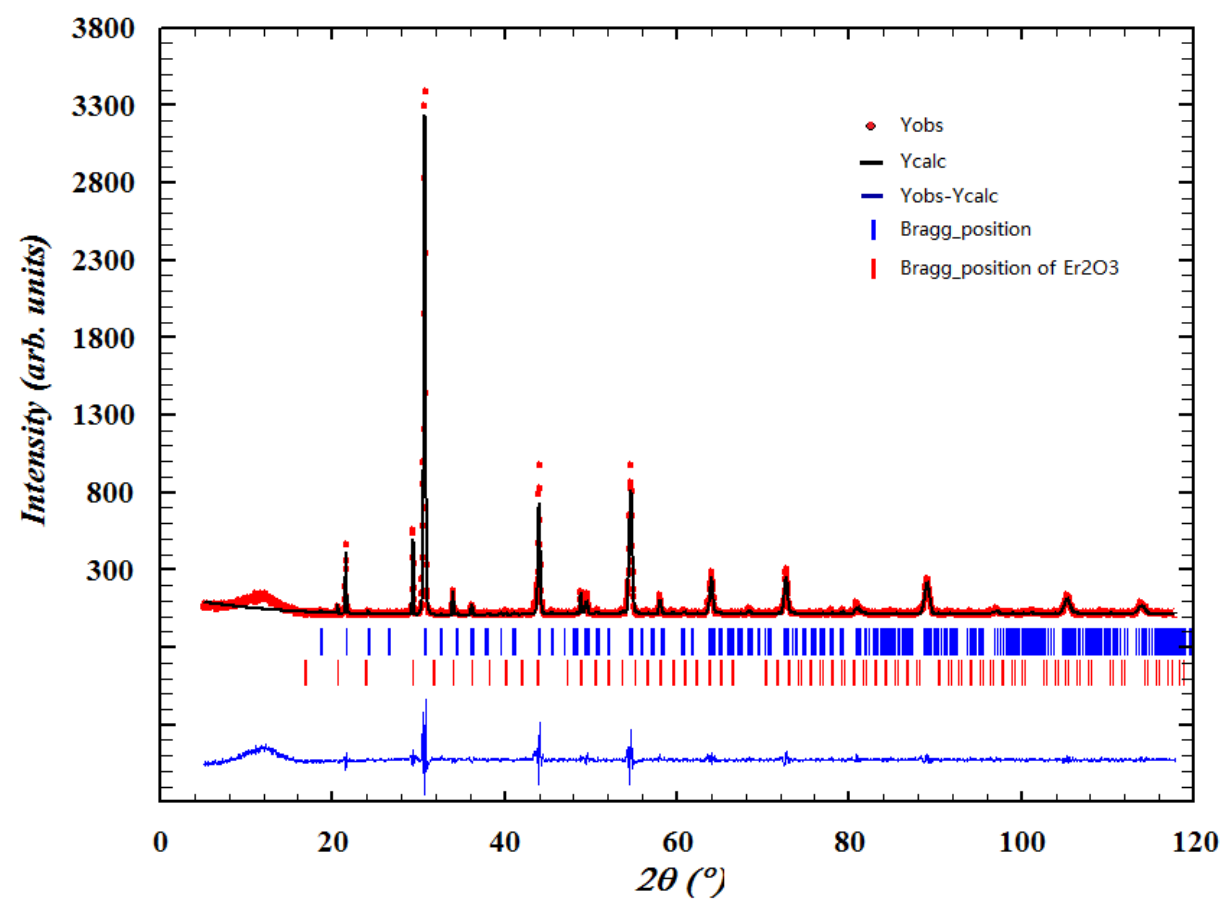

TmSbSr2O6 Perovskita

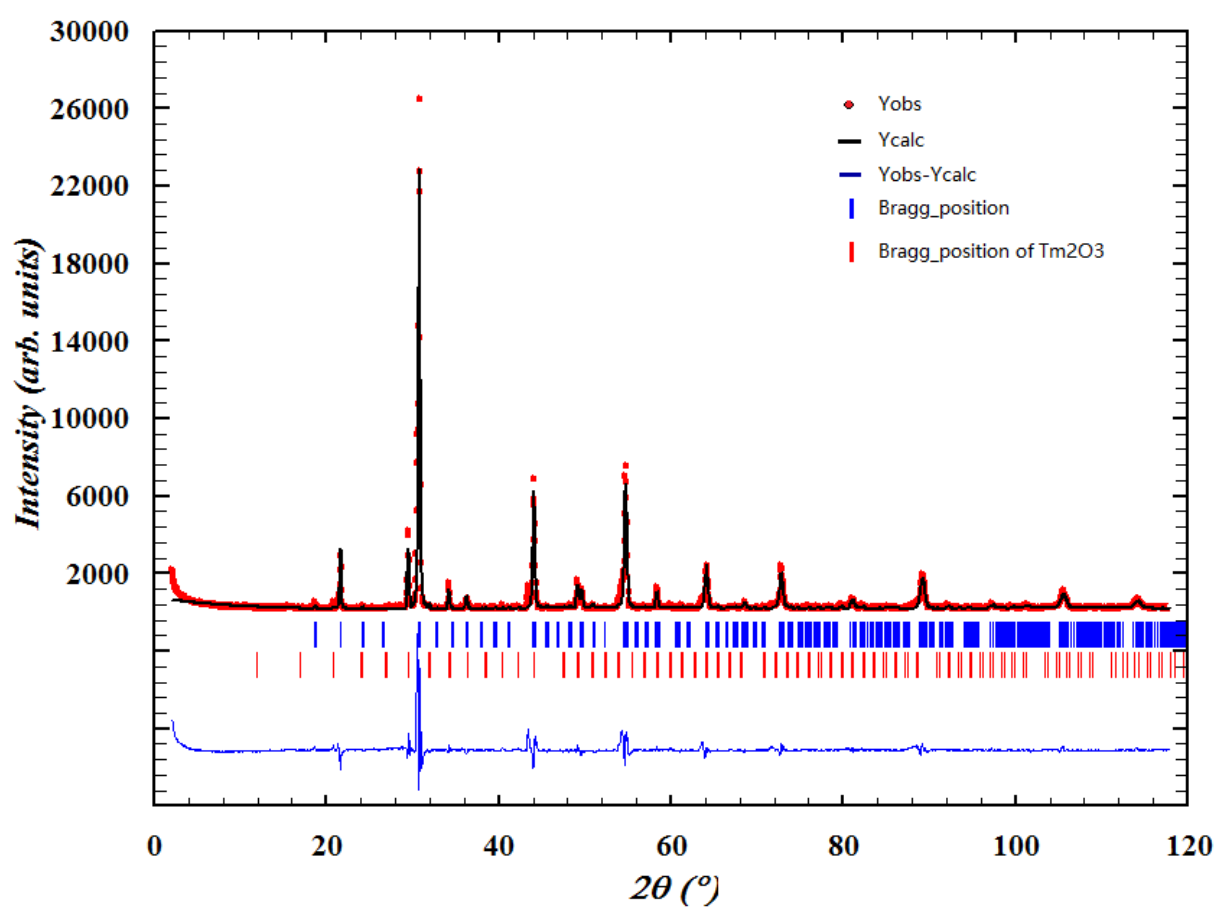


YbSbSr2O6 Perovskita

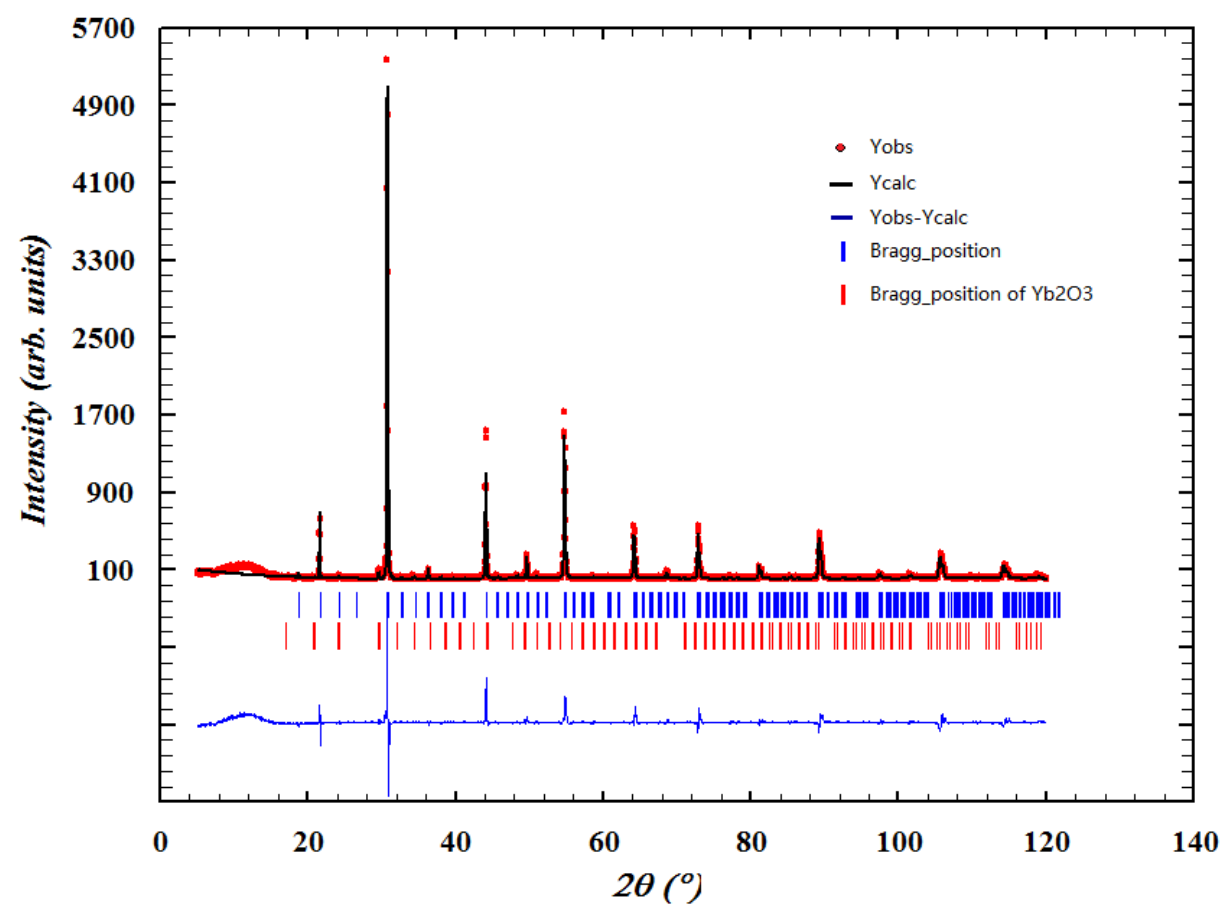

LuSbSr2O6 Perovskita

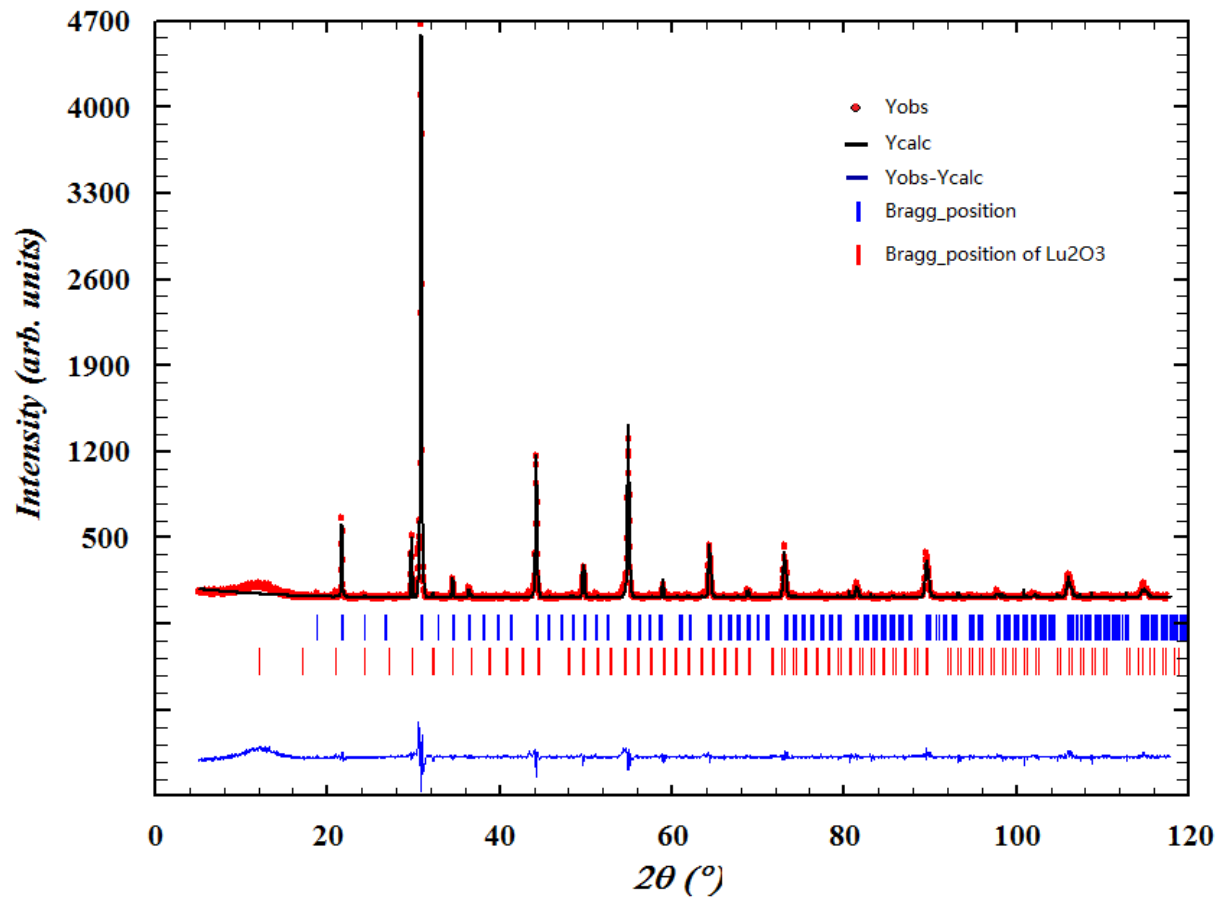




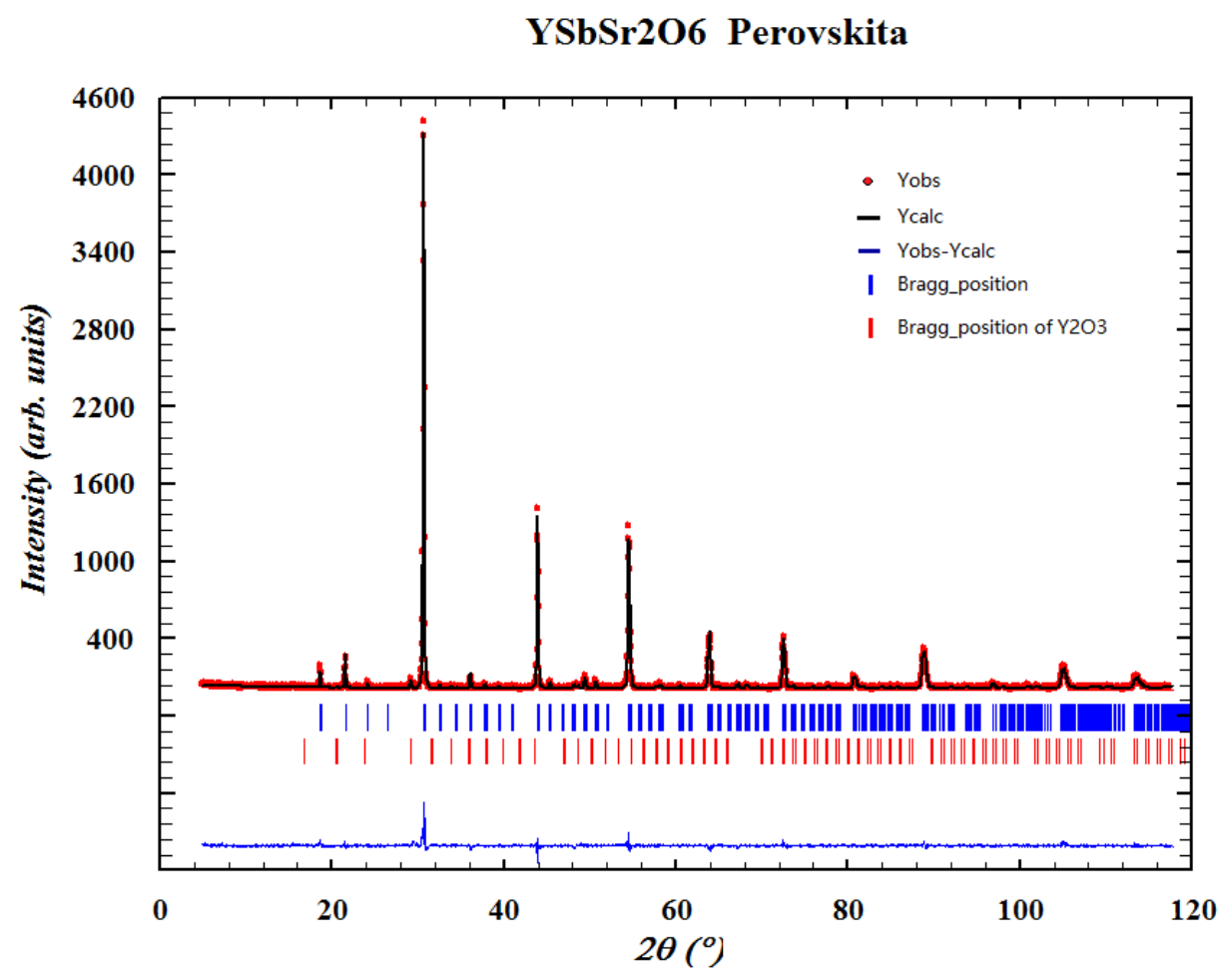

Fig. 3.27 Observed (open symbols) and calculated (straight line) X-ray powder diffraction pattern for $\mathrm{Sr}_{2} \mathrm{LnSbO}_{6}$ compounds. The short vertical lines below the patterns mark the positions of Bragg reflections. The bottom continuous line is the difference between the observed and the calculated intensity. 


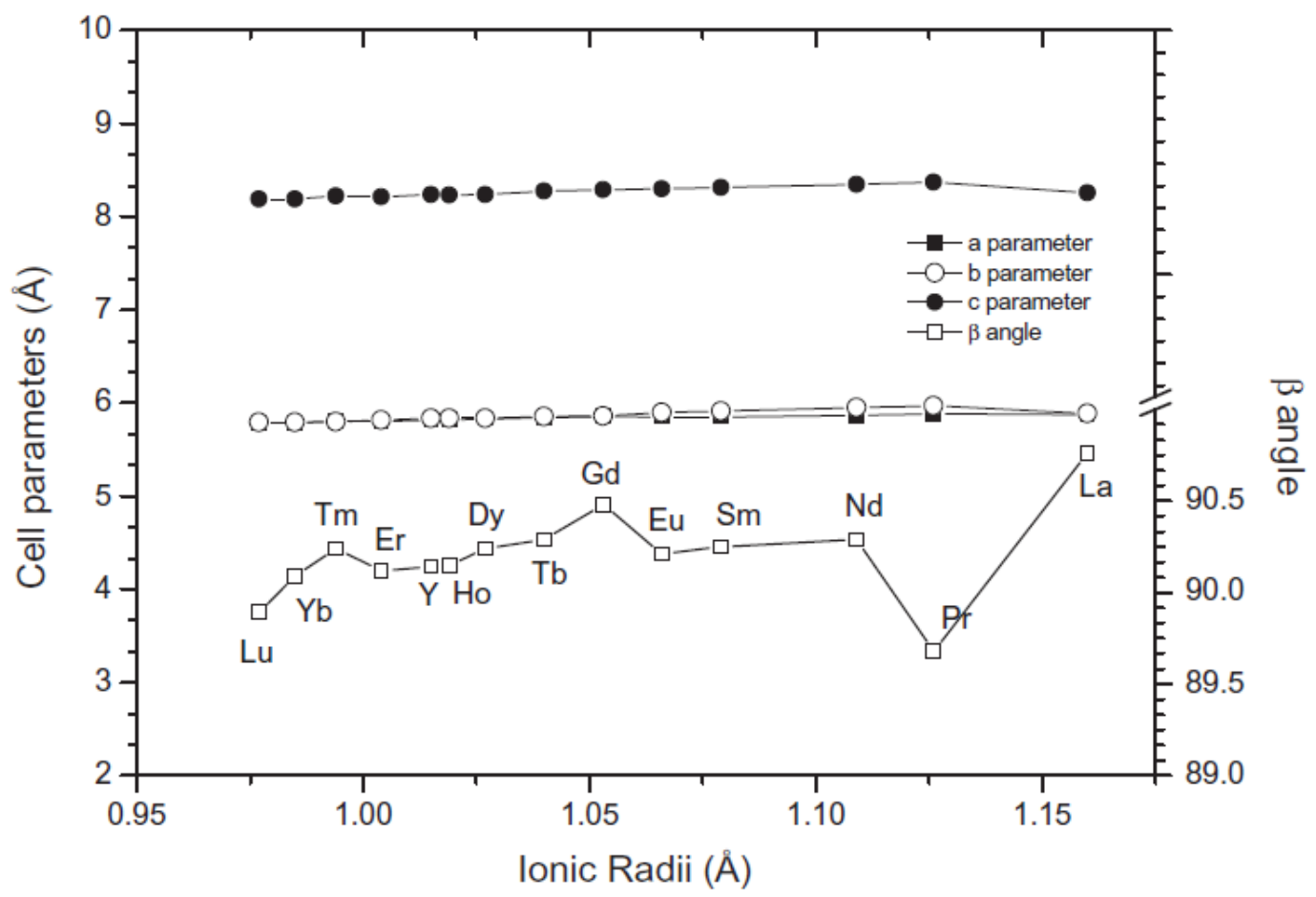

Fig. 3.28 Lattice parameters for $\mathrm{Sr}_{2} \mathrm{RESbO}_{6}$ versus ionic radius of the rare earth.

Table 3.7 Unit cell parameters and volume, obtained for different compounds $\mathrm{LnSbSrO}_{6}(\mathrm{Ln}=\mathrm{La}$ to $\mathrm{Lu}$ and $\mathrm{Y})$.

\begin{tabular}{lllllll}
\hline $\mathrm{Ln}$ & $\mathrm{a}(\AA)$ & $\mathrm{b}(\AA)$ & $\mathrm{c}(\AA)$ & $\beta\left({ }^{\circ}\right)$ & $\mathrm{V}\left(\AA^{3}\right)$ & $\mathrm{Chi}^{2}$ \\
\hline $\mathrm{La}$ & $5.874(18)$ & $5.891(23)$ & $8.256(23)$ & $90.76(10)$ & $285.6(20)$ & 5.01 \\
$\mathrm{Pr}$ & $5.8837(5)$ & $5.9724(4)$ & $8.3739(8)$ & $89.68(6)$ & $294.25(4)$ & 6.04 \\
$\mathrm{Nd}$ & $5.868(7)$ & $5.9518(6)$ & $8.348(10)$ & $90.29(7)$ & $291.54(6)$ & 5.01 \\
$\mathrm{Sm}$ & $5.8534(1)$ & $5.9128(1)$ & $8.3128(1)$ & $90.25(8)$ & $287.7(8)$ & 5.23 \\
$\mathrm{Eu}$ & $5.8533(7)$ & $5.8999(6)$ & $8.302(10)$ & $90.21(9)$ & $286.71(6)$ & 5.00 \\
$\mathrm{Gd}$ & $5.857(3)$ & $5.8619(3)$ & $8.2894(4)$ & $90.48(2)$ & $284.59(3)$ & 1.70 \\
$\mathrm{~Tb}$ & $5.844(10)$ & $5.856(10)$ & $8.275(20)$ & $90.29(1)$ & $283.15(9)$ & 6.12 \\
$\mathrm{Dy}$ & $5.834(10)$ & $5.84(10)$ & $8.239(10)$ & $90.24(1)$ & $280.75(9)$ & 3.31 \\
$\mathrm{Y}$ & $5.8169(6)$ & $5.8362(5)$ & $8.234(10)$ & $90.14(1)$ & $279.69(6)$ & 1.43 \\
$\mathrm{Ho}$ & $5.8194(6)$ & $5.8396(5)$ & $8.239(10)$ & $90.14(8)$ & $279.97(6)$ & 4.58 \\
$\mathrm{Er}$ & $5.8047(2)$ & $5.8202(2)$ & $8.2168(3)$ & $90.12(2)$ & $277.6(2)$ & 2.55 \\
$\mathrm{Tm}$ & $5.804(20)$ & $5.801(20)$ & $8.225(20)$ & $90.24(2)$ & $276.9(20)$ & 4.02 \\
$\mathrm{Yb}$ & $5.7896(4)$ & $5.7966(3)$ & $8.1895(5)$ & $90.09(4)$ & $274.83(3)$ & 4.07 \\
$\mathrm{Lu}$ & $5.79057(0)$ & $5.79703(0)$ & $8.19302(0)$ & $89.89(0)$ & $273.94(0)$ & 4.44 \\
\hline
\end{tabular}




\subsubsection{Vibrationalstudy byFTIR and Raman spectral.}

The FT-Raman and FT-IR spectra of the $\mathrm{Sr}_{2} \mathrm{RESbO}_{6}$ samples are shown in Fig. 3.29. The observed wavelength numbers of the bands $\left(\mathrm{cm}^{-1}\right)$ in the Raman spectra, their relative intensities and band assignments are given in Table 3.8. The IR bands characteristics of the samples are also tabulated in Table 3.8.

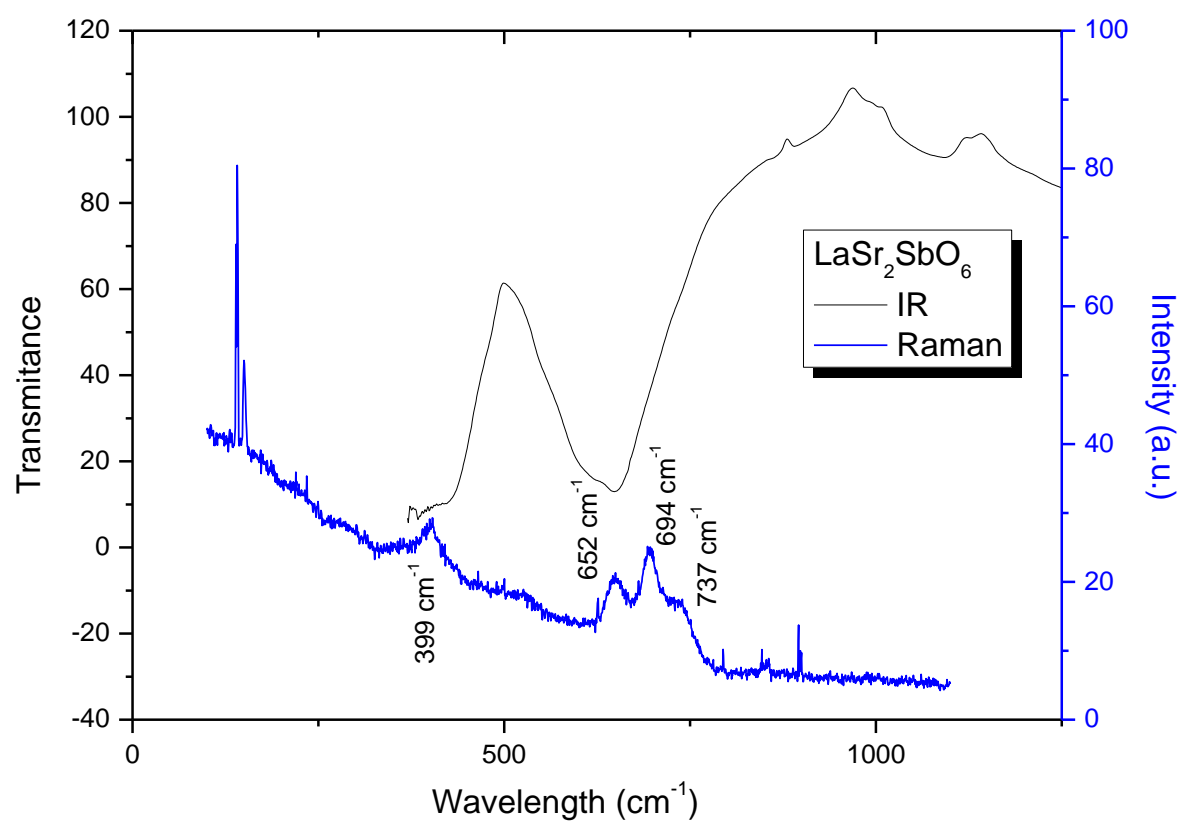

Fig. 3.29 a. The FT-IR and Raman spectra of $\mathrm{Sr}_{2} \mathrm{LaSbO}_{6}$ compounds. 

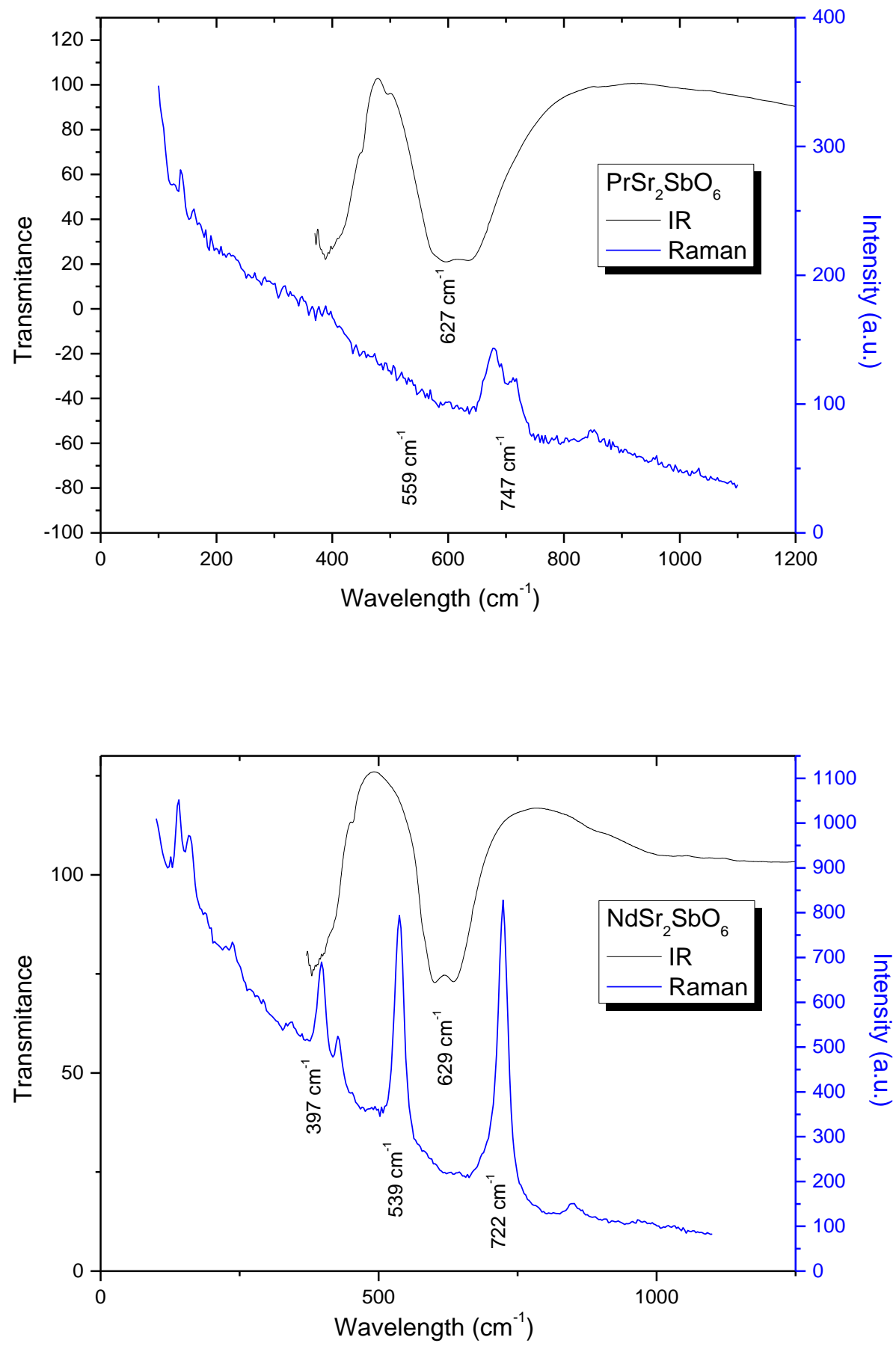

Fig. 3.29 b The FT-IR and Raman spectra of $\mathrm{Sr}_{2} \mathrm{LnSbO}_{6}$ (when $\mathrm{Ln}=\mathrm{Pr}$ and $\mathrm{Nd}$ ) compounds. 

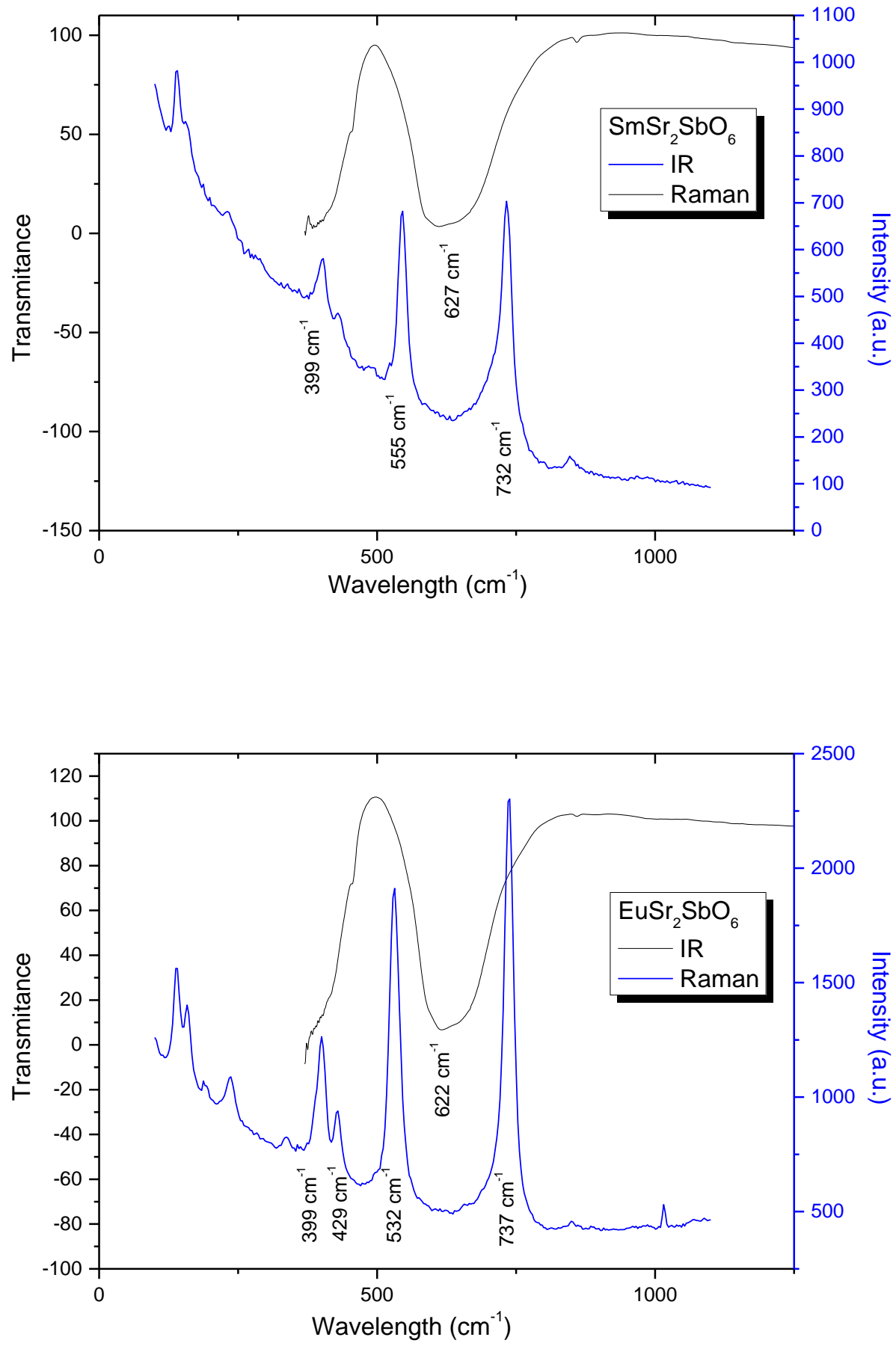

Fig. 3.29 c The FT-IR and Raman spectra of $\mathrm{Sr}_{2} \mathrm{LnSbO}_{6}$ (when $\mathrm{Ln}=\mathrm{Sm}$ and $\mathrm{Eu}$ ) compounds. 

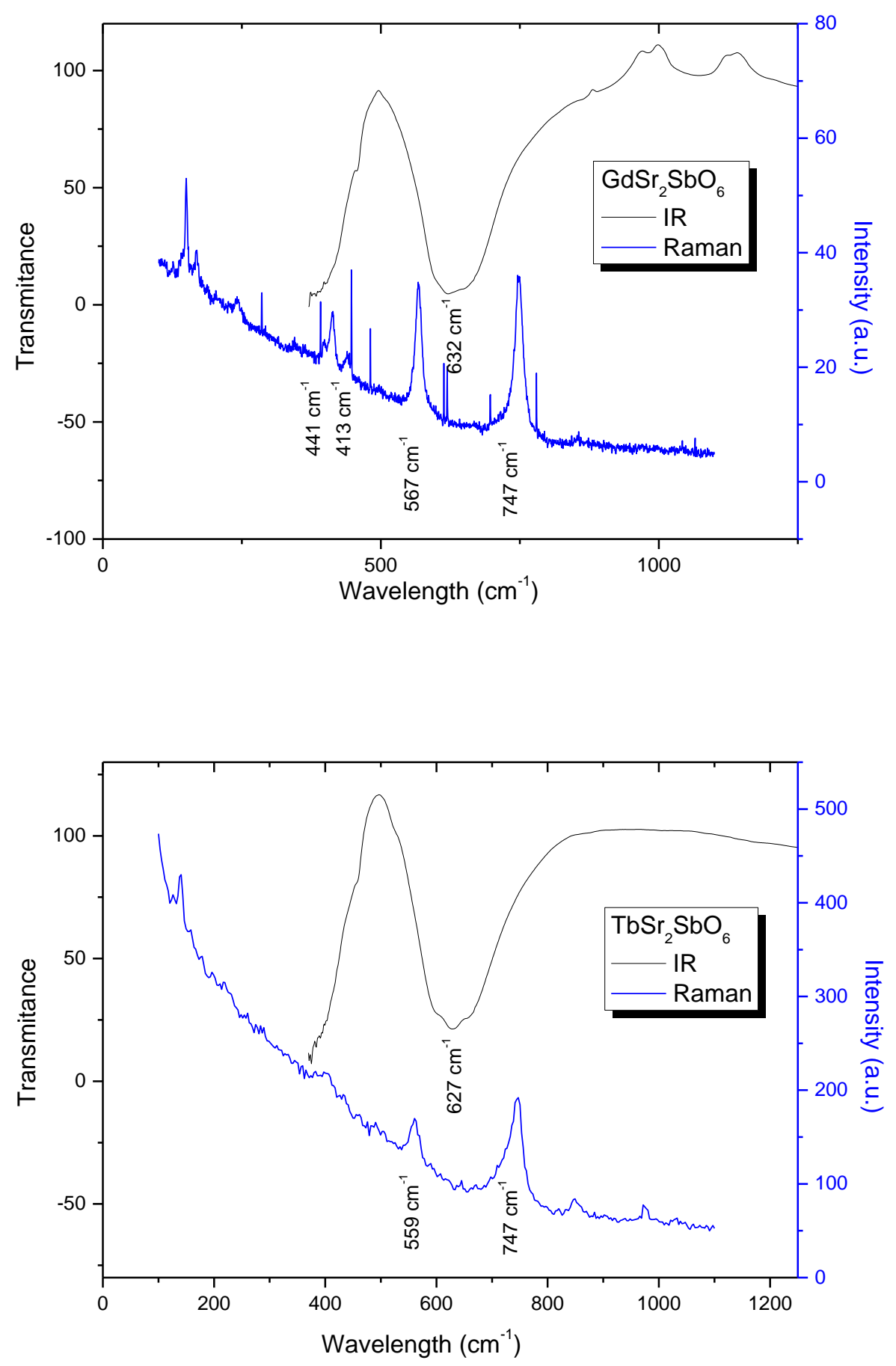

Fig. $3.29 \mathrm{~d}$ The FT-IR and Raman spectra of $\mathrm{Sr}_{2} \mathrm{LnSbO}_{6}$ (when $\mathrm{Ln}=\mathrm{Gd}$ and $\mathrm{Tb}$ ) compounds. 

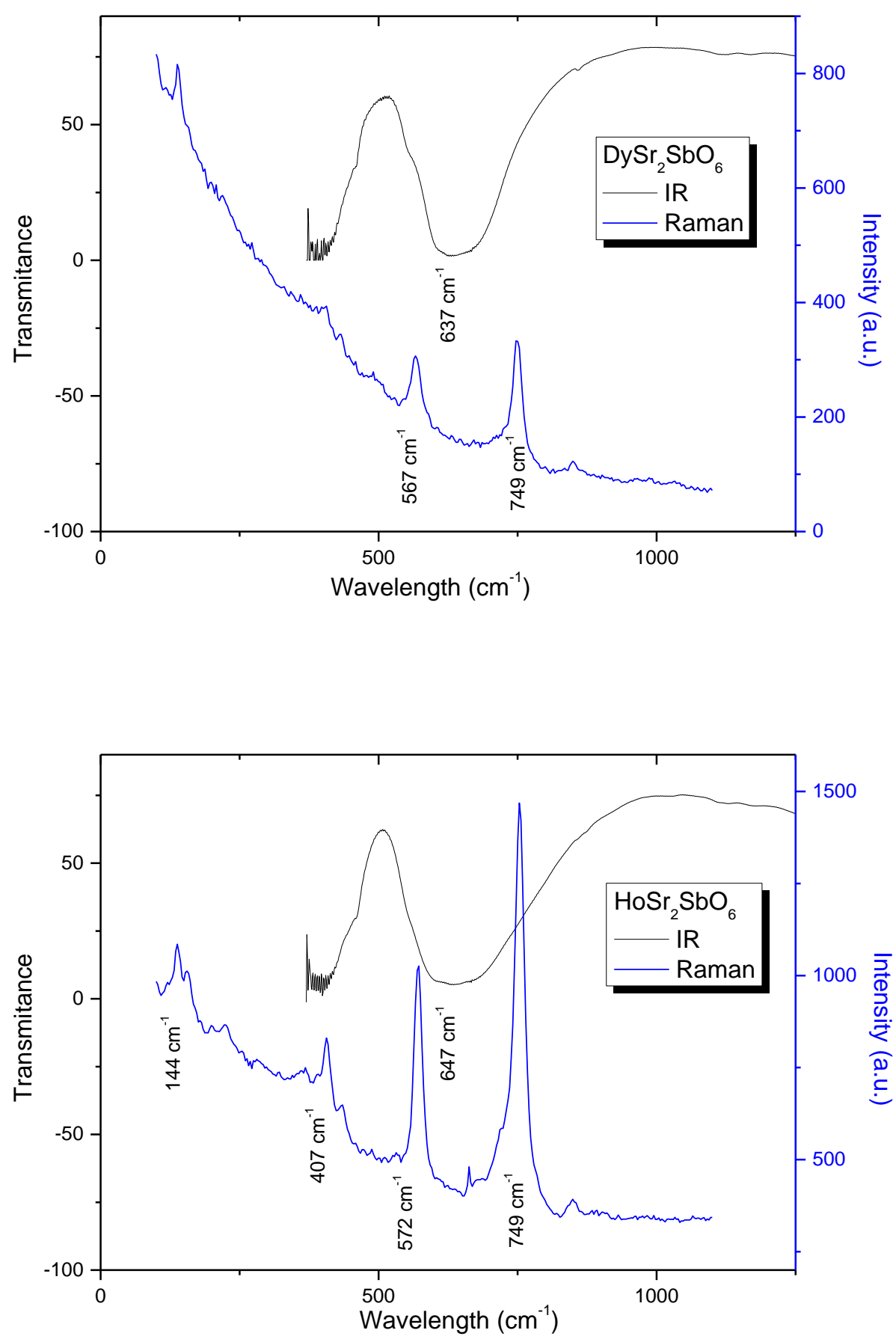

Fig. 3.29 e The FT-IR and Raman spectra of $\mathrm{Sr}_{2} \mathrm{LnSbO}_{6}$ (when $\mathrm{Ln}=\mathrm{Dy}$ and $\mathrm{Ho}$ ) compounds. 

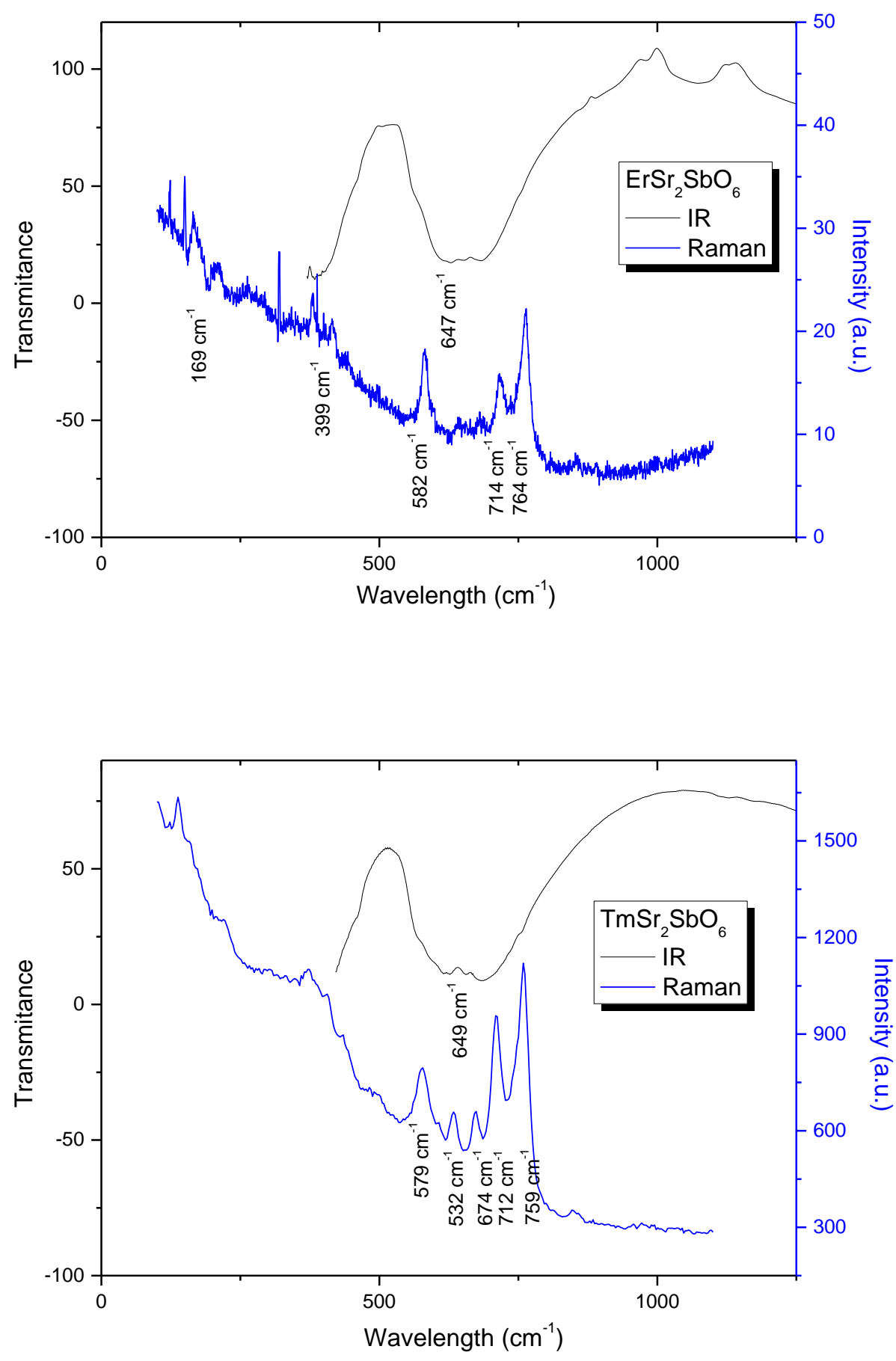

Fig. $3.29 \mathrm{f}$ The FT-IR and Raman spectra of $\mathrm{Sr}_{2} \mathrm{LnSbO}_{6}$ (when $\mathrm{Ln}=\mathrm{Er}$ and $\mathrm{Tm}$ ) compounds. 

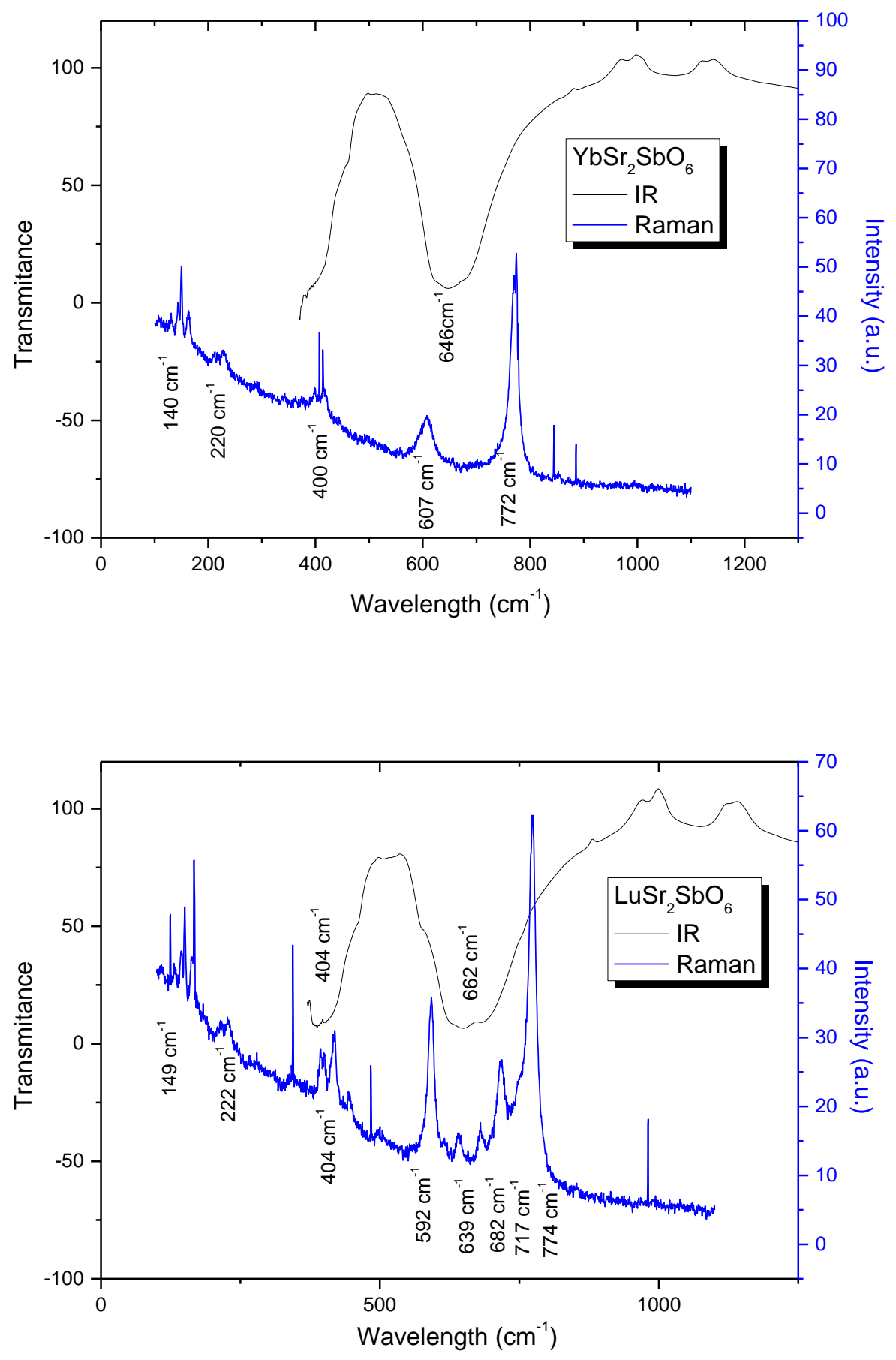

Fig. $3.29 \mathrm{~g}$ The FT-IR and Raman spectra of $\mathrm{Sr}_{2} \mathrm{LnSbO}_{6}$ (when $\mathrm{Ln}=\mathrm{Yb}$ and $\mathrm{Lu}$ ) compounds. 


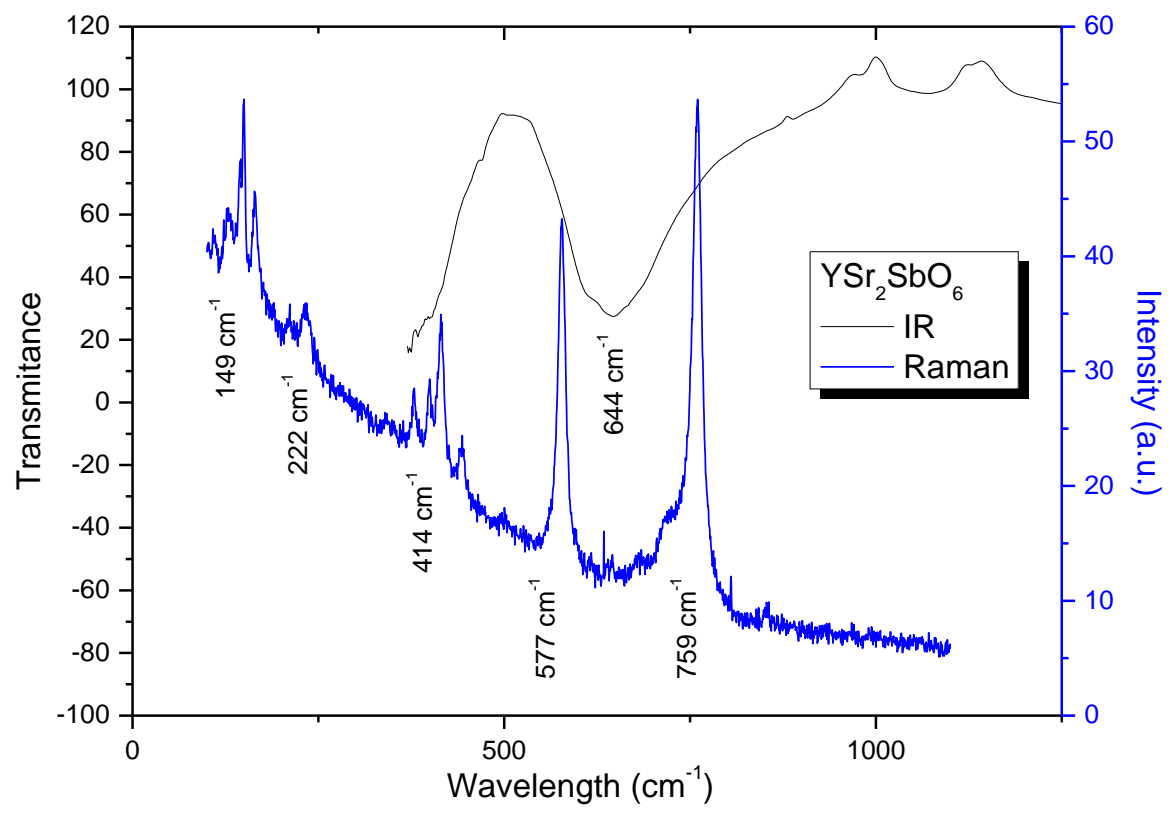

Fig. 3.29 h The FT-IR and Raman spectra of $\mathrm{Sr}_{2} \mathrm{YSbO}_{6}$ compounds.

In all cases the Raman spectra show several strong modes (as example 759, 577,414 and $147 \mathrm{~cm}^{-1}$ in the Yttrium sample and others weaker features.

These modes are similar to those found in the Raman spectrum of $\mathrm{Ba}_{2} \mathrm{YSbO}_{6}$ obtained by Vijayakumaret etc. [10]. They established that the space group is Fm3m cubic group. This author found four strong modes at 760, 572, 380 and $108 \mathrm{~cm}^{-1}$ that were attributed to the four Raman active modes, $A_{1 g}, E_{g}$ and two $\mathrm{T}_{2 \mathrm{~g}}$ modes, predicted by the theoretical analysis for the Fm3m cubic group. In addition, an Infrared band at around $691 \mathrm{~cm}^{-1}$ is attributed to the cubic mode $\mathrm{T}_{1 \mathrm{u}}$ only Infrared-active.

In our case the corresponding $T_{2 g}$ triplet around the $414 \mathrm{~cm}^{-1}$ has been split into its components and seems to be also active in the infrared. In addition, abroad infrared band is placed around the $644 \mathrm{~cm}^{-1}$. This band seems to be analogous to the band at $691 \mathrm{~cm}^{-1}$ of $\mathrm{Ba}_{2} \mathrm{YSbO}_{6}$, but it is compatible with an overlap of several vibration modes.

When $\mathrm{Ba}$ is substituted by $\mathrm{Sr}$, the changes in the Raman and IR spectra are a further indication of the monoclinic structure of $\mathrm{Sr}_{2} \mathrm{YSbO}_{6}$. Table 3.9 presents the 
different selection rules, the frequencies of the observed modes and the correlations between the modes of the cubic and monoclinic phase. The bands located at 759, 577,414 and $147 \mathrm{~cm}^{-1} \mathrm{can}$ be assigned to different modes for the group P2 ${ }_{1}$ (see Table 3.9). As mentioned above the infrared band at $644 \mathrm{~cm}^{-1}$ is extremely broad. It could be assigned to an overlap between $A_{u}+2 B_{u}$ modes (from the splitting of cubic mode $\mathrm{T}_{14}$ ), and $\mathrm{A}_{g}$ and $\mathrm{B}_{g}$ modes which are Infrared-allowed in the monoclinic case.

In this sample, it is also important to note that in the Raman spectrum at around $414 \mathrm{~cm}^{-1}$ we can be observed at least four bands attributable not only to the splitting of the triplet $\mathrm{T}_{2 \mathrm{~g}}$. These bands should be assigned to an overlap of $A_{g}+B_{g}$ modes with the $A_{u}+B_{u}$ modes (derived respectively from the cubic $T_{2 g}$ and $\mathrm{T}_{2 u}$ ). On the contrary, in $\mathrm{Ba}_{2} \mathrm{YSbO}_{6}$ sample [3.54] $\mathrm{T}_{2 u}$ cubic mode is Raman-forbidden and it appears only weakly, close to the $T_{2 g}$ mode located at $380 \mathrm{~cm}^{-1}$, probably due to distortions of the cubic crystal structure. In our case this mode is split and the corresponding monoclinic modes $\left(A_{u}+B_{u}\right)$ are Raman-allowed and overlap with $\mathrm{A}_{\mathrm{g}}+\mathrm{B}_{\mathrm{g}}$ modes.

In other samples, the picture is similar although there are some features that should be indicated. $\mathrm{Sr}_{2} \mathrm{TmSbO}_{6}$ Raman spectrum shows several additional bands at 712, 674 and $632 \mathrm{~cm}^{-1}$. They correspond to the $A_{u}+2 B u$ modes (from $T_{14}$ cubic mode) showing Raman activity due to possible distortion of the monoclinic cell. Similar weaker additional bands are detected in $\mathrm{Sr}_{2} \mathrm{ErSbO}_{6}$ and $\mathrm{Sr}_{2} \mathrm{LuSbO}_{6}$ samples.

The wavenumbers of the $\mathrm{A}_{\mathrm{g}}$ mode increases as the rare earth changes from $\mathrm{Nd}$ to $L u$ and the RE cation ionic radius decreases (see Fig. 3.30). The small deviations about this behavior corresponds to $Y$ and $T m$. In the case of $Y$, it was expected some kind of discrepancy. The Raman spectrum of Tm sample (Fig.3.29) shows the distortion of the monoclinic cell more developed.

In $\mathrm{Sr}_{2} \mathrm{LaSbO}_{6}$ and $\mathrm{Sr}_{2} \mathrm{PrSbO}_{6}$ samples, Raman spectra are different to that presented by all other samples. Several attempts to assign bands to different modes of distortions of the monoclinic cell have been inconclusive. We suggest that additional information is needed on the crystal structure of both samples in 
order to conclude and assign unequivocally the observed vibrational bands. An alternative crystal structure should be searched by neutron diffraction technique.

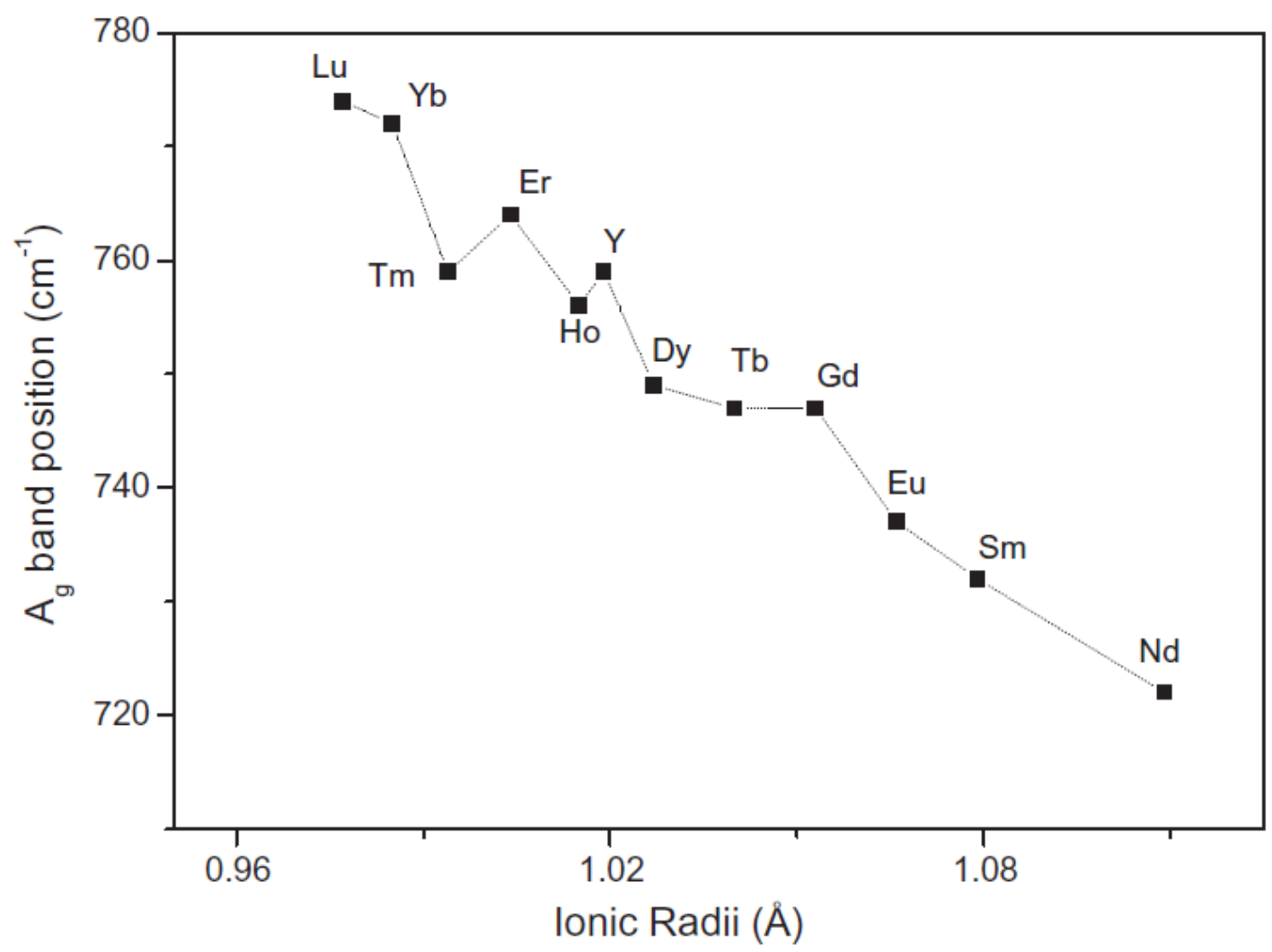

Fig. 3.30 Variation of $\mathrm{Ag}$ mode wave numbers of the $\mathrm{Sr}_{2} \mathrm{RESbO}_{6}(\mathrm{RE}=\mathrm{Nd}, \mathrm{Sm}$, $\mathrm{Eu}, \mathrm{Gd}, \mathrm{Tb}, \mathrm{Dy}, \mathrm{Y}, \mathrm{Ho}, \mathrm{Er}, \mathrm{Tm}, \mathrm{Yb}$, and Lu) vs. ionic radii of the rare earth. 
Table 3.8 The observed bands $\left(\mathrm{cm}^{-1}\right)$, their relative intensities and the band assignments of the Raman and Infrared spectra for $\mathrm{Sr}_{2} \mathrm{RESbO}_{6}(\mathrm{RE}=\mathrm{La}$ to $\mathrm{Lu}$ and $\mathrm{Y})$. A band with wavenumbers followed by $\left(^{*}\right)$ is an unassigned band. A band with wavenumbers in parentheses is a very weak band.

\begin{tabular}{|c|c|c|c|c|c|c|c|c|c|c|c|c|c|}
\hline RE=La & RE=Pr & RE=Nd & RE=Sm & RE=Eu & RE=Gd & RE=Tb & RE=Dy & RE=Y & RE=Ho & RE=Er & RE=Tm & RE=Yb & RE=Lu \\
assignments
\end{tabular}


Table 3.9 Factor group analysis, selection rules and observed optic mode frequencies in $\mathrm{Ba}_{2} \mathrm{YSbO}_{6}$ [3.54] and $\mathrm{Sr}_{2} \mathrm{YSbO}_{6}$. Arrangement of the table indicates correlations between the vibration modes in both phases.

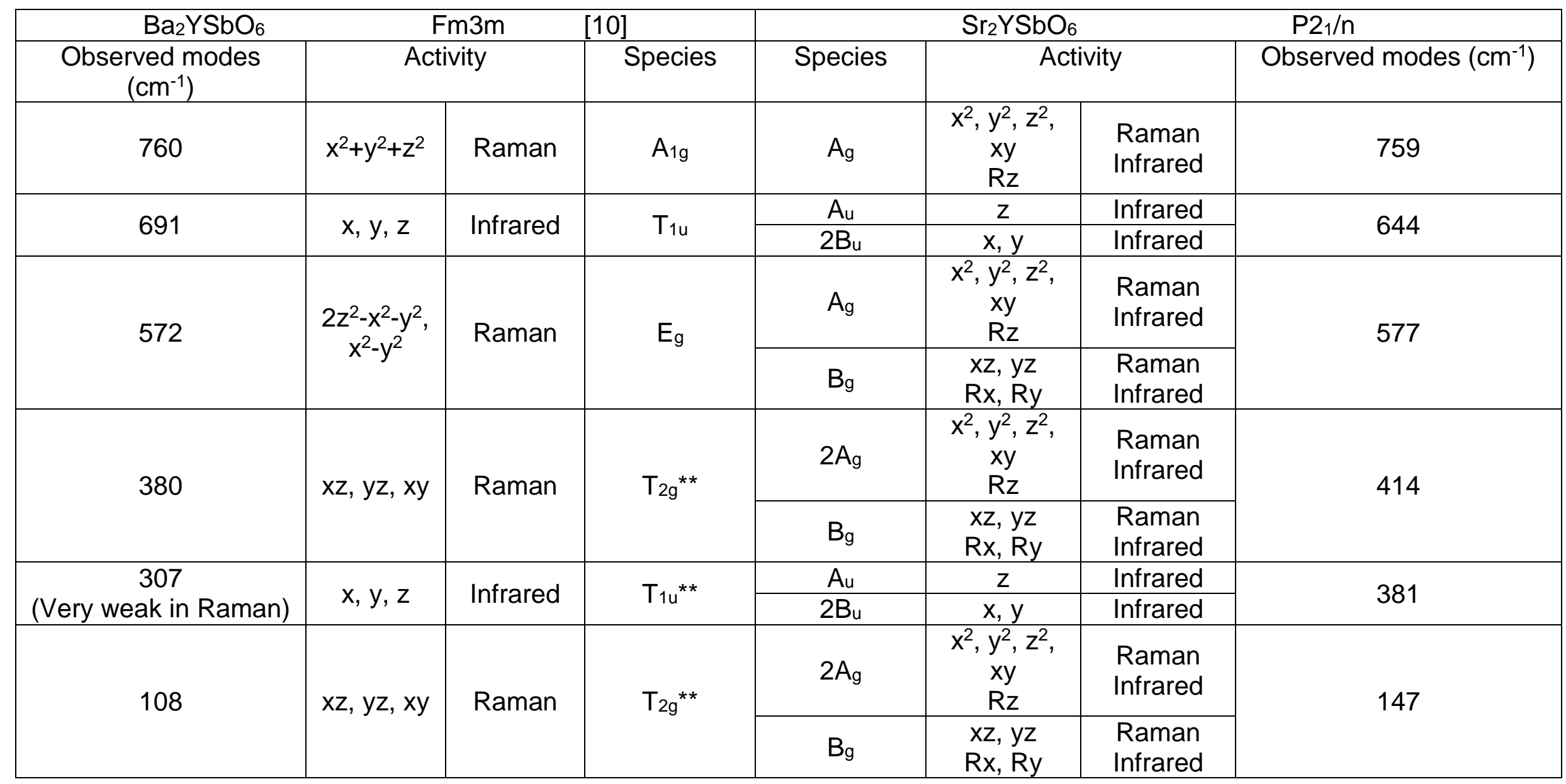




\subsubsection{Magnetic properties.}

In the present work we report the preliminary magnetic characterization of the whole family $\mathrm{Sr}_{2} \mathrm{RSbO}_{6}(\mathrm{R}=\mathrm{La}-\mathrm{Lu})$ of double perovskites. Magnetic susceptibility measurements for this family of compounds reveal a paramagnetic behaviour down to temperatures of $2 \mathrm{~K}$, see Figure 3.31. At high temperature the Magnetic properties follow Curie-Weiss law. The downwards or upwards deviation at low temperature from the Curie-Weiss behaviour observed for some of these $\mathrm{Sr}_{2} \mathrm{RSbO}_{6}$ oxides can be fully explained taking into account the splitting of the ground term of the $\mathrm{R}^{3+}$ cation under the influence of the crystal field without considering any magnetic phenomena as for example magnetic frustration [3.55] and/or cooperative magnetic interactions. It is not observed lanthanide magnetic ordering between $\mathrm{RT}$ and $4 \mathrm{~K}$.

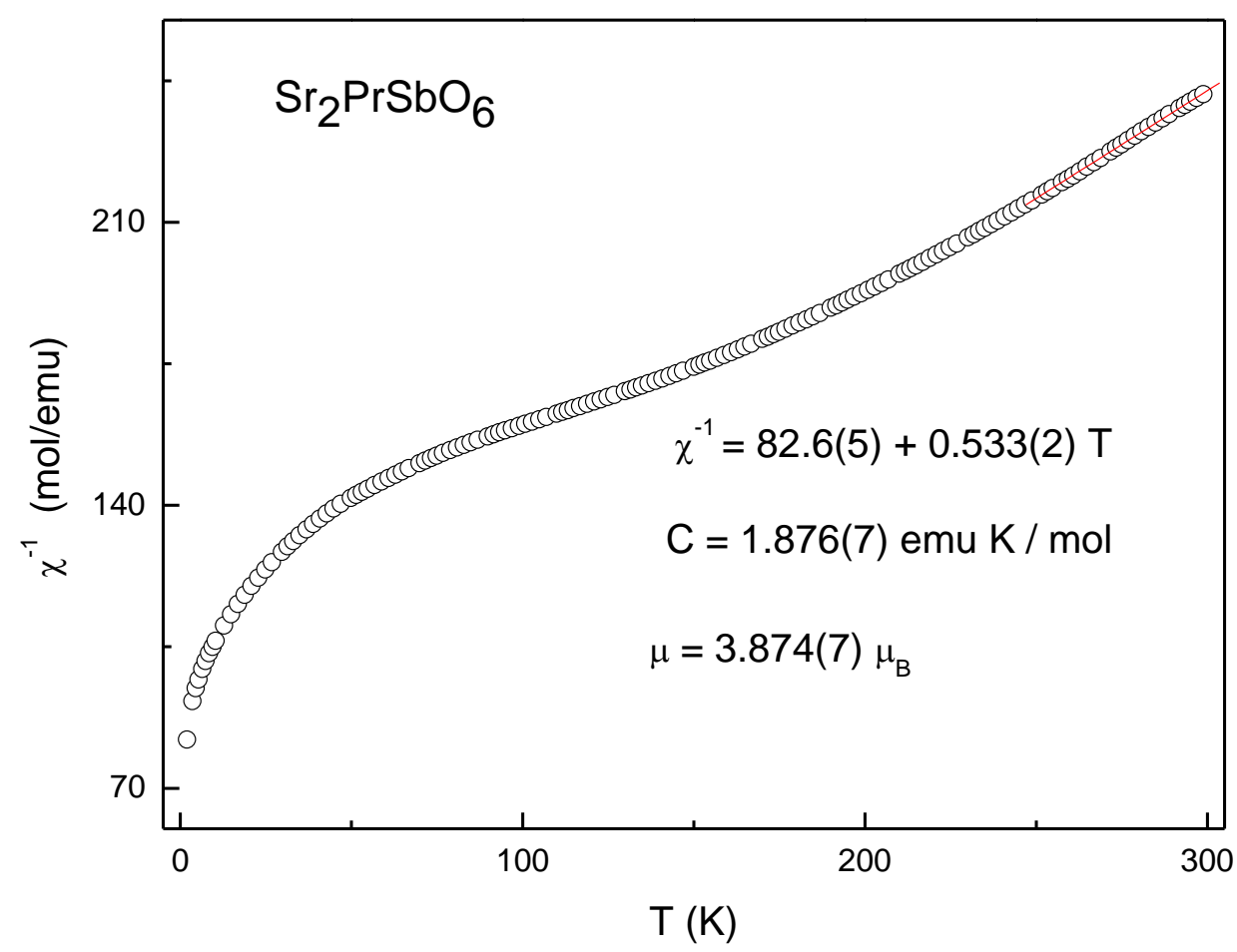

Figure 3.31 a. Temperature dependence of the magnetic susceptibility for the $\mathrm{Sr}_{2} \mathrm{PrSbO}_{6}$ oxide. 

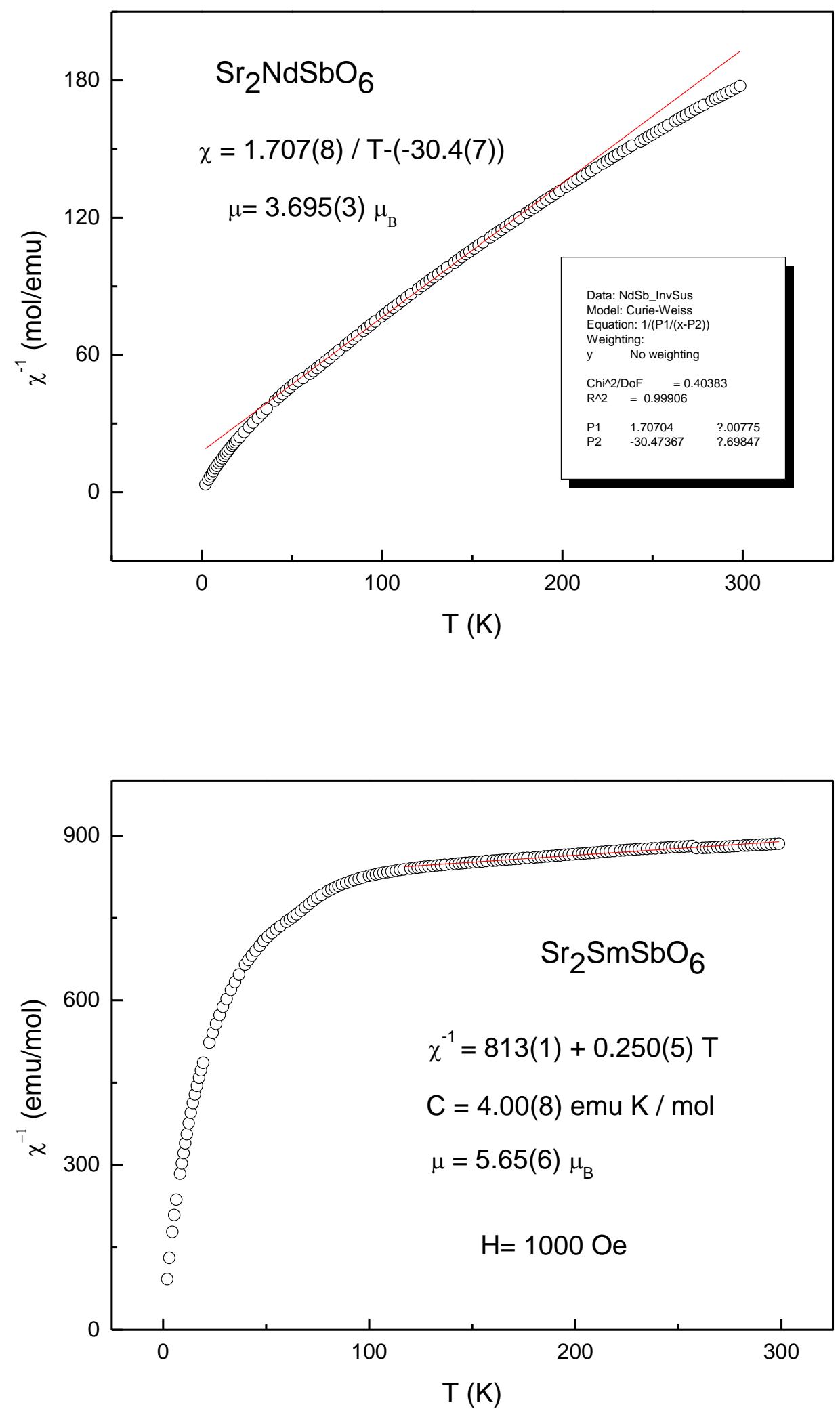

Figure $3.31 \mathrm{~b}$. Temperature dependence of the magnetic susceptibility for the $\mathrm{Sr}_{2} \mathrm{LnSbO}_{6}$ (when $\mathrm{Ln}=\mathrm{Nd}$ and $\mathrm{Sm}$ ) oxides. 

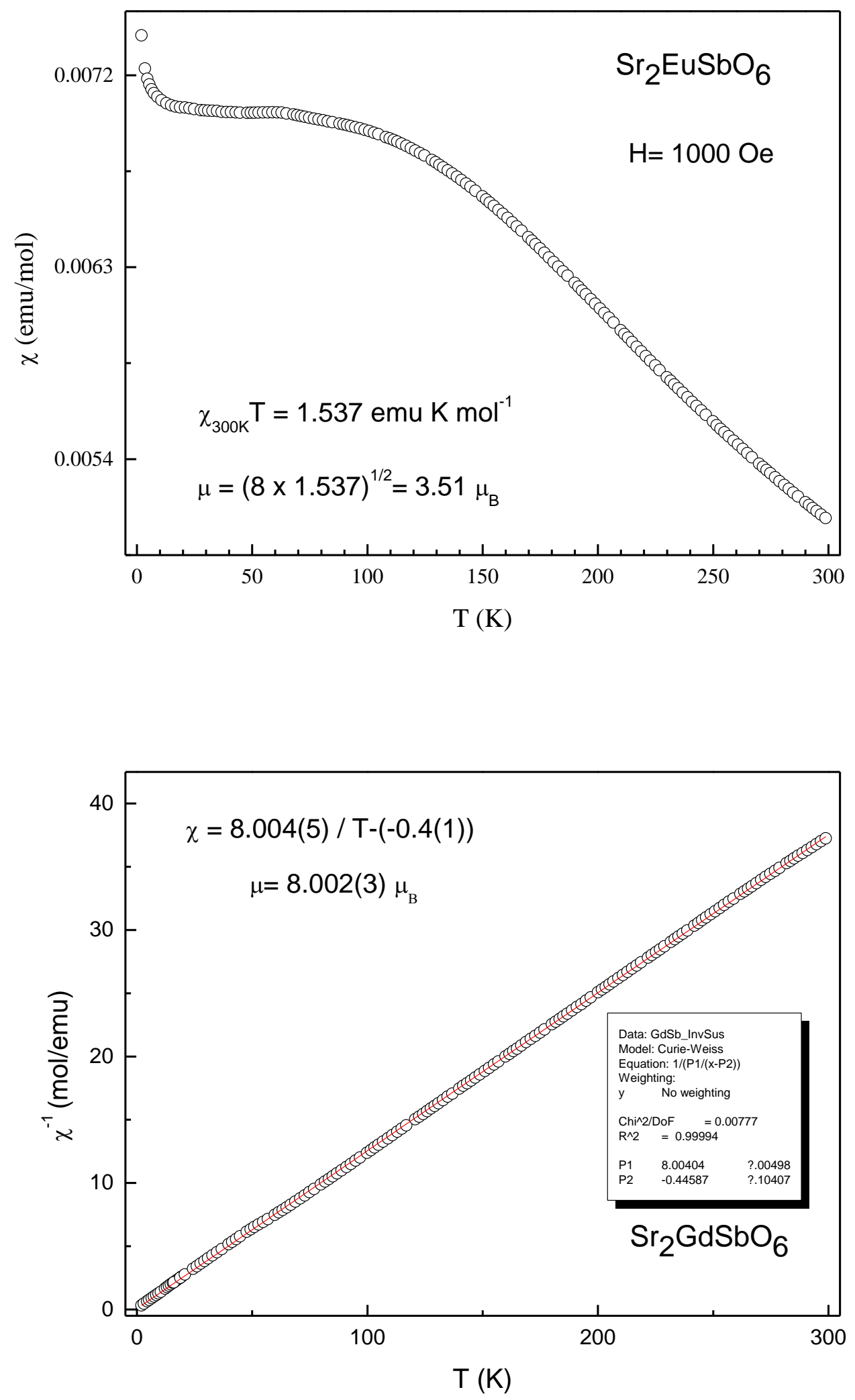

Figure $3.31 \mathrm{c}$. Temperature dependence of the magnetic susceptibility for the $\mathrm{Sr}_{2} \mathrm{LnSbO}_{6}$ (when $\mathrm{Ln}=\mathrm{Eu}$ and $\mathrm{Gd}$ ) oxides. 

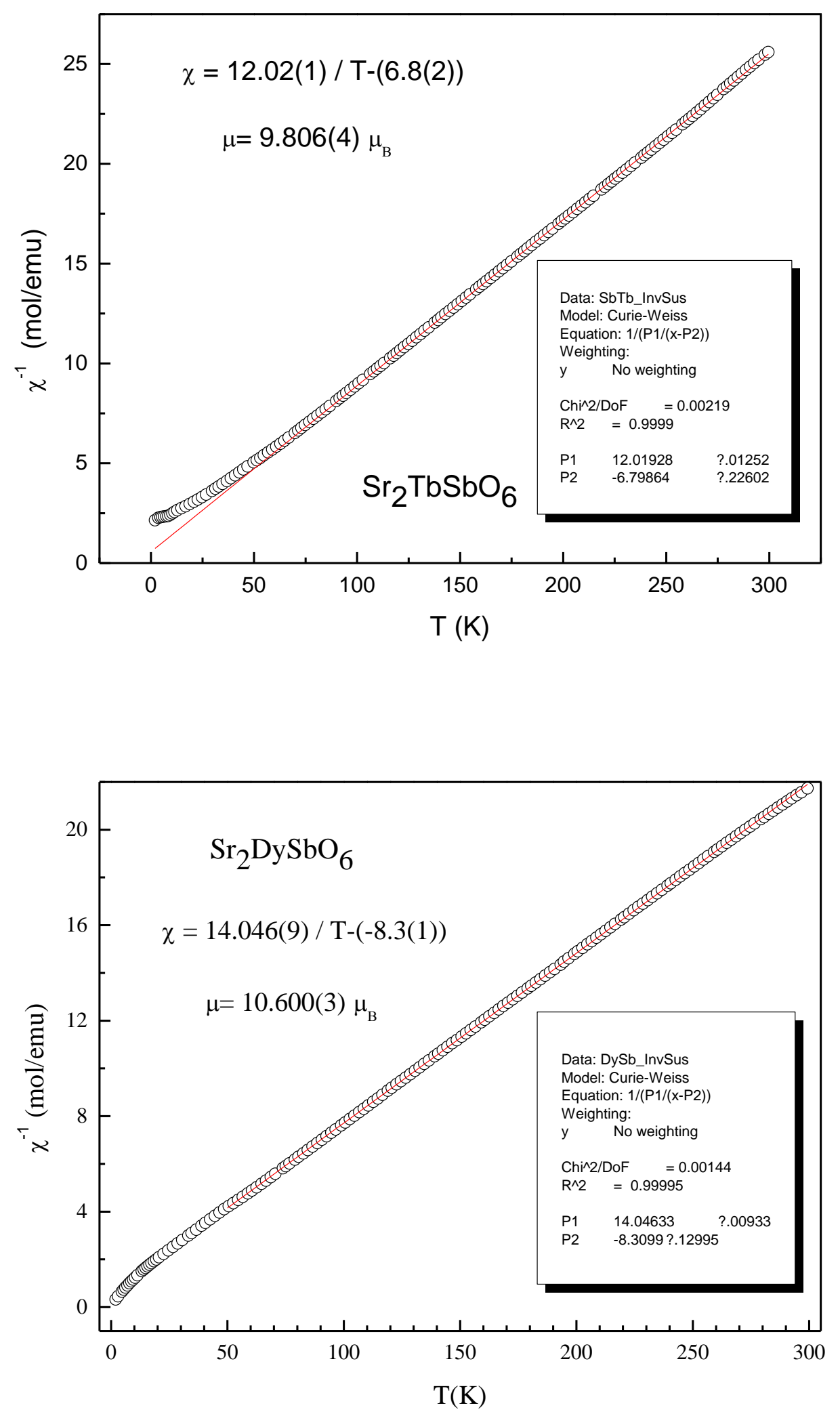

Figure $3.31 \mathrm{~d}$. Temperature dependence of the magnetic susceptibility for the $\mathrm{Sr}_{2} \mathrm{LnSbO}_{6}$ (when $\mathrm{Ln}=\mathrm{Tb}$ and $\mathrm{Dy}$ ) oxides. 

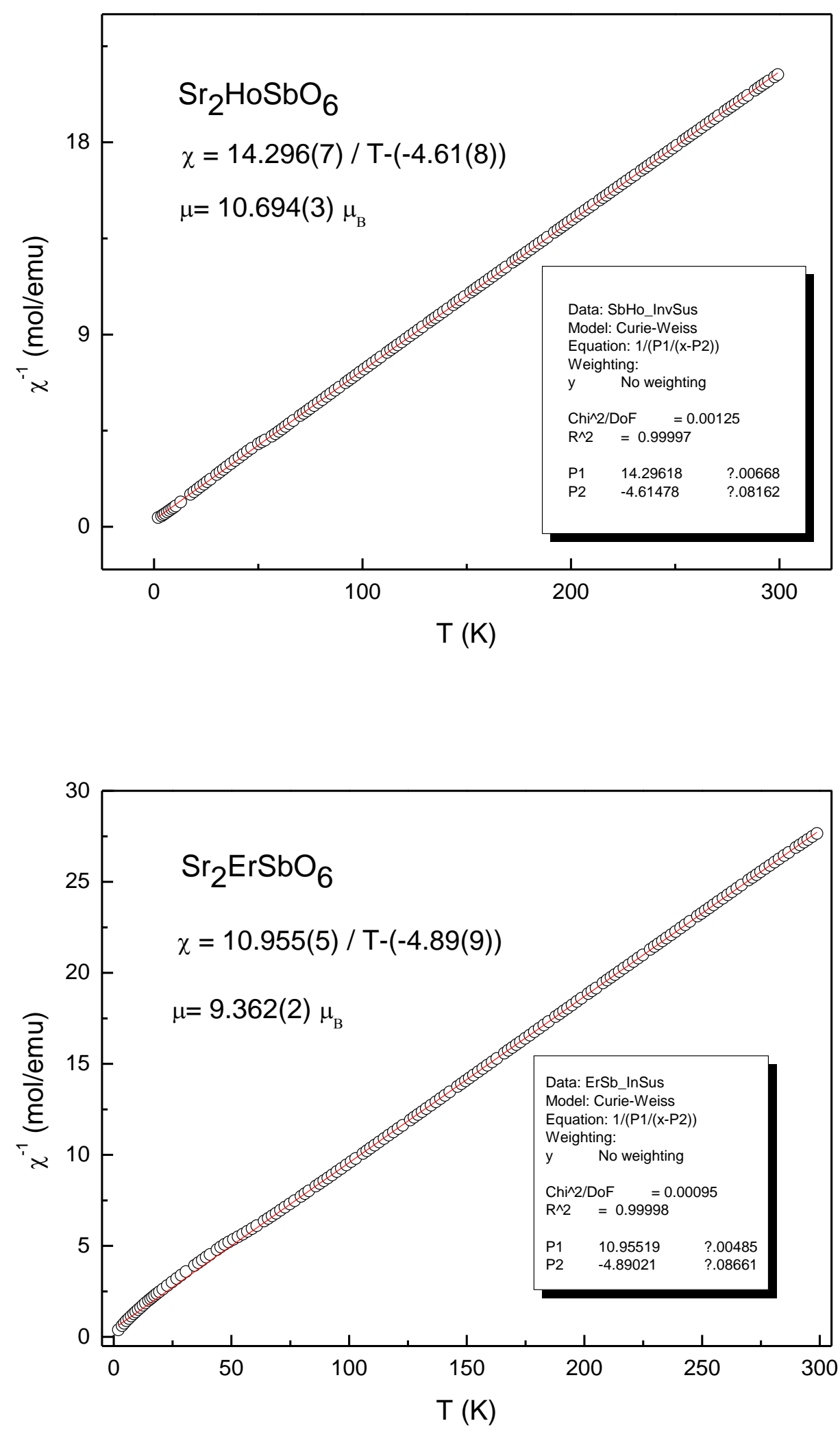

Figure 3.31 e. Temperature dependence of the magnetic susceptibility for the $\mathrm{Sr}_{2} \mathrm{LnSbO}_{6}$ (when $\mathrm{Ln}=\mathrm{Ho}$ and $\mathrm{Er}$ ) oxides. 

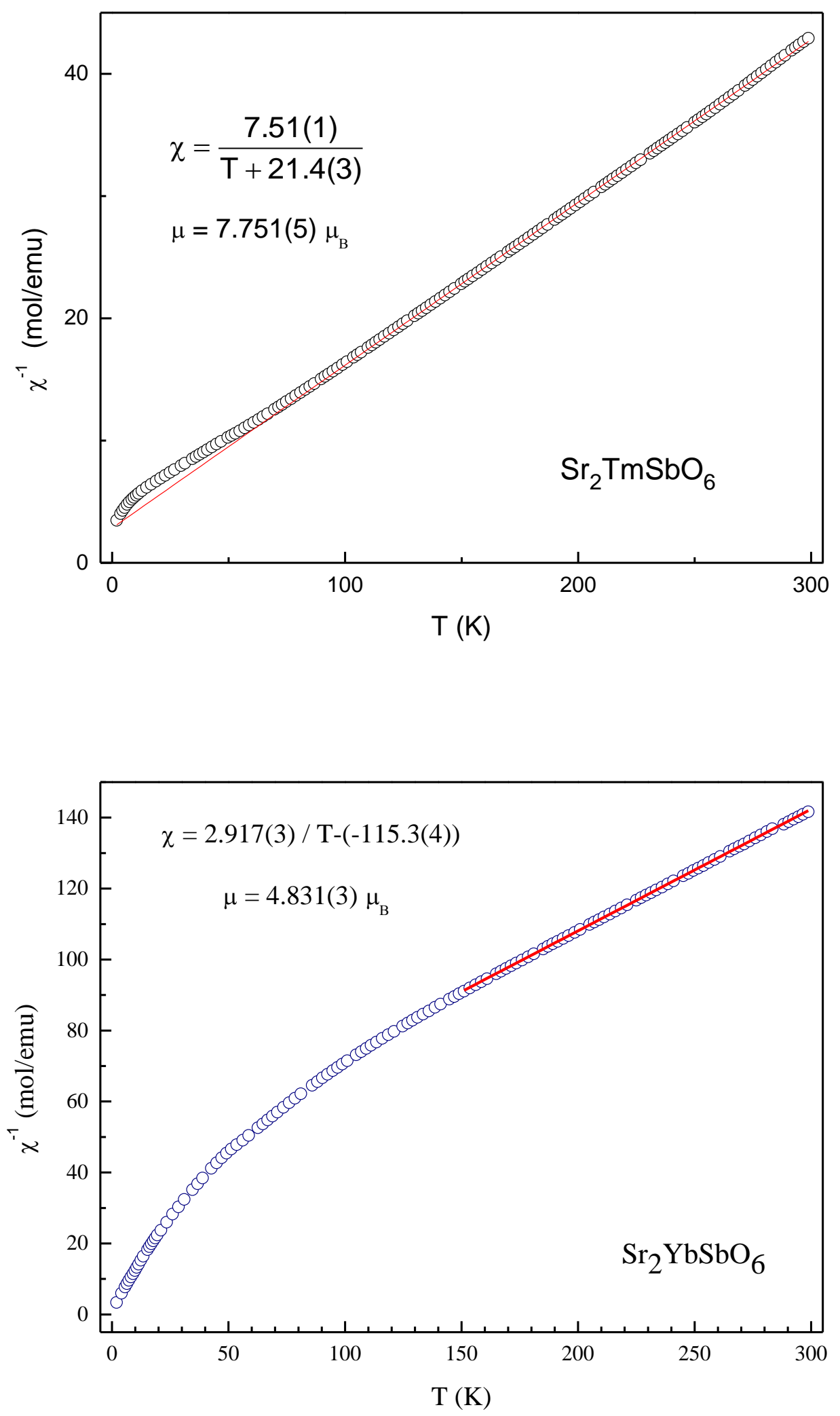

Figure $3.31 \mathrm{f}$. Temperature dependence of the magnetic susceptibility for the $\mathrm{Sr}_{2} \mathrm{LnSbO}_{6}$ (when $\mathrm{Ln}=\mathrm{Tm}$ and $\mathrm{Yb}$ ) oxides. 
The table 3.10 notes the value of $\mathrm{L}, \mathrm{S}$ and $\mathrm{J}$ for fourteen lanthanides, the values of $\mathrm{g}$ and expressions of moment were calculated based on the theory of Hund and Van Vleck and finally the experimental moment was obtained. It is seen that the interpretation of the experimental moment values is quite correct compared with the theoretic calculations.

Table 3.10 Observed and theoretical magnetic moments for $\mathrm{Sr}_{2} \mathrm{LnSbO}_{6}$ compounds

\begin{tabular}{|c|c|c|c|c|c|c|c|c|c|}
\hline Ln & & & & & & & \multicolumn{3}{|c|}{ Magnetic moment / $\mu \mathrm{B}$} \\
\hline & $f^{n}$ & $\begin{array}{l}\text { Groun } \\
\text { d level }\end{array}$ & $\mathbf{L}$ & $\mathbf{S}$ & $\mathbf{J}^{\star}$ & g & Hund & $\begin{array}{l}\text { Van Vleck } \\
\text { \& Franck }\end{array}$ & Exp. \\
\hline $\mathrm{La}$ & 0 & ${ }^{1} S_{0}$ & 0 & 0 & 0 & 0 & 0 & 0 & Diamag. \\
\hline $\mathrm{Ce}$ & 1 & ${ }^{2} \mathrm{~F}_{5 / 2}$ & 3 & $1 / 2$ & $5 / 2$ & $6 / 7$ & 2.54 & 2.56 & \\
\hline $\mathrm{Pr}$ & 2 & ${ }^{3} \mathrm{H}_{4}$ & 5 & 1 & 4 & $4 / 5$ & 3.58 & 3.62 & 3.87 \\
\hline $\mathrm{Nd}$ & 3 & $\left.{ }^{4}\right|_{9 / 2}$ & 6 & $3 / 2$ & $9 / 2$ & $8 / 11$ & 3.62 & 3.68 & 3.70 \\
\hline $\mathrm{Pm}$ & 4 & $5 / 4$ & 6 & 4 & 4 & $3 / 5$ & & & \\
\hline $\mathrm{Sm}$ & 5 & ${ }^{6} \mathrm{H}_{5 / 2}$ & 5 & $5 / 2$ & $5 / 2$ & $2 / 7$ & 0.84 & $1.55 / 1.65$ & 5.65 \\
\hline $\mathrm{Eu}$ & 6 & ${ }^{7} \mathrm{~F}_{0}$ & 3 & 3 & 0 & 0 & 0 & $3.40-3.51$ & 3.51 \\
\hline $\mathrm{Gd}$ & 7 & ${ }^{8} S_{7 / 2}$ & 0 & $7 / 2$ & $7 / 2$ & 2 & 7.94 & 7.94 & 8.00 \\
\hline $\mathrm{Tb}$ & 8 & ${ }^{7} \mathrm{~F}_{6}$ & 3 & 3 & 6 & $3 / 2$ & 9.76 & 9.7 & 9.81 \\
\hline Dy & 9 & ${ }^{6} \mathrm{H}_{15 / 2}$ & 5 & $5 / 2$ & $15 / 2$ & $4 / 3$ & 10.6 & 10.6 & 10.60 \\
\hline $\mathrm{Ho}$ & 10 & $\left.5\right|_{8}$ & 6 & 2 & 8 & $5 / 4$ & 10.6 & 10.6 & 10.69 \\
\hline $\mathrm{Er}$ & 11 & $4 I_{15 / 2}$ & 6 & $3 / 2$ & $15 / 2$ & $6 / 5$ & 9.6 & 9.6 & 9.36 \\
\hline $\mathrm{Tm}$ & 12 & ${ }^{3} \mathrm{H}_{6}$ & 5 & 1 & 6 & $7 / 6$ & 7.6 & 7.6 & 7.75 \\
\hline $\mathrm{Yb}$ & 13 & ${ }^{2} \mathrm{~F}_{7 / 2}$ & 3 & $1 / 2$ & $7 / 2$ & $8 / 7$ & 4.5 & 4.5 & 4.83 \\
\hline $\mathrm{Lu}$ & 14 & ${ }^{1} S_{0}$ & 0 & 0 & 0 & 0 & 0 & 0 & Diamag \\
\hline
\end{tabular}

\subsubsection{Fluorescence Properties of $\mathrm{Sr}_{2} \mathrm{LnSbO}_{6}$ Oxides}

The photoluminescence excitation and emission spectra of $\mathrm{Sr}_{2} \mathrm{LnSbO}_{6}$ compounds were measured, however there is nearly no characteristic band observed for most rare earth ions except for $\mathrm{Eu}^{3+}$ and $\mathrm{Tb}^{3+}$.

The photoluminescence excitation and emission spectra of $\mathrm{Sr}_{2} \mathrm{EuSbO}_{6}$ were illustrated in Fig. 3.32. The results were not like observed in the scheelite system. 
The photoluminescence excitation spectra, under monitored at $615 \mathrm{~nm}$, consists of several strong bands ranging from $350 \mathrm{~nm}$ to $600 \mathrm{~nm}$ which are attributed to intra-configurational $4 \mathrm{f}-4 \mathrm{f}$ transitions of $\mathrm{Eu}^{3+}$ in the lattice. The intense bands centered at $362 \mathrm{~nm}, 381 \mathrm{~nm}, 393 \mathrm{~nm}, 413 \mathrm{~nm}, 465 \mathrm{~nm}$ and $528 \mathrm{~nm}$ were assigned to ${ }^{7} \mathrm{~F}_{0} \rightarrow{ }^{5} \mathrm{D}_{4},{ }^{7} \mathrm{~F}_{0} \rightarrow{ }^{5} \mathrm{~L}_{7},{ }^{7} \mathrm{~F}_{0} \rightarrow{ }^{5} \mathrm{~L}_{6},{ }^{7} \mathrm{~F}_{0} \rightarrow{ }^{5} \mathrm{D}_{3},{ }^{7} \mathrm{~F}_{0} \rightarrow{ }^{5} \mathrm{D}_{2}$ and ${ }^{7} \mathrm{~F}_{0} \rightarrow{ }^{5} \mathrm{D}_{1}$ transitions respectively. However, the efficiency of the transitions ${ }^{7} \mathrm{~F}_{0} \rightarrow{ }^{5} \mathrm{D}_{3}$, ${ }^{7} \mathrm{~F}_{0} \rightarrow{ }^{5} \mathrm{D}_{2}$ and ${ }^{7} \mathrm{~F}_{0} \rightarrow{ }^{5} \mathrm{D}_{1}$ is lower than that observed in the scheelite compounds and the transition ${ }^{7} \mathrm{~F}_{0} \rightarrow{ }^{5} \mathrm{~L}_{6}$ (centered at $393 \mathrm{~nm}$ corresponding to the violet light) is dominant.

The emission bands present nearly the same under excited at different wavelength (excited at $394 \mathrm{~nm}$ and $465 \mathrm{~nm}$ ), and exhibit a characteristic $\mathrm{Eu}^{3+}$ emission except for some intensity varieties. The intense bands centered at 580 $\mathrm{nm}, 594 \mathrm{~nm}, 615 \mathrm{~nm}, 647 \mathrm{~nm}, 710 \mathrm{~nm}$ and $751 \mathrm{~nm}$ were assigned to ${ }^{5} \mathrm{D}_{0} \rightarrow{ }^{7} \mathrm{~F}_{0}$, ${ }^{5} \mathrm{D}_{0} \rightarrow{ }^{7} \mathrm{~F}_{1},{ }^{5} \mathrm{D}_{0} \rightarrow{ }^{7} \mathrm{~F}_{2},{ }^{5} \mathrm{D}_{0} \rightarrow{ }^{7} \mathrm{~F}_{3},{ }^{5} \mathrm{D}_{0} \rightarrow{ }^{7} \mathrm{~F}_{4}$ and ${ }^{5} \mathrm{D}_{0} \rightarrow{ }^{7} \mathrm{~F}_{5}$ transitions respectively. The bands centered at $537 \mathrm{~nm}$ can be attributed to the ${ }^{5} D_{1} \rightarrow{ }^{7} F_{0}$ transition. Unlike in the $\mathrm{AgLn}\left(\mathrm{WO}_{4}\right)\left(\mathrm{MoO}_{4}\right)$ scheelite system, the most intensity emission bands were located at $594 \mathrm{~nm}$ (corresponding to ${ }^{5} \mathrm{D}_{0} \rightarrow{ }^{7} \mathrm{~F}_{2}$ transition) which give rise to orange luminescence instead of $615 \mathrm{~nm}$ (corresponding to ${ }^{5} \mathrm{D}_{0} \rightarrow{ }^{7} \mathrm{~F}_{2}$ transition). Furthermore, it gives efficient infrared luminescence at $710 \mathrm{~nm}$ and $751 \mathrm{~nm}$.

According to the Judd-Ofelt theory, the $\mathrm{Eu}^{3+}$ emission lines are hypersensitive to the environment of $\mathrm{Eu}^{3+}$ ions which can be used as a local structure probe. In the photoluminescence emission spectra of $\mathrm{Sr}_{2} \mathrm{EuSbO}_{6}$, the strongest emission lines centered at $594 \mathrm{~nm}$ are attributed to the ${ }^{5} \mathrm{D}_{0} \rightarrow{ }^{7} \mathrm{~F}_{1}$ transition. The intensity of lines originating from ${ }^{5} \mathrm{D}_{0} \rightarrow{ }^{7} \mathrm{~F}_{0}(580 \mathrm{~nm}),{ }^{5} \mathrm{D}_{0} \rightarrow{ }^{7} \mathrm{~F}_{2}(615 \mathrm{~nm}),{ }^{5} \mathrm{D}_{0} \rightarrow{ }^{7} \mathrm{~F}_{3}(647 \mathrm{~nm})$, ${ }^{5} \mathrm{D}_{0} \rightarrow{ }^{7} \mathrm{~F}_{4}(710 \mathrm{~nm})$ and ${ }^{5} \mathrm{D}_{0} \rightarrow{ }^{7} \mathrm{~F}_{5}(751 \mathrm{~nm})$ transitions is weaker comparing to ${ }^{5} \mathrm{D}_{0} \rightarrow{ }^{7} \mathrm{~F}_{2}$ transition. The magnetic dipole transition ${ }^{5} \mathrm{D}_{0} \rightarrow{ }^{7} \mathrm{~F}_{1}$ is dominant indicating the existence of a high symmetry with inversion center on the respective $\mathrm{Eu}^{3+}$ sites which means the $\mathrm{Eu}^{3+}$ ions located in the center of the octahedral in the double perovskite structure. However, the ${ }^{5} \mathrm{D}_{0} \rightarrow{ }^{7} \mathrm{~F}_{1}$ transition split into two bands at $588 \mathrm{~nm}$ and $594 \mathrm{~nm}$ indicating that $\mathrm{Eu}^{3+}$ ions located in $C_{4 h}, D_{4 h}, D_{3 d}, S_{6}, C_{6 h}$ or $D_{6 h}$, rather than expected one band for symmetry group $O_{h}$. 


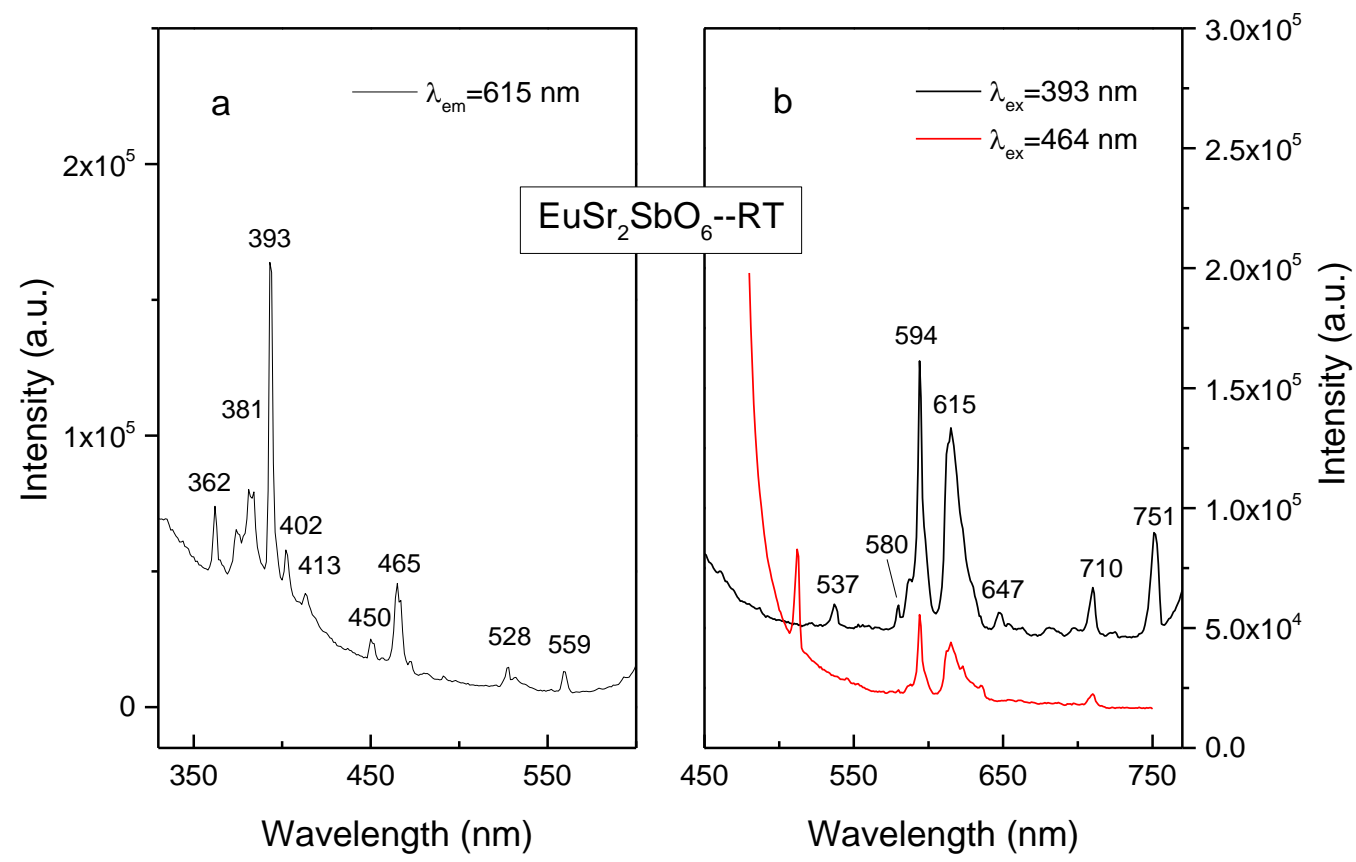

Fig. 3.32 Photoluminescence excitation spectrum (monitored at $615 \mathrm{~nm}$ ) and emission spectrum (excited at $393 \mathrm{~nm}$ and $465 \mathrm{~nm}$ ) of $\mathrm{Sr}_{2} \mathrm{EuSbO}_{6}$ compounds.

In order to get information more precise, the $\mathrm{Sr}_{2} \mathrm{EuSbO}_{6}$ compounds were also put in a Dewar at the liquid nitrogen temperature for the fluorescence property measurement (as shown in Fig. 3.33). The photoluminescence excitation spectrum of $\mathrm{Sr}_{2} \mathrm{EuSbO}_{6}$ under low temperature was observed as similar as measured under room temperature. However the electric dipole transition ${ }^{5} \mathrm{D}_{0} \rightarrow{ }^{7} \mathrm{~F}_{2}$ (at $615 \mathrm{~nm}$ ) was dominant rather than the magnetic dipole transition ${ }^{5} \mathrm{D}_{0} \rightarrow{ }^{7} \mathrm{~F}_{1}$ in the low temperature emission spectrum. According to the Judd-Ofelt theory, the electric dipole transition ${ }^{5} \mathrm{D}_{0} \rightarrow{ }^{7} \mathrm{~F}_{2}$ is dominant when $\mathrm{Eu}^{3+}$ occupies non-centrosymmetric site in the lattice. Since $\mathrm{Sr}_{2} \mathrm{EuSbO}_{6}$ crystallizes in distorted double perovskite structure (monoclinic, due to tilting of the octahedral), the surroundings of the $\mathrm{Eu}^{3+}$ ion do not have exact inversion symmetry. Indeed, the splitting of the lines indicates a low symmetry for $\mathrm{Eu}^{3+}$ in $\mathrm{Sr}_{2} \mathrm{EuSbO}_{6}$. The number of lines for ${ }^{5} D_{0} \rightarrow{ }^{7} F_{1}$ transition is 2 and for ${ }^{5} D_{0} \rightarrow{ }^{7} F_{2}$ transition is 4 . 


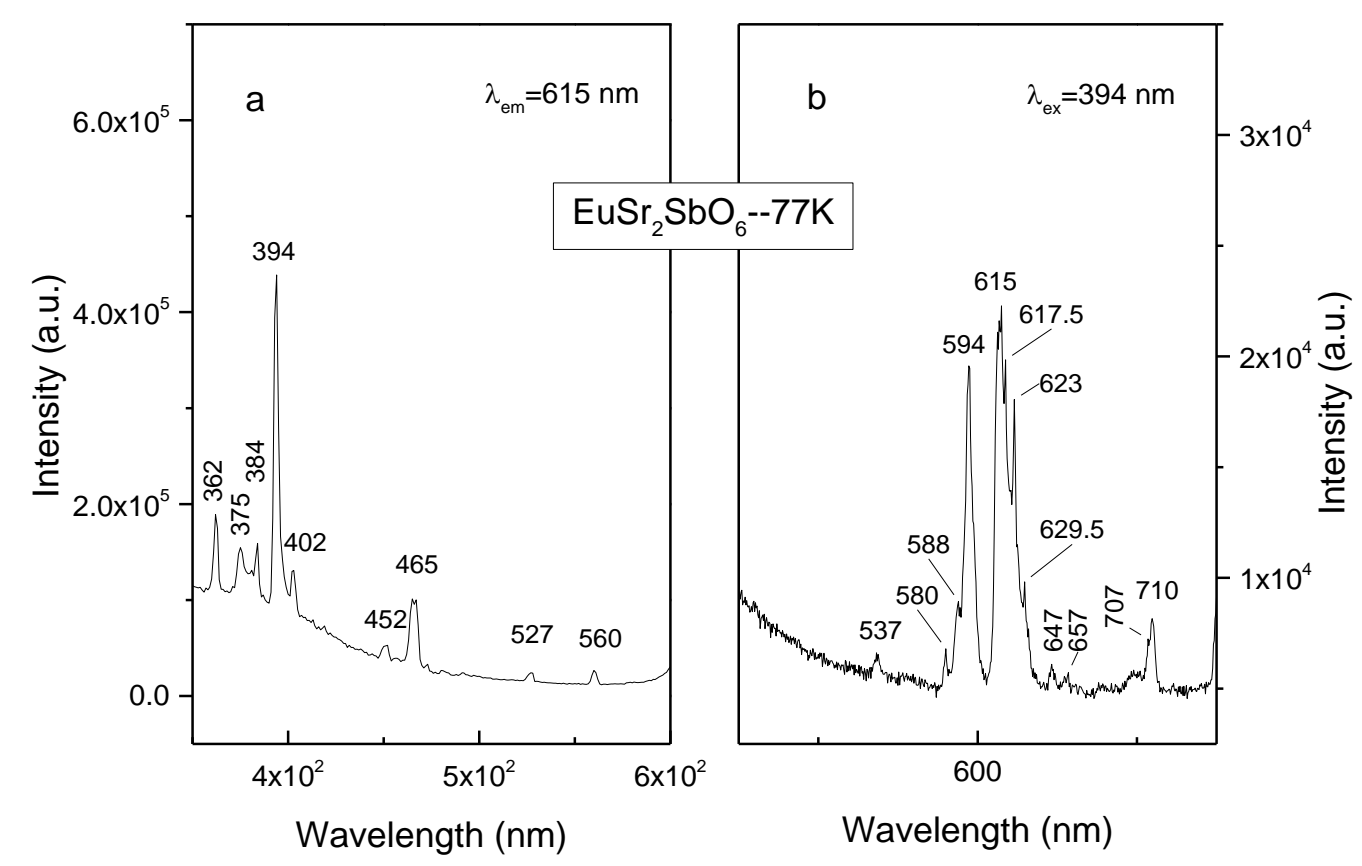

Fig. 3.33 Photoluminescence excitation spectrum (monitored at $615 \mathrm{~nm}$ ) and emission spectrum (excited at $394 \mathrm{~nm}$ ) of $\mathrm{Sr}_{2} \mathrm{EuSbO}_{6}$ compounds at low temperature in Dewar with liquid nitrogen temperature.

Photoluminescence excitation spectra of $\mathrm{Sr}_{2} \mathrm{TbSbO}_{6}$ compounds were monitored at $545 \mathrm{~nm}$ at both room temperature and liquid nitrogen temperature (see Fig. 3-34). The excitation spectra did not show any strong band under the $545 \mathrm{~nm}$ monitoring, it only exhibited a broad band ranging from 300 to $450 \mathrm{~nm}$ overlapping with some small intense lines at $285 \mathrm{~nm}, 298 \mathrm{~nm}, 331 \mathrm{~nm}, 399 \mathrm{~nm}$ and a sharp strong band at $496 \mathrm{~nm}$. The broad band can be ascribed to the charge transfer of $\mathrm{O}^{2-}-\mathrm{W}^{6+} / \mathrm{Mo}^{6+}$, which overlaps some $4 \mathrm{f}-4 \mathrm{f}$ transitions of $\mathrm{Tb}^{3+}$. For $\mathrm{Tb}^{3+}$ ions with $4 f^{8}$ electrons configuration, the ground states are ${ }^{7} \mathrm{~F}_{6}$. Comparing with the excitation spectra at room temperature, the $\mathrm{Sr}_{2} \mathrm{TbSbO}_{6}$ sample presented a new intense line at $299 \mathrm{~nm}$ at $77 \mathrm{~K}$.

Varieties intense peaks from $300 \mathrm{~nm}$ to $500 \mathrm{~nm}$ were chosen to excite $\mathrm{Sr}_{2} \mathrm{TbSbO}_{6}$ sample at room temperature, however no efficient characteristic bands of $\mathrm{Tb}^{3+}$ was observed. At $77 \mathrm{~K}$, the temperature of liquid nitrogen, unexpected strong band at $357 \mathrm{~nm}$ and a broad band from $450 \mathrm{~nm}$ to $530 \mathrm{~nm}$ 
(centered at $498 \mathrm{~nm}$ ) appeared in the emission spectra of the $\mathrm{Sr}_{2} \mathrm{TbSbO}_{6}$ samples when excited by $298 \mathrm{~nm}$. The strong emission band located at $357 \mathrm{~nm}$ can be can be attributed to the ${ }^{5} \mathrm{D}_{2} \rightarrow{ }^{7} \mathrm{~F}_{6}$ transitions of $\mathrm{Tb}^{3+}$. However the broad band centered at $498 \mathrm{~nm}$ is a little complicate. It should be attributed to overlaps of transitions from excited ${ }^{5} \mathrm{D}_{4}$ state to varieties configurations of ${ }^{7} \mathrm{~F}_{6}$ ground state of $\mathrm{Tb}^{3+}$ ions.

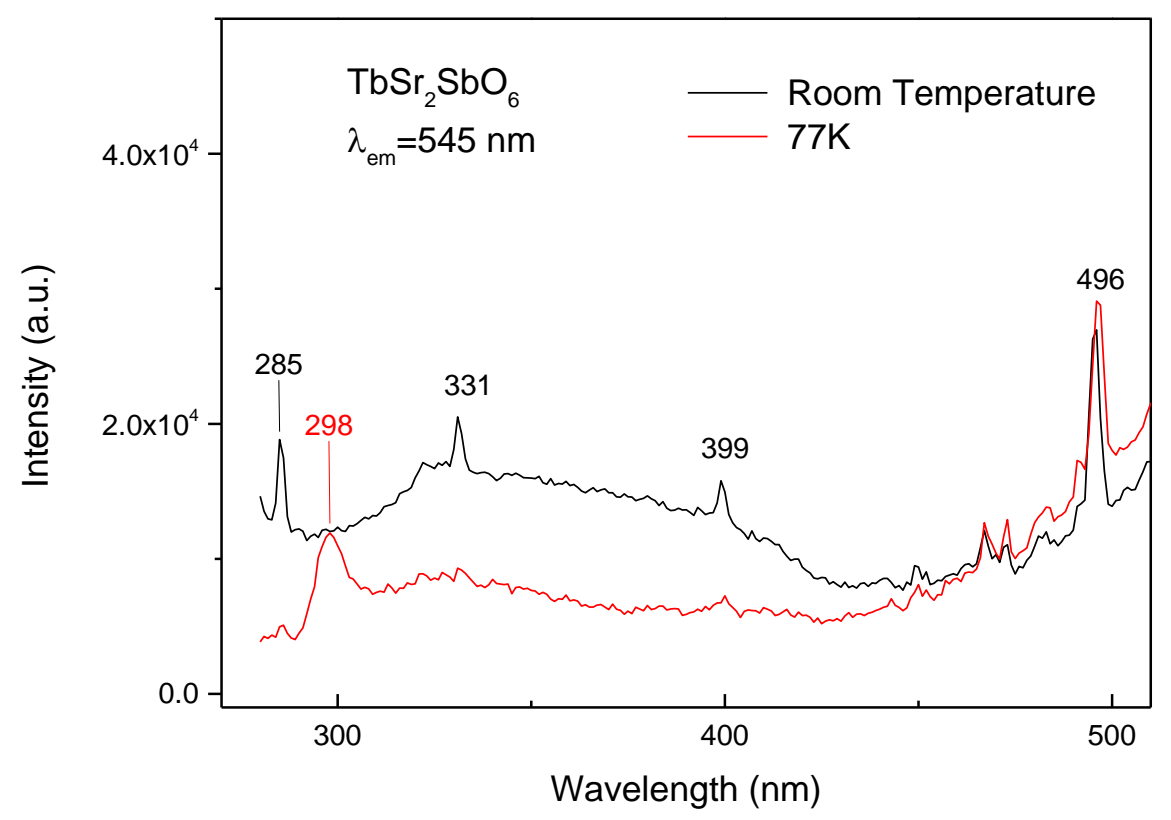

Fig. 3.34 Photoluminescence excitation spectrum (monitored at $545 \mathrm{~nm}$ ) of $\mathrm{Sr}_{2} \mathrm{TbSbO}_{6}$ compounds at room temperature (black) and low temperature in Dewar with liquid nitrogen temperature (red) 


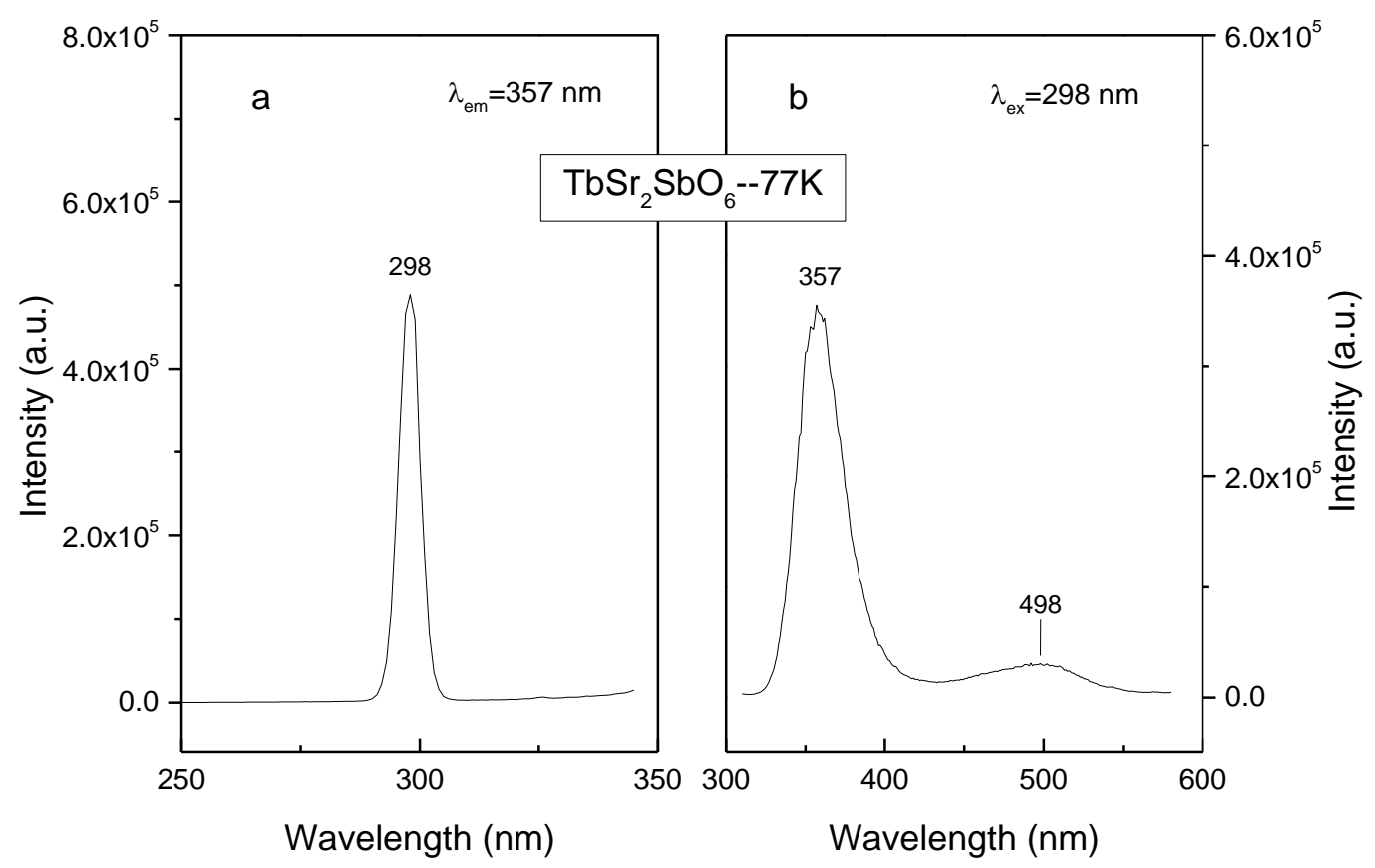

Fig. 3.35 Photoluminescence excitation spectrum (monitored at $357 \mathrm{~nm}$ ) and emission spectrum (excited at $298 \mathrm{~nm}$ ) of $\mathrm{Sr}_{2} \mathrm{TbSbO}_{6}$ compounds at low temperature in Dewar with liquid nitrogen temperature. 


\section{References}

[3.1] W. Jeitschko, Crystal structure of $\mathrm{La}_{2}\left(\mathrm{MoO}_{4}\right)_{3}$, a new ordered defect Scheelite type.Acta Cryst. B29 (1973) 2074-2081.

[3.2] L. Zhang, M. Lei, Y. Wang, J. Li, Y. Wang, J. Liu, Crystal Growth and Spectral Properties of $\mathrm{Yb}^{3+}: \mathrm{KY}\left(\mathrm{WO}_{4}\right)$ 2. J. RARE EARTH 24 (2006) 125-128.

[3.3] F. Shi, J. Meng, Y. Ren, Preparation, structure and some physical properties of scheelite-related $\mathrm{AgLnMo}_{2} \mathrm{O}_{8}$ compounds. J. Alloys Compd. 233 (1996) 56-60.

[3.4] S. P. S. Porto, J. F. Scott,Raman Spectra of $\mathrm{CaWO}_{4}, \mathrm{SrWO}_{4}, \mathrm{CaMoO}_{4}$, and SrMoO4. Phys. Rev. 157 (3) (1996), 716-719.

[3.5] L. Macalik, J. Hanuza, A.A. Kaminskii, Polarized Raman spectra of the oriented $\mathrm{NaY}\left(\mathrm{WO}_{4}\right)_{2}$ and $\mathrm{KY}\left(\mathrm{WO}_{4}\right)_{2}$ single crystals.J. Mol. Struct. 555 (2000)289-297.

[3.6] J. Hanuza, M. Maczka, J. H. van der Maas, Polarized IR and Raman spectra of tetragonal $\mathrm{NaBi}\left(\mathrm{WO}_{4}\right)_{2}, \mathrm{NaBi}\left(\mathrm{MoO}_{4}\right)_{2}$ and $\mathrm{LiBi}\left(\mathrm{MoO}_{4}\right)_{2}$ single crystals with scheelite structure.J. Mol. Struct. 348 (1995)349-352.

[3.7] N. Yamada, S. Shionoya, Vibronic transitions of $\mathrm{Eu}^{3+}$ ions in $\mathrm{CaWO}_{4}$ and other tungstates. J. Phys. Soc. Jpn. 31 (1971)841-851.

[3.8] H. Karunadasa, Q. Huang, B. G. Ueland, P. Schiffer, R. J. Cava, $\mathrm{Ba}_{2} \mathrm{LnSbO}_{6}$ and $\mathrm{Sr}_{2} \mathrm{LnSbO}_{6}(\mathrm{Ln}=\mathrm{Dy}, \mathrm{Ho}, \mathrm{Gd})$ double perovskites: Lanthanides in the geometrically frustrating fcc lattice. Proc. Natl. Acad. Sci. USA 100 (14) (2003) 8097-8102.

[3.9] W. M. Yen, S. Shionoya, H. Yamamoto, Phosphor Handbook Second Edition. 2006.

[3.10] L. Bonelli, F. Cornacchia, M. Tonelli, D. A. Lis, K. A. Subbotin, V. A. Smirnov, E. V. Zharikov, Spectroscopic properties of Er:NaLa $\left(\mathrm{WO}_{4}\right)_{2}$ crystals and effect of Ce codoping onto the excited state energy transformation in this crystal. J. Lumin. 135 (2013) 178-186. 
[3.11] A. Katelnikovas, J. Plewa, S. Sakirzanovas, D. Dutczak, D. Enseling, F. Baur, H. Winkler, A. Kareiva, T. Jüstel, Synthesis and optical properties of $\mathrm{Li}_{3} \mathrm{Ba}_{2} \mathrm{La}_{3}\left(\mathrm{MoO}_{4}\right)_{8}: \mathrm{Eu}^{3+}$ powders and ceramics for pcLEDs. J. Mater. Chem. 22 (2012) 22126-22134.

[3.12] W. Shi, A. Feng, H. Tang, Z. Ding, Y. Ma, M. Wu, G. Li, Preparation, characterization, and luminescence of $\mathrm{Eu}^{3+}$-doped gadolinium tungstate, $\mathrm{Y}_{3} \mathrm{Al}_{5} \mathrm{O}_{12}$ :Ce phosphor, and their mixtures. Opt. Mater. 35 (2013) 609-616.

[3.13] Q. Dan, T. Wanjun, Efficient energy transfer and tunable emission in $\mathrm{NaLa}\left(\mathrm{MoO}_{4}\right)\left(\mathrm{WO}_{4}\right): \mathrm{Tb}^{3+} / \mathrm{Eu}^{3+}$ phosphors. Ceram. Int. 42 (2016) 1538-1544.

[3.14] S. Shi, X. Liu, J. Gao, J. Zhou, Spectroscopic properties and intense red-light emission of ( $\mathrm{Ca}, \mathrm{Eu}, \mathrm{M}) \mathrm{WO}_{4}(\mathrm{M}=\mathrm{Mg}, \mathrm{Zn}, \mathrm{Li})$. Spectrochim. Acta Part A 69 (2008) 396-399.

[3.15] Z. Wang, H. Liang, Q. Wang, L. Luo, M. Gong, Luminescent properties of $\mathrm{Tb}^{3+}$ activated double molybdates and tungstates. Mater. Sci. Eng., B 164 (2009) 120-123.

[3.16] Y. Liu, X. Yue, K. Cai, H. Deng, M. Zhang, Microwave-assist hydrothermal synthesis and luminescence of $\mathrm{NaGd}\left(\mathrm{WO}_{4}\right): \mathrm{Tb}^{3+}$ phosphors: A case study for the energy saving in the synthesis of phosphors. Energy 93 (2015) 1413-1417.

[3.17] Y. Tian, B. Chen, B. Tian, J. Sun, X. Li, J. Zhang, L. Cheng, H. Zhong, H. Zhong, Q. Meng, R. Hua, lonic liquid-assisted hydrothermal synthesis of dendrite-like NaY(MoO4)2: $\mathrm{Tb}^{3+}$ phosphor. Physica B 407 (2012) 2556-2559.

[3.18] C. Colón, A. Alonso-Medina, F. Fernández, R. Sáez'Puche, V. Volkov, C. Cascales C. Zaldo, Correlation between Polymorphism and Optical Bandwidths in $\mathrm{AgNd}\left(\mathrm{WO}_{4}\right)_{2}$. Chem. Mater. 17 (26) (2005) 6635-6643.

[3.19] F. Fernández-Martínez , C. Colón, J. L. Montero, E. Atanes, C. Rivero, Synthesis and characterization of $\mathrm{LnAg}\left(\mathrm{WO}_{4}\right)\left(\mathrm{MoO}_{4}\right)$. J. Alloys Compd. 451 (2008) 317-319. 
[3.20] J. Hanuza, A. Benzar, A. Haznar, M. Maczka, A. Pietraszko, J.H. van der Maas, Structure and vibrational dynamics of tetragonal $\mathrm{NaBi}\left(\mathrm{WO}_{4}\right)_{2}$ scheelite crystal. Vib. Spectrosc. 12 (1996) 25-36.

[3.21] V. Ramakrishnan, G. Aruldhas, Raman and infrared studies of $\mathrm{NaLa}(\mathrm{MoO} 4)_{2}$. Spectrochim. Acta 41A (11) (1985) 1301-1303.

[3.22] D. L. Rousseau, R. P. Bauman, S. P. S. Porto, Normal mode determination in crystals. J. Raman Spectrosc. 10 (1) (1981) 253-290.

[3.23] N. Yamada, S. Shionoya, Vibronic transitions of $\mathrm{Eu}^{3+}$ ions in $\mathrm{CaWO}_{4}$ and other tungstates. J. Phys. Soc. Jpn. 31 (1971) 841-851.

[3.24] F. B. Xiong, Z. W. Zhang, H. F. Lin, L. J. Wang, Y. C. Xu, W. Z. Zhu, Luminescent properties of deep red light-emitting phosphors NaGd($\left(\mathrm{WO}_{4}\right)_{2}: \mathrm{Pr}^{3+}$ for blue LED. Opt. Mater. 42 (2015) 394-398.

[3.25] J. Chen, X. Gong, Y. Lin, Y. Chen, Z. Luo, Y. Huang, Synthesis and spectral property of $\mathrm{Pr}^{3+}$-doped tungstate deep red phosphors. J. Alloys Compd. 492 (2010) 667-670.

[3.26] D. Balaji, A. Durairajan, D.Thangaraju, K. Kavi Rasu, S. Moorthy Babu, Investigation of structural and luminescent properties of $\mathrm{Pr}^{3+}$ activated CsGd(WO4)2 by sol-gel synthesis. Mater. Sci. Eng. B 178 (2013) 762-767.

[3.27] A. Durairajan, D. Balaji, K. Kavi Rasu, S. Moorthy Babu, M. A. Valente, D. Thangaraju, Y. Hayakawa, Sol-gel synthesis and photo luminescence analysis of $\mathrm{Sm}^{3+}: \mathrm{NaGd}\left(\mathrm{WO}_{4}\right)_{2}$ phosphors. J. Lumin. 170 (2016) 743-748.

[3.28] Y. Zhiping, D. Hongyan, L. Pengfei, H. Chuncai, L. Xiaoshuang, W. Can, L. Fachun, Photoluminescence properties of $\mathrm{Sm}^{3+}$-doped $\mathrm{LiY}\left(\mathrm{MoO}_{4}\right)_{2}$ red phosphors. J. RARE EARTHS 32 (5) (2014) 404-408.

[3.29] P. Nachimuthu, R. Jagannathan, V. Nirmal Kumar, D. Narayana Rao, Absorption and emission spectral studies of $\mathrm{Sm}^{3+}$ and $\mathrm{Dy}^{3+}$ ions in $\mathrm{PbO}^{3} \mathrm{PbF}_{2}$ glasses. J. Non-Cryst. Solids 217(1997) 215-223. 
[3.30] Y. Wang, C. Lin, H. Zheng, D. Sun, L. Li, B. Chen, Fluorescent and chromatic properties of visible-emitting phosphor $\mathrm{KLa}\left(\mathrm{MoO}_{4}\right)_{2}: \mathrm{Sm}^{3+}$. J. Alloys Compd. 559 (2013) 123-128.

[3.31] Y. Jin, J. Zhang, S. Lu, H. Zhao, X. Zhang, X. Wang, Fabrication of $\mathrm{Eu}^{3+}$ and $\mathrm{Sm}^{3+}$ codoped micro/nano sized $\mathrm{MMoO}_{4}(\mathrm{M}=\mathrm{Ca}, \mathrm{Ba}$, and $\mathrm{Sr})$ via facile hydrothermal method and their photoluminescence properties through energy transfer. J. Phys. Chem. C 112(15) (2008) 5860-5864.

[3.32] F. Shi, J. Meng, Y. Ren, Q. Su, Structure, luminescence and magnetic properties of AgLnW2O8 ( $\mathrm{Ln}=\mathrm{Eu}, \mathrm{Gd}, \mathrm{Tb}$ and Dy) compounds. J. Phys. Chem. Solids 59 (1) (1998) 105-110.

[3.33] J. Huang, J. Loriers, P. Porcher, Spectroscopic Properties of $\mathrm{Ln}_{2} \mathrm{MoO}_{6}$ : $\mathrm{Eu}^{3+}$. J. Solid State Chem. 43 (1982) 87-96.

[3.34] Z. Tang, L. Zhou, F. Wang, L. Zhou, Synthesis, characterization and luminescence study of $\mathrm{Eu}(\mathrm{III})$ tungstates and molybdates nanotubes using carbon nanotubes as templates. Spectrochim. Acta, Part A 72 (2009) 348-355.

[3.35] P.A. Loiko, E.V. Vilejshikova, X. Mateos, J.M. Serres, V.I. Dashkevich, V.A. Orlovich, A.S. Yasukevich, N.V. Kuleshov, K.V. Yumashev, S.V. Grigoriev, S.M. Vatnik, S.N. Bagaev, A.A. Pavlyuk, Spectroscopy of tetragonal Eu:NaGd(WO 4$)_{2}$ crystal. Opt. Mater. 57 (2016) 1-7.

[3.36] W. Shi, A. Feng, H. Tang, Z. Ding, Y. Ma, M. Wu, G. Li, Preparation, characterization, and luminescence of $\mathrm{Eu}^{3+}$-doped gadolinium tungstate, $\mathrm{Y}_{3} \mathrm{Al}_{5} \mathrm{O}_{12}$ :Ce phosphor, and their mixtures. Opt. Mater. 35 (2013) 609-616.

[3.37] Y. Liu, X. Yu, K. Cai, H. Deng, M. Zhang, Microwave-assist hydrothermal synthesis and luminescence of $\mathrm{NaGd}\left(\mathrm{WO}_{4}\right): \mathrm{Tb}^{3+}$ phosphors: A case study for the energy saving in the synthesis of phosphors. Energy 93 (2015) 1413-1417.

[3.38] Q. Dan, T. Wanjun, Efficient energy transfer and tunable emission in $\mathrm{NaLa}\left(\mathrm{MoO}_{4}\right)\left(\mathrm{WO}_{4}\right): \mathrm{Tb}^{3+} / \mathrm{Eu}^{3+}$ phosphors. Ceram. Inter. 42 (2016)1538-1544. 
[3.39] Y. Tian, B. Chen, B. Tian, J. Sun, X. Li, J. Zhang, L. Cheng, H. Zhong, H. Zhong, Q. Meng, R. Hua, lonic liquid-assisted hydrothermal synthesis of dendrite-like NaY(MoO4)2: $\mathrm{Tb}^{3+}$ phosphor. Physica B 407 (2012) 2556-2559.

[3.40] J. Huang, J. Huang, Y. Lin, X. Gong, Y. Chen, Z. Luo, Y. Huang, Spectroscopic properties of $\mathrm{Dy}^{3+}$-doped $\mathrm{NaGd}\left(\mathrm{MoO}_{4}\right)_{2}$ crystal. J. Alloys Compd. 664 (2016) 266-271.

[3.41] L. Li, W. Zi, G. Li, S. Lan, G. Ji, S. Gan, H. Zou, X. Xu, Hydro thermal synthesis and luminescent properties of $\mathrm{NaLa}\left(\mathrm{MoO}_{4}\right)_{2}: \mathrm{Dy}^{3+}$ phosphor. J. Solid State Chem. 191 (2012) 175-180.

[3.42] M. Jayasimhadri, B.V. Ratnam, K. Jang, H.S. Lee, B. Chen, S. Yi, J. Jeong, L.R. Moorthy, Greenish-Yellow Emission from Dy ${ }^{3+}$-Doped $\mathrm{Y}_{2} \mathrm{O}_{3}$ Nanophosphors. J. Am. Ceram. Soc. 93 (2) (2010) 494-499.

[3.43] S. Asiri Naidu, S. Boudin, U.V. Varadaraju, B. Raveau, Host-sensitized emission of $\mathrm{LilnW}_{2} \mathrm{O}_{8}$ wolframites: From red-Eu ${ }^{3+}$ to white-Dy ${ }^{3+}$ phosphors. J. Solid State Chem. 184 (2011) 2566-2570.

[3.44] R. Fartas, M. Diaf, H. Boubekri, L. Guerbous, J.P. Jouart, Synthesis and study of spectroscopic properties of $\mathrm{CdF}_{2}$ crystals codoped with luminescent rare earth ions $\left(\mathrm{Ho}^{3+} \mathrm{Yb}^{3+}\right)$. J. Alloys Compd. 606 (2014) 73-80.

[3.45] B. Vengala Rao, S. Buddhudu, Emission analysis of $\mathrm{Pr}^{3+} \& \mathrm{Ho}^{3+}$ : $\mathrm{Ca}_{4} \mathrm{GdO}\left(\mathrm{BO}_{3}\right)_{3}$ powder phosphors. J Mater Sci. 43 (2008) 233-236.

[3.46] J. Yuan, S.X. Shen, D.D. Chen, Q. Qian, M.Y. Peng, and Q.Y. Zhang, Efficient $2.0 \mu \mathrm{m}$ emission in $\mathrm{Nd}^{3+} / \mathrm{Ho}^{3+}$ co-doped tungsten tellurite glasses for a diode-pump 2.0um laser. J. Appl. Phys. 113 (2013) 173507.

[3.47] K. Choa, J.Choi, K.M. Kim, J. Lee, J.H. Ryu, Upconversion luminescence of $\mathrm{Ho}^{3+} / \mathrm{Tm}^{3+} / \mathrm{Yb}^{3+}$ tri-doped $\mathrm{NaLa}\left(\mathrm{MoO}_{4}\right)_{2}$ phosphors. Ceram. Int. 41 (2015) 668-674. 
[3.48] J. Tang, C. Cheng, Y. Chen, Y. Huang, Yellow-green upconversion photoluminescence in $\mathrm{Yb}^{3+}, \mathrm{Ho}^{3+}$ co-doped $\mathrm{NaLa}\left(\mathrm{MoO}_{4}\right)_{2}$ phosphor. J. Alloys Compd. 609 (2014) 268-273.

[3.49] C.S. Lim, Microwave-modified sol-gel process of $\mathrm{NaY}\left(\mathrm{WO}_{4}\right)_{2}: \mathrm{Ho}^{3+} / \mathrm{Yb}^{3+}$ phosphors and the upconversion of their photoluminescence properties. Ceram. Int. 41 (2015) 2616-2621.

[3.50] C. Sun, F.Yang, C. Tu, Spectroscopic properties of $\mathrm{Tm}^{3+} / \mathrm{Ho}^{3+}$ co-doped $\mathrm{NaLa}\left(\mathrm{WO}_{4}\right)_{2}$ single crystal. J. Lumin. 132 (2012) 1232-1236.

[3.51] L. Bonelli, F. Cornacchia, M. Tonelli, D.A. Lis, K.A. Subbotin, V.A. Smirnov, E.V. Zharikov, Spectroscopic properties of Er:NaLa(WO 4$)_{2}$ crystals and effect of Ce codoping onto the excited state energy transformation in this crystal. J. Lumin. 135 (2013) 178-186.

[3.52] X. Huang, W. Zhao, G. Wang, X. Li, Q. Yu, Polarized spectral analysis of $\mathrm{Er}^{3+}$ ions in $\mathrm{Er}^{3+}: \mathrm{LiGd}\left(\mathrm{MoO}_{4}\right)_{2}$ crystal. J. Alloys Compd. 509 (2011) 6578-6584.

[3.53] Y.W. Wei, Y.J. Chen, Y.F. Lin, X.H. Gong, Z.D. Luo, Y.D. Huang, Spectral properties of $\mathrm{Tm}^{3+}$-doped $\mathrm{LiLa}\left(\mathrm{MoO}_{4}\right)_{2}$ crystal. J. Alloys Compd. 484 (2009) 529-534.

[3.54] C. Vijayakumar, H. Padma Kumar, Sam Solomon, J.K. Thomas, P. R. S. Wariar, Annamma John, FT-Raman and FT-IR vibrational spectroscopic studies of nanocrystalline $\mathrm{Ba}_{2} \mathrm{RESbO}_{6}(\mathrm{RE}=\mathrm{Sm}, \mathrm{Gd}$, Dy and $\mathrm{Y})$ perovskites. J. Alloys Compd. 480 (2) (2009) 167-170.

[3.55] H. Karunadasa, Q. Huang, B. G. Ueland, P. Schiffer, R. J. Cava, $\mathrm{Ba}_{2} \mathrm{LnSbO}_{6}$ and $\mathrm{Sr}_{2} \mathrm{LnSbO}_{6}(\mathrm{Ln}=\mathrm{Dy}, \mathrm{Ho}, \mathrm{Gd})$ double perovskites: Lanthanides in the geometrically frustrating fcc lattice. PNAS. 10(14) (2003) 8097-8102. 


\section{CHAPTER 4 ---- CONCLUSIONS}

The synthesis and characterization of $\mathrm{AgCe}\left(\mathrm{WO}_{4}\right)_{2}$ and $\mathrm{Eu} \times \mathrm{Ce}_{(1-x)} \mathrm{Ag}\left(\mathrm{WO}_{4}\right)_{2}$ were studied in this work. Well crystallized $\mathrm{AgCe}\left(\mathrm{WO}_{4}\right)_{2}$ and $\mathrm{Eu}_{x} \mathrm{Ce}(1-\mathrm{x}) \mathrm{Ag}\left(\mathrm{WO}_{4}\right)_{2}$, despite the relatively high air instability of the trivalent $\mathrm{Ce}$ ion, was obtained beyond the temperature $750{ }^{\circ} \mathrm{C}$ by the ceramic method. The XRD results reveal that the compounds have scheelite-type structures with I 41/a space group.

The high temperature $\mathrm{X}$-ray diffraction was introduced in to investigate the heat stability. $\mathrm{Ag}_{2} \mathrm{~W}_{2} \mathrm{O}_{7}$ and $\mathrm{Ce}_{2}\left(\mathrm{WO}_{4}\right)_{3}$ were found in the compounds under the temperature range of $550{ }^{\circ} \mathrm{C}-660{ }^{\circ} \mathrm{C}$ which manifest the existence of decomposition. Through the XRD, FT-IR and Raman measurements we can

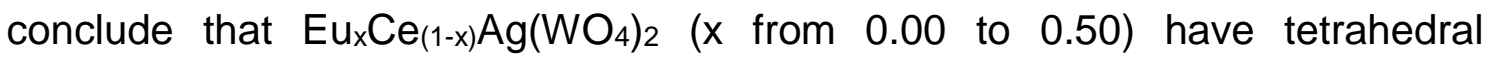
symmetry with the $\mathrm{C}_{4 \mathrm{~h}}^{6}$ symmetry group. Because of the analogous of the radius of $\mathrm{Ce}^{3+}$ ion and $\mathrm{Eu}^{3+}$ ion, the $\mathrm{Eu}^{3+}$ well occupied the a site and there is no appreciable distortion of the tetragonal structure as the increasing concentration of $\mathrm{Eu}^{3+}$.

Magnetic susceptibility measurements was introduced in for the compounds $\mathrm{Ce}_{(1-\mathrm{x})} \mathrm{Ag}_{(1+\mathrm{x})}\left(\mathrm{WO}_{4}\right)_{2}$ to confirm the existence of trivalent $\mathrm{Ce}^{3+}$ ions. The trivalent $\mathrm{Ce}^{3+}$ ions stay stable in the Ag-based system even with imbalanced charge proportion $\mathrm{Ce}^{3+} / \mathrm{Ag}^{+}$. No obviously sudden decrease of the magnetic susceptibility $\mathrm{X}$ was observed as the concentration decrease of cerium in the $\mathrm{Ce}_{(1-x)} \mathrm{Ag}_{(1+x)}\left(\mathrm{WO}_{4}\right)_{2}$ compounds which indicated that the trivalent $\mathrm{Ce}^{3+}$ ions did not convert to tetravalent $\mathrm{Ce}^{4+}$ ions for charge compensation.

Optical luminescence properties of $\mathrm{AgCe}\left(\mathrm{WO}_{4}\right)_{2}$ were measured however no specific spectra of $\mathrm{Ce}^{3+}$ was observed in the visible range. In order to determine the crystal field energy level diagrams to simulate the temperature variation of the magnetic susceptibility with the crystal field formalism, doped $\mathrm{Eu}^{3+}$ and $\mathrm{Tb}^{3+}$ were used as local structure probe. It is found that the spectra of $\mathrm{Eu}^{3+}$ was quenched by the presence of $\mathrm{Ce}^{3+}$. $\mathrm{Tb}^{3+}$ presented its own spectra in the $\mathrm{AgCe}\left(\mathrm{WO}_{4}\right)_{2}$ compound with small doped concentration. Therefore, the $\mathrm{Tb}^{3+}$ is qualified as a 
local structure probe which can further help us to determine the crystal field energy level of the $\mathrm{AgCe}\left(\mathrm{WO}_{4}\right)_{2}$.

Otherwise, the refined XRD data indicated that the doped $\mathrm{Eu}^{3+}$ and $\mathrm{Tb}^{3+}$ well occupied the $\mathrm{Ce}^{3+}$ site and there is no appreciable distortion of the tetragonal structure.

Well crystallized polycrystalline powders of the silver rare earth tungstate-molybdate family, $\mathrm{AgLn}\left(\mathrm{WO}_{4}\right)\left(\mathrm{MoO}_{4}\right)$, with scheelite-like structure have been synthesized by ceramic method. X-ray diffraction analysis was carried out and the refinement was performed in the tetragonal space group I 41/a (No. 88). The FTIR and Raman Spectra were discussed on the basis of factor group analysis and normal coordinate calculations. It is found that in $\operatorname{AgPr}\left(\mathrm{WO}_{4}\right)\left(\mathrm{MoO}_{4}\right)$ and $\mathrm{AgTb}\left(\mathrm{WO}_{4}\right)\left(\mathrm{MoO}_{4}\right)$ samples, Raman spectra are different from the other $\mathrm{AgLn}\left(\mathrm{WO}_{4}\right)\left(\mathrm{MoO}_{4}\right)$ samples. Several attempts to assign bands to different modes of distortions of the tetragonal cell have been investigated without more achievement. Photo luminescent excitation and emission spectra with various rare earth ions was presented and discussed in the silver based host material.

The $\mathrm{Sr}_{2} \mathrm{RESbO}_{6}$ double perovskites $(\mathrm{RE}=\mathrm{La}$ to $\mathrm{Lu}$ and $\mathrm{Y}$ ) were also synthesized by ceramic method with a high temperature $\left(>1200^{\circ} \mathrm{C}\right)$. The reaction process was performed by the differential thermal analysis. The structure and phase purity of the well prepared double perovskites were examined by X-ray diffraction pattern and vibrational FTIR-Raman spectroscopy. The diffraction patterns show that these compounds have lower symmetry than the cubic which can be described by a monoclinic symmetry cell, space group $\mathrm{P} 21 / \mathrm{n}$. However, in the cases of Sr2LaSbO6 and Sr2PrSbO6 an alternative structure was suggested searching by neutron diffraction technique.

The study of the magnetic properties, though not one of the most important objectives in this report, has been carried out from the measurement susceptibility in a wide temperature range: $4.2-300 \mathrm{~K}$. At high temperature the Magnetic properties follow Curie-Weiss law. The downwards or upwards deviation at low temperature from the Curie-Weiss behaviour observed for some of these $\mathrm{Sr}_{2} \mathrm{RESbO}_{6}$ oxides can be explained as the splitting of the ground term 
of the $\mathrm{RE}^{3+}$ cation under the influence of the crystal field. It is not observed lanthanide magnetic ordering between RT and 4K.

No characteristic bands were observed for most rare earth ions in the photoluminescence excitation and emission spectra of $\mathrm{Sr}_{2} \mathrm{LnSbO}_{6}$ compounds except for $\mathrm{Sr}_{2} \mathrm{EuSbO}_{6}$ and $\mathrm{Sr}_{2} \mathrm{TbSbO}_{6}$. Strong luminescent peaks were observed at orange and red region in the $\mathrm{Sr}_{2} \mathrm{EuSbO}_{6}$ compounds, however the dominant peak alternate between orange and red at room temperature and liquid nitrogen temperature respectively. This behavior is probably due to the quenching of thermal vibrations in the structure.

A strong band at $357 \mathrm{~nm}$ and a broad band from $450 \mathrm{~nm}$ to $530 \mathrm{~nm}$ (centered at $498 \mathrm{~nm}$ ) were observed in the emission spectra of the $\mathrm{Sr}_{2} \mathrm{TbSbO}_{6}$ samples when excited by $298 \mathrm{~nm}$ at liquid nitrogen temperature. The strong emission band at $357 \mathrm{~nm}$ can be can be attributed to the ${ }^{5} \mathrm{D}_{2} \rightarrow{ }^{7} \mathrm{~F}_{6}$ transitions of $\mathrm{Tb}^{3+}$ and the broad band centered at $498 \mathrm{~nm}$ can be attributed to overlaps of transitions from excited ${ }^{5} \mathrm{D}_{4}$ state to varieties configurations of ${ }^{7} \mathrm{~F}_{6}$ ground state of $\mathrm{Tb}^{3+}$ ions. 


\section{BIBLIOGRAPHY}

A. Durairajan, D. Balaji, K. Kavi Rasu, S. Moorthy Babu, M. A. Valente, D. Thangaraju, Y. Hayakawa, Sol-gel synthesis and photo luminescence analysis of $\mathrm{Sm}^{3+}: \mathrm{NaGd}\left(\mathrm{WO}_{4}\right)_{2}$ phosphors. J. Lumin. 170 (2016) 743-748.

A. Katelnikovas, J. Plewa, S. Sakirzanovas, D. Dutczak, D. Enseling, F. Baur, H. Winkler, A. Kareiva, T. Jüstel, Synthesis and optical properties of $\mathrm{Li}_{3} \mathrm{Ba}_{2} \mathrm{La}_{3}\left(\mathrm{MoO}_{4}\right)_{8}: \mathrm{Eu}^{3+}$ powders and ceramics for pcLEDs. J. Mater. Chem. 22 (2012) 22126-22134.

A. Xie, X. Yuan, Y. Shi, F. Wang, J. Wang, Photoluminescence Characteristics of Energy Transfer Between $\mathrm{Eu}^{3+}$ and $\mathrm{Bi}^{3+}$ in $\mathrm{LiEu}_{1-\mathrm{x}} \mathrm{Bi}_{\mathrm{x}}(\mathrm{WO})_{0.5}(\mathrm{MoO})_{1.5}$. J. Am. Ceram. Soc. 92 (10) (2009) 2254-2258.

B. Vengala Rao, S. Buddhudu, Emission analysis of $\mathrm{Pr}^{3+}$ \& $\mathrm{Ho}^{3+}: \mathrm{Ca}_{4} \mathrm{GdO}\left(\mathrm{BO}_{3}\right)_{3}$ powder phosphors. J Mater Sci. 43 (2008) 233-236.

B. Yan, L. Lin, J. Wu, F. Lei, Photoluminescence of Rare Earth Phosphors $\mathrm{Na}_{0.5} \mathrm{Gd}_{0.5} \mathrm{WO}_{4}: \mathrm{RE}^{3+}$ and $\mathrm{Na}_{0.5} \mathrm{Gd}_{0.5}\left(\mathrm{Mo}_{0.75} \mathrm{~W}_{0.25}\right)_{4}: \mathrm{RE}^{3+}(\mathrm{RE}=\mathrm{Eu}, \mathrm{Sm}, \mathrm{Dy})$. J. Fluoresc. 21 (2011) 203-211.

C. Chiu, C. Liu, S. Huang, T. Chen, White-Light-Emitting Diodes Using Red-Emitting $\mathrm{LiEu}\left(\mathrm{WO}_{4}\right)_{2-x}\left(\mathrm{MoO}_{4}\right)_{x}$ Phosphors. J. Electrochem. Soc. 154 (7) (2007) 181-184.

C. Colón, A. Alonso-Medina, F. Fernández, R. Sáez-Puche, V. Volkov, C. Cascales, C. Zaldo, Correlation between Polymorphism and Optical Bandwidths in $\mathrm{AgNd}\left(\mathrm{WO}_{4}\right)$ 2. Chem. Mater. 1726 (2005) 6635-6643.

C. Li, J. Lin, Rare earth fluoride nano-/microcrystals: synthesis, surface modification and application. J. Mater. Chem. 20 (2010) 6831-6847.

C. S. Lim, Microwave-modified sol-gel process of $\mathrm{NaY}\left(\mathrm{WO}_{4}\right)_{2}: \mathrm{Ho}^{3+} / \mathrm{Yb}^{3+}$ phosphors and the upconversion of their photoluminescence properties. Ceram. Int. 41 (2015) 2616-2621. 
C. Sun, F. Yang, C. Tu, Spectroscopic properties of $\mathrm{Tm}^{3+} / \mathrm{Ho}^{3+}$ co-doped $\mathrm{NaLa}\left(\mathrm{WO}_{4}\right)_{2}$ single crystal. J. Lumin. 132 (2012) 1232-1236.

C. Vijayakumar, H. Padma Kumar, Sam Solomon, J.K. Thomas, P. R. S. Wariar, Annamma John, FT-Raman and FT-IR vibrational spectroscopic studies of nanocrystalline $\mathrm{Ba}_{2} \mathrm{RESbO}_{6}(\mathrm{RE}=\mathrm{Sm}, \mathrm{Gd}$, Dy and $\mathrm{Y}$ ) perovskites. J. Alloys Compd. 480 (2) (2009) 167-170.

D. Balaji, A. Durairajan, D.Thangaraju, K. Kavi Rasu, S. Moorthy Babu, Investigation of structural and luminescent properties of $\mathrm{Pr}^{3+}$ activated CsGd(WO4)2 by sol-gel synthesis. Mater. Sci. Eng. B 178 (2013) 762-767.

D. Balaji, K. Kavirasu, A. Durairajan, S. Moorthy Babu, Photoluminescence properties of novel $\mathrm{Sm}^{3+}$ and $\mathrm{Dy}^{3+}$ co-activated CsGd($\left(\mathrm{WO}_{4}\right)_{2}$ phosphors. J. Alloys Compd. 637 (2015) 350-360.

D. Bloch, R. Lemaire, Metallic Alloys and Exchange-Enhanced Paramagnetism, Application to Rare-Earth-Cobalt Alloys. Phys. Rev. B 2 (1970) 2648.

D. Errandonea, F. J. Manjón, Presure effects on the structure and electronic properties of $A B X_{4}$ scintillating crystals. Progress Mater. Sci. 53 (2008) 711-773.

D. J. Gardiner, P. R. Graves, Practical Raman Spectroscopy, Springer Verlag. 1989.

D. L. Rousseau, R. P. Bauman, S. P. S. Porto, Normal mode determination in crystals. J. Raman Spectrosc. 10 (1) (1981) 253-290.

E. Sani, A. Toncelli, M. Tonelli, D. A. Lis, E. V. Zharikov, K. A. Subbotin, V. A Smirnov, Effect of cerium codoping in $\mathrm{Er}^{3+}, \mathrm{Ce}^{3+}: \mathrm{NaLa}\left(\mathrm{MoO}_{4}\right)_{2}$ crystals. J. Appl. Phys. 97 (12) (2005) 123531-1-123531-6.

E. Tomaszewicz, H. Fuks, J. Typek, B. Sawicki, M. Oboz, T. Groń, T. Mydlarz, Preparation, thermal stability and magnetic properties of new $\mathrm{AgY}_{1-\mathrm{x}} \mathrm{Gd}_{\times}\left(\mathrm{WO}_{4}\right)_{2}$ ceramic materials. Ceram. Int. 41 (2015) 5734-5748. 
F. B. Xiong, Z. W. Zhang, H. F. Lin, L. J. Wang, Y. C. Xu, W. Z. Zhu, Luminescent properties of deep red light-emitting phosphors $\mathrm{NaGd}\left(\mathrm{WO}_{4}\right)_{2}: \mathrm{Pr}^{3+}$ for blue LED. Opt. Mater. 42 (2015) 394-398.

F. Cao, Y. Tian, Y. Che, L. Xiao, Q. Wu, Luminescence investigation of red phosphors $\mathrm{Ca} 0.54 \mathrm{Sr} 0.34-1.5 \times \mathrm{Eu} 0.08 \mathrm{Sm}_{\times}\left(\mathrm{MoO}_{4}\right)_{\text {y }}\left(\mathrm{WO}_{4}\right)_{1-\mathrm{y}}$ for UV-white LED device. J. Lumin. 129 (2009) 585-588.

F. Fernández-Martínez , C. Colón, J. L. Montero, E. Atanes, C. Rivero, Synthesis and characterization of $\mathrm{LnAg}\left(\mathrm{WO}_{4}\right)\left(\mathrm{MoO}_{4}\right)$. J. Alloys Compd. 451 (2008) 317319.

F. Shi, J. Meng, Y. Ren, Preparation, structure and some physical properties of scheelite-related AgLnMo2 $\mathrm{O}_{8}$ compounds. J. Alloys Compd. 233 (1996) 56-60.

F. Shi, J. Meng, Y. Ren, Q. Su, Structure, luminescence and magnetic properties of AgLnW2O8 ( $\mathrm{Ln}=\mathrm{Eu}, \mathrm{Gd}, \mathrm{Tb}$ and Dy) compounds. J. Phys. Chem. Solids 59 (1) (1998) 105-110.

G. Benoît, J. Véronique, A. Arnaud, G. Alain, Luminescence properties of tungstates and molybdates phosphors: Illustration on $\operatorname{ALn}\left(\mathrm{MO}_{4}\right)_{2}$ compounds (A = alkaline cation, $\mathrm{Ln}=$ lanthanides, $\mathrm{M}=\mathrm{W}, \mathrm{Mo}$ ). Solid State Sci. 13 (2011) 460-467.

G. Li, S. Lan, L. Li, M. Li, W. Bao, H. Zou, X. Xu, S. Gan, Tunable luminescence properties of $\mathrm{NaLa}\left(\mathrm{MoO}_{4}\right)_{2}: \mathrm{Ce}^{3+}, \mathrm{Tb}^{3+}$ phosphors for near UV-excited white light-emitting-diodes. J. Alloys Compd. 513 (2012) 145-149.

G. Tyler, Rare earth elements in soil and plant systems-A review. Plant and Soil 267 (2004) 191- 206.

H. Fuks, S. M. Kaczmarek, G. Leniec, L. Macalik, B. Macalik, J. Hanuza, EPR and vibrational studies of some tungstates and molybdates single crystals. Opt. Mater. 32 (2010) 1560-1567.

H. Karunadasa, Q. Huang, B. G. Ueland, P. Schiffer, R. J. Cava, Ba $\mathrm{LnSbO}_{6}$ and $\mathrm{Sr}_{2} \mathrm{LnSbO}_{6}(\mathrm{Ln}=\mathrm{Dy}, \mathrm{Ho}, \mathrm{Gd})$ double perovskites: Lanthanides in the 
geometrically frustrating fcc lattice. PNAS 100 (14) (2003) 8097-8102.

H. Karunadasa, Q. Huang, B. G. Ueland, P. Schiffer, R. J. Cava, Ba2LnSbO 6 and $\mathrm{Sr}_{2} \mathrm{LnSbO}_{6}(\mathrm{Ln}=\mathrm{Dy}, \mathrm{Ho}, \mathrm{Gd})$ double perovskites: Lanthanides in the geometrically frustrating fcc lattice. PNAS. 100 (14) (2003) 8097-8102.

J. Chen, X. Gong, Y. Lin, Y. Chen, Z. Luo, Y. Huang, Synthesis and spectral property of $\mathrm{Pr}^{3+}$-doped tungstate deep red phosphors. J. Alloys Compd. 492 (2010) 667-670.

J. H. Huang, Y. J. Chen, X. H. Gong, Y. F. Lin, Z. D. Luo, Y. D. Huang, Spectral Properties and 1.5-1.6 $\mu \mathrm{m}$ Laser Operation of Er:Yb:NaCe(WO4)2 Crystal. Laser Phys. 22 (1) (2012) 146-151.

J. Hanuza, A. Benzar, A. Haznar, M. Maczka, A. Pietraszko, J.H. van der Maas, Structure and vibrational dynamics of tetragonal $\mathrm{NaBi}\left(\mathrm{WO}_{4}\right)_{2}$ scheelite crystal. Vib. Spectrosc. 12 (1996) 25-36.

J. Hanuza, M. Maczka, J. H. van der Maas,Polarized IR and Raman spectra of tetragonal $\mathrm{NaBi}\left(\mathrm{WO}_{4}\right)_{2}, \mathrm{NaBi}\left(\mathrm{MoO}_{4}\right)_{2}$ and $\mathrm{LiBi}\left(\mathrm{MoO}_{4}\right)_{2}$ single crystals with scheelite structure.J. Mol. Struct. 348 (1995) 349-352.

J. Huang, J. Huang, Y. Lin, X. Gong, Y. Chen, Z. Luo, Y. Huang, Spectroscopic properties of Dy ${ }^{3+-d o p e d ~} \mathrm{NaGd}\left(\mathrm{MoO}_{4}\right)_{2}$ crystal. J. Alloys Compd. 664 (2016) 266-271.

J. Huang, J. Loriers, P. Porcher, Spectroscopic Properties of $\mathrm{Ln}_{2} \mathrm{MoO}_{6}: \mathrm{Eu}^{3+}$. J. Solid State Chem. 43 (1982) 87-96.

J. Liu, J.M. Cano-Torres, C. Cascales, F. Esteban-Betegón, M.D. Serrano, V. Volkov, C. Zaldo, M. Rico, U. Griebner, V. Petrov, Growth and continuous-wave laser operation of disordered crystals of $\mathrm{Yb}^{3+}: \mathrm{NaLa}\left(\mathrm{WO}_{4}\right)_{2}$ and $\mathrm{Yb}^{3+}: \mathrm{NaLa}\left(\mathrm{MoO}_{4}\right) 2$. Phys. Stat. Sol.(a)202(4) (2005)R29-R31.

J. Rodriguez-Carvajal, T. Roisnel, FullProf. 98 and WinPLOTR: New Windows 95/NT Applications for Diffraction. Commission for Powder Diffraction, International Union of Crystallography. Newsletter 20 (1998) 35. 
J. Tang, C. Cheng, Y. Chen, Y. Huang, Yellow-green upconversion photoluminescence in $\mathrm{Yb}^{3+}, \mathrm{Ho}^{3+}$ co-doped $\mathrm{NaLa}\left(\mathrm{MoO}_{4}\right)_{2}$ phosphor. J. Alloys Compd. 609 (2014) 268-273.

J. Yan, X. Xiao, J. Yu, D. Mao, G. Lu, White light emission materials of self-assembled rare earth molybdates $\mathrm{NaRe}\left(\mathrm{MoO}_{4}\right)_{2}$ micro-particles: the controllable synthesis, growth mechanism and luminescent properties. Cryst. Res. Technol. 50 (7) (2015) 580-593.

J. Yuan, S.X. Shen, D.D. Chen, Q. Qian, M.Y. Peng, and Q.Y. Zhang, Efficient $2.0 \mu \mathrm{m}$ emission in $\mathrm{Nd}^{3+} / \mathrm{Ho}^{3+}$ co-doped tungsten tellurite glasses for a diode-pump 2.0um laser. J. Appl. Phys. 113 (2013) 173507.

K. Choa, J.Choi, K.M. Kim, J. Lee, J.H. Ryu, Upconversion luminescence of $\mathrm{Ho}^{3+} / \mathrm{Tm}^{3+} / \mathrm{Yb}^{3+}$ tri-doped $\mathrm{NaLa}\left(\mathrm{MoO}_{4}\right)_{2}$ phosphors. Ceram. Int. 41 (2015) 668-674.

K. Kavi Rasu, D. Balaji, S. Moorthy Badu, Spectroscopic properties of $\mathrm{Eu}^{3+}$ : KLa(WO4)2 novel red phosphors, J. Lumin. 170 (2016) 547-555.

K. Kawano, K. Arai, H. Yamada, N. Hashimoto, R. Nakata, Application of rare-earth complexes for photovoltaic precursors. Sol. Energy Mater. Sol. Cells 48 (1-4) (1997) 35-41.

L. Bonelli, F. Cornacchia, M. Tonelli, D. A. Lis, K. A. Subbotin, V. A. Smirnov, E. V. Zharikov, Spectroscopic properties of $\mathrm{Er}: \mathrm{NaLa}\left(\mathrm{WO}_{4}\right)_{2}$ crystals and effect of $\mathrm{Ce}$ codoping onto the excited state energy transformation in this crystal. J. Lumin. 135 (2013) 178-186.

L. Li, W. Zi, G. Li, S. Lan, G. Ji, S. Gan, H. Zou, X. Xu, Hydro thermal synthesis and luminescent properties of $\mathrm{NaLa}\left(\mathrm{MoO}_{4}\right)_{2}: \mathrm{Dy}^{3+}$ phosphor. J. Solid State Chem. 191 (2012) 175-180.

L. Macalik, J. Hanuza, A.A. Kaminskii, Polarized Raman spectra of the oriented $\mathrm{NaY}\left(\mathrm{WO}_{4}\right)_{2}$ and $\mathrm{KY}\left(\mathrm{WO}_{4}\right)_{2}$ single crystals.J. Mol. Struct. 555 (2000)289-297. 
L. Macalik, J. Hanuza, J. Sokolnicki, J. Legendziewicz, Optical properties of $\mathrm{Pr}^{3+}$ in lanthanum double molybdates and tungstates: $\mathrm{KLa}_{1-\mathrm{x}} \mathrm{Pr}_{\mathrm{x}}\left(\mathrm{MO}_{4}\right)_{2}(\mathrm{M}=\mathrm{Mo}, \mathrm{W} ; \mathrm{x}$ s1). Spectrochim. Acta Part A 55 (1999) 251-262.

L. Zhang, M. Lei, Y. Wang, J. Li, Y. Wang, J. Liu, Crystal Growth and Spectral Properties of $\mathrm{Yb}^{3+}: \mathrm{KY}\left(\mathrm{WO}_{4}\right)_{2}$. J. RARE EARTH 24 (2006) 125-128.

M. Jayasimhadri, B.V. Ratnam, K. Jang, H.S. Lee, B. Chen, S. Yi, J. Jeong, L.R. Moorthy, Greenish-Yellow Emission from Dy ${ }^{3+}$-Doped $\mathrm{Y}_{2} \mathrm{O}_{3}$ Nanophosphors. J. Am. Ceram. Soc. 93 (2) (2010) 494-499.

M. Rico, J. Liu, U. Griebner, V. Petrov, M.D. Serrano, F. Esteban-Betegón, C. Cascales, C. Zaldo, Tunable laser operation of ytterbium in disordered single crystals of Yb:NaGd(WO4)2. Opt. Express 12 (22) (2004)5362-5367.

N. Yamada, S. Shionoya, Vibronic transitions of $\mathrm{Eu}^{3+}$ ions in $\mathrm{CaWO}_{4}$ and other tungstates. J. Phys. Soc. Jpn. 31 (1971)841-851.

P. Boutinaud, M. Bettinelli, F. Diaz, Intervalence charge transfer in $\mathrm{Pr}^{3+}$ and $\mathrm{Tb}^{3+}$-doped double tungstate crystals $\mathrm{KRE}\left(\mathrm{WO}_{4}\right)_{2}(\mathrm{RE}=\mathrm{Y}, \mathrm{Gd}, \mathrm{Yb}, \mathrm{Lu})$. Opt. Mater. 32 (2010) 1659-1663.

P. J. Saines, J. R. Spencer, B. J. Kennedy, M. Avdeev, Structures and crystal chemistry of the double perovskites $\mathrm{Ba}_{2} \mathrm{LnB}^{\prime} \mathrm{O}_{6}\left(\mathrm{Ln}=\right.$ lanthanide $\mathrm{B}^{\prime}=\mathrm{Nb}^{5+}$ and $\mathrm{Ta}^{5+}$ ): Part I. Investigation of $\mathrm{Ba}_{2} \mathrm{LnTaO}_{6}$ using synchrotron X-ray and neutron powder diffraction. J. Solid State Chem. 180 (2007) 2991-3000.

P. J. Saines, J. R. Spencer, B. J. Kennedy, Y. Kubota, C. Minakata, H. Hano, K. Kato, M. Takata. Structures and crystal chemistry of the double perovskites $\mathrm{Ba}_{2} \mathrm{LnB}^{\prime} \mathrm{O}_{6}\left(\mathrm{Ln}=\right.$ lanthanide and $\mathrm{B}^{\prime}=\mathrm{Nb}$ and $\mathrm{Ta}$ ): Part II - Temperature dependence of the structures of Ba2LnB'O6. J. Solid State Chem. 180 (2007) 3001-3007.

P. Nachimuthu, R. Jagannathan, V. Nirmal Kumar, D. Narayana Rao, Absorption and emission spectral studies of $\mathrm{Sm}^{3+}$ and $\mathrm{Dy}^{3+}$ ions in $\mathrm{PbO}-\mathrm{PbF}_{2}$ glasses. J. Non-Cryst. Solids 217(1997) 215-223. 
P. A. Loiko, E.V. Vilejshikova, X. Mateos, J.M. Serres, V.I. Dashkevich, V.A. Orlovich, A.S. Yasukevich, N.V. Kuleshov, K.V. Yumashev, S.V. Grigoriev, S.M. Vatnik, S.N. Bagaev, A.A. Pavlyuk, Spectroscopy of tetragonal Eu:NaGd($\left(\mathrm{WO}_{4}\right)_{2}$ crystal. Opt. Mater. 57 (2016) 1-7.

Q. Dan, T. Wanjun, Efficient energy transfer and tunable emission in $\mathrm{NaLa}\left(\mathrm{MoO}_{4}\right)\left(\mathrm{WO}_{4}\right)$ : Tb ${ }^{3+} / \mathrm{Eu}^{3+}$ phosphors. Ceram. Int. 42 (2016) 1538-1544.

R. Fartas, M. Diaf, H. Boubekri, L. Guerbous, J.P. Jouart, Synthesis and study of spectroscopic properties of $\mathrm{CdF}_{2}$ crystals codoped with luminescent rare earth ions $\left(\mathrm{Ho}^{3+} \mathrm{Yb}^{3+}\right)$. J. Alloys Compd. 606 (2014) 73-80.

R. Mukherjee, S. Saha, A. Dutta, T. P. Sinha, Dielectric and Raman spectroscopic studies of $\mathrm{A}_{2} \mathrm{ErSbO}_{6}(\mathrm{~A}=\mathrm{Ba}, \mathrm{Sr}$ and $\mathrm{Ca})$. J. Alloy. Compd. 651 (2015) 222-229.

S. Asiri Naidu, S. Boudin, U.V. Varadaraju, B. Raveau, Host-sensitized emission of $\mathrm{LilnW}_{2} \mathrm{O}_{8}$ wolframites: From red-Eu ${ }^{3+}$ to white-Dy ${ }^{3+}$ phosphors. J. Solid State Chem. 184 (2011) 2566-2570.

S. P. S. Porto, J. F. Scott,Raman Spectra of $\mathrm{CaWO}_{4}, \mathrm{SrWO}_{4}, \mathrm{CaMoO}_{4}$, and SrMoO4. Phys. Rev. 157 (3) (1996), 716-719.

S. Shi, X. Liu, J. Gao, J. Zhou, Spectroscopic properties and intense red-light emission of (Ca, Eu, M)WO 4 (M = Mg, Zn, Li). Spectrochim. Acta Part A 69 (2008) 396-399.

Toshio Kimura, Molten Salt Synthesis of Ceramic Powders. Advances in Ceramics - Synthesis and Characterization, Processing and Specific Applications. Edited by Prof. Costas Sikalidis. 2011

V Moizan, V Nazabal, J Troles, P Houizot, JL Adam, J. Doualan, R. Moncorgé, F. Smektala, G. Gadret, S. Pitois, G. Canat, Er ${ }^{3+}$-doped GeGaSbS glasses for mid-IR fibre laser application: Synthesis and rare earthspectroscopy. Opt. Mater. 31 (2008) 39-46. 
V. Ramakrishnan, G. Aruldhas, Raman and infrared studies of $\mathrm{NaLa}\left(\mathrm{MoO}_{4}\right)_{2}$. Spectrochim. Acta 41A (11) (1985) 1301-1303.

W. Jeitschko, Crystal structure of $\mathrm{La}_{2}\left(\mathrm{MoO}_{4}\right)_{3}$, a new ordered defect Scheelite type.Acta Cryst. B29 (1973) 2074-2081.

W. M. Yen, S. Shionoya, H. Yamamoto, Phosphor Handbook Second Edition. 2006.

W. Shi, A. Feng, H. Tang, Z. Ding, Y. Ma, M. Wu, G. Li, Preparation, characterization, and luminescence of $\mathrm{Eu}^{3+}$-doped gadolinium tungstate, $\mathrm{Y}_{3} \mathrm{Al}_{5} \mathrm{O}_{12}$ :Ce phosphor, and their mixtures. Opt. Mater. 35 (2013) 609-616.

X. Huang, W. Zhao, G. Wang, X. Li, Q. Yu, Polarized spectral analysis of $\mathrm{Er}^{3+}$ ions in $\mathrm{Er}^{3+}: \mathrm{LiGd}\left(\mathrm{MoO}_{4}\right)_{2}$ crystal. J. Alloys Compd. 509 (2011) 6578-6584.

Y. Chen, F. Cao, Y. Tian, L. Xiao, L. Li, Optimized photoluminescence by charge compensation in a novel phosphor system. Physica B 405 (2010) 435-438.

Y. Du, H. Jiao, D. He, Hydrothermal Synthesis and Luminescence of AgGdo.9Eu0.1(WO4)2 Phosphor. Acta Chim. Sinica 6921 (2011) 2550-2554.

Y. H. Tsang, D. J. Binks, B. D. O. Richards, A. Jha, Spectroscopic and lasing studies of $\mathrm{Ce}^{3+}: \mathrm{Er}^{3+}: \mathrm{Yb}^{3+}: \mathrm{YVO}_{4}$ crystals. Laser Phys. Lett. 8 (10) (2011) 729-735.

Y. Han, Y. Wang, S. Huang, F. Jin, S. Gai, N. Niu, L. Wang, P. Yang, Controlled synthesis and luminescence properties of doped $\mathrm{NaLa}\left(\mathrm{WO}_{4}\right)_{2}$ microstructures. J. Ind. Eng. Chem. 34 (2016) 269-277.

Y. J. Chen, J. H. Huang, Y. Q. Zou, Y. F. Lin, Z. D. Luo, Y. D Huang, Diode-pumped $\mathrm{Er}^{3+}: \mathrm{Yb}^{3+}: \mathrm{NaCe}_{0,43} \mathrm{Gd}_{0,57}\left(\mathrm{WO}_{4}\right)_{2}$ pulse laser passively Q-switched with a $\mathrm{Co}^{2+}: \mathrm{Mg}_{0,4} \mathrm{Al}_{2,4} \mathrm{O}_{4}$ saturable absorber at $1.53 \mu \mathrm{m}$. Laser Phys. 24 (2014) 045810 .

Y. Jin, J. Zhang, S. Lu, H. Zhao, X. Zhang, X. Wang, Fabrication of Eu ${ }^{3+}$ and $\mathrm{Sm}^{3+}$ codoped micro/nano sized $\mathrm{MMoO}_{4}(\mathrm{M}=\mathrm{Ca}, \mathrm{Ba}$, and $\mathrm{Sr})$ via facile hydrothermal method and their photoluminescence properties through energy transfer. J. Phys. Chem. C 112(15) (2008) 5860-5864. 
Y. Liu, X. Yu, K. Cai, H. Deng, M. Zhang, Microwave-assist hydrothermal synthesis and luminescence of $\mathrm{NaGd}\left(\mathrm{WO}_{4}\right): \mathrm{Tb}^{3+}$ phosphors: A case study for the energy saving in the synthesis of phosphors. Energy 93 (2015) 1413-1417.

Y. Tian, B. Chen, B. Tian, J. Sun, X. Li, J. Zhang, L. Cheng, H. Zhong, H. Zhong, Q. Meng, R. Hua, lonic liquid-assisted hydrothermal synthesis of dendrite-like $\mathrm{NaY}\left(\mathrm{MoO}_{4}\right)_{2}: \mathrm{Tb}^{3+}$ phosphor. Physica B 407 (2012) 2556-2559.

Y. W. Wei, Y.J. Chen, Y.F. Lin, X.H. Gong, Z.D. Luo, Y.D. Huang, Spectral properties of $\mathrm{Tm}^{3+}$-doped $\mathrm{LiLa}\left(\mathrm{MoO}_{4}\right)_{2}$ crystal. J. Alloys Compd. 484 (2009) 529-534.

Y. Wang, C. Lin, H. Zheng, D. Sun, L. Li, B. Chen, Fluorescent and chromatic properties of visible-emitting phosphor $\mathrm{KLa}\left(\mathrm{MoO}_{4}\right)_{2}: \mathrm{Sm}^{3+}$. J. Alloys Compd. 559 (2013) 123-128.

Y. Zhiping, D. Hongyan, L. Pengfei, H. Chuncai, L. Xiaoshuang, W. Can, L. Fachun, Photoluminescence properties of $\mathrm{Sm}^{3+}$-doped $\mathrm{LiY}\left(\mathrm{MoO}_{4}\right)_{2}$ red phosphors. J. RARE EARTHS 32 (5) (2014) 404-408.

Z. Lu, T. Wanjun, Synthesis and luminescence properties of $\mathrm{Eu}^{3+}$-activated $\mathrm{NaLa}\left(\mathrm{MoO}_{4}\right)\left(\mathrm{WO}_{4}\right)$ phosphor. Ceram. Int. 38 (2012) 837-840.

Z. Tang, L. Zhou, F. Wang, L. Zhou, Synthesis, characterization and luminescence study of $\mathrm{Eu}(\mathrm{III})$ tungstates and molybdates nanotubes using carbon nanotubes as templates. Spectrochim. Acta, Part A 72 (2009) 348-355.

Z. Wang, H. Liang, Q. Wang, L. Luo, M. Gong, Luminescent properties of $\mathrm{Tb}^{3+}$ activated double molybdates and tungstates. Mater. Sci. Eng. B 164 (2009) 120-123. 